\title{
IntechOpen
}

\section{Solar Radiation Applications}

Edited by Segun Raphael Bello

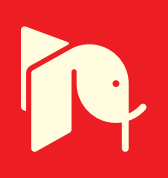





\section{SOLAR RADIATION APPLICATIONS}

Edited by Segun Raphael Bello 


\section{Solar Radiation Applications}

http://dx.doi.org/10.5772/58739

Edited by Segun Raphael Bello

\section{Contributors}

Jose Maria Cabeza Lainez, Jesus Alberto Pulido Arcas, Antonio Eduardo Hora Machado, Antonio Otávio Toledo Patrocínio, Karen Araújo Borges, Lidiaine Maria Dos Santos, Tatiana Aparecida Silva, Mariana Fornazier Borges, Alam Gustavo Trovó, Werick Alves Machado, Bruno Pontes Caixeta, Samuel Manzini De Oliveira, Marcela Dias França, WenSheng Ou, Chin Kim Lo, Yun Seng Lim, Faidz Abd Rahman, Kalju Eerme, Margit Aun, Uno Veismann, A.V. Salker, Segun R. R. Bello, Ezebiulo C. N., Adegbulugbe T. A., Eke Kenneth Ahanotu

\section{(c) The Editor(s) and the Author(s) 2015}

The moral rights of the and the author(s) have been asserted.

All rights to the book as a whole are reserved by INTECH. The book as a whole (compilation) cannot be reproduced, distributed or used for commercial or non-commercial purposes without INTECH's written permission.

Enquiries concerning the use of the book should be directed to INTECH rights and permissions department (permissions@intechopen.com).

Violations are liable to prosecution under the governing Copyright Law.

\section{(c))BY}

Individual chapters of this publication are distributed under the terms of the Creative Commons Attribution 3.0 Unported License which permits commercial use, distribution and reproduction of the individual chapters, provided the original author(s) and source publication are appropriately acknowledged. If so indicated, certain images may not be included under the Creative Commons license. In such cases users will need to obtain permission from the license holder to reproduce the material. More details and guidelines concerning content reuse and adaptation can be foundat http://www.intechopen.com/copyright-policy.html.

\section{Notice}

Statements and opinions expressed in the chapters are these of the individual contributors and not necessarily those of the editors or publisher. No responsibility is accepted for the accuracy of information contained in the published chapters. The publisher assumes no responsibility for any damage or injury to persons or property arising out of the use of any materials, instructions, methods or ideas contained in the book.

First published in Croatia, 2015 by INTECH d.o.o.

eBook (PDF) Published by IN TECH d.o.o.

Place and year of publication of eBook (PDF): Rijeka, 2019.

IntechOpen is the global imprint of IN TECH d.o.o.

Printed in Croatia

Legal deposit, Croatia: National and University Library in Zagreb

Additional hard and PDF copies can be obtained from orders@intechopen.com

Solar Radiation Applications

Edited by Segun Raphael Bello

p. cm.

ISBN 978-953-51-2124-4

eBook (PDF) ISBN 978-953-51-6376-3 


\section{We are IntechOpen, \\ the world's leading publisher of Open Access books}

Built by scientists, for scientists

\section{$3,800+$}

Open access books available

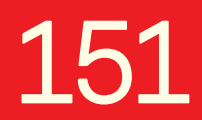

Countries delivered to

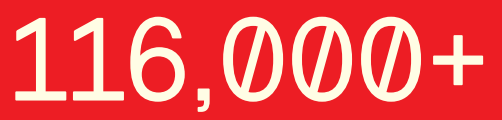

International authors and editors
$120 \mathrm{M}+$

Downloads

Our authors are among the

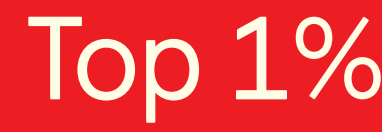

most cited scientists

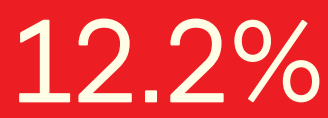

Contributors from top 500 universities

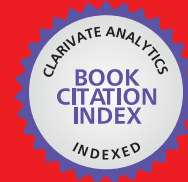

WEB OF SCIENCE ${ }^{\mathrm{TM}}$

Selection of our books indexed in the Book Citation Index in Web of Science ${ }^{\mathrm{TM}}$ Core Collection (BKCI)

Interested in publishing with us?

Contact book.department@intechopen.com

Numbers displayed above are based on latest data collected.

For more information visit www.intechopen.com

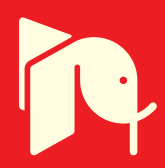





\section{Meet the editor}

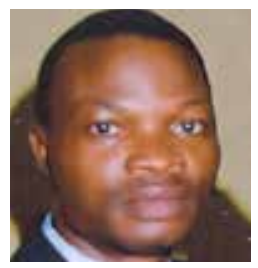

Segun Raphael BELLO - born in Ajowa Akoko, Ondo

State, Nigeria - is a doctoral student of the University of Ibadan, Nigeria, a senior lecturer and research fellow. He has wide experience in machinery design, renewable energy resource utilization and workplace ergonomics. Bello is a registered member of the apex engineering regulatory body in Nigeria - COREN, Nigeria Society of Engineers and Nigeria Institution of Agricultural Engineers. He has written several research articles for international conferences, journals, workshops and over 15 textbooks in various engineering applications and technologies. He is an editor to several publishing groups including Sustainable Agriculture Group (SAG) and InTech. He is also a reviewer for international journals including the International Commission of Agricultural Engineering (CIGR). In 2011, he was an enlisted member of Nigeria academia. In the same year, he received the Pillar of Nation Building award for his significant contributions to research and development. He is married with four children. 



\section{Contents}

Preface XI

Section 1 Solar Heating and Surface Geometry 1

Chapter 1 Radiative Heat Transfer for Curvilinear Surfaces 3

Jose Maria Cabeza Lainez, Jesus Alberto Pulido Arcas, Manuel-

Viggo Castilla, Carlos Rubio Bellido and Juan Manuel Bonilla

Martínez

Chapter 2 Steady State Thermal Analysis of a Tri-Wing Solar Chimney 27

R. S. Bello, C. N. Ezebuilo, T. A. Adegbulugbe and K. A. Eke

Chapter 3 Performance Characteristics of Modelled Tri-Wing Solar Chimney and Adaptation to Wood Drying 53

R. S. Bello, C. N. Ezebuilo, K. A. Eke and T. A. Adegbulugbe

Section 2 Photo-Degradation \& Instrumentation 73

Chapter 4 Solar-Light-Assisted Photo-degradation of Azo Dyes Using Some Transition Metal Oxides 75

A.V. Salker

Chapter 5 Applications of Mesoporous Ordered Semiconductor Materials - Case Study of TiO2 87

Antonio E. H. Machado, Karen A. Borges, Tatiana A. Silva, Lidiaine M. Santos, Mariana F. Borges, Werick A. Machado, Bruno P. Caixeta, Marcela Dias França, Samuel M. Oliveira, Alam G. Trovó and Antonio O.T. Patrocínio

Chapter 6 Instrumentation and Measurement of Ground-Level Ultraviolet Irradiance and Spectral Composition in Estonia 119 Kalju Eerme, Margit Aun and Uno Veismann 


\section{Section 3 Solar Applications in Architecture 141}

Chapter 7 Development of Novel Building-Integrated Photovoltaic (BIPV) System in Building Architectural Envelope 143

Wen-Sheng Ou

Chapter 8 New Computational Techniques for Solar Radiation in Architecture 157 Jose M. Cabeza-Lainez, Jesus A. Pulido Arcas, Carlos Rubio Bellido, Manuel-Viggo Castilla, Luis Gonzalez-Boado and Benito SanchezMontanes Macias 


\section{Preface}

The book, Solar Radiation, edited by Prof. Elisha E. Babatunde and published by InTech, provides a good background on the principles, fundamentals and future of solar radiation and energy utilization. Two essential components of solar energy which are derivable from the sun-radiant light (passive solar power) and heat (active solar powers) - have been harnessed for decades using a range of ever-evolving and cutting-edge technologies. Such technologies include solar photovoltaics, photo emitters, BIPVs and solar thermal systems.

However, recently, there has been active research in the optimization of these energy resources due to improvements in panel instrumentation, geometry and orientation. Additionally, the more rigorous methods that are used to model inter-reflections within curvilinear surfaces for simplified analytical evaluations, material doping, photo-cell materials and heterogeneous photo-catalytic degradation through solar light illumination on semiconductor surfaces, are equally becoming attractive advances in the cell material oxidation process.

Some of the advances in solar energy research are presented in the following three sections of this book:

Section 1: Solar Heating and Surface Geometry

Section 2: Photo-degradation and Instrumentation

Section 3: Solar Application in Architecture

Optimally harnessing this vital and clean energy potential will make the future of the world more promising and reassuring.

Bello, R. S. Federal College of Agriculture, Ishiagu, Nigeria 

Solar Heating and Surface Geometry 



\title{
Chapter 1
}

\section{Radiative Heat Transfer for Curvilinear Surfaces}

\author{
Jose Maria Cabeza Lainez, \\ Jesus Alberto Pulido Arcas, Manuel-Viggo Castilla, \\ Carlos Rubio Bellido and \\ Juan Manuel Bonilla Martínez
}

Additional information is available at the end of the chapter

http://dx.doi.org/10.5772/59797

\section{Introduction}

Curved surfaces have not been thoroughly considered in radiative transfer analysis mainly due to the difficulties arising from the integration process and perhaps because of the lack of spatial vision of researchers. When dealing with them, application of the iterative method or direct calculation through integration does not provide with an exact solution, so that only approximate expressions or tables are given for a very limited number of forms [1]. In this way, a vast repertoire of significant shapes remains neglected and energy waste is evident. For this reason, further research on the matter, starting from a different approach was considered worth doing.

In previous researches from the authors, form factor calculation has been undertaken for several types of emitters. In all cases, geometric properties of those, revealed as the most powerful tool that shapes radiant interchange $[3,4,5,6]$. This included mainly rectangular shapes, plane forms and the volumes that can be composed with such primary geometries.

Following the same approach to radiative transfer through the basic understanding of the spatial and geometric properties of volumes, in this chapter new form factors derived from a combination of curvilinear surfaces are hereby presented. Starting from the properties of the sphere and with simple calculus, new laws are devised, which enable the authors to discover a set of configuration factors for caps and various segments of the sphere. The procedure is subsequently extended to the paraboloid, the ellipsoid or the cone, useful in issues such as rocket nozzle design and organic shapes contained in human physique. Appropriate combination of the said forms with truncated cones, produces highly articulate shapes, which 
frequently occur in the technical domains but were not feasible for exact calculation during a number of years. The research is duly accomplished by presenting the equations needed to evaluate interreflections in curvilinear geometries. Thus, heat transfer simulation is enhanced by such results leading to create innovative software which has been expanded in turn by the authors.

\section{Outline of the problem}

The reciprocity principle enunciated by Lambert in 1760 and expressed in Eqn. (1), yields the following well-known integral equation (2) that acts as the theoretical basis for form factor calculation between two surfaces.

$$
\begin{gathered}
d \varnothing_{1-2}=\left(E_{b 1}-E_{b 2}\right) \cos \theta_{1}^{*} \cos \theta_{2}^{*} \frac{d A_{1}^{*} d A_{2}}{\pi^{*} r^{2}} \\
\varnothing_{1-2}=\left(E_{b 1}-E_{b 2}\right) \int_{A_{1}} \int_{A_{2}} \cos \theta_{1}^{*} \cos \theta_{2} * \frac{d A_{1}^{*} d A_{2}}{\pi^{*} r^{2}}
\end{gathered}
$$

Where the terms are depicted in Figure 1,

$\mathrm{E}_{\mathrm{bi}}=$ radiant power emitted by the corresponding surface 1 or 2

$\mathrm{A}_{\mathrm{i}}=$ area of surface, $\mathrm{dA}_{\mathrm{i}}=$ differential of area

$\mathrm{r}=$ distance radiovector

$\theta_{\mathrm{i}}=$ angle between radiovector at differential element $i$ and the normal to the surface

The previous expression states that radiant interchange for every given form depends on its shape and its relative position in the three-dimensional space (Figure 1). From the times of Lambert to our days, researchers and scientists in the fields of geometric optics and radiative transfer have sought to provide solutions to the canonical equation (2) for a variety of forms [1]. This is no minor feat, since the said equation leads in most cases to a quadruple integration and the fourth degree primitive of even simple mathematical expressions often implies lengthy calculations.

Given the fact that this equation depends on geometric parameters, it is reasonable to think that there should be an easier way to approach the problem rather than dealing directly with the integral; also, with the aid of computer simulation, mathematical solutions of complex functions can be approached in a simple and friendly way. Curvilinear forms present some characteristics that make them suitable for a different treatment in terms of radiative transfer.

\section{Form factors derived from the sphere}

Starting from simple forms several form factors can be calculated without hardly any calculus; later, this logic can be applied to more complex configurations. Let us consider first the simplest 


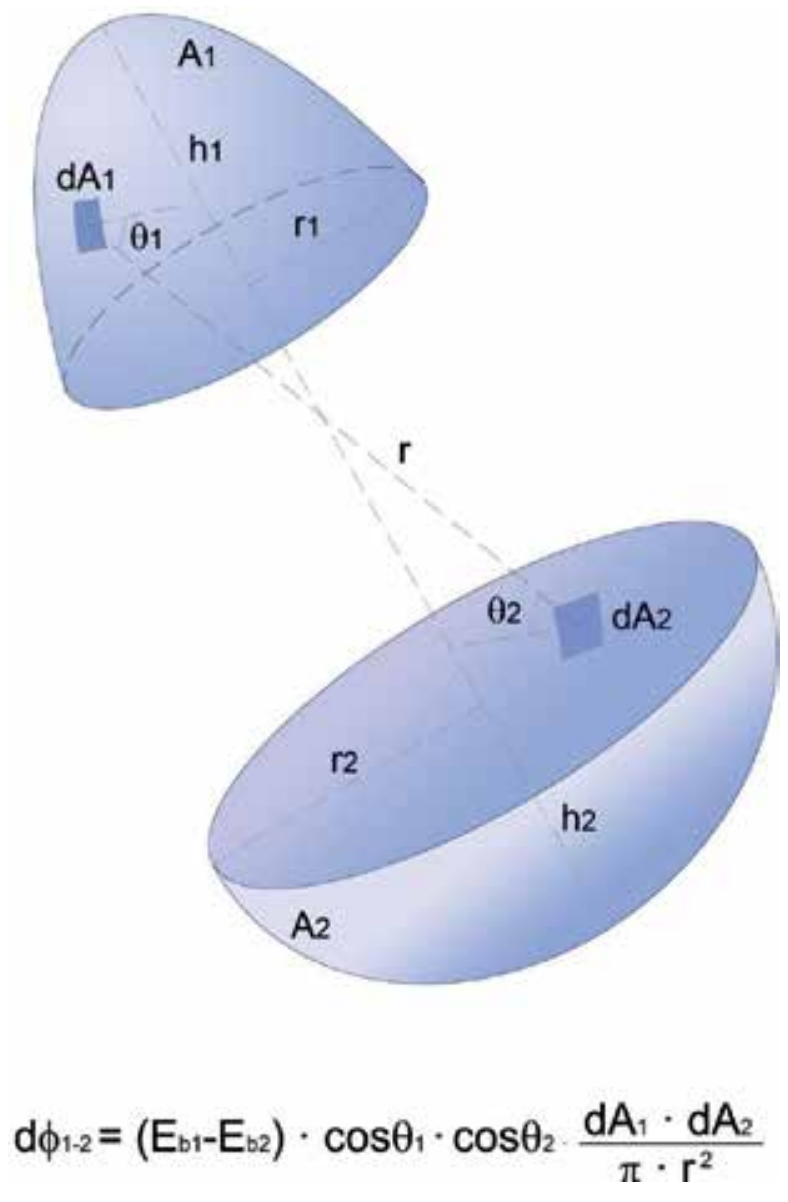

Figure 1. The reciprocity principle and equation for arbitrary surfaces $A_{1}$ and $A_{2}$

form, a sphere that irradiates energy from its inner surface; the irradiated energy is entirely received by itself; so that, being the sphere surface 1 , the only factor that has to be considered is:

$$
\mathrm{F}_{11}=1
$$

Bearing this in mind, in a similar surface, for instance a hemisphere, the form factor is accordingly $\mathrm{F}_{11}=1 / 2$. The configuration factor of a differential area to a disk of radius $r$ under the center of the disk at precisely the distance $r$, provides a hint in that it is also $1 / 2$ [2]. For a point of the hemisphere the factor required is $1 / 2$.

Stimulated by this result, volumes composed of only two surfaces, one being planar and the other spherical, were analyzed. The first case was the spherical cap which is a generalization of the hemisphere. 


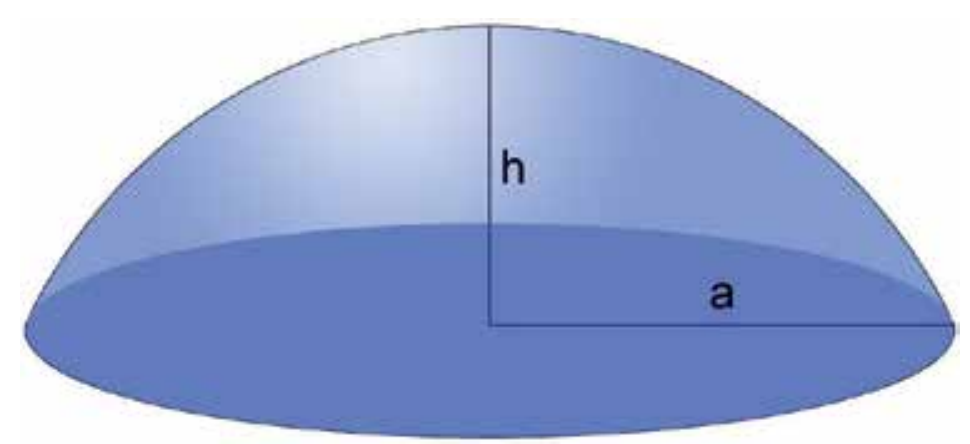

Figure 2. A spherical cap of height $h$ and radius of the base a

Extending the reciprocity principle to a spherical cap (Fig. 2) of radius $\mathrm{R}$ (surface 1), and its entire base (surface 2) the factor was obtained from the relation $A_{1} F_{12}=A_{2} \quad F_{21}$; since $\mathrm{F}_{21}=1$, and there is no $\mathrm{F}_{22}$ for planar surfaces, $F_{12}=A_{2} / A_{1}{ }^{\prime}$ in this particular case:

$$
\begin{gathered}
F_{12}=\frac{a^{2}}{a^{2}+h^{2}} \\
F_{11}=\frac{h^{2}}{a^{2}+h^{2}}=\frac{h}{2^{*} R}
\end{gathered}
$$

Two important laws are inferred from here, which have been defined as Cabeza-Lainez laws: Cabeza-Lainez first law:

If a volume is encircled by two surfaces preseting one of them positive of thempositive curvature, and the second being planar, the exchange factor from the curved surfaceto the other equals the inverse ratio of areas of the aforementioned figures. The notion of positive curvature of the element is introduced to foresee stagnation of radiant flux.

Cabeza-Lainez second law:

Within a spherical surface the form factor of any given area over itself is precisely the fraction between that area and the sphere

The second law requires of more deduction as follows

Given that a spherical cap represents an $Y^{\text {th }}$ fraction of the total area of the sphere of radius $R$, and recalling from trigonometry that,

$$
\left(h^{2}+a^{2}\right)=2 R h
$$

Thus, 


$$
Y\left(h^{2}+a^{2}\right)=4 R^{2}(5) ; Y=2 \frac{R}{h}(6) ; h=2 \frac{R}{Y}
$$

Consequently,

$$
F_{11}=\frac{h}{2 R}=\frac{h^{2} Y}{4 R^{2}}=\frac{1}{Y}
$$

Cabeza-Lainez second law:

The configuration factor of an $Y^{\text {th }}$ part of the sphere over itself is precisely the inverse of $Y$.

Thus, the assumption for the hemisphere is confirmed; in the quarter of sphere $\mathrm{F}_{11}$ has to be $1 / 4$ and successively for every portion of the given sphere.

This law will hold true even if we are not dealing with spherical caps but for any fragment of the surface. Taking a critical look at the canonical equation (1) adapted to the sphere, it is logical to establish a relationship between $\mathrm{r}, \cos \theta$ and the radius $\mathrm{R}$ (Figure 3 ).

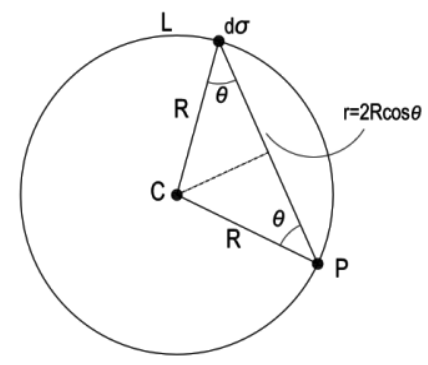

Figure 3. Differential surfaces in the sphere of centre $C$ and luminance $L$ used to find the radiative exchange

Substituting, these terms in the canonical equation (1):

$$
\varnothing_{1-2}=\frac{E_{b 1}}{4 \pi R^{2}} \int_{A_{1}} \int_{A_{2}} d A_{1} d A_{2}
$$

$4 \pi R^{2}$ is the total area of the sphere. Thus, the radiative flux transfer is dependent on the size of the surfaces but not on their position in the sphere and for given areas it is also a constant. Trying to obtain $F_{11}=\frac{\varnothing_{11}}{E_{b 1} \cdot A_{1}}$ from equation (7) gives the expression:

$$
F_{11}=\frac{A_{1}}{4 \pi R^{2}}=\frac{1}{Y}
$$

This means that spherical surfaces present these unique properties (Eqs. 3 and 8) which are crucial for our discussion crucial for our discussion. 
Now Cabeza-Lainez laws can be applied to more complex volumes that involve portions of the sphere. Considering a sector of the sphere comprised between to semicircles forming an internal angle $x$ from 0 to 180 degrees:

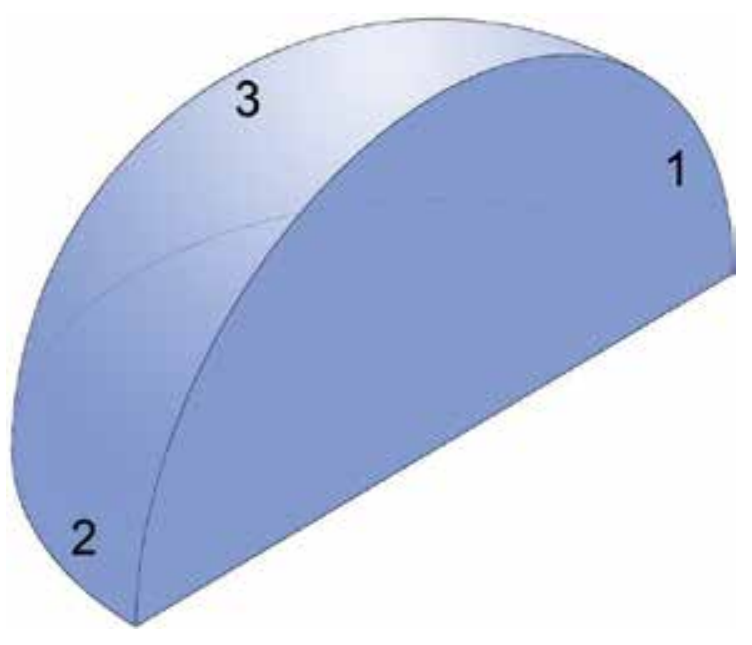

Figure 4. Denomination of surfaces in a sector of the sphere, 1 and 2 are planar semicircles, 3 is curved.

As has been discussed, the $Y$ portion of the sphere is, in this case $1 / Y=x / 360$ and thus,

$$
F_{33}=\frac{x}{360}
$$

Accordingly,

$$
F_{31}=F_{32}=\frac{1}{2}\left(1-\frac{x}{360}\right)
$$

And introducing the areas of the semicircles, ${ }^{\pi} R^{2} / 2$

$$
F_{13}=F_{23}=\frac{x}{90}\left(1-\frac{x}{360}\right)
$$

Following the discussion, these pair of semicircles can form any angle $\mathrm{x}$ between 0 and 360 degrees (Fig. 5). So that, the following equation, which has not been found expressed previously in the literature, is proposed in order to obtain the energy balance between the half disks, where $x$ represents the value of their internal angle (Figure 5). 


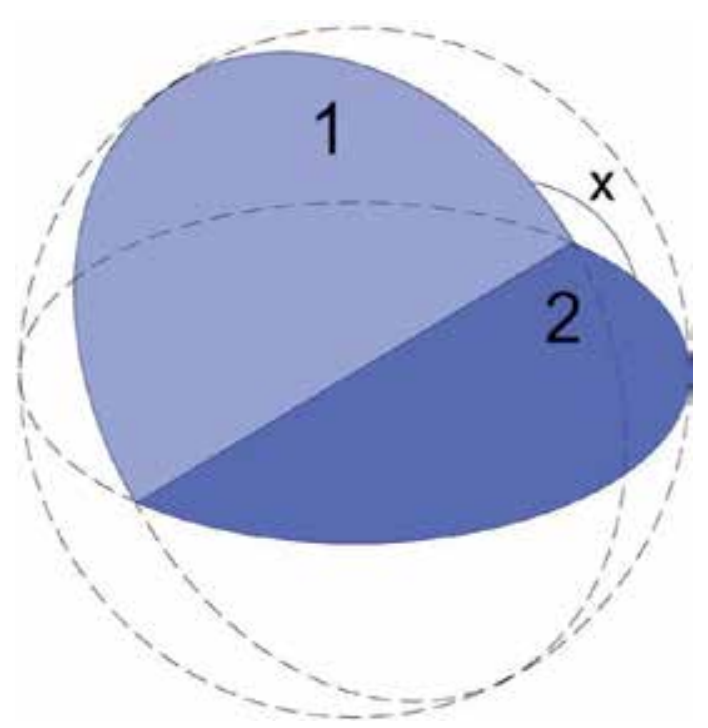

Figure 5. Two semicircles of the same radius $R$ with a common edge forming an angle $X$

$$
F_{12}=1-\frac{x}{90}+\frac{x^{2}}{32400}
$$

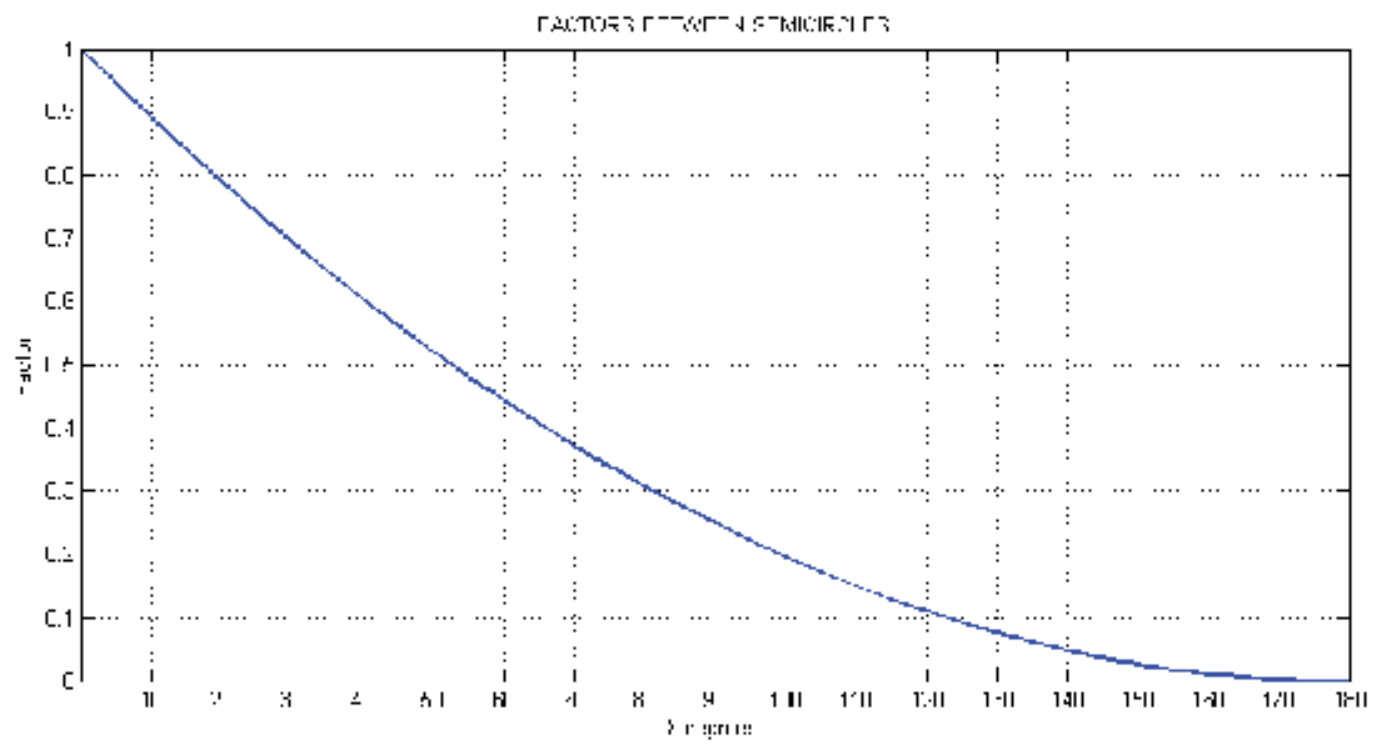

Figure 6. Radiative exchanges between two semicircles with a common edge and forming an internal angle $x$ 
The latter expression (Eq. 14) is a good indicator of the factor between two inclined and equal surfaces with a common edge. If they are not too dissimilar from the semicircle, a factor that is usually lengthy and cumbersome to calculate can be devised easily.

Let us now return to the first principle, the expression $\frac{h}{2 R}$ (Eq. 5), applied to the spherical cap. Form factors between the contained surfaces are as follows:

$$
\begin{gathered}
F_{11}=\frac{h}{2 R}=\frac{h^{2}}{h^{2}+a^{2}} \\
F_{12}=\frac{a^{2}}{h^{2}+a^{2}} \\
F_{21}=1
\end{gathered}
$$

If we introduce at this point the dimensionless parameter $\beta$, we can simplify equation 16 as,

$$
\begin{gathered}
\beta^{2}=\frac{h^{2}}{a^{2}} \\
F_{12}=\frac{1}{\beta^{2}+1}
\end{gathered}
$$

Since this principle is more general than the second one, we can extend it to non-spherical surfaces.

\section{Application to common surfaces}

\subsection{Prolate semispheroid}

Surface 1 is the spheroid and surface 2 is the circular disk that works as a base to the former, $\mathrm{h}>\mathrm{a}$.

Firstly the dimensionless parameter $\mathrm{m}$ is introduced:

$$
m=\sqrt{1-\frac{a^{2}}{h^{2}}}
$$

By virtue of the first principle,

$$
F_{12}=\frac{a^{*} m}{a^{*} m+h^{*} \arcsin (m)}
$$




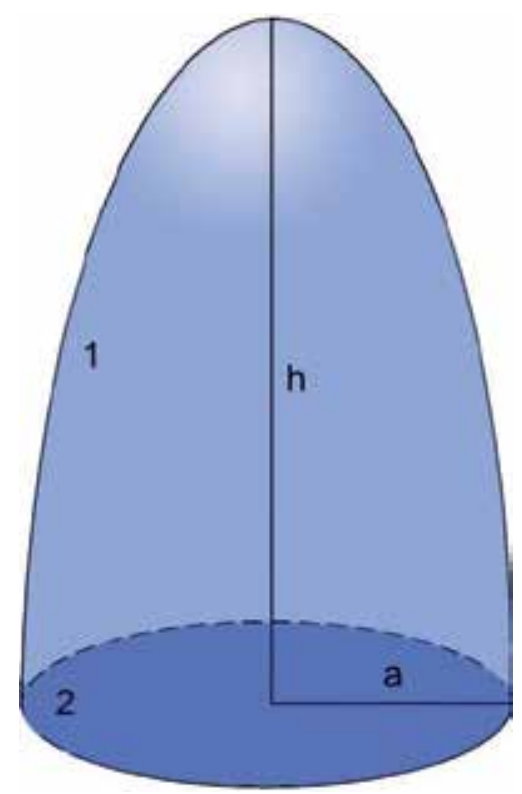

Figure 7. Prolate spheroid

$$
\begin{gathered}
F_{21}=1 \\
F_{11}=\frac{h^{*} \arcsin (m)}{a^{*} m+h^{*} \arcsin (m)}
\end{gathered}
$$

And making,

$$
\begin{gathered}
\beta^{2}=\frac{h^{2}}{a^{2}} ; m=\sqrt{1-\frac{1}{\beta^{2}}} \\
F_{12}=\frac{\sqrt{1-\frac{1}{\beta^{2}}}}{\sqrt{1-\frac{1}{\beta^{2}}}+\beta^{*} \arcsin \left(\sqrt{1-\frac{1}{\beta^{2}}}\right)}
\end{gathered}
$$

\subsection{Oblate semiespheroid}

Surface 1 is the spheroid and surface 2 is the circular disk that works as a base to the former, $\mathrm{h}<\mathrm{a}$

Denote the parameter $\mathrm{m}_{1}$

$$
m_{1}=\sqrt{\frac{a^{2}}{h^{2}}-1}
$$




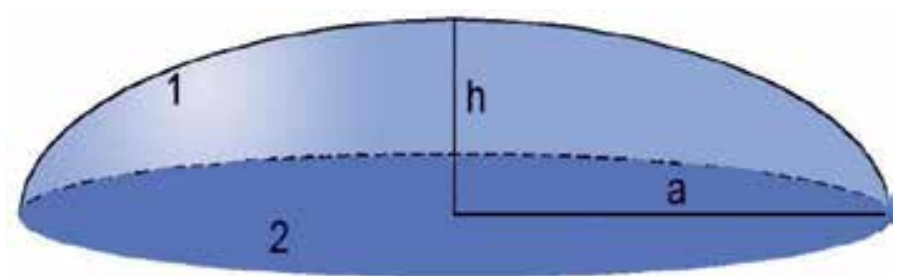

Figure 8. Oblate spheroid

$$
F_{12}=\frac{a^{*} m_{1}}{a^{*} m_{1}+h^{*} \operatorname{arcsinh}\left(m_{1}\right)} ; F_{21}=1
$$

By the first principle and,

$$
F_{11}=\frac{h^{*} \operatorname{arcsinh}\left(m_{1}\right)}{a^{*} m_{1}+h^{*} \operatorname{arcsinh}\left(m_{1}\right)}
$$

With the same procedure as before to make the expression dimensionless

$$
\begin{gathered}
m_{1}=\sqrt{\frac{1}{\beta^{2}}-1} \\
F_{12}=\frac{m_{1}}{m_{1}+\beta^{*} \operatorname{arcsinh}\left(m_{1}\right)}
\end{gathered}
$$

\subsection{Paraboloid of revolution}

Surface 1 is the paraboloid and surface 2 is the circular disk that works as a base to the former

$$
\begin{gathered}
F_{12}=\frac{6^{*} a^{*} h^{2}}{\left[\left(a^{2}+4^{*} h^{2}\right)^{3 / 2}-a^{3}\right]} ; F_{21}=1 \\
F_{11}=1-\frac{6^{*} a^{*} h^{2}}{\left[\left(a^{2}+4^{*} h^{2}\right)^{3 / 2}-a^{3}\right]} \\
\beta=\frac{h}{a} ; F_{12}=\frac{6^{*} \beta^{2}}{\left[\left(1+4^{*} \beta^{2}\right)^{3 / 2}-1\right]}
\end{gathered}
$$

\subsection{Right cone}

1 is the surface of the cone and 2 is the circular base

$$
F_{12}=\frac{a}{\sqrt{a^{2}+h^{2}}} ; F_{21}=1
$$




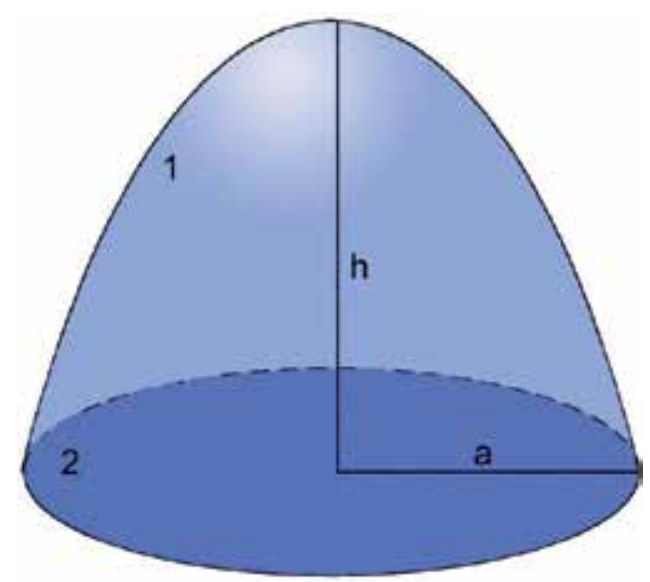

Figure 9. Paraboloid of revolution

$$
F_{11}=1-\frac{a}{\sqrt{a^{2}+h^{2}}}
$$

Introducing the parameter $\beta$,

$$
F_{12}=\frac{1}{\sqrt{1+\beta^{2}}}
$$

It is possible to compare the performance in terms of $F_{12}$, of all the figures found up to now, where the cone shows better performance followed by the paraboloid.

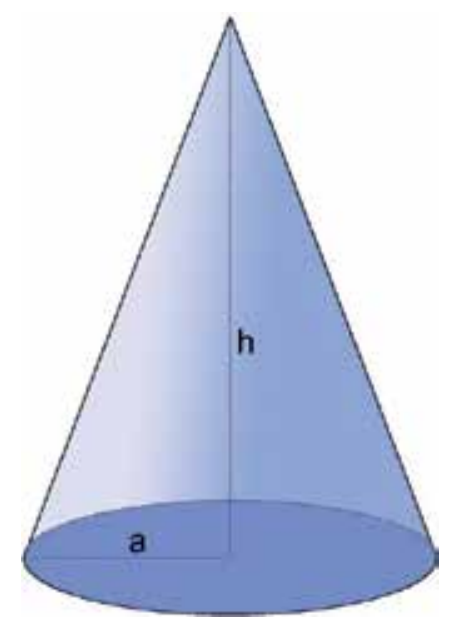

Figure 10. Cone 


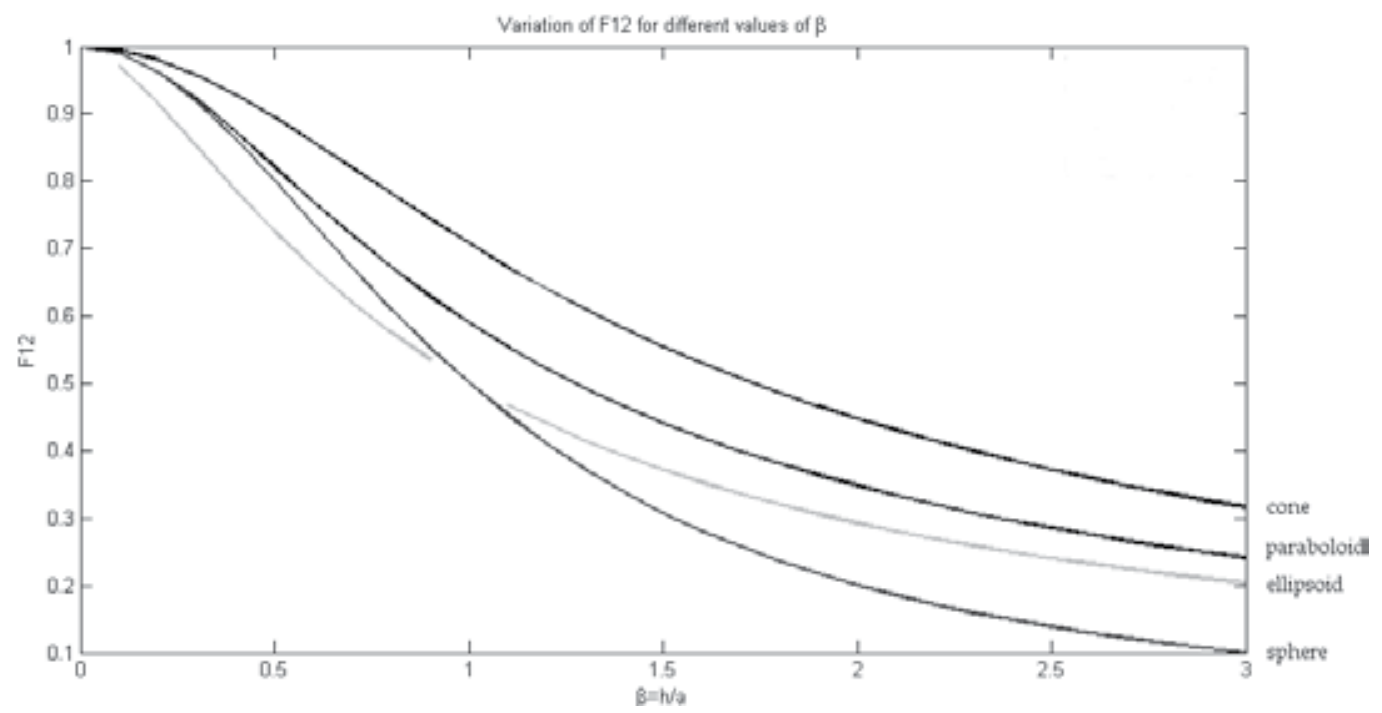

Figure 11. Comparison of form factors for different shapes

\subsection{Ellipsoid}

In this case, 1 is the surface of the ellipsoid and 2 is the elliptic base; $y$ is a parameter equal to 1.6. The example shows that the first principle is not limited to surfaces of revolution.

$$
\begin{gathered}
F_{12}=\frac{a^{*} b \sqrt[*]{3}}{2 \sqrt[x]{a^{y *} b^{y}+a^{y *} h^{y}++b^{y *} h^{y}}} ; F_{21}=1 \\
F_{11}=1-\frac{a^{*} b^{*} \sqrt[y]{3}}{2 \sqrt[*]{a^{y *} b^{y}+a^{y *} h^{y}++b^{y *} h^{y}}}
\end{gathered}
$$

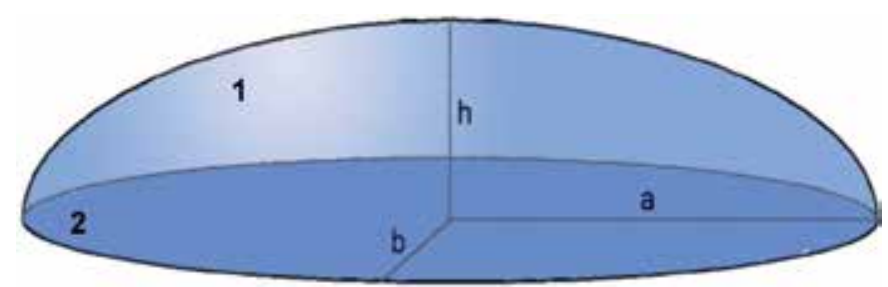

Figure 12. Ellipsoid

As the area of the ellipsoid is not exact, we can expect errors on the range of $1 \%$ depending on the values of $a, b$ and $h$.

This principle can be also used in other surfaces, for example, for two complementary caps within the sphere of radius $r$, 


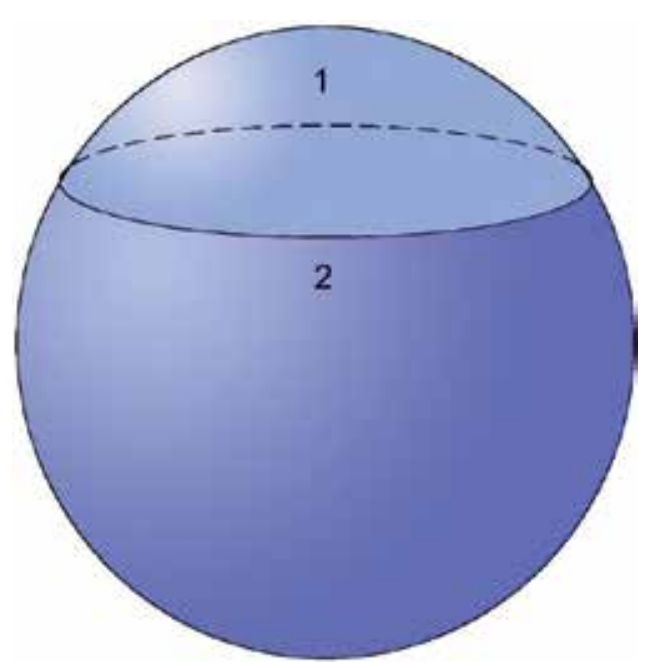

Figure 13. Sphere divided in two caps of diverse heights

As an immediate consequence of Cabeza-Lainez laws, $r$ being the radius of the inner circle and $h$ the respective heights of the caps,

$$
\begin{gathered}
F_{11}=F_{21}=\frac{h_{1}^{2}}{h_{1}^{2}+r^{2}}=\frac{r^{2}}{h_{2}^{2}+r^{2}}=\frac{h_{1}{ }^{*} h_{2}}{h_{2}^{2}+r^{2}}=\frac{h_{1}{ }^{2}+r^{2}}{\left(h_{1}+h_{1}\right)^{2}}=\frac{h_{1}}{\left(h_{1}+h_{2}\right)}=\frac{h_{1}}{2^{*} R} \\
F_{22}=F_{12}=\frac{h_{2}^{2}}{h_{2}^{2}+r^{2}}=\frac{r^{2}}{h_{1}^{2}+r^{2}}=\frac{h_{1}{ }^{*} h_{2}}{h_{1}^{2}+r^{2}}=\frac{h_{2}}{\left(h_{1}+h_{2}\right)}
\end{gathered}
$$

If now the caps within the same sphere are of any size and arbitrary position,

In this case by virtue of Cabeza-Lainez Law,

$$
F_{11}=\frac{h_{1}^{2}}{h_{1}^{2}+a^{2}} ; F_{22}=\frac{h_{2}^{2}}{h_{2}^{2}+a_{2}^{2}}
$$

And now we need to apply the canonical equation 9 again, substituting the respective areas of the caps; $A_{1}=2 \cdot \pi \cdot R \cdot h_{1} \cdot ; A_{2}=2 \cdot \pi \cdot R \cdot h_{2}$

$$
\begin{gathered}
\varnothing_{1-2}=\frac{E_{b 1}}{4^{*} \pi^{*} R^{2}} \int_{A_{1}} \int_{A_{2}} d A_{1}^{*} d A_{2} \\
F_{12}=\frac{h_{1}{ }^{*} h_{2}}{h_{1}{ }^{2}+a^{2}} ; F_{21}=\frac{h_{1}{ }^{*} h_{2}}{h_{2}{ }^{2}+a_{2}{ }^{2}}
\end{gathered}
$$




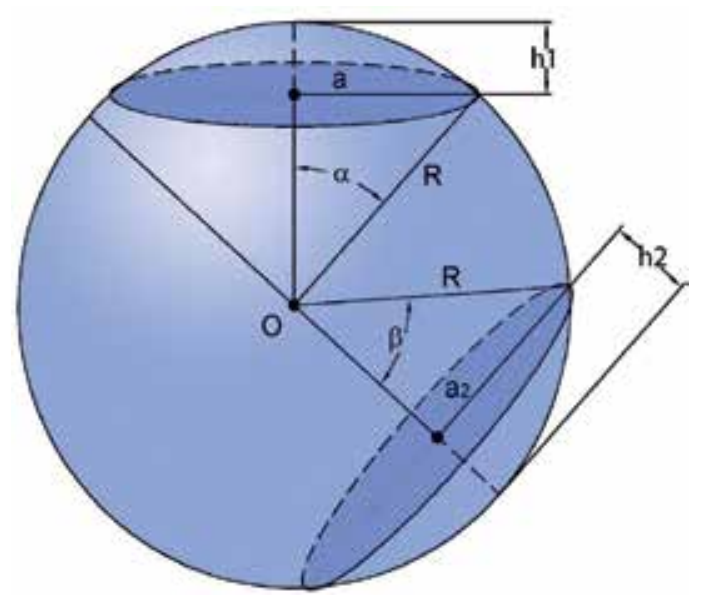

Figure 14. Two caps of arbitrary size

In the special situation that the caps are parallel, which equates a truncated cone, the flux would be $E_{b 1} \cdot \pi \cdot h_{1} \cdot h_{2}$ and the fraction of energy from disk 1 to disk 2 (or their surrounding caps), equates $h_{1}{ }^{*} h_{2} / a^{2}$ or $h_{1}{ }^{*} h_{2} / a_{2}^{2}$. In the case that the bases are of equal radius $\mathrm{a}, \mathrm{h} 1=\mathrm{h} 2=\mathrm{h}$. If the perpendicular distance between the disks, called 2b, is known (Figure 15), the height of the cap would be,

$$
h=\sqrt{a^{2}+b^{2}}-b
$$

Thus, the fraction is obtained as,

$$
F_{12}=F_{21}=\frac{a^{2}+2^{*} b^{2}-2^{*} b^{*} \sqrt{a^{2}+b^{2}}}{a^{2}}
$$

By virtue of equation 45 it is feasible to address radiative transfer in several figures composed of three surfaces and limited by parallel disks like truncate paraboloids, caps and especially cylinders. Appropriate equations can be easily formed in which only two values need to be found. To the circles in the extremes of the cylinder a spherical cap could be connected (fig. 16) and the radiative transfer would not be altered significantly since we have previously described the performance of caps limited by circles. In the particular case that the cap is a hemisphere, the factor already determined ought to be multiplied by 0.5 and subsequently for different curvatures, bearing in mind that the unity is the circle and null would imply a "theoretical" whole sphere ${ }^{1}$

1 Note that values under 0.5 can also be found for this relationship in a sort of globular cap with an area bigger than the hemisphere. 


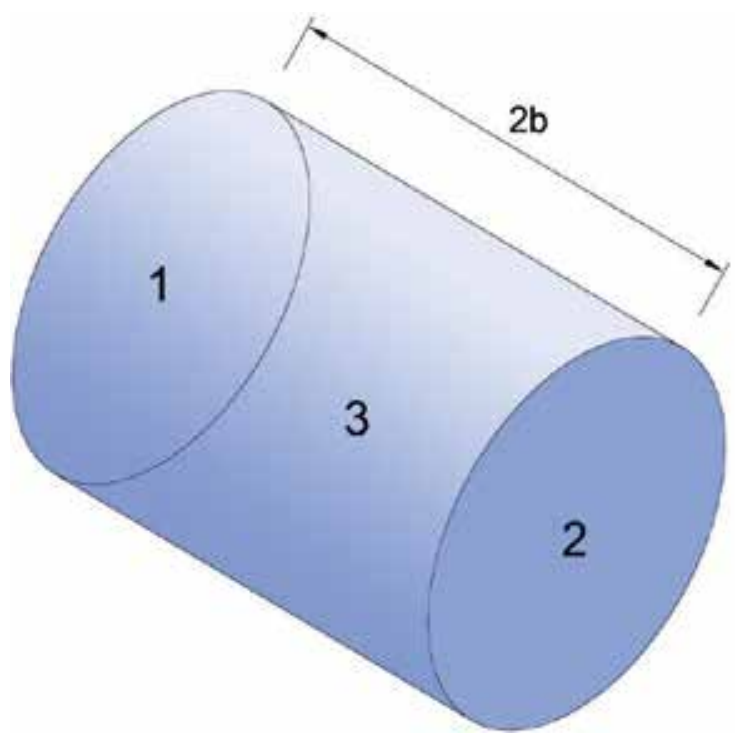

Figure 15. Surfaces defined by a cylindrical volume used to find the radiative transfer

The space of figure 16 has been used throughout the history of buildings in cathedrals, opera houses, museums and assembly halls. If both extremes are curved, such shape is still found at bunkers, water tanks and pressure vessels of power reactors.

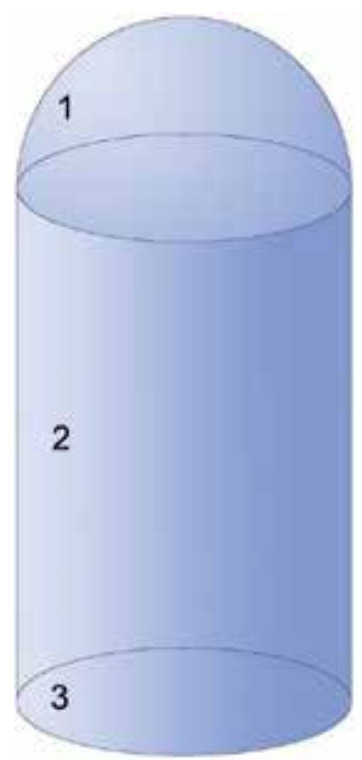

Figure 16. Volume composed of a cylinder and a spherical cap used to find the radiative transfer among those surfaces 


\subsection{Two opposed spherical caps with a common axis}

In order to calculate the radiative exchanges in this relatively complex figure, we need to determine beforehand the following nine geometric parameters that depend on the geometric variables shown in Figure 17.

$$
\begin{gathered}
z=\frac{r_{1}^{2}-r_{2}^{2}}{4^{*} b} ; R=\sqrt{(z+b)^{2}+r_{2}^{2}} \\
l=\sqrt{\left(r_{1}-r_{2}\right)^{2}+4^{*} b^{2}} \\
Q=R^{2}-z^{2}+b^{2}-2^{*} R^{*} b \\
Q_{1}=r_{1}^{2}-Q ; Q_{2}=r_{2}^{2}-Q \\
D_{1}=h_{1}^{2}+r_{1}^{2} \\
D_{2}=h_{2}^{2}+r_{2}^{2} \\
D_{3}=l^{*}\left(r_{1}+r_{2}\right)
\end{gathered}
$$

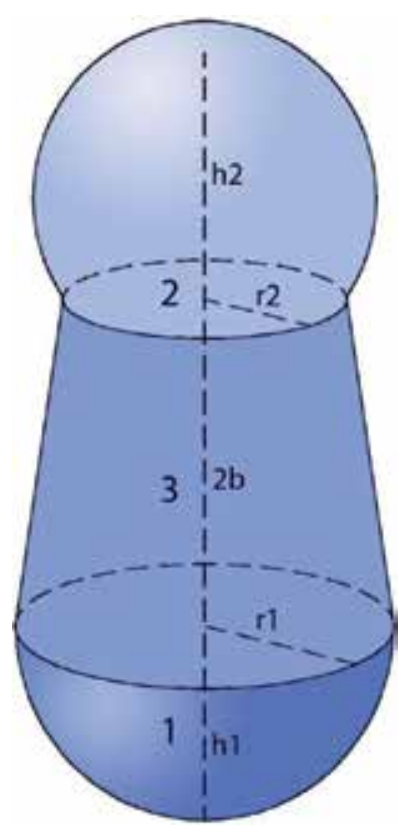

Figure 17. Volume composed by spherical cap, truncated cone and hemispheroid. 
And then we would obtain the corresponding nine form factors involved,

$$
\begin{gathered}
F_{11}=\frac{h_{1}^{2}}{D_{1}} ; F_{12}=\frac{Q}{D_{1}} ; F_{13}=\frac{Q_{1}}{D_{1}} \\
F_{22}=\frac{h_{2}^{2}}{D_{2}} ; F_{21}=\frac{Q}{D_{2}} ; F_{23}=\frac{Q_{2}}{D_{2}} \\
F_{31}=\frac{Q_{1}}{D_{3}} ; F_{32}=\frac{Q_{2}}{D_{3}} ; F_{33}=1-\frac{Q_{1+} Q_{2}}{D_{3}}
\end{gathered}
$$

In this simple way the problem is completely solved

\subsection{Straight cone}

This is a limit case of the previous discussion.

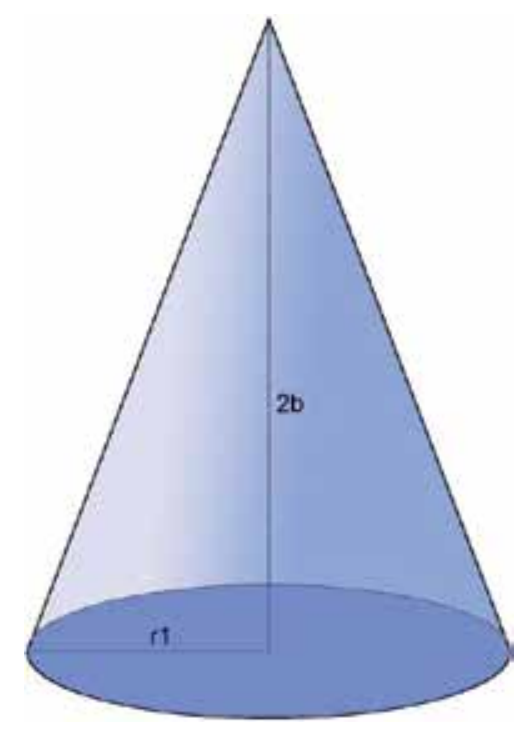

Figure 18. Right cone with a circular base

As the former also includes the cone, by making $r_{0}=0$ and $h_{1}=h_{2}=0$, $Q_{2}=0, \quad z=\frac{r_{1}^{2}}{4 b}, R=z+b, \quad Q=0, \quad Q_{1}=0, \quad Q_{2}=0$

$$
l=\sqrt{r_{1}^{2}+4^{*} b^{2}}
$$

If $D_{1}=r_{1}^{2}, D_{2}=0$ then 


$$
D_{3}=\sqrt{r_{1}^{2}+4^{*} b^{2}}
$$

Only three factors remain,

$$
\begin{gathered}
F_{11}=1 \\
F_{31}=\frac{r_{1}}{\sqrt{r_{1}^{2}+4^{*} b^{2}}} \\
F_{33}=1-\frac{r_{1}}{\sqrt{r_{1}^{2}+4^{*} b^{2}}}
\end{gathered}
$$

$\mathrm{F}_{31}$ is obviously the ratio of areas of the cone to its base which proves that the equation is true, by virtue of Cabeza-Lainez Law.

\subsection{Paraboloid, truncated cone and spheroid}

If for instance, the upper extreme of the volume is a paraboloid and the lower surface is an oblate ellipsoid (Figure 19), we can still maintain the same factors with the following simple adaptations,

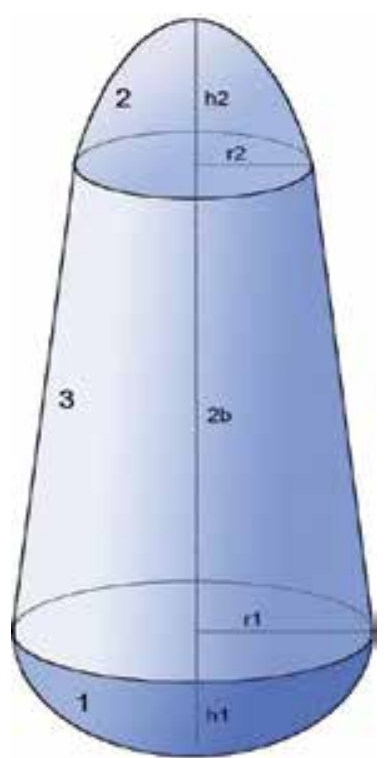

Figure 19. Volume composed by a paraboloid, a truncated cone and a spheroid.

$$
F_{22}=1-\frac{6^{*} r_{2}{ }^{*} h_{2}{ }^{2}}{\left.\left[\left(r_{2}{ }^{2}+4^{*} h_{2}\right)^{3}\right)^{3 / 2}-r_{2}{ }^{3}\right]}
$$


as in the paraboloid alone

$$
\begin{aligned}
& F_{21}=\frac{6^{*} h_{2}^{2 *} Q}{r_{2}^{*}\left[\left(r_{2}^{2}+4^{*} h_{2}^{2}\right)^{3 / 2}-r_{2}^{3}\right]} \\
& F_{23}=\frac{6^{*} h_{2}^{2 *}\left(r_{2}^{2}-Q\right)}{r_{2}^{*}\left[\left(r_{2}^{2}+4^{*} h_{2}^{2}\right)^{3 / 2}-a_{2}^{3}\right]} \\
& F_{11}=\frac{h_{1}^{*} \operatorname{arcsinh}\left(m_{1}\right)}{r^{*} m_{1}+h_{1}^{*} \operatorname{arcsinh}\left(m_{1}\right)}
\end{aligned}
$$

as it were in the oblate elipsoid alone

$$
\begin{gathered}
m_{1} \text { is now }=\sqrt{\frac{r_{1}^{2}}{h_{1}^{2}}-1} \\
F_{12}=\frac{m_{1}^{*} Q}{r_{1}^{*}\left(r^{*} m_{1}+h_{1}^{*} \operatorname{arcsinh}\left(m_{1}\right)\right)} \\
F_{13}=\frac{m_{1}^{*}\left(r_{1}^{2}-Q\right)}{r_{1}^{*}\left(r_{1}^{*} m_{1}+h_{1}^{*} \operatorname{arcsinh}\left(m_{1}\right)\right)}
\end{gathered}
$$

$\mathrm{F}_{31}, \mathrm{~F}_{32}$ and $\mathrm{F}_{33}$ have the same values as before as these correspond to the truncated cone and bear only nominal relation with the surfaces of the extremes,

$$
\begin{gathered}
F_{31}=\frac{Q_{1}}{D_{3}} \\
F_{32}=\frac{Q_{2}}{D_{3}} \\
F_{33}=1-\frac{Q_{1+} Q_{2}}{D_{3}}
\end{gathered}
$$

Similar results will be obtained when the truncate is a paraboloid instead of a cone as it is the case in rocket nozzles.

\subsection{Summary of the findings}

All the aforementioned form factors have been obtained by logical deduction. In order to provide researchers and designers with all this factors in a compact format, the following table is presented, which comprises all the volume configurations presented in this chapter.

$\mathrm{F}_{21}$ is always the unit as shown by first law 


\begin{tabular}{|c|c|c|c|}
\hline SURF. & Area of the revolution surface & $\mathrm{F}_{1_{\rightarrow_{1}}}$ & $\mathrm{~F}_{1_{\rightarrow_{2}}}$ \\
\hline $\begin{array}{l}\text { Prolate semi- } \\
\text { spheroid with } \\
\text { circular base }\end{array}$ & $\begin{array}{c}2 \pi a^{2} \frac{\operatorname{arcsen}(m)(h+a m)}{a m} \\
m=\sqrt{1-a^{a^{2}} / h^{2}}\end{array}$ & $\frac{h^{*} \arcsin (m)}{a^{*} m+h^{*} \arcsin (m)}$ & $\frac{a^{*} m}{a^{*} m+h^{*} \arcsin (m)}$ \\
\hline $\begin{array}{l}\text { Oblate semi- } \\
\text { spheroid with } \\
\text { elliptic base }\end{array}$ & $\begin{array}{c}2 \pi a^{2} \frac{\operatorname{arcsenh}(m)(h+a m)}{a m} \\
m=\sqrt{a^{2} / h^{2}-1}\end{array}$ & $\frac{h^{*} \operatorname{arcsinh}\left(m_{1}\right)}{a^{*} m_{1}+h^{*} \operatorname{arcsinh}\left(m_{1}\right)}$ & $\frac{a^{*} m_{1}}{a^{*} m_{1}+h^{*} \operatorname{arcsinh}\left(m_{1}\right)}$ \\
\hline $\begin{array}{l}\text { Revolution } \\
\text { paraboloid with } \\
\text { circular base }\end{array}$ & $\pi \frac{\sqrt[3]{a^{2}+4 h^{2}}-a^{3}}{6 a^{3} h^{2}}$ & $1-\frac{6^{*} a^{*} h^{2}}{\left[\left(a^{2}+4^{*} h^{2}\right)^{3 / 2}-a^{3}\right]}$ & $\frac{6^{*} a^{*} h^{2}}{\left[\left(a^{2}+4^{*} h^{2}\right)^{3 / 2}-a^{3}\right]}$ \\
\hline $\begin{array}{l}\text { Straight cone with } \\
\text { circular base }\end{array}$ & $\pi a \sqrt{a^{2}+h^{2}}$ & $1-\frac{a}{\sqrt{a^{2}+h^{2}}}$ & $\frac{a}{\sqrt{a^{2}+h^{2}}}$ \\
\hline Revolution & $4 \pi\left(\frac{a^{y} b^{y}+a^{y} h^{y}+b^{y} h}{3}\right)^{1 / y}$ & $(a b \sqrt[4]{3}) / 2$ & $(a b \sqrt[4]{3}) / 2$ \\
\hline Ellipsoid & $y=8 / 5$ & $\sqrt[y]{a^{y} b^{y}+a^{y} h^{y}++b^{y} h^{y}}$ & $\sqrt[y]{a^{y} b^{y}+a^{y} h^{y}++b^{y} h^{y}}$ \\
\hline
\end{tabular}

Table 1. Resume of form factors for curved surfaces.

\section{Interreflections amongst surfaces in a closed volume}

Until this point the discussion has dealt with primary transmission of energy but, in a closed space, if the surfaces have some degree of reflectivity a significant part of the flux would be re-irradiated and the concepts of emitters and receivers entwine.

Under such circumstance, the global balance of radiant power can be found through expression 71 ,

$$
E_{t o t}=E_{d i r}+E_{r e f}
$$

$E_{\text {dir }}$ is defined as the direct power received while $E_{\text {ref }}$ stands for the reflected energy. The two quantities added yield the global balance of radiant energy $E_{\text {tot }}$. If the problem entails several surfaces, expression 71 is expanded for an array of equations. To resolve it, we define beforehand the matrices $F_{d}$ and $F_{r}$, whose elements are described as follows in a three-dimensional fashion, (see figure 16):

$$
F_{d}=\left(\begin{array}{lll}
F_{11}^{*} \rho_{1} & F_{12}^{*} \rho_{2} & F_{13}^{*} \rho_{3} \\
F_{21}^{*} \rho_{1} & F_{22}^{*} \rho_{2} & F_{23}^{*} \rho_{3} \\
F_{31}{ }^{*} \rho_{1} & F_{32}^{*} \rho_{2} & F_{33}^{*} \rho_{3}
\end{array}\right)
$$




$$
F_{\mathrm{r}}=\left(\begin{array}{ccc}
1 & -F_{12}{ }^{*} \rho_{2} & -F_{13}{ }^{*} \rho_{3} \\
-F_{21}^{*} \rho_{1} & 1 & -F_{23}^{*} \rho_{3} \\
-F_{31}^{*} \rho_{1} & -F_{32}^{*} \rho_{2} & 1
\end{array}\right)
$$

Each term in equations 72 and 73 is presented in the form $F_{i j}\left(F_{11}, F_{12} \ldots\right)$. This stands for the configuration factors already found, from one of the surfaces $i$ to another adjacent surface $j$. The term $\varrho_{\mathrm{i}}$ is defined as the reflective quotient which corresponds to a given surface $i$.

A detailed explanation for the phenomenon is given in [3]. Formerly, as volumes considered were limited by planes, all the elements in the diagonal of matrix $\mathrm{F}_{d}$ were equal to zero and we could not deal with the problem while, for curved surfaces, the values of the diagonal are different from null and need to be calculated with the expressions hereby presented.

Once the value of these matrices is obtained, it is easy to establish the following relationship between direct and reflected radiation:

$$
\begin{gathered}
F_{r}{ }^{*} E_{r e f}=F_{d}^{*} E_{d i r} \\
F_{r d}=F_{r}^{-1 *} F_{d} \\
E_{r e f}=F_{r d}^{*} E_{d i r}
\end{gathered}
$$

As the value of reflected radiation is known, the problem is solved. However, we have to bear in mind that the number of surfaces should be augmented depending on the dimensions of the case study. The procedure for interreflection can be considered iterative depending on the accuracy that is required for a particular problem [3].

The simplest case of repeated reflections appears in the sphere and is wont to be employed in lieu of the former calculations with matrices.From expression 9 and successive, it was deducted that energy impinging on a point of the sphere from an emitter contained in the same surface equates the quotient between the area of the emitting surface and the total area $4 \pi R 2$, and it can be expressed under the form W/A.

After a relevant number of reflections, the total power distributed over the sphere is defined by:

$$
E_{r e f}=E^{*} \frac{W}{A} *\left(\rho+\rho^{2}+\ldots \rho^{n}\right)
$$

As,

$$
\lim _{n \rightarrow \infty}\left(\frac{\rho^{n+1}-1}{\rho-1}-1\right)=\frac{\rho}{1-\rho}
$$




$$
E_{r e f}=E * \frac{W}{A} *\left(\frac{\rho}{1-\rho}\right)
$$

In the precedent discussion $\varrho$ includes the mean of all reflection quotients $\varrho_{i}$ inside the sphere, while E represents the direct power exiting from the source. Such expression would be technically applicable to all kinds of surfaces, but its accuracy dwindles when the actual volume is not akin to a sphere. If such is the case, equation 79 would be less acceptable.

Since the reflectivity of the internal surfaces can be changed on demand, the way to treat glazed elements or voids is to assign them a high absorption coefficient to ensure that those elements play a limited role in the global energy balance.

\section{Conclusions}

An ever-increasing number of configuration factors for curved geometries, has been deducted. The authors have extracted the former in total conformity with the procedures of optical mechanics and thus the new factors can be termed as exact in contrast with other random or discretized methods.

This represents an indubitable advance of knowledge for radiative heat transfer that is already being implemented in computer models. However, the details of the simulation procedures are not discussed in this chapter in the credence that other scientists will arrive with perfect ease to the required algorithms.

Thus, this new form factors have been programmed in computer algorithms, creating a powerful tool that is able to enrich the repertoire of forms and spaces suitable for simulation. This procedure will benefit energy-conscious engineering and architecture, as has been demonstrated by the authors in previous publications $[7,8,9,10]$ Indeed, the prototypes based on the science of heat transfer are sure to progress in their accuracy and sophistication. Radiative devices and fixtures can be conceived departing from the findings exposed previously on a more scientific basis and this will be beneficial to expand the innumerable boons of solar radiation.

Contemplating the ruins of the colossal statues of Ramses in Egypt, Shelley once wrote:

My name is Ozymandias, King of Kings, Look on my works ye Mighty And Despair

\section{Acknowledgements}

Jose Cabeza would like to thank his family in Japan and Spain for failing to understand his work. 


\section{Author details}

Jose Maria Cabeza Lainez ${ }^{1,2^{*}}$, Jesus Alberto Pulido Arcas ${ }^{3}$, Manuel-Viggo Castilla ${ }^{4}$, Carlos Rubio Bellido ${ }^{4}$ and Juan Manuel Bonilla Martínez ${ }^{5}$

*Address all correspondence to: crowley@us.es

1 Universidad de Sevilla, Spain

2 Hokkaido University, Japan

3 Canon Foundation Fellow. University of Shiga Prefecture, Japan

4 Universidad de Sevilla, Spain

5 Universidad Politécnica de Cataluña, Spain

\section{References}

[1] John R. Howell, A Catalogue of Radiation Heat Transfer Configuration Factors. 3rd ed., 2010. On-line version available at: http://www.engr.uky.edu/rtl/ Catalog/.

[2] Buschman, Albert Jr. and Pittman, Claud M., 1961, "Configuration factors for exchange of radiant energy between axisymmetrical sections of cylinders, cones, and hemispheres and their bases," NASA TN D-944.

[3] Cabeza-Lainez Jose M. Solar Radiation In buildings. Performance and Simulation procedures. InTech. 2012.

[4] Cabeza Lainez Jose M. New Configuration Factors for Curved Surfaces. Journal of Quantitative Spectroscopy and Radiative Transfer (JQSRT). Vol. 117. March 2013.

[5] Cabeza Lainez Jose M. New configuration factor between a circle, a sphere and a differential area at random positions. Journal of Quantitative Spectroscopy and Radiative Transfer (JQSRT). Vol. 133. November 2013

[6] Cabeza Lainez Jose M. Fundamentals of Luminous Radiative Transfer. Netbiblo. 256 pg. December 2010.

[7] Cabeza Lainez Jose M, Jimenez Verdejo Juan R. The Japanese Experience of Environmental Architecture through the Works of Bruno Taut and Antonin Raymond. Journal of Asian Architecture and Building Engineering (JAABE). Pp. 33-40. May 2007.

[8] Cabeza-Lainez Jose M. Lighting Features in Japanese Traditional Architecture. In Lessons from Vernacular Architecture. Earthscan Routledge. 215 pp. August 2013. 
[9] Cabeza Lainez Jose M. The quest for light in Indian Architectural Heritage. Journal of Asian Architecture and Building Engineering. Pp. 39-46. May 2008.

[10] Cabeza Lainez Jose M, Jimenez Verdejo Juan R. The Key-role of Eladio Dieste, Spain and the Americas in the Evolution from Brickwork to Architectural Form. Journal of Asian Architecture and Building Engineering (JAABE). Pp. 355-362. November 2009. 


\title{
Chapter 2
}

\section{Steady State Thermal Analysis of a Tri-Wing Solar Chimney}

\author{
R. S. Bello, C. N. Ezebuilo, T. A. Adegbulugbe and \\ K. A. Eke
}

Additional information is available at the end of the chapter

http://dx.doi.org/10.5772/59721

\section{Introduction}

The solar chimney is one of the technologies which work on the principle of buoyancy, in which air is heated through the greenhouse effect generated by solar radiation (heat energy) at low cost. The solar chimney is a passive solar ventilation system (non-mechanical) that can be installed on roofs or in walls. The heat is transferred based on the convective cooling principle which works on the fact that hot air rises upward; these chimneys reduce unwanted heat during the day by displacing interior (warm) air with exterior (cool) air. Solar chimneys are mainly made of a black, hollow thermal mass with an opening at the top as an exit for the hot air. The air in the room exits from the top of the chimney (Figure 1). The process can also be reversed for room heating.

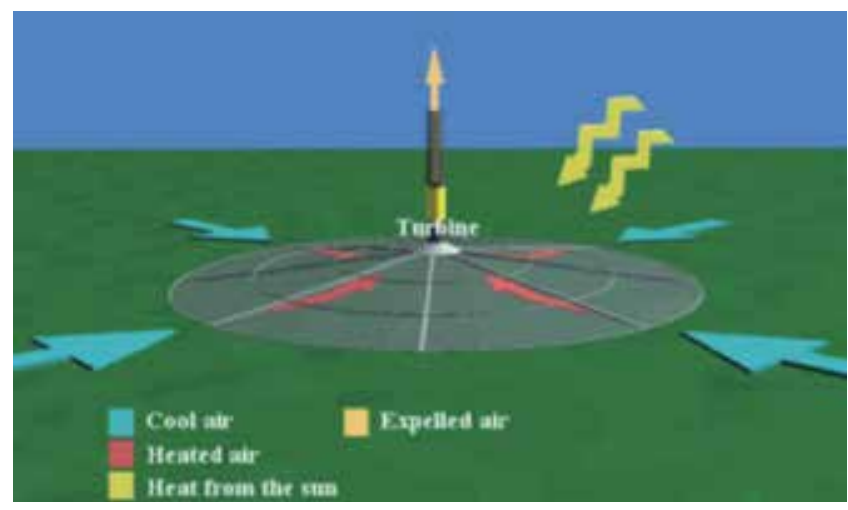

Figure 1. Solar chimney [1] 
Solar chimney performance analysis for natural circulation dryers reported that simple air heater increases ventilation up to some extent but not sufficiently [1]. Also, Duffie, and Beckman, (2003) experimentally analyzed an inclined window-sized roof solar chimney and found its summer performance to increase. Duffie, and Beckman, (2003) equally studied the effects of various performance parameters like chimney width and height and solar radiation on flat-plate collectors. The thermal analysis on tri-wing collectors both at steady and transient states is an entirely new area of collector configuration research with limited research outcomes.

\subsection{Project objective}

For effective design of tri-wing solar chimney, solar parametric equations were utilized to model drying conditions at chimney inlet and outlet to maximize the differentials between system temperatures and air densities and their effects on drying applications. The air density depends on the temperature; hence, it also implies that the maximum differentials between the chimney air temperature and the ambient temp should give the best chimney performance.

The first mathematical model for the solar chimney design (Trombe wall) was given by $[3,16]$, and they also reported the concept of increasing airflow by increasing solar irradiation. This theoretical study also reported an air change per hour with change in the coefficient of fluid (air) discharge. Alter, (2011) reported the mathematical model of a conventional vertical chimney which operates under natural convention conditions where the temperature of the air inside the chimney is warmer than outside. Shiv et al., (2013) reported that solar chimney as a solar air heater may be represented by position (as vertical or horizontal chimney), or as a part of a wall (in the form of Trombe wall) or as a roof solar collector [6]. The roof solar chimney is the most convenient and mature technology used for buoyancy-driven natural ventilation systems $[7,8,9]$.

A complete analysis of the tri-wing collector with a mathematical model is cumbersome because of its distinct features compared to an ordinary flat-plate model comparison of its performance effectiveness with experimental design data using high-precision apparatus and equipment offers a realistic solution. The objective of this study is to use analytical method to derive expressions for modelling drying effects of buoyant airflow created by solar heating of a tri-wing collector.

\section{Experimental setup}

The solar chimney used in modelling drying conditions is shown in Figure 2. The experimental solar chimney is a hollow cylindrical channel of glass glazing. The walls of the chimney were made as smooth as possible to reduce pressure losses due to wall friction. The absorbing surface (collector) is a tri-wing multi-flapped selective absorber plate draped inside the glazed glass. This chimney is mounted above the room space (drying chamber) through which dry air passes. 


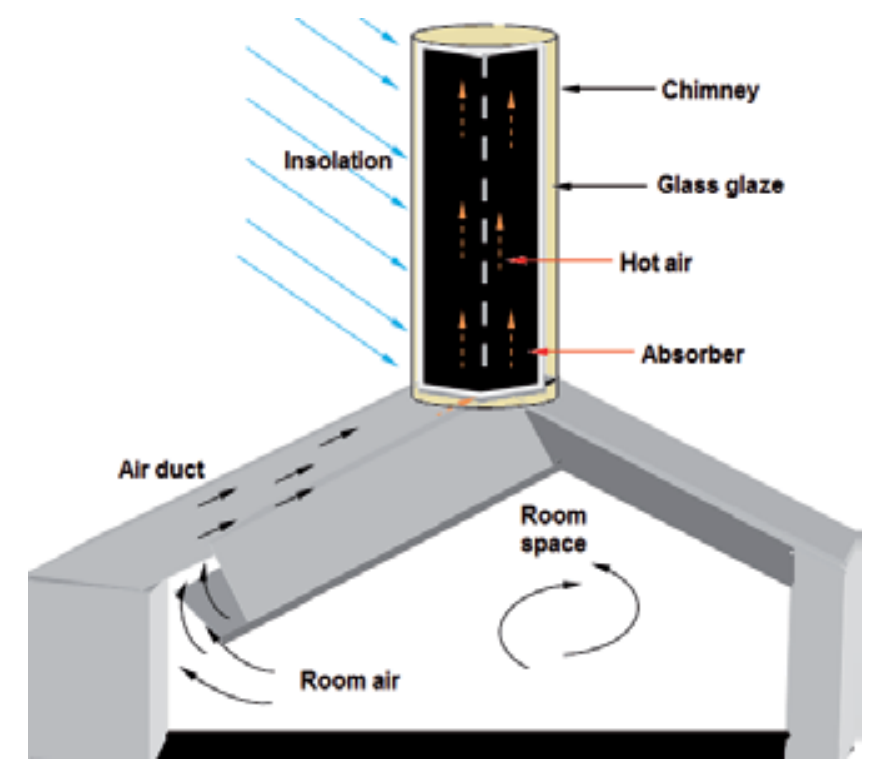

Figure 2. Schematic diagram of solar chimney

\section{Solar incident radiation on each wing}

The incident angle of radiation reaching any collector surface is expressed by the general expression

$$
\operatorname{Cos} \theta=-\sin \delta \cos \varphi \cos \gamma+\cos \delta \sin \varphi \cos \gamma \cos \omega+\cos \delta \sin \gamma \sin \omega
$$

This expression was used to model the following equations for each of the wings in terms of $\omega$ as

$$
\operatorname{Cos} \theta=-(0.1761+0.053 \cos \omega+0.81 \sin \omega) \text { for wing } 1
$$

$$
\operatorname{Cos} \theta=-(0.353+0.1106 \cos \omega) \text { for wing } 2
$$

$$
\operatorname{Cos} \theta=-(0.1764-0.053 \cos \omega-.1764-0.0 \omega) \text { for wing } 3
$$

Previously the expression for all the wings has been derived as

$$
\operatorname{Cos} \theta_{z}=0.9288 \operatorname{Cos} \theta-.9288
$$




\section{System heat transfer mechanism in the model}

A complex differential analysis is required to fully analyze the multi-flapped collector due to shadows and the transient heat flow of flaps at different potentials (Figure 3). For instance, when the sun is between the azimuth of east and south, wings 1 and 2 receive full-area radiation at different incident angles, while wing 3 receives partial-area direct radiation due to the shadow of wing 2 cast on it. The case is reverse when the sun is between the azimuths of south and west, the critical time of changeover. When the sun is over the azimuth of $0^{\circ}$, wings 1 and 3 receive full-area direct radiation at different incident angles, and wing 2 receives partial direct radiation. This only happens intermittently (Figure 3).

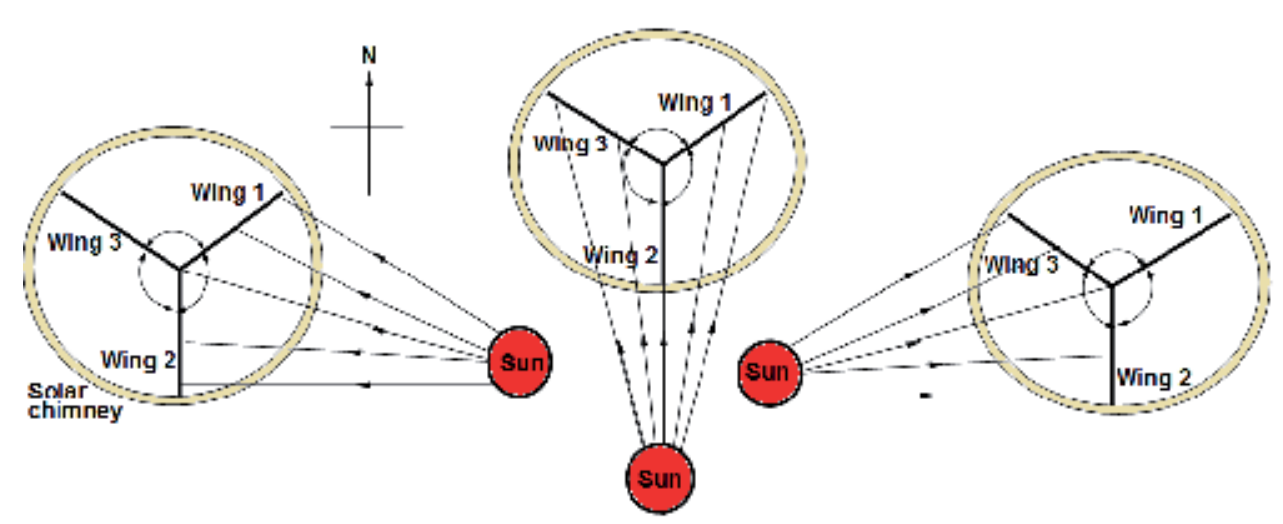

Figure 3. Azimuth positions of the solar insolation with respect to the three absorber surfaces

The analysis of a tri-axially configured surface is cumbersome because of its distinct features compared to an ordinary flat-plate model; to overcome this, an assumption is made that the collector absorber material is a highly conductive metal such that heat due to absorbed radiation is evenly distributed in all the flaps. This implies that solar radiation incident on the collector is such that there is no temperature gradient anywhere in the collector (i.e. the absorber is isothermal at any point in time).

\subsection{Assumptions on analytical methods}

In the course of analysis of this solar collector, a number of overriding assumptions were made which made the correlation of analyzed values comparable to experimental data values. Experimental data for this type of solar collector at the study location (Nsukka, Enugu state, Nigeria) was not available; however, such correlations provide a complete analytical method. Such assumptions considered a vertical tri-wing absorber collector heated by insolation to a temperature $T_{p}$ with free convection boundary layer effects and also considered a zero air stream velocity which could be increased to some maximum value and then decreased to zero again due to free stream conditions, provided the gap between the plate and the cover is much greater than the boundary layer thickness. 
To effectively model flow within the solar chimney, the analytical method employed required the following steps:

1. First, determination of available solar radiation data in the study location.

2. Second, evaluation of optical properties of glazing materials (assumed to be same as that of flat glazed collectors).

3. Third, consideration of the electrical analogy of the system (from which the collector efficiency factor $F^{\prime}$ expression and the overall collector heat loss $U_{L}$ expression were derived).

4. Last, the heat transfer analysis and collector performance.

\subsection{Solar insolation data at experimental setup location}

The experimental setup was located at Nsukka, Nigeria, longitude $7^{\circ} 23^{\prime} 45^{\prime \prime}$ E and latitude $6^{\circ}$ $51^{\prime} 24^{\prime \prime} \mathrm{N}$ [10], and the data acquisition method was adopted from the works of [11]. Solar data of the year and declination of that day were taken. This data was used as a case study (data presented in another chapter of this book) with the assumption that insolation recorded for a particular month is approximately the same for the same month for every other year. Also obtained from the literature were the measurement of instantaneous values of total insolation $I_{T}$ against diffuser $I_{d}$ and beam $I_{b}$ insolations. From the instantaneous values, an expression relating to the total and beam insolations was deduced by the method of least squares for a third-order polynomial that fits the distribution of data. The polynomial is deduced as

$$
\mathrm{I}_{\mathrm{b}}=0.01524 \mathrm{I}_{\mathrm{T}}^{3}-0.0152 \mathrm{I}_{\mathrm{T}}^{2}+0.988 \mathrm{I}_{\mathrm{T}}-0.9882\left(\frac{\mathrm{MJ}}{\mathrm{m}^{2}}\right) \text { for } \mathrm{I}_{\mathrm{T}}>0.22\left(\frac{\mathrm{MJ}}{\mathrm{m}^{2}}\right)
$$

And with linear regression of natural logarithm of data distribution,

$$
\begin{gathered}
\mathrm{I}_{\mathrm{b}}=\mathrm{e}^{\left(1.761 \ln _{\mathrm{T}}-1.761\right.}\left(\frac{\mathrm{KJ}}{\mathrm{m}^{2}}\right) \text { for } \mathrm{I}_{\mathrm{T}}>220\left(\frac{\mathrm{KJ}}{\mathrm{m}^{2}}\right) \\
\mathrm{I}_{\mathrm{d}}=\mathrm{I}_{\mathrm{T}}-\mathrm{I}_{\mathrm{b}}
\end{gathered}
$$

where $I_{T}=$ total insolation, $I_{b}=$ direct beam insolation and $I_{d}=$ diffuse insolation.

These parameters were used to compute instantaneous values of hourly insolation for the day of the year when data were taken.

Solar radiation on a tilted collector is made up of the beam radiation component, the diffuse radiation component and the ground-reflected diffuse radiation components. Hence, the total hourly solar radiation on a tilted surface is the summation of the three components: 


$$
\mathrm{I}_{\mathrm{c}}=\mathrm{I}_{\mathrm{bc}}+\mathrm{I}_{\mathrm{dc}}+\mathrm{I}_{\mathrm{dgc}}
$$

where subscript c denotes solar radiation on the collector. Furthermore,

$$
I_{c}=I_{b c} R_{b}+I_{d}[(1+\cos \beta) / 2]+\left(I_{d}+I_{b}\right) \rho[1 / 2(1-\cos \beta)]
$$

For the case study, considering the collector being a vertical wall and no vegetation covering the ground, $\beta=90^{\circ}$ and $\varrho=0.2$. Substituting these conditions into the equation of the total hourly radiation on the collector gives

$$
I_{c}=I_{b c} R_{b}+0.5 I_{d}+0.1\left(I_{d}+I_{b}\right)\left(R_{b}+0.1\right) I_{b}+0.6 I_{d}
$$

Both sides of each wing are exposed to diffuse radiation, while only one side of the wings is exposed to direct beam radiation depending on the area factor receiving this direct radiation. Hence, the total radiation aimed at each wing of the collector is

$$
\mathrm{I}_{\mathrm{ci}}=\forall \mathrm{I}_{\mathrm{b}} \mathrm{R}_{\mathrm{bi}}+2\left[0.5 \mathrm{I}_{\mathrm{d}}+0.1\left(\mathrm{I}_{\mathrm{d}}+\mathrm{I}_{\mathrm{b}}\right)\right]=\left(\forall \mathrm{R}_{\mathrm{b}}+0.2\right) \mathrm{I}_{\mathrm{b}}+1.2 \mathrm{I}_{\mathrm{d}}
$$

Thus, the total radiation aimed at the whole collector in the chimney is

$$
\mathrm{I}_{\mathrm{c}}=\mathrm{I}_{\mathrm{c} 1}+\mathrm{I}_{\mathrm{c} 2}+\mathrm{I}_{\mathrm{c} 3}
$$

Numbered subscripts 1, 2 and 3 denote wing positions.

\section{Optical properties of glazing and absorption of solar radiation}

The determination of collector performance requires the evaluation of the amount of solar radiation actually absorbed by the collector through glazing. Optical properties (transmittance, reflectance and absorptance) of the glaze cover, affects the absorption of solar radiation. These optical properties depend on the thickness of glazing and the refractive index and extinction coefficient of the glaze material. At a particular zenith angle of the sun, there are different incident angles of radiation on the circumference of the cylindrical glazing of the collector, unlike the flat-plate collector which has one uniform incident angle of radiation throughout the surface of glaze. Due to this feature, the evaluation of optical properties of a cylindrical glaze is complex. Though the glaze is cylindrical, the absorber plate is flat; hence, it was assumed that optical properties of a flat glass glazing are approximate to that of a cylindrical glass glazing. According to [12], expressions for reflection of unpolarized radiation passing from a medium with refractive index $n_{1}$ to another with refractive index $n_{2}$ are 


$$
r_{r}=\frac{\sin ^{2}\left(\theta_{2}-\theta_{1}\right)}{\sin ^{2}\left(\theta+\theta_{1}\right)} \text { and } r_{1}=\frac{\tan ^{2}\left(\theta_{2}-\theta_{1}\right)}{\tan ^{2}\left(\theta_{2}+\theta_{1}\right)}
$$

where $\theta_{1}$ and $\theta_{2}$ are the angles of incidence and refraction. The average of reflectance of unpolarized radiation [12] is then

$$
\mathrm{r}=0.5\left(\mathrm{r}_{\perp}+\mathrm{r}_{\|}\right)
$$

where $r_{\perp}$. and $r_{\|}$represents perpendicular and parallel reflectance components of the unpolarized radiation. The angle of refraction, $\theta_{2}$, is related to the refractive indices and the incident angle by Snell's law expressed as

$$
\theta_{2}=\sin ^{-i}\left[\frac{n_{1}}{n_{2}\left(\sin \theta_{1}\right)}\right]
$$

For air, $\mathrm{n}_{1}$ is approximately equal to 1 . Consequently, the expressions for transmission of unpolarized radiation passing through a slab of glass from one interface to another interface and neglecting absorption decomposed to perpendicular and parallel components are as follows:

For a perpendicular component,

$$
\tau_{\perp}=\left[\frac{1-\tau_{\perp}}{1+\tau_{\perp}}\right]
$$

For a parallel component,

$$
\tau_{\|}=\left[\frac{1-\tau_{\|}}{1+\tau_{\|}}\right]
$$

where $\tau_{\perp}$ and $\tau_{\|}$represent the perpendicular component and the parallel component of transmittance of unpolarized radiation for single cover glaze.

The average transmittance of these two components is 


$$
\tau_{r}=\frac{\left(\tau_{\perp}+\tau_{\|}\right)}{2}
$$

In order to account for absorption, a loss factor was introduced by Bourguer's law:

$$
\tau_{2}=e^{-\left[k L / \cos \theta_{2}\right]}
$$

where $\mathrm{k}$ is the extinction coefficient (which varies from $4 \mathrm{~m}^{-1}$ for white glass to $32 \mathrm{~m}^{-1}$ for green glass). $\mathrm{L}$ is the thickness of the glass. In this study, the thickness of cover glass was taken to be $2.5 \mathrm{~mm}$, the extinction coefficient $5 \mathrm{~m}^{-1}$ and the refractive index 1.526 . The product $\mathrm{k} . \mathrm{L}=0.0025 \mathrm{~m}$ $\mathrm{x} 5 \mathrm{~m}^{-1}=0.0125$.

Some of the radiation passing through the glaze and striking the absorber plate is reflected back to the cover system. However, not all of this radiation is lost, since some of it is reflected back to the plate. The multiple reflections and absorptions between the plate and the cover is the greenhouse effect. To account for this greenhouse phenomenon, the actual fraction of incident radiation absorbed by the plate is called the transmittance-absorptance product, $(\tau \alpha)$. tThis is reasonably approximated as

$$
(\tau \alpha)=\mathrm{A}(\tau) \alpha_{\mathrm{p}}
$$

The constant A ranges from 1.01 to 1.02, but for conservativeness, 1.01 is preferred:

$$
(\tau \alpha)=1.01(\tau) \alpha_{\mathrm{p}}
$$

For transmittance of diffuse radiation, the effective incident angle $\theta_{1}$ for vertical collectors is $59.5^{\circ}$ for both ground and sky diffuse radiation. Hence, the effective refractive angle $\theta_{2}$ of diffuse radiation from Snell's law is

$$
\theta_{2}=\sin ^{-\mathrm{i}}\left[\frac{\mathrm{n}_{1}}{\mathrm{n}_{2}}\left(\sin \theta_{1}\right)\right]
$$

Likewise, the reflection components are

$$
\begin{aligned}
& r_{\perp}=\frac{\sin ^{2}\left(\theta_{2}-\theta_{1}\right)}{\sin ^{2}\left(\theta_{2}+\theta_{1}\right)} \\
& r_{\|}=\frac{\tan ^{2}\left(\theta_{2}-\theta_{1}\right)}{\tan ^{2}\left(\theta_{2}+\theta_{1}\right)}
\end{aligned}
$$


The transmittance components are

$$
\begin{gathered}
\tau_{\perp}=\frac{\left(1-\tau_{\perp}\right)}{\left(1+\tau_{\perp}\right)} \\
\tau_{\|}=\frac{\left(1-\tau_{\|}\right)}{\left(1+\tau_{\|}\right)}
\end{gathered}
$$

Cover absorptance $\tau_{a}$ was evaluated with the relation

$$
\tau_{\mathrm{a}}=\mathrm{e}^{-\mathrm{wasev} \theta_{2}}
$$

Hence, the resultant transmittance for diffuse radiation is

$$
\tau_{\mathrm{d}}=\tau_{\mathrm{r}} \cdot \tau_{\mathrm{a}}
$$

Since all necessary optical properties of the glass glazing have been evaluated, the amount of solar radiation actually absorbed by the collector can be easily deduced. The total incident radiation aimed at each wing of the collector is

$$
\mathrm{I}_{\mathrm{ci}}=\forall \mathrm{I}_{\mathrm{b}} \mathrm{R}_{\mathrm{bi}}+2\left[0.5 \mathrm{I}_{\mathrm{d}}+0.1\left(\mathrm{I}_{\mathrm{d}}+\mathrm{I}_{\mathrm{b}}\right)\right]
$$

the total absorbed solar radiation of each wing is

$$
\begin{aligned}
\mathrm{S}_{\mathrm{i}} & =(\tau \alpha)_{\mathrm{b}} \forall \mathrm{I}_{\mathrm{b}} \mathrm{R}_{\mathrm{bi}}+2(\tau \alpha)_{\mathrm{b}}\left[0.5 \mathrm{I}_{\mathrm{d}}+0.1\left(\mathrm{I}_{\mathrm{d}}+\mathrm{I}_{\mathrm{b}}\right)\right] \\
& =(\tau \alpha)_{\mathrm{b}} \forall \mathrm{I}_{\mathrm{b}} \mathrm{R}_{\mathrm{bi}}+(\tau \alpha)_{\mathrm{b}}\left[\mathrm{I}_{\mathrm{d}}+0.2\left(\mathrm{I}_{\mathrm{d}}+\mathrm{I}_{\mathrm{b}}\right)\right]
\end{aligned}
$$

The mean absorbed solar radiation, $\mathrm{S}$, of the whole collector plate is evaluated by the relation

$$
S=1 / 3\left[S_{1}+S_{2}+S_{3}\right]
$$




\section{The collector efficiency factor and the collector loss coefficient}

Considering the unusual configuration of the tri-wing absorber plate, a section of it was reduced to a vertical flat-plate collector over both sides of the plate without back insulation. This implies that a wing of the absorber can be treated as a flat-plate air heater with flow over both sides of the plate. The determination of the collector efficiency factor $\mathrm{F}^{\prime}$ and the collector loss coefficient $\mathrm{U}_{\mathrm{L}}$ provided the basis for the analytical prediction of collector performance when used in the Hottel-Whillier-Bliss equation [12, 13]:

$$
\mathrm{q}_{\mathrm{u}}=\mathrm{F}^{\prime}\left[\mathrm{S}-\mathrm{U}_{1}\left(\mathrm{~T}_{\mathrm{r}}-\mathrm{T}_{\mathrm{a}}\right)\right]
$$

The collector efficiency factor F' is defined as the ratio of the actual useful energy gain to the useful gain that would result if the collector absorbing surface had been at the local fluid temperature, that is

$$
F^{\prime}=\frac{q_{u}}{\left[S-U_{1}\left(T_{r}-T_{a}\right)\right]}
$$

where $\mathrm{q}_{\mathrm{u}}$ is the actual useful heat collector rate, $\mathrm{S}$ is absorbed radiation and $\mathrm{T}_{\mathrm{r}}$ is average fluid temperature.

The collector loss coefficient $U_{1}$ is defined as the lumped overall heat loss value of the whole collector to the operating temperature difference of the collector, that is

$$
\mathrm{U}_{1}=\mathrm{E}_{\text {loss }}\left(\mathrm{T}_{\mathrm{p}}-\mathrm{T}_{\mathrm{a}}\right)
$$

where $\mathrm{E}_{\text {loss }}=$ heat loss, $\mathrm{T}_{\mathrm{p}}=$ absorber plate temperature and $\mathrm{T}_{\mathrm{a}}=$ ambient temperature of surrounding air.

To conform to the performance equation of a flat-plate collector, the configuration of the chimney collector is transformed to suit the equation. Criteria for the transformation are as follows:

1. The total area of the tri-wing absorber plate is equal to the total area of the flat absorber plate.

2. The height of the chimney collector is the same as the height of the resulting flat absorber plate.

3. The area of the circular inlet column of the chimney collector and the rectangular area inlet column of the resulting flat-plate collector are equal throughout the height of the collector. 
4. The resulting flat-plate absorber is positioned within the rectangular column such that the flow is halved.

5. Size difference of the glass glazing of the two cases is neglected. The resulting flat-plate collector has an absorber plate $5.3 \mathrm{~m}$ in height and $2.4 \mathrm{~m}$ in breadth enclosed by a rectangular channel of glass glazing measuring $2.46 \mathrm{~m}$ by $0.8587 \mathrm{~m}$ in length and breadth. Thus, the flow width on either side of the plate is about $43 \mathrm{~cm}$.

\subsection{Electrical analogy}

According to [12], the usual procedure of deriving $\mathrm{F}^{\prime}$ and $\mathrm{U}_{1}$ is by converting a schematic diagram of the collector system to a thermal network of electrical analogy and analyzing the resulting circuit. A schematic diagram with equivalent thermal network is shown in Figure 4.
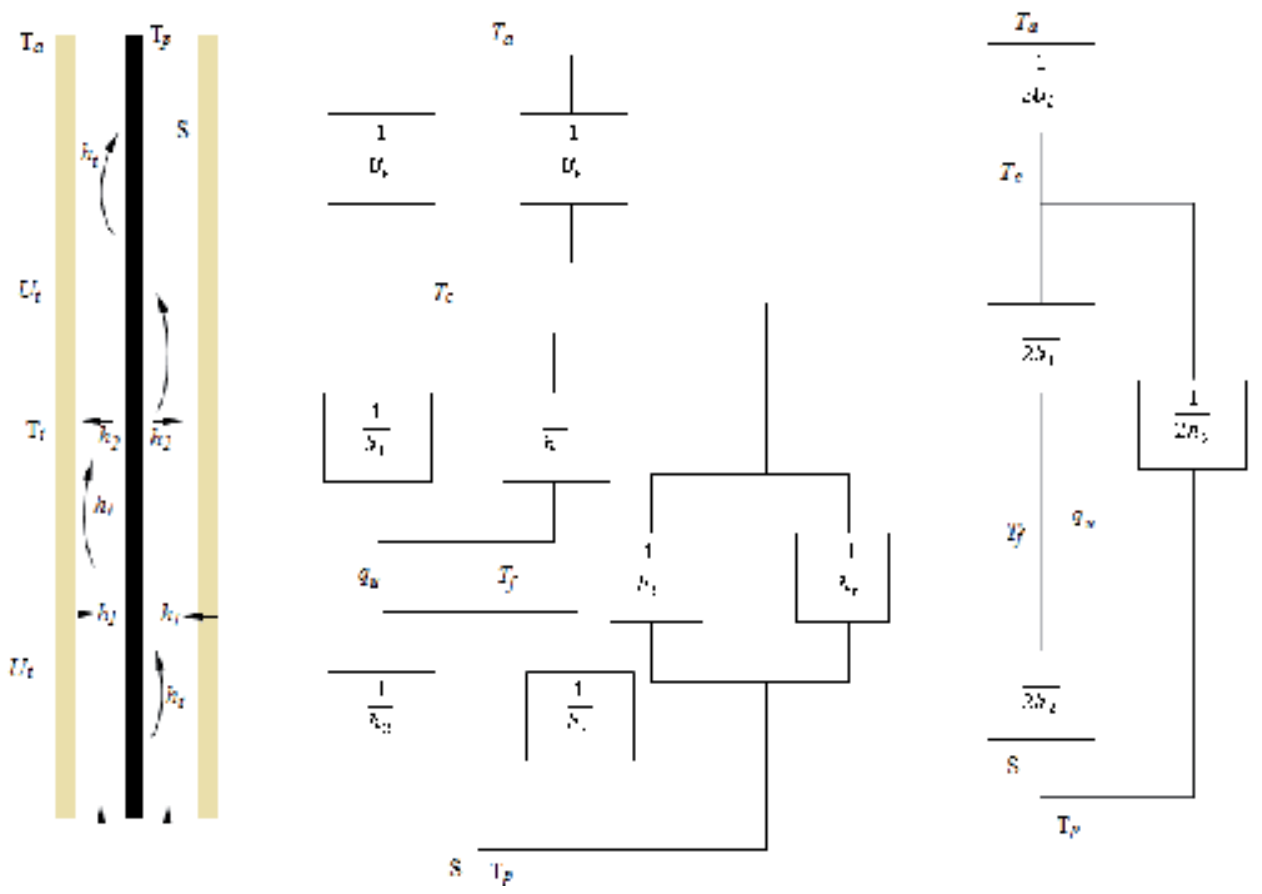

Figure 4. Schematic diagram with equivalent thermal network

At the leading edge of the flat absorber plate, airflow is halved to flow on both sides of the plate. Absorbed solar energy heats up the plates to a temperature $\mathrm{T}_{\mathrm{p}}$, and energy is transferred to fluid at temperature $T_{r}$ through the convection heat transfer coefficient $h_{2}$ and to the cover glass through the linearized radiation heat transfer coefficient $h_{1}$. Energy is also transferred to the cover glass from the fluid though the convective heat transfer coefficient $h_{t}$ and finally energy is lost to the ambient air through the combined convection and radiation coefficient $U_{t}$ from the cover glass. 


\section{Energy balance equations}

Energy balance equations on the cover, the plates and the fluid are derived as follows:

$$
\begin{gathered}
2 \mathrm{U}_{\mathrm{t}}\left(\mathrm{T}_{\mathrm{a}}-\mathrm{T}_{\mathrm{c}}\right)+2 \mathrm{~h}_{1}\left(\mathrm{~T}_{\mathrm{p}}-\mathrm{T}_{\mathrm{c}}\right)+2 \mathrm{~h}_{2}\left(\mathrm{~T}_{\mathrm{r}}-\mathrm{T}_{\mathrm{c}}\right)=0 \\
\mathrm{~S}+2 \mathrm{~h}_{1}\left(\mathrm{~T}_{\mathrm{c}}-\mathrm{T}_{\mathrm{p}}\right)+2 \mathrm{~h}_{2}\left(\mathrm{~T}_{\mathrm{r}}-\mathrm{T}_{\mathrm{p}}\right)=0 \\
2 \mathrm{~h}_{1}\left(\mathrm{~T}_{\mathrm{c}}-\mathrm{T}_{\mathrm{r}}\right)+2 \mathrm{~h}_{2}\left(\mathrm{~T}_{\mathrm{p}}-\mathrm{T}_{\mathrm{r}}\right)=\mathrm{q}_{\mathrm{u}}
\end{gathered}
$$

Simplifying and expanding the expressions as a function of heat transfer coefficients and temperatures yields

$$
\begin{gathered}
\mathrm{U}_{\mathrm{t}} \mathrm{T}_{\mathrm{a}}-\mathrm{U}_{\mathrm{t}} \mathrm{T}_{\mathrm{c}}+\mathrm{h}_{\mathrm{r}} \mathrm{T}_{\mathrm{p}}-\mathrm{h}_{\mathrm{r}} \mathrm{T}_{\mathrm{c}}+\mathrm{h}_{1} \mathrm{~T}_{\mathrm{r}}-\mathrm{h}_{1} \mathrm{~T}_{\mathrm{c}}=0 \\
0.5 \mathrm{~S}+\mathrm{h}_{1} \mathrm{~T}_{\mathrm{c}}-\mathrm{h}_{1} \mathrm{~T}_{\mathrm{p}}+\mathrm{h}_{2} \mathrm{~T}_{\mathrm{r}}-\mathrm{h}_{2} \mathrm{~T}_{\mathrm{p}}=0
\end{gathered}
$$

Equations (40) and (41) can be expressed as

$$
\begin{aligned}
& \mathrm{A}=\mathrm{BT}_{\mathrm{c}}-=\mathrm{T}_{\mathrm{p}} \\
& \mathrm{D}=\mathrm{ET}_{\mathrm{p}}-=\mathrm{T}_{\mathrm{c}}
\end{aligned}
$$

where $A=U_{t} T_{a}+h_{1} T_{r^{\prime}} B=U_{t}+h_{r}+h_{1}, C=h_{r}, D=0.5 S+h_{2} T_{r}$ and $E=h_{r}+h_{2}$.

Solving equations (42) and (43) simultaneously and re-substituting values into equations (40) and (41),

$$
\begin{gathered}
\mathrm{T}_{\mathrm{p}}=\frac{\mathrm{AC}+\mathrm{BD}}{\left[\mathrm{BE}-\mathrm{C}^{2}\right]}=\frac{\left(\mathrm{U}_{\mathrm{t}} \mathrm{T}_{\mathrm{a}}+\mathrm{h}_{1} \mathrm{~T}_{\mathrm{r}}\right) \mathrm{h}_{\mathrm{r}}+\left(\mathrm{U}_{\mathrm{t}}+\mathrm{h}_{\mathrm{r}}+\mathrm{h}_{1}\right) 0.5 \mathrm{~S}+\mathrm{h}_{2} \mathrm{~T}_{\mathrm{r}}}{\left(\mathrm{U}_{\mathrm{t}}+\mathrm{h}_{\mathrm{r}}+\mathrm{h}_{1}\right)\left(\mathrm{h}_{\mathrm{r}}+\mathrm{h}_{2}\right)-\mathrm{h}_{\mathrm{r}}^{2}} \\
\mathrm{~T}_{\mathrm{p}}=\frac{\mathrm{AE}+\mathrm{CD}}{\left[\mathrm{BE}-\mathrm{C}^{2}\right]}=\frac{\left(\mathrm{U}_{\mathrm{t}} \mathrm{T}_{\mathrm{a}}+\mathrm{h}_{1} \mathrm{~T}_{\mathrm{r}}\right)\left(\mathrm{h}_{\mathrm{r}}+\mathrm{h}_{2}\right)+\left(0.5 S+\mathrm{h}_{2} \mathrm{~T}_{\mathrm{r}}\right) \mathrm{h}_{\mathrm{r}}}{\left(\mathrm{U}_{\mathrm{t}}+\mathrm{h}_{\mathrm{r}}+\mathrm{h}_{1}\right)\left(\mathrm{h}_{\mathrm{r}}+\mathrm{h}_{2}\right)-\mathrm{h}_{\mathrm{r}}^{2}}
\end{gathered}
$$


Subtracting $\mathrm{T}_{\mathrm{r}}$ from both sides of equations (44) and (45),

$$
\begin{gathered}
\mathrm{T}_{\mathrm{p}}-\mathrm{T}_{\mathrm{r}}=\frac{\mathrm{U}_{\mathrm{t}} \mathrm{h}_{\mathrm{r}}\left(\mathrm{T}_{\mathrm{a}}-\mathrm{T}_{\mathrm{r}}\right)+0.5 \mathrm{~S}\left(\mathrm{U}_{\mathrm{t}}+\mathrm{h}_{\mathrm{r}}+\mathrm{h}_{1}\right)}{\left(\mathrm{U}_{\mathrm{t}}+\mathrm{h}_{\mathrm{r}}+\mathrm{h}_{1}\right)\left(\mathrm{h}_{\mathrm{r}}+\mathrm{h}_{2}\right)-\mathrm{h}_{\mathrm{r}}^{2}} \\
\mathrm{~T}_{\mathrm{c}}-\mathrm{T}_{\mathrm{r}}=\frac{\left(\mathrm{U}_{\mathrm{t}} \mathrm{h}_{\mathrm{r}}+\mathrm{U}_{\mathrm{t}} \mathrm{h}_{2}\right)\left(\mathrm{T}_{\mathrm{a}}-\mathrm{T}_{\mathrm{r}}\right)+0.5 \mathrm{Sh}_{\mathrm{r}}}{\left(\mathrm{U}_{\mathrm{t}}+\mathrm{h}_{\mathrm{r}}+\mathrm{h}_{1}\right)\left(\mathrm{h}_{\mathrm{r}}+\mathrm{h}_{2}\right)-\mathrm{h}_{\mathrm{r}}^{2}}
\end{gathered}
$$

Substituting equations (46) and (47) into equation (39),

$$
0.5 \mathrm{q}_{\mathrm{u}}=\frac{0.5 \mathrm{~S}\left(\mathrm{~h}_{1} \mathrm{~h}_{\mathrm{r}}+\mathrm{U}_{\mathrm{t}} \mathrm{h}_{2}+\mathrm{h}_{\mathrm{r}} \mathrm{h}_{2}+\mathrm{h}_{1} \mathrm{~h}_{2}\right)+\mathrm{U}_{\mathrm{t}}\left(\mathrm{h}_{1} \mathrm{~h}_{\mathrm{r}}+\mathrm{h}_{\mathrm{r}} \mathrm{h}_{2}+\mathrm{h}_{1} \mathrm{~h}_{2}\right)+\left(\mathrm{T}_{\mathrm{a}}-\mathrm{T}_{\mathrm{r}}\right)}{\left(\mathrm{U}_{\mathrm{t}}+\mathrm{h}_{\mathrm{r}}+\mathrm{h}_{1}\right)\left(\mathrm{h}_{\mathrm{r}}+\mathrm{h}_{2}\right)-\mathrm{h}_{\mathrm{r}}^{2}}
$$

Rearranging equation (46),

$$
\mathrm{q}_{\mathrm{u}}=\frac{\mathrm{S}\left(\mathrm{h}_{1} \mathrm{~h}_{\mathrm{r}}+\mathrm{U}_{\mathrm{t}} \mathrm{h}_{2}+\mathrm{h}_{\mathrm{r}} \mathrm{h}_{2}+\mathrm{h}_{1} \mathrm{~h}_{2}\right)}{\left(\mathrm{U}_{\mathrm{t}}+\mathrm{h}_{\mathrm{r}}+\mathrm{h}_{1}\right)\left(\mathrm{h}_{\mathrm{r}}+\mathrm{h}_{2}\right)-\mathrm{h}_{\mathrm{r}}{ }^{2}}-\frac{2 \mathrm{U}_{\mathrm{t}}\left(\mathrm{h}_{1} \mathrm{~h}_{\mathrm{r}}+\mathrm{h}_{\mathrm{r}} \mathrm{h}_{2}+\mathrm{h}_{1} \mathrm{~h}_{2}\right)+\left(\mathrm{T}_{\mathrm{a}}-\mathrm{T}_{\mathrm{r}}\right)}{\left(\mathrm{U}_{\mathrm{t}}+\mathrm{h}_{\mathrm{r}}+\mathrm{h}_{1}\right)\left(\mathrm{h}_{\mathrm{r}}+\mathrm{h}_{2}\right)-\mathrm{h}_{\mathrm{r}}{ }^{2}}
$$

Comparing equation (49) with the Hottel-Whillier-Bliss equation, $\mathrm{q}_{\mathrm{u}}=\mathrm{F}^{\prime}\left[\mathrm{S}-\mathrm{U}_{\mathrm{L}}\left(\mathrm{T}_{\mathrm{r}}-\mathrm{T}_{\mathrm{a}}\right)\right]$, it can be deduced that

$$
\begin{gathered}
F^{\prime}=\frac{h_{1} h_{r}+U_{t} h_{2}+h_{r} h_{2}+h_{1} h_{2}}{\left(U_{t}+h_{r}+h_{1}\right)\left(h_{r}+h_{2}\right)-h_{r}{ }^{2}} \\
U_{L}=\frac{2 U_{t}\left(h_{1} h_{r}+h_{r} h_{2}+h_{1} h_{2}\right)+\left(T_{a}-T_{r}\right)}{\left(h_{1} h_{r}+U_{t} h_{r}+h_{r} h_{2}\right)+h_{1} h_{2}}
\end{gathered}
$$

It has been demonstrated experimentally that $h_{1}=h_{2}=h$ according to Duffie and Beckman; therefore, equations (47) and (48) reduce to

$$
F^{\prime}=\frac{h\left(U_{t}+2 h_{r}+h\right)}{\left(U_{t}+h_{r}+h_{1}\right)\left(h_{r}+h_{2}\right)-h_{r}^{2}} \text { and } U_{L}=\frac{2 U_{t}\left(2 h_{r}+h\right)+\left(T_{a}-T_{r}\right)}{\left(U_{t}+2 h_{r}\right)+h}
$$


It is necessary to outline expressions of heat coefficients as functions of $\mathrm{F}^{\prime}$ and $\mathrm{U}_{\mathrm{L}}$. These heat coefficients are expressed as

$$
\mathrm{U}_{\mathrm{t}}=\left(\mathrm{h}_{\text {wind }}+\mathrm{h}_{\text {rea }}\right)
$$

where $h_{\text {rea }}$ is the radiative loss coefficient between the cover and ambient air expressed as

$$
\mathrm{h}_{\text {rea }}=\varepsilon_{\mathrm{c}} \alpha\left(\mathrm{T}_{\mathrm{c}}^{2}+\mathrm{T}_{\mathrm{s}}^{2}\right)\left(\mathrm{T}_{\mathrm{c}}-\mathrm{T}_{\mathrm{s}}\right)
$$

where glass cover emittance $\varepsilon_{\mathrm{c}}=0.88$, Stefan-Boltzmann constant $\alpha=5.6 \times 10^{-1} \mathrm{w} / \mathrm{m}^{2} \mathrm{k}^{4}$ and sky temperature $\mathrm{T}_{\mathrm{s}}=0.0552 \mathrm{~T}_{\mathrm{a}}^{1.5}$.

The convective atmospheric heat loss coefficient due to wind, $\mathrm{h}_{\text {wind }}$ is dependent on the prevailing wind velocity given by [14] as

$$
\mathrm{h}_{\text {wind }}=5.8+3.8 \mathrm{v}
$$

where $\mathrm{v}\left(\mathrm{ms}^{-1}\right)$ is the wind velocity $\left(2 \mathrm{~ms}^{-1}\right)$ for the study location); thus,

$$
\mathrm{h}_{\text {wind, location }}=5.8+3.8 \times 2=13.4 \mathrm{w} / \mathrm{m}^{2}{ }^{\circ} \mathrm{C}
$$

The radiative heat loss coefficient between the plate and the cover after linearization is given as

$$
\mathrm{h}_{\mathrm{r}}=\frac{\sigma}{\left(\varepsilon_{\mathrm{c}}^{-\mathrm{h}}+\varepsilon_{\mathrm{p}}^{-\mathrm{h}}-\mathrm{h}\right)\left(\mathrm{T}_{\mathrm{c}}^{2}+\mathrm{T}_{\mathrm{p}}^{2}\right)\left(\mathrm{T}_{\mathrm{c}}-\mathrm{T}_{\mathrm{p}}\right)}
$$

where absorber plate emittance $\varepsilon_{\mathrm{p}}=1-\alpha_{\mathrm{p}}=0.1$.

\section{Heat transfer and collector performance analysis}

A review of the principles and theories governing natural free convection heat transfer [4] is done for the determination of other collector performance parameters. Thus, considering a vertical absorber plate of one wing of the collector heated by insolation to a temperature $T_{p}$, $a$ free convection boundary layer is formed. The boundary layer is such that at the wall of the plate, the velocity of air stream is zero. This increases to some maximum value and then 
decreases to zero due to free stream conditions, provided the gap between the plate and the cover is much greater than the boundary layer thickness. The equation of motion for such a system is derived from the Navier-Stokes momentum equation of fluid flow given by [15]:

$$
\varrho\left(\frac{\partial u}{\partial x}+v \frac{\partial u}{\partial y}\right)=-\varrho g+\frac{\mu \partial^{2} u}{\partial y^{2}}
$$

where $\mathrm{Q}$ is the density of air; $\mathrm{x}$ is the displacement in the vertical direction, the direction of buoyant flow; $y$ is the displacement perpendicular to the direction of buoyant flow; $\mathrm{U}$ is the velocity component in the $\mathrm{x}$-direction; $\mathrm{v}$ is the velocity component in the $\mathrm{y}$-direction; $\mathrm{p}$ is air pressure; $\mu$ is the dynamic viscosity of air and $g$ is acceleration due to gravity of value $9.18\left(\mathrm{~ms}^{-2}\right)$.

Equation (58) can be expressed as

$$
\left(U \frac{\partial u}{\partial x}+v \frac{\partial u}{\partial y}\right)=\frac{\partial p}{\partial x}-\rho g+\mu \frac{\partial^{2} u}{\partial y^{2}}
$$

where $\frac{\partial p}{\partial x}=g . \varrho_{\infty}$ and $Q_{\infty}$ is the free stream air density.

The density difference can be expressed in terms of the volume coefficient of expansion, $\beta$, defined by

$$
=\frac{1}{V}\left(\frac{\partial V}{\partial T}\right)_{p}=\frac{1}{V_{\infty}}\left[\frac{V-V_{\infty}}{T-T_{\infty}}\right]=\left[\frac{\rho-\rho_{\infty}}{T-T_{\infty}}\right]
$$

Substituting equation (59) into (58) brings the momentum equation to

$$
\varrho\left(U \frac{\partial u}{\partial x}+V \frac{\partial u}{\partial y}\right)=\operatorname{eg} \beta\left(T-T_{\infty}\right)+\mu \frac{\partial^{2} u}{\partial y^{2}}
$$

integrating equation (61) with respect to y from the boundary layer thickness $\delta$ to the plate surface; since the velocity in the flow direction $\mathrm{u}$ is much greater than the velocity component perpendicular to the flow direction $\mathrm{v}$, hence $\mathrm{v}$ tends to zero compared to $\mathrm{u}$. The integral momentum equation becomes

$$
\frac{\mathrm{d}}{\mathrm{dx}}\left[\int_{0}^{\delta} \rho \mathrm{u}^{2} \mathrm{dy}\right]=\int_{0}^{\delta} \mathrm{\beta} \beta g\left(\mathrm{~T}-\mathrm{T}_{\infty}\right) \mathrm{dy}-\mu \frac{\partial \mathrm{u}}{\partial \mathrm{y}}=0
$$


The functional relation between the temperature distribution and the boundary layer thickness is needed to solve equation (61). From the prevailing conditions of the system, temperature $\mathrm{T}=\mathrm{T}_{\mathrm{p}}$ at $\mathrm{y}=0, \mathrm{~T}=\mathrm{T}_{\infty}$ at $\mathrm{y}=\delta$ and $\frac{\mathrm{dt}}{\mathrm{dy}}=0$ at $\mathrm{y}=\delta$, a parabolic temperature function can be assumed to represent the temperature profile of the system with respect to $\mathrm{y}$.

Therefore, let the function be of the form

$$
\mathrm{T}=\mathrm{Ay}^{2}+\mathrm{By}+\mathrm{C}
$$

Substituting the conditions of flow into equation (61) gives

$$
\mathrm{T}-\mathrm{T}_{\mathrm{p}}=\mathrm{Ay} \mathrm{y}^{2}-\mathrm{An} \delta \mathrm{y} \text { and } \mathrm{T}_{\mathrm{p}}-\mathrm{T}_{\infty}=2 \mathrm{~A} \delta^{2}-2 \delta^{2}=\mathrm{A} \delta^{2}
$$

Also the expression for the velocity profile is necessary to solve the integral momentum equation which can be deduced from the following flow conditions: $u=0$ at $y=0, u=0$ at $y=\delta$ and $\frac{\partial^{2} u}{\partial y^{2}}=-\beta g\left(T-T_{\infty}\right) / v$ at $y=0$. These four flow conditions can be fitted into a cubic equation of the form

$$
\frac{\mathrm{u}}{\mathrm{u}_{\mathrm{x}}}=\mathrm{Ay^{3 }}+\mathrm{By^{2 }}+\mathrm{Cy}+\mathrm{D}
$$

where $\mathrm{u}_{\mathrm{x}}$ is a fictitious velocity which is a function of displacement in the $\mathrm{x}$-direction. Applying the conditions of flow into the cubic equation gives

$$
\left.\begin{array}{l}
\mathrm{D}=0, \\
\mathrm{C}=\left[\frac{\beta \mathrm{g}\left(\mathrm{T}_{\mathrm{p}}-\mathrm{T}_{\infty}\right) \delta}{4 \mathrm{v}}\right], \\
\mathrm{B}=\left[-\frac{\beta \mathrm{g}\left(\mathrm{T}_{\mathrm{p}}-\mathrm{T}_{\infty}\right)}{2 \mathrm{v}}\right], \\
\mathrm{A}=\left[-\frac{\beta \beta \mathrm{g}\left(\mathrm{T}_{\mathrm{p}}-\mathrm{T}_{\infty}\right)}{4 \mathrm{v} \delta}\right]
\end{array}\right\}
$$


Substituting these expressions into equation (65) and evaluating yields

$$
\frac{\mathrm{u}}{\mathrm{u}_{\mathrm{x}}}=\frac{\left[\frac{\beta \mathrm{g} \delta^{2}\left(\mathrm{~T}_{\mathrm{p}}-\mathrm{T}_{\infty}\right)}{4 \mathrm{u}_{\mathrm{x}} \mathrm{v}}\right] \mathrm{y}}{\left(1-\frac{\mathrm{y}}{\delta}\right)^{2}}
$$

The terms involving $\left(\mathrm{T}_{\mathrm{p}}-\mathrm{T}_{\infty}\right), \delta^{2}$ and $\mathrm{u}_{\mathrm{x}}$ may be incorporated into the function $\mathrm{u}_{\mathrm{x}}$ so that the velocity profile can be reduced to

$$
\frac{\mathrm{u}}{\mathrm{u}_{\mathrm{x}}}=\frac{\mathrm{y} / \delta}{\left(1-\frac{\mathrm{y}}{\delta}\right)^{2}}
$$

Now the momentum equation of equation (61) when solved has its terms reduced to

$$
\begin{aligned}
\int_{0}^{\delta}: u^{2} d y & =\int_{0}^{\delta} \frac{u_{x}^{2}}{\delta^{2}}\left[\left(y^{2}-\frac{4 y^{3}}{\delta}+\frac{6 y^{4}}{\delta^{2}}-\frac{4 y^{5}}{\delta^{3}}+\frac{y^{6}}{\delta^{4}}\right] d y\right. \\
= & \frac{u_{x}^{2}}{\delta^{2}}\left(\frac{y^{3}}{3}-\frac{y^{4}}{\delta}+\frac{\frac{5 y^{6}}{\delta^{3}}}{\delta^{4}}+\frac{y^{7}}{\delta^{4}}\right) y_{o}^{\delta} \\
& =u_{x}^{2} \delta\left(\frac{1}{3}-=\frac{6}{5}-\frac{2}{3}+\frac{1}{7}\right) \\
& \Rightarrow \int_{0}^{\delta}: u^{2} d y=\frac{u_{x}^{2} \delta}{1.05}
\end{aligned}
$$

Solving equation (69) in terms of temperature variables,

$$
\begin{gathered}
\int_{0}^{\delta}:\left(\mathrm{T}-\mathrm{T}_{\infty}\right) \mathrm{dy}=\int_{0}^{\delta}:\left(\mathrm{T}_{\mathrm{p}}-\mathrm{T}_{\infty}\right)\left(1-\frac{2 \mathrm{y}}{\delta}+\frac{\mathrm{y}^{3}}{\delta^{2}}\right)_{0}^{\delta}=\left(\mathrm{T}_{\mathrm{p}}-\mathrm{T}_{\infty}\right) \delta\left(1-1+\frac{1}{3}\right) \\
\Rightarrow \int_{0}^{\delta}:\left(\mathrm{T}-\mathrm{T}_{\infty}\right) d y=\frac{1}{3}\left(\mathrm{~T}_{\mathrm{p}}-\mathrm{T}_{\infty}\right) \delta
\end{gathered}
$$




$$
\begin{gathered}
\left.\frac{\delta u}{\delta y}\right|_{y=0}=\left.\frac{U x}{\delta}\left(y-\frac{2 y^{2}}{\delta}+\frac{y^{3}}{\delta^{2}}\right)\right|_{y=0}=\left.\frac{U x}{\delta}\left(1-\frac{4 y}{\delta}+\frac{3 y^{2}}{\delta^{2}}\right)\right|_{y=0} \\
\left.\Rightarrow \frac{\delta u}{\delta y}\right|_{y=0}=\frac{U x}{\delta}
\end{gathered}
$$

Substituting equations (67), (68) and (70) into equation (61),

$$
\frac{1}{1.05}\left(\frac{\mathrm{d}}{\mathrm{dx}} \mathrm{u}_{\mathrm{x}}^{2}\right)=\frac{1}{3} \mathrm{~g} \beta\left(\mathrm{T}_{\mathrm{p}}-\mathrm{T}_{\infty}\right) \delta-\frac{\mathrm{vx}}{\delta}
$$

where $\mathrm{v}=\frac{\mu}{\varrho}$ is known as kinematic viscosity.

The energy equation for free convection of the collector system is expressed as

$$
\mathrm{QC}_{\mathrm{p}}\left(\frac{\mathrm{U} \partial \mathrm{T}}{\partial \mathrm{x}}+\mathrm{V} \frac{\mathrm{U} \partial \mathrm{T}}{\partial \mathrm{y}}\right)=\mathrm{k} \frac{\partial^{2} \mathrm{~T}}{\partial \mathrm{y}^{2}}, \text { or }\left(\frac{\mathrm{U} \partial \mathrm{T}}{\partial \mathrm{x}}+\mathrm{V} \frac{\mathrm{U} \partial \mathrm{T}}{\partial \mathrm{y}}\right)=\alpha \frac{\partial^{2} \mathrm{~T}}{\partial \mathrm{y}^{2}}
$$

where $\alpha=\frac{\mathrm{k}}{\mathrm{QC} \mathrm{C}_{\mathrm{p}}}$ is called the thermal diffusivity. The integral form of equation (72) with velocity tending to zero is

$$
\frac{\mathrm{d}}{\mathrm{dx}} \int_{0}^{\delta}: \mathrm{U}\left(\mathrm{T}-\mathrm{T}_{\infty}\right) \mathrm{dy}=\left.\alpha \frac{\mathrm{dT}}{\mathrm{dy}}\right|_{\mathrm{y}}=0
$$

From equation (67), it can be deduced that the relation of the order of magnitude between $u_{x}$ and $\delta$ is $u_{x}-\delta^{2}$. Inserting this relation into equation (68) and solving yields $\delta-x^{1 / 2}$. Hence, it can be assumed that

$$
\mathrm{u}_{\mathrm{x}}=\mathrm{Ax} \mathrm{x}^{1 / 2} \text { and } \delta=\mathrm{Bx}^{1 / 4}
$$

Introducing these expressions into equations (67) and (74) yields

$$
\frac{5}{240} \mathrm{~A}^{2} \mathrm{~B} x^{1 / 4}=g \beta\left(T-\mathrm{T}_{\infty}\right)\left(\frac{\mathrm{Bx} \mathrm{x}^{1 / 4}}{3}\right)-\left(\frac{\mathrm{A}}{\mathrm{B}}\right) \mathrm{vx^{1/4 }}
$$

Solving for $\mathrm{A}$ and $\mathrm{B}$ in the above equation, 


$$
\begin{gathered}
A=5.17 v(0.952+\operatorname{Pr})^{-.95}\left[g \beta\left(T-T_{\infty}\right) \frac{x^{3}}{v^{2}}\right]^{-x 95}[\operatorname{Pr}]^{-r 95} \\
B=3.93 \operatorname{Pr}^{-\frac{1}{4}}\left[g \beta\left(T-T_{\infty}\right) \frac{x^{3}}{v^{2}}\right]^{-x 3 .}[\operatorname{Pr}]^{-\mathrm{r} 3 .}
\end{gathered}
$$

Substituting the expression for A into equation (77) gives the fictitious velocity $u_{x}$ at any point $x$ as

$$
\mathrm{u}_{\mathrm{x}}=5.17 \mathrm{v}(0.952+\operatorname{Pr})^{-\frac{1}{2}}\left(\mathrm{Gr}_{\mathrm{x}}\right)^{-\mathrm{r}}
$$

where $G r_{x}$ is the Grashof number at point $x$, this is given by

$$
G r_{x}=g \beta\left(T-T_{\infty}\right) \frac{x^{3}}{v^{2}}
$$

The resultant expression for boundary layer thickness from equation (75) is

$$
\frac{\delta}{\mathrm{x}}=\mathrm{Bx}^{-\mathrm{Be}}=3.93 \operatorname{Pr}^{-\frac{1}{2}}(0.952+\operatorname{Pr})^{\frac{1}{4}}\left(\mathrm{Gr}_{\mathrm{x}}\right)^{-\frac{1}{4}}
$$

The heat transfer coefficient may be evaluated using equation (62)

$$
\mathrm{q}_{\mathrm{p}}=-\mathrm{kA} \frac{\mathrm{dT}}{\mathrm{dy}}=\mathrm{kA}\left(\frac{2}{\delta}\right)\left(\mathrm{T}_{\mathrm{p}}-\mathrm{T}_{\infty}\right)=\mathrm{hA}\left(\mathrm{T}_{\mathrm{p}}-\mathrm{T}_{\infty}\right)
$$

where it was derived that $\mathrm{h}=\frac{2 \mathrm{k}}{\delta}$. Hence, the dimensionless equation for the heat transfer coefficient becomes the expression for Nusselt number $\mathrm{Nu}_{\mathrm{x}}$ :

$$
\mathrm{Nu}_{\mathrm{x}}=0.508 \operatorname{Pr}^{-\frac{1}{2}}(0.952+\operatorname{Pr})^{-\frac{1}{4}}\left(\mathrm{Gr}_{\mathrm{x}}\right)^{-\frac{1}{4}}
$$

In the case study, it was assumed that solar heating of the collector is one of the constant heat flux conditions. In such a case, a modified Grashof number is introduced: 


$$
\mathrm{Gr}_{\mathrm{x}}^{*}=\mathrm{Gr}_{\mathrm{x}} \cdot \mathrm{Nu}_{\mathrm{x}}=\frac{\mathrm{g} \beta \mathrm{x}^{4} \mathrm{q}_{\mathrm{p}}}{\mathrm{kv}^{2}}
$$

where $q_{p}$ is the plate heat flux. The local heat transfer coefficient is correlated as

$$
\mathrm{Nu}_{\mathrm{x}}=\frac{\mathrm{hx}}{\mathrm{k}}=0.6\left(\mathrm{Gr}_{\mathrm{x}} \mathrm{Pr}\right)^{0.2}, 10^{5}<\mathrm{Gr}_{\mathrm{x}}^{*}<10^{11}, \mathrm{q}_{\mathrm{p}}=\text { constant }
$$

For the turbulent range, the average heat transfer coefficient for the constant heat flux cause is obtained from

$$
\mathrm{h}=\frac{1}{\mathrm{~L}} \int_{0}^{1} \mathrm{~h}_{\mathrm{x}} \mathrm{d}_{\mathrm{x}}=1.25 \mathrm{~h}_{\mathrm{x}}
$$

It has been established that during distribution the local heat transfer coefficient is essentially with $x$ when turbulent free convection is encountered. In such a case, the average heat transfer coefficient is $h=h_{x}$. The mean velocity of air stream due to natural convection was obtained from evaluating the mean value of velocity distribution of equation (64) as

$$
u=u_{x} \int_{0}^{1}\left[\frac{y}{\delta}\left(1-\frac{y}{\delta}\right)\right] d\left(\frac{y}{\delta}\right)=0.0833 U_{x}
$$

The volumetric flow rate is

$$
\mathrm{V}_{\mathrm{o}}=\mathrm{C}_{\mathrm{d}} \mathrm{A}_{\mathrm{o}} \mathrm{U}
$$

The coefficient of discharge $C_{d}$ is taken as 0.6 as adapted from [1]. Then the mass flow rate is obtained from the expression

$$
\dot{\mathrm{m}}=\rho \mathrm{V}_{\mathrm{o}}
$$

In the previous section, expressions for the overall collector heat loss coefficient $U_{L}$ and the collector efficiency factor F', which are very important performance parameters, were derived. These parameters are applied in the evaluation of useful energy rate extracted from the collector. To incorporate the flow rate and express the system energy equation using the collector inlet temperature, another performance parameter is introduced as the collector heat removal factor. The collector heat removal factor $F_{R}$ is defined as the ratio of actual useful heat 
collector rate to useful heat collector rate attainable with the entire collector surface at the inlet fluid temperature. This is stated mathematically as

$$
F_{R}=\frac{m_{p}\left(T_{o}-T_{1}\right)}{A_{c}\left[S-U_{L}\left(T_{1}-T_{a}\right)\right]}=\left[\frac{m_{p}}{A_{c} U_{L}}\right]\left[1-e^{-\frac{A_{c} U_{L} F}{m C_{p}}}\right]
$$

Thus, the energy equation of the system becomes

$$
\mathrm{Q}_{\mathrm{u}}=2 \mathrm{~A}_{\mathrm{c}} \mathrm{F}_{\mathrm{R}}\left[\mathrm{S}-\mathrm{U}_{\mathrm{L}}\left(\mathrm{T}_{1}-\mathrm{T}_{\mathrm{a}}\right)\right]
$$

The efficiency of the whole collector system $\eta$ defined as the ratio of the useful heat extracted from the collector $Q_{u}$ to the total incident solar radiation on the collector is mathematically expressed as

$$
\eta=\frac{Q_{u}}{A_{c} I_{T}}=2 F_{R}\left[(\tau \alpha)_{c}-\frac{U_{L}}{I_{T}}\left(T_{1}-T_{a}\right)\right]
$$

where $(\tau \alpha)$ is the effective transmittance-absorptance product of the collector glazing,

$$
(\tau \alpha)_{\mathrm{c}}=\frac{\mathrm{S}_{\mathrm{T}}}{\mathrm{I}_{\mathrm{T}}}
$$

where temperatures $T_{1}$ and $T_{a}$ are the collector's inlet and outlet temperatures, respectively.

\section{Results and discussions}

The modelled parameters from the analysis of the momentum equation provide a platform to analyze the thermal behaviour on each wing based on the use of a selective surface. This was used to graphically illustrate the heat flow pattern in the chimney and the radiative effects on the emitting and receiving surfaces. At any position of the sun, only two wings of the collector receive full-area direct radiation. At a smaller zenith angle, a larger portion of the farthest wing is lightened, while a smaller portion is lightened at a higher zenith angle. Figure 5 gives the direct beam area ratio $\forall$ for the three wings of the collector with respect to midpoint solar time. 


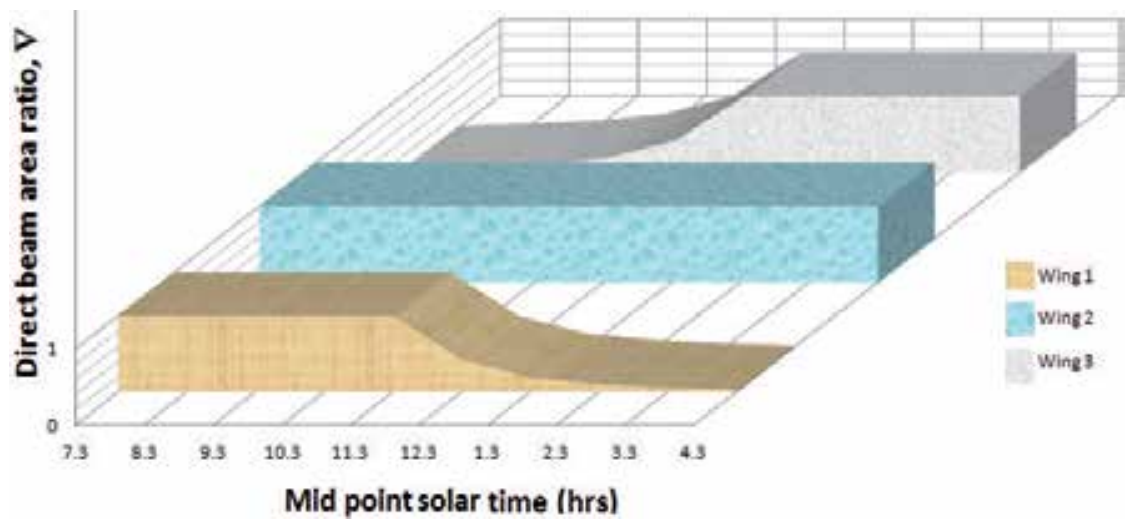

Figure 5. Direct beam area ratio $\forall$ for the three wings

The shading of the wings was taken into account to evaluate the actual direct beam radiation absorbed by each wing so that the average radiation absorbed by the whole collector can be deduced. To investigate the shape of the lightened area of a wing at any time interval, the zenith angle and the hour angle are required. The shape of the lightened region of the shadowed wing is always triangular depending on the zenith angle of the sun. Five variants of the shadowed wing model are shown in Figure 6.

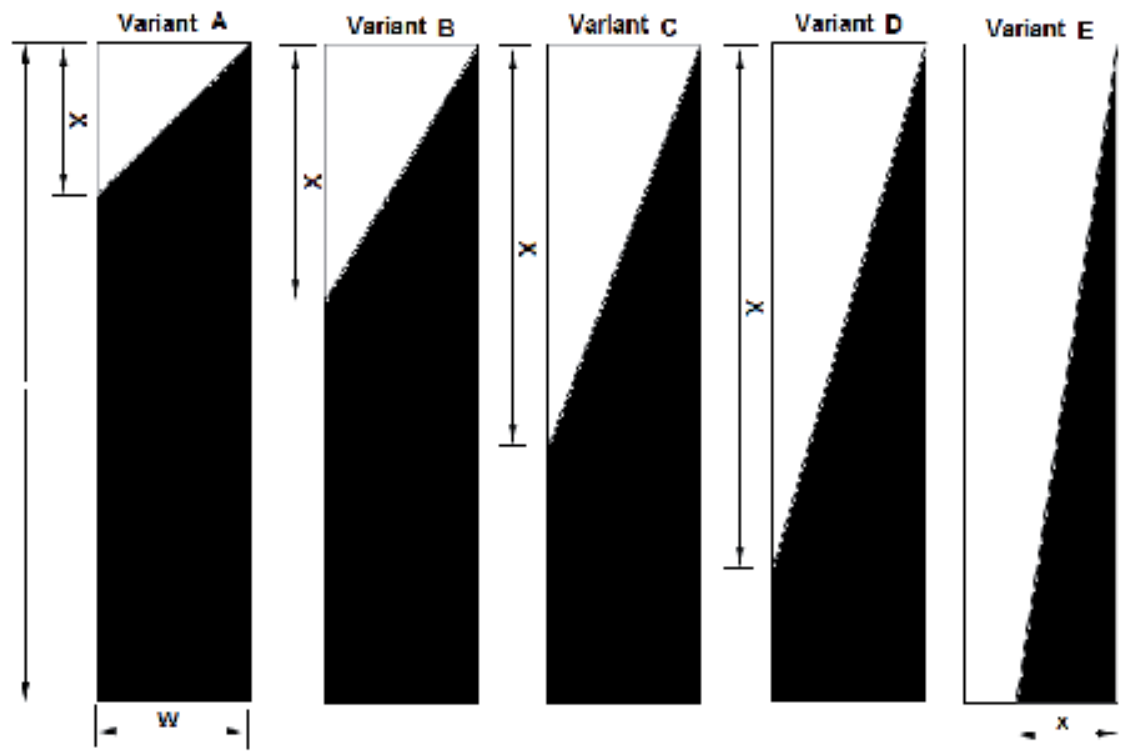

Figure 6. Variants of the shadowed wing model

Figure 7 shows the graph of temperature elevation and mass flow rate and insolation which points out that increase in temperature elevation is not always consequent on increase in the 
mass flow rate as illustrated by the negative gradient of mass flow rate between 11.30 am and $1.30 \mathrm{pm}$ compared to the positive gradient of temperature elevation within the same insolation range.

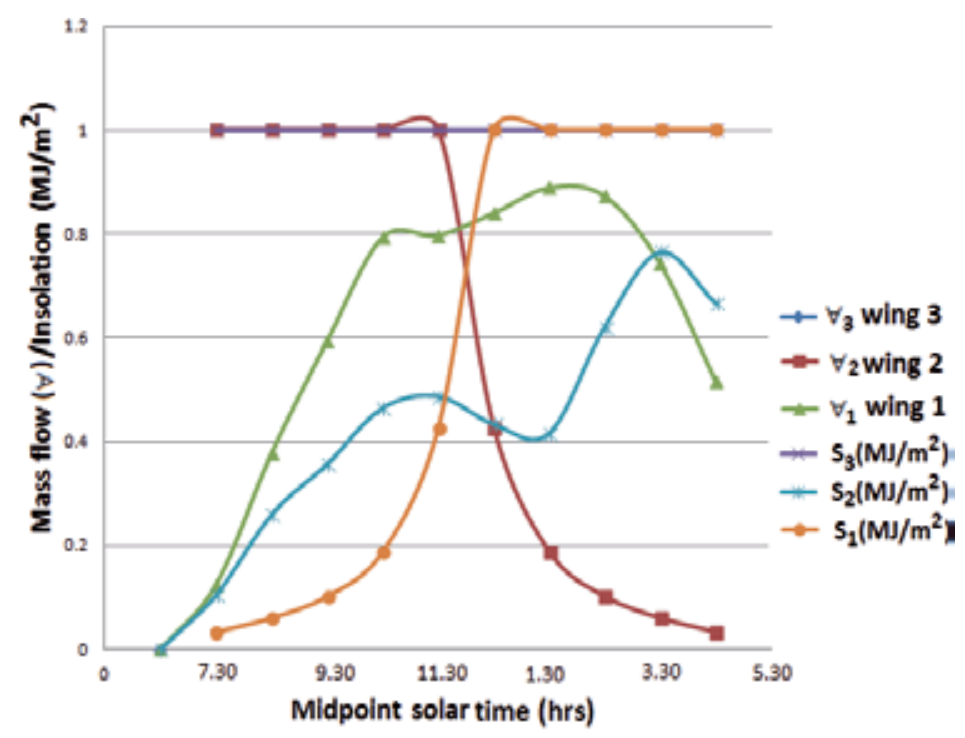

Figure 7. Graph of temperature elevation and mass flow rate and insolation

\section{Conclusion}

The result shows that modelling buoyant airflow within the chimney and the variation of air temperature elevation with insolation is minimal while the chimney has better efficiency at lower values of solar radiation. Thus, the method of analysis of thermal performance for this type of solar chimney has been accomplished. Nevertheless, a method of complete analytical evaluations that will give satisfactory results can be achieved by obtaining a table of correlation factor from experimental data values to analytical values of this kind.

\section{Author details}

R. S. Bello ${ }^{1^{*}}$, C. N. Ezebuilo ${ }^{1}$, T. A. Adegbulugbe ${ }^{2}$ and K. A. Eke ${ }^{1}$

*Address all correspondence to: segemi2002@yahoo.com

1 Federal College of Agriculture, Ishiagu, Nigeria

2 Federal College of Agriculture, Moor Plantation, Ibadan, Nigeria 


\section{References}

[1] Ekechukwu, O. V. and Norton, B. (1997), "Design and measured performance of a solar chimney for natural circulation solar-energy dryers", Renewable energy, Vol. 10, pp 81-90.

[2] Mathur, J. and Mathur, S. (2006), "Summer-performance of inclined roof solar chimney for natural ventilation", Energy and Buildings, Vol. 38 No. 10, pp. 1156-1163.

[3] Bansal, N.K., Mathur, J. and Bhandari, M.S. (1993), “Solar chimney for enhanced stack ventilation", Building and Environment, Vol. 28 No. 3, pp. 373-377.

[4] Ong, K. S. (2001), A Mathematical Model of a Solar Chimney. Monash University Malaysia 46150 Petaling Jaya, Malaysia.

[5] Shiv Lal, S.C. Kaushik, P.K. Bhargav, 2013. Solar chimney: A sustainable approach for ventilation and building space conditioning. International Journal of Development and Sustainability Online ISSN: 2168-8662 - www.isdsnet.com/ijds Volume 2 Number 1 (2013): Pages 277-297

[6] Alter, L. (2011), “The Trombe wall: Low tech solar design makes a comeback”, available at:http://www.treehugger.com/sustainable-product-design/the-trombe-wall-lowtech-solar-design-makes-a-comeback.html/ (assesses October 2012).

[7] Khedari, J. (2000), “Ventilation impact of a solar chimney on indoor temperature fluctuation and air change in a school building", Energy and Buildings, Vol. 32 No. 1, pp. 89-93.

[8] Zhai, X., Dai, Y. and Wang, R. (2005), “Comparison of heating and natural ventilation in a solar house induced by two roof solar collectors", Applied Thermal Engineering, Vol. 25 No. 5-6, pp. 741-757.

[9] Hirunlabh, J., Khedari, J. and Bunnag T. (1997), “Experimental study of a roof solar collector towards the natural ventilation of new houses", Energy and Buildings, Vol. 26 No. 2, pp. 159-164

[10] Wikipedia, 2014. Mach number. http://en.wikipedia.org/wiki/Mach_number.

[11] Onyeogu and Ibekwe, (2001). Measuring insolation data at Nsukka using a flat plate collector. Unpublished MSc thesis submitted to Dept of Mech Engr University of Nigeria Nsukka, Nigeria.

[12] Duffie, J. A. and Beckman, W. A. (2003), Solar Energy Thermal Processes. John and Sons Pub NY.

[13] Bello R. S. and Odey S. O. (2009), "Development of hot water solar oven for low temperature thermal processes", Leonardo Electronic Journal of Practices and Technologies, No. 14, 73-84 Romania. ISSN: 1583-1078 URL: www.lejpt.academicdirect.org/ A14/073_084.pdf 
[14] McAdams, W. H. (1954), Heat Transmission, 3rd edition, McGraw-Hill, New York.

[15] Holman J. P. (1976), Heat Transfer, National students edition, McGraw-Hill, Inc. 

Chapter 3

\title{
Performance Characteristics of Modelled Tri-Wing Solar Chimney and Adaptation to Wood Drying
}

\author{
R. S. Bello, C. N. Ezebuilo, K. A. Eke and \\ T. A. Adegbulugbe \\ Additional information is available at the end of the chapter \\ http://dx.doi.org/10.5772/59423
}

\section{Introduction}

Chimneys have been used for ventilation and space conditioning for centuries particularly in Europe by the Romans as well as in the Middle East and north east by Persians [1]. The concept of solar energy utilization in the chimney was proposed in 1960 by Trombe and Michel at the C.N.R.S. laboratory in France [2]. In the early stages of solar chimney development, it was exclusively used for space heating, but presently its use has been diversified both for heating and building ventilation technology, like passive solar applications [3, 4], low thermal applications [5] and thermogenerators [6] which can be used for comforts in buildings, as well as for agriculture [7]. Other uses of solar energy processes are classified as thermal processes, which include distillation of seawater to produce potable water, refrigeration and air conditioning, power production by solar-generated steam, cooking, water heating and the use of solar furnaces to produce high temperatures for experimental studies [6]. Solar energy technologies such as photovoltaic cells, thermoelectric cells, thermionic cells, thermo-emissive cells, etc. are also being used in small-scale applications in commercial projects.

The first mathematical modelling for the solar chimney (Trombe wall) design was given by Bansal et al., 1993 who also reported the concept of increasing the airflow by increasing solar irradiation. This theoretical study also reported an air change per hour with change in the coefficient of fluid (air) discharge. Ong, (2001) reported the mathematical model of a conventional vertical chimney which operates under the natural convention condition where the temperature of the air inside the chimney is warmer than outside. Shiv, et al., (2013) presented solar chimney as a solar air heater whose position may be vertical or horizontal, and according to the position, it could be regarded a part of a wall (in the form of Trombe wall) or a roof solar collector [10]. The roof solar chimney is the most convenient and mature technology used for buoyancy-driven natural ventilation systems $[1,12,13]$. 


\section{Working principle of solar chimney}

The solar chimney is one of the technologies which work on the principle of buoyancy, where air is heated through the greenhouse effect generated by solar radiation (heat energy) at low costs. The solar chimney is a passive solar ventilation system (non-mechanical) that can be installed on roofs or in walls. The heat is transferred through the convective cooling principle based on the fact that hot air rises upward; these chimneys reduce unwanted heat during the day by displacing interior (warm) air with exterior (cool) air. Solar chimneys are mainly made of a black, hollow thermal mass with an opening at the top as an exit for the hot air. The air in the room exits from the top of the chimney. The process can also be reversed for room heating. The configuration of a typical Trombe wall solar chimney is shown in Figure 1.

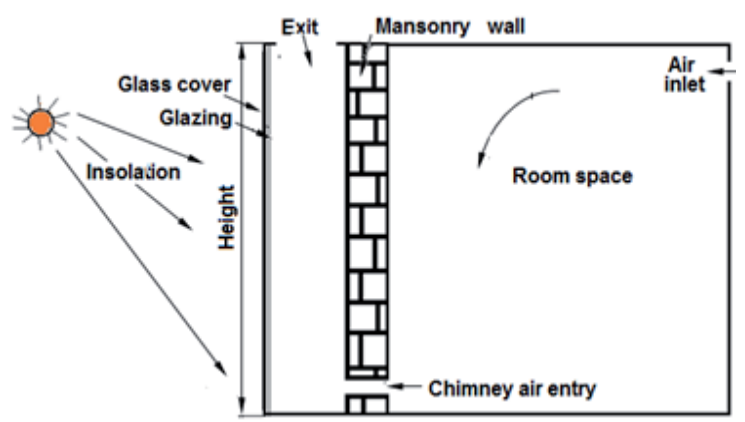

Figure 1. Solar chimney used in building ventilation

\section{Classification of solar chimney}

A detailed review of the solar chimney identified the following classifications:

1. The solar chimney can be classified according to its position as (i) a vertical solar chimney or (ii) an inclined solar chimney.

2. The solar chimney for building ventilation is classified according to its position as (i) a wall solar chimney, or Trombe wall; (ii) a roof solar chimney; and (iii) an integrated wall and roof solar chimney.

3. The solar chimney performance depends on the glazing, either single glazing, double glazing or triple glazing. The ventilation rate mainly depends on the height of the solar chimney, so it is one of the bases for classification, as (i) small height, (ii) medium height and (iv) large height.

4. The solar chimney is also classified according to its use for (i) building ventilation (circulation), (ii) building heating (dwelling), (iii) air dryer (crop dryer) and (iv) power generation. 
5. The classification of the solar chimney is also associated with the cooling and heating of buildings. It means that the solar chimney can be classified based on integrated approaches as (i) integrated with evaporative cooling system, (ii) integrated with earth-airtunnel heat exchanger and (iii) integrated with absorption and adsorption cooling.

6. The solar-radiation-receiving area is covered with a glass cover; the small radiations entering the system through glass cover as well as large wavelength radiation exiting from glass cover should be minimum to generate maximum greenhouse effect,. The greenhouse effect is associated with solar radiation and the number of glazing. The solar chimney is classified according to the number of glazing as (i) single glazing and (ii) multi-glazing.

\subsection{Solar chimney performance}

Ekechukwu and Norton, (1997) analyzed the performance of solar chimney for natural circulation of solar energy dryers and reported that the simple air heater increases ventilation up to some extent but not sufficiently. Mathur and Mathur, (2006) also experimentally analyzed the window-sized solar chimney and found a better summer performance of the inclined roof solar chimney. They studied the effects of various performance parameters like chimney width and height and solar radiation.

The performance of the solar chimney can be improved by using glazing, increasing height and air gap, integrating the Trombe wall with a roof solar collector (single pass and double pass) and selecting an appropriate inclination angle. Lee and Strand, (2009) investigated the effect of these parameters along with chimney height, air gap and potential for different climatic conditions. Hirunlabh, (1999) investigated the effect of glazing on the performance of the solar chimney and found that double glazing is a suitable option as compared to single and triple glazing. Gan, (1998) analyzed the glazed solar chimney experimentally and the data validated by simulation in a passively cooled building (PCB) and found that the airflow rate should be increased up to $17 \%$ in summer by using double glazing.

The solar chimney has the following merits: no mechanical parts, low maintenance, no electrical consumption, no global warming effects, no pollution and can be used for both heating and cooling. Its only demerit is the increase in the cost of building [11].

\subsection{Buoyancy in solar chimney}

Buoyant forces result due to free convection heat transfer from the solar heated plate of the collector to the surrounding air. This results into upward motion of the fluid (air) against gravity due to change in air density arising from the process. Since air buoyancy is proportional to the temperature difference, reduced heat losses and increased heat transfer rates will give a better performance. The atmospheric density decreases with increase in altitude; this effect restrains the height of chimney because the density of the air exiting from the chimney must always be less than the ambient air density [9]. If the density of air from the chimney is equal to the ambient air density, there will be stagnation in the flow, and if the chimney air density is further lessen, then the air backflow against the ambient will result, thereby resulting in local heat losses, which may stall buoyancy-induced forces. To cushion this effect, some form of insolation is needed at the upper section of the chimney. 


\subsection{Project objective}

The object of this analysis is to investigate the drying effect of buoyant airflow created by solar heating of a tri-wing collector in the chimney and its application in the drying of agricultural products. To ensure effective design of the solar chimney, solar parametric equations were utilized to model drying conditions such as the maximum differential between the ambient air density and chimney outlet air density and its effects on agricultural drying applications. The air density depends on the temperature; hence, it also implies that the maximum difference between the chimney air temperature and the ambient temperature should give the best chimney performance. A complete analysis of the tri-wing collector with a mathematical model is cumbersome because of its distinct features compared to an ordinary flat-plate model; however, a comparison of its performance and effectiveness with experimental design data carried out with high-precision apparatus and equipment offers a realistic solution.

\section{Experimental setup}

A properly designed solar chimney should aim at maximum heat transfer from the received insolation to air as well as be of optimum height so as not to exceed the height at which the chimney air temperature cools to that of the ambient air. However, short chimney heights could result in low pressure heads. Based on these facts, the configuration of the experimental solar chimney was made $5.3 \mathrm{~m}$ high and $1.64 \mathrm{~m}$ in diameter for a hollow cylindrical channel of glass glazing. The walls of the chimney were made as smooth as possible to reduce pressure losses due to wall friction.

The absorbing surface (collector) is a tri-wing multi-flapped selective absorber plate draped inside the glazed glass. This chimney is mounted above the room space (drying chamber) through which dry air passes (Figure 2).

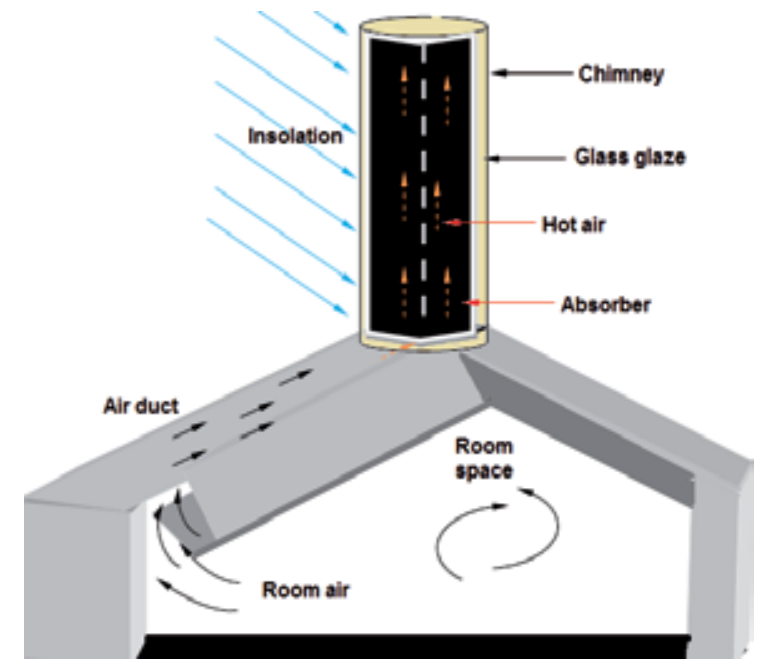

Figure 2. Schematic diagram of solar chimney 


\subsection{Features of solar chimney}

Some distinguishing features of this solar chimney include the following:

1. Cylindrical glazing: The cylindrical glazing of the chimney makes the analysis of the transmittance-absorptance product differs from that of a flat cover glazing.

2. Multi-flapped absorber plate: The multi-flapped absorber plate of other existing chimneytype collectors has unequal insolation for each flap, and shadows are cast on adjacent flaps.

3. Back insulation: No back insulation is provided in the collector. This feature is an added heat transfer advantage in that absorbed radiation is transferred from both sides of the plate to air with elimination of back insulation losses.

\subsection{Collector configuration solar insolation}

The absorber plate is made of cast iron to eliminate heat flow resistance due to welds and a well-polished selective plate with high solar absorptance, $\alpha$, of 0.9 . The three wings of the collector were separated equiangularly at $120^{\circ}$ and denoted as 1, 2, 3, with wing 2 aligned at zero azimuth angle while wings 1 and 3 at $120^{\circ}$ azimuths, respectively. This implies that the collector is oriented such that wing 2 is aligned with geographic south. This symmetrical arrangement makes the thermal analysis easy on the configuration (Figure 3).

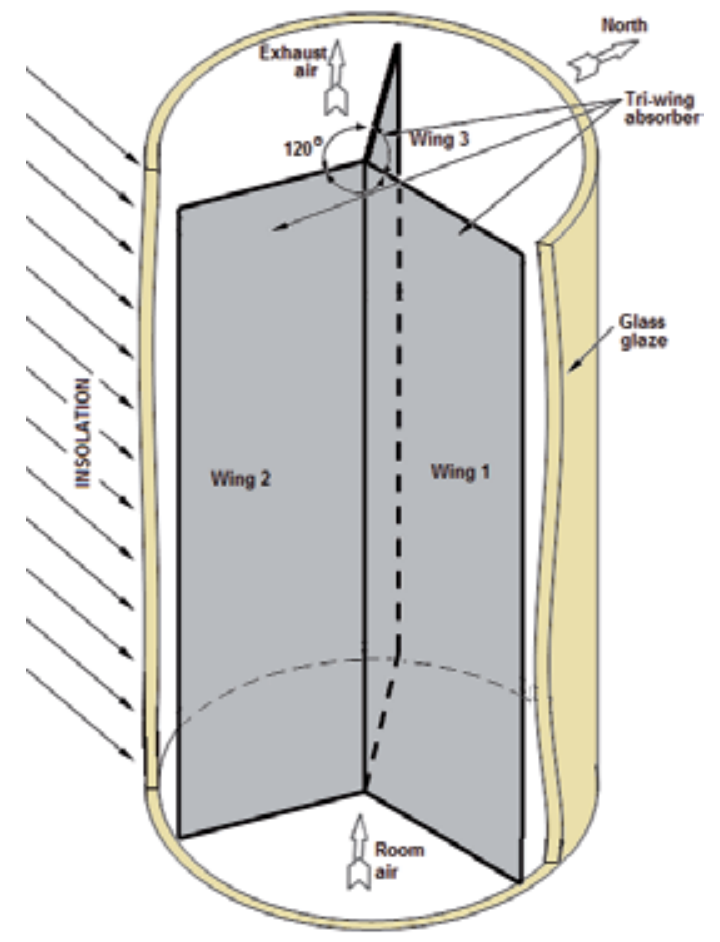

Figure 3. Schematic diagram of a solar chimney system 
At any point in time, all the collector wings receive an equal amount of diffuse solar radiation but uneven direct beam radiation due to the shadow cast on adjacent wings. At any position of the sun, only two wings of the collector receive full-area direct radiation. For instance, when the sun is between the azimuth of east and south, wings 1 and 2 receive full-area radiation at different incident angles, while wing 3 receives partial-area direct radiation due to the shadow of wing 2 cast on it. The case is reverse when the sun is between the azimuths of south and west, the critical time of changeover. When the sun is over the azimuth of $0^{\circ}$, wings 1 and 3 receive full-area direct radiation at different incident angles and wing 2 receives partial direct radiation. This only happens intermittently (Figure 4).

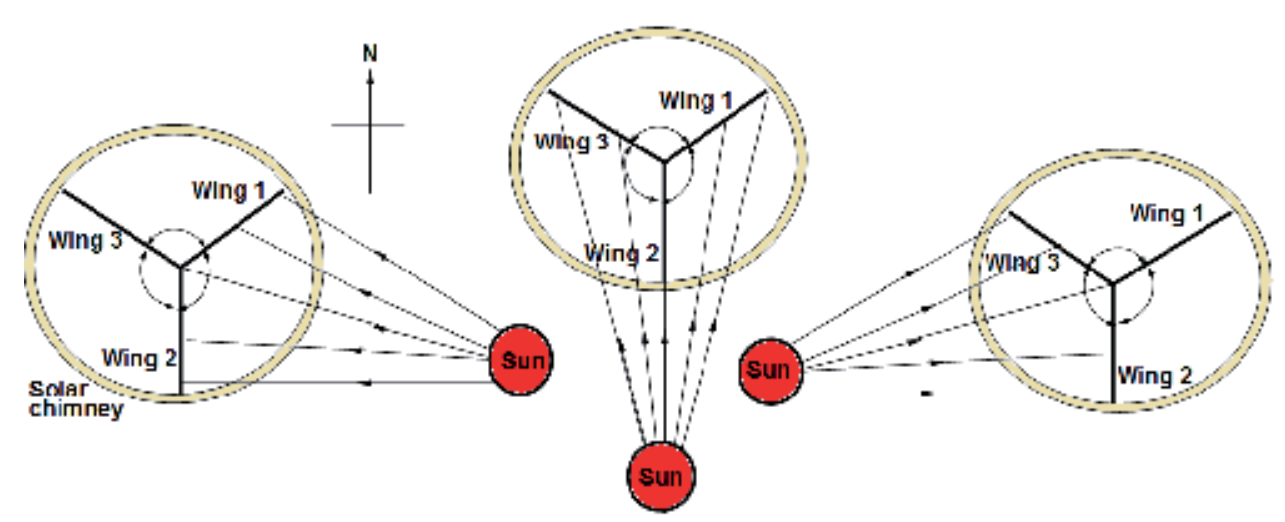

Figure 4. Azimuth positions of the solar insolation with respect to the three absorber surfaces

The shading of the wings must be accounted for to evaluate the actual direct beam radiation absorbed by each wing so that average radiation absorbed by the whole collector can be deduced. To achieve this, a factor of direct beam area ratio, $(\forall)$, is introduced. This is the ratio of the area of a wing of the collector lightened by direct beam radiation to the area of the whole wing. The shape of the lightened region of the shadowed wing is always triangular depending on the zenith angle of the sun. At a smaller zenith angle, a larger portion of the farther wing is lightened, while a smaller portion is lightened at a higher zenith angle.

To evaluate the absorbed solar radiation on a tilted surface with respect to a horizontal surface, the values of the ratio of beam radiation, $R_{b}$, on the vertical surface of the collector to that on the horizontal surface are required. The values of $R_{b}$ will be evaluated using equation (1) for wings 1,2 and 3 at the surface azimuth angle given as $-120^{\circ}, 0^{\circ}$ and $120^{\circ}$, respectively:

$$
\mathrm{R}_{\mathrm{b}}=\frac{\operatorname{Cos} \theta}{\operatorname{Cos} \theta_{\mathrm{z}}}
$$

where $\theta$ is the incident angle of radiation given as 


$$
\operatorname{Cos} \theta=-\sin \delta \cos \varphi \cos \gamma+\cos \delta \sin \varphi \cos \gamma \cos \omega+\cos \delta \sin \gamma \sin \omega
$$

This is expressed for each of the wings in terms of $\omega$. The values of zenith angle $\theta_{z}$ in each wing are evaluated at the midpoint of an hourly time interval from $7.00 \mathrm{am}$ to $5.00 \mathrm{pm}$ of solar time. The zenith angle is expressed as [19]

$$
\theta_{\mathrm{z}}=\operatorname{Cos}^{-\mathrm{o}}[\cos \delta \cos \varphi \cos \omega+\sin \delta \sin \varphi]
$$

\section{System heat transfer mechanism in the model}

A complete heat transfer analysis of the multi-flapped collector involves a complex differential analysis of the absorbed radiation due to shadows and transient heat flow of flaps at different potentials. A complete analysis with a mathematical model is cumbersome because of its distinct features compared to an ordinary flat-plate model.

To overcome this, it was assumed that the collector absorber material is made of a highly conductive metal such that heat due to absorbed radiation is evenly distributed in all the collector flaps. This implies that solar radiation incident on the collector is such that there is no temperature gradient anywhere in the collector (i.e. the absorber is isothermal at any point in time). Despite the varying volume of air in this process, the flow analysis is considered as an incompressible airflow due to prevalent low velocities much below a Mach number of 0.3 [17]. The Mach number is a dimensionless quantity and a measure of compressibility of flow representing the ratio of speed of an object moving through a fluid and the local speed of sound given by

$$
\mathrm{M}=\frac{\mathrm{v}_{\text {object }}}{\mathrm{v}_{\text {sound }}}
$$

where $\mathrm{M}$ is the Mach number in the medium, $\mathrm{v}_{\text {object }} v$ is the velocity of the source relative to the medium, and $\mathrm{v}_{\text {sound }} v$ is the speed of sound in the medium.

If $\mathrm{M}<0.2-0.3$ and the flow is (quasi)-steady and isothermal, compressibility effects will be small and a simplified incompressible flow model can be used. This implies that the density variation produced by the pressure and temperature variations is significantly small to be important. This is because the dynamic nature of the flow process represented by the square of the ratio of local flow velocity to speed of sound, $U^{2} / V^{2}$, known as the square of the Mach number, is much less than the ratio of inertia force to viscous force of the flow, $\mathrm{QUL} / \mu$, known as the Reynolds number. This condition for incompressibility of flow expressed as $\mathrm{M}^{2}<<R e$ is satisfied in the flow analysis of the solar chimney. 
Principles and theories governing natural free convection heat transfer are required for the determination of collector performance parameters. The effective performance of a solar chimney of this type is usually investigated through experimental data using high-precision apparatus and equipment. The absorbed solar radiation by the collector surface is transferred from both sides of the plate to air with the elimination of back insulation losses. In the course of analysis of this chimney-type solar collector, a number of assumptions were made to override these features such that the analyzed values of the collector correlates with the experimental values.

\section{Solar insolation data at experimental setup location}

The experimental setup was located at Nsukka, Nigeria, longitude $7^{\circ} 23^{\prime} 45^{\prime \prime}$ E and latitude $6^{\circ}$ $51^{\prime} 24^{\prime \prime} \mathrm{N}$ [18], and the data acquisition method was adopted from the works of [9]. Solar data readings were taken on 23 rd November at the location for analytical purposes. This implies that the day of the year is

$$
I_{n}=304+23=327
$$

Declination of that day is given by

$$
\delta=23.45 \sin [0.9863(284+n)]=20.8^{\circ}
$$

where sis the declination, $\omega$ is the hour angle and $\varphi$ is the latitude. The values of $\theta_{\mathrm{z}}$ are tabulated in Table 1.

\begin{tabular}{lcccccccccc}
\hline Solar time interval & $7-8$ & $8-9$ & $9-10$ & $10-11$ & $11-12$ & $12-1$ & $1-2$ & $2-3$ & $3-4$ & $4-5$ \\
\hline Midpoint time & 7.30 & 8.30 & 9.30 & 10.30 & 11.30 & 12.30 & 1.30 & 2.30 & 3.30 & 4.30 \\
\hline Hour angle & -67.5 & -52.5 & -37.5 & -22.5 & -7.5 & 7.5 & 22.5 & 37.5 & 52.5 & 67.5 \\
\hline Zenith angle & 71.6 & 58.3 & 45.8 & 35.1 & 28.3 & 28.3 & 35.1 & 45.8 & 58.3 & 71.6 \\
\hline
\end{tabular}

Table 1. Solar insolation data at experimental setup location

A sample of measured data for the month of November is given in Table 2 indicating the values of the total hourly solar radiation for all the 30 days of the month. This data was used as a case study with the assumption that insolation recorded for a particular month is approximately the same for the same month for every other year. This implies that insolation recorded in November 1975 is approximately the same as that recorded in November 2001. 


\begin{tabular}{cccc}
\hline Solar time & $\mathbf{I}_{\mathrm{T}}\left(\mathbf{K J} / \mathbf{m}^{2}\right)$ & $\mathbf{I}_{\mathrm{b}}\left(\mathbf{K J} / \mathbf{m}^{2}\right)$ & $\mathbf{I}_{\mathbf{d}}\left(\mathbf{K J} / \mathbf{m}^{2}\right)$ \\
\hline 7.30 & 1022.29 & 228.15 & 79.34 \\
\hline 8.30 & 897.85 & 228.15 & 667.69 \\
\hline 9.30 & 804.32 & 228.15 & 576.17 \\
\hline 10.30 & 685.39 & 228.15 & 457.25 \\
\hline 11.30 & 620.17 & 225.88 & 394.29 \\
\hline 12.30 & 544.57 & 225.88 & 318.69 \\
\hline 1.30 & 468.72 & 223.63 & 245.09 \\
\hline 2.30 & 403.43 & 223.63 & 179.79 \\
\hline 3.30 & 365.04 & 221.41 & 143.63 \\
\hline 4.30 & 336.97 & 221.41 & 115.56 \\
\hline
\end{tabular}

Table 2. Measured instantaneous values of solar insolation for the day 23rd November 1975

Table 3 shows the values of hourly insolation for 23rd November 2002 for which the values of beam and diffuse insolations above were deduced.

\begin{tabular}{ccccccccccc}
\hline Time & $\mathbf{7 - 8}$ & $\mathbf{8 - 9}$ & $\mathbf{9 - 1 0}$ & $\mathbf{1 0 - 1 1}$ & $\mathbf{1 1 - 1 2}$ & $\mathbf{1 2 - 1}$ & $\mathbf{1 - 2}$ & $\mathbf{2 - 3}$ & $\mathbf{3 - 4}$ & $\mathbf{4 - 5}$ \\
\hline $\mathrm{I}_{\mathrm{T}}\left(\mathrm{KJ} / \mathrm{m}^{2}\right)$ & 133.2 & 466.2 & 865.8 & 1287.6 & 1338.6 & 1420.8 & 1465.2 & 1332.0 & 976.8 & 532.8 \\
\hline $\mathrm{I}_{\mathrm{b}}\left(\mathrm{KJ} / \mathrm{m}^{2}\right)$ & 24.64 & 242.3 & 637.1 & 1062.1 & 1114.4 & 1199.2 & 11245.2 & 1107.6 & 747.8 & 307.8 \\
\hline $\mathrm{I}_{\mathrm{d}}\left(\mathrm{KJ} / \mathrm{m}^{2}\right)$ & 108.5 & 223.9 & 228.7 & 225.51 & 224.22 & 221.63 & 219.96 & 224.4 & 228.9 & 224.9 \\
\hline
\end{tabular}

Table 3. Computed instantaneous values of hourly insolation for 23rd November 2002

Solar radiation components on a tilted collector are made up of the beam radiation component, the diffuse radiation component and the ground-reflected diffuse radiation components. Hence, the total hourly solar radiation on a collector surface is the summation of the three components:

$$
\mathrm{I}_{\mathrm{c}}=\mathrm{I}_{\mathrm{bc}}+\mathrm{I}_{\mathrm{dc}}+\mathrm{I}_{\mathrm{dgc}}
$$

where subscript $\mathrm{c}$ denotes solar radiation on the collector. For the case study, considering the collector being a vertical wall and no vegetation covering the ground, $\beta=90^{\circ}$ and $\varrho=0.2$. Both sides of each wing are exposed to diffuse radiation, while only one side of the wings is exposed to direct beam radiation depending on the area factor receiving this direct radiation. Hence, the total radiation aimed at each wing of the collector is 


$$
\mathrm{I}_{\mathrm{ci}}=\forall \mathrm{I}_{\mathrm{b}} \mathrm{R}_{\mathrm{bi}}+2\left[0.5 \mathrm{I}_{\mathrm{d}}+0.1\left(\mathrm{I}_{\mathrm{d}}+\mathrm{I}_{\mathrm{b}}\right)\right]=\left(\forall \mathrm{R}_{\mathrm{b}}+0.2\right) \mathrm{I}_{\mathrm{b}}+1.2 \mathrm{I}_{\mathrm{d}}
$$

where $i$ is numbered subscripts 1,2 and 3 denoting wing positions. The values are tabulated in Table 4 .

\begin{tabular}{ccccccccccc}
\hline Time & $\mathbf{7 - 8}$ & $\mathbf{8 - 9}$ & $\mathbf{9 - 1 0}$ & $\mathbf{1 0 - 1 1}$ & $\mathbf{1 1 - 1 2}$ & $\mathbf{1 2 - 1}$ & $\mathbf{1 - 2}$ & $\mathbf{2 - 3}$ & $\mathbf{3 - 4}$ & $\mathbf{4 - 5}$ \\
\hline $\mathrm{I}_{\mathrm{c} 1}\left(\mathrm{KJ} / \mathrm{m}^{2}\right)$ & 0.1783 & 0.5165 & 0.6529 & 0.5924 & 0.6480 & 0.6999 & 0.6653 & 0.6049 & 0.4958 & 0.3100 \\
\hline $\mathrm{I}_{\mathrm{c} 2}\left(\mathrm{KJ} / \mathrm{m}^{2}\right)$ & 0.1659 & 0.5098 & 0.8013 & 1.0682 & 1.0714 & 1.1294 & 1.1991 & 1.1853 & 1.0189 & 0.5780 \\
\hline $\mathrm{I}_{\mathrm{c} 3}\left(\mathrm{KJ} / \mathrm{m}^{2}\right)$ & 0.1376 & 0.3403 & 0.4675 & 0.6612 & 0.6723 & 0.6738 & 0.6413 & 0.9272 & 1.0420 & 0.8696 \\
\hline $\mathrm{I}_{\mathrm{r}}\left(\mathrm{KJ} / \mathrm{m}^{2}\right)$ & 0.4818 & 1.366 & 1.9217 & 2.2735 & 2.3917 & 2.5031 & 2.5057 & 2.7174 & 2.5567 & 1.8086 \\
\hline
\end{tabular}

Table 4. Computed values of hourly insolation on each wing

\section{Optical performance of glazing and absorption of solar radiation}

Several optical properties (such as transmittance, reflectance and absorptance) of the glaze cover, most of which depend on the incident angle, affect the absorption of solar radiation. These optical properties in turn depend on the thickness of glazing and the refractive index and extinction coefficient of the glaze material.

Some of the radiation passing through the glaze and striking the absorber plate is reflected back to the cover system. However, not all of this radiation is lost since some of it is reflected back to the plate. The multiple reflections and absorptions between the plate and the cover is the greenhouse effect. To account for this greenhouse phenomenon, the actual fraction of incident radiation absorbed by the plate is called the transmittance-absorptance product $(\tau \alpha)$. This was reasonably approximated by [19] as

$$
(\tau \alpha)=\mathrm{A}(\tau) \alpha_{\mathrm{p}}
$$

The constant A ranges from 1.01 to 1.02, but for conservativeness, 1.01 is preferred:

$$
(\tau \alpha)=1.01(\tau) \alpha_{\mathrm{p}}
$$

For transmittance of diffuse radiation, the effective incident angle $\theta_{1}$ for vertical collectors is $59.5^{\circ}$ for both ground and sky diffuse radiation. Hence, the effective refractive angle $\theta_{2}$ of diffuse radiation from Snell's law is 


$$
\theta_{2}=\sin ^{-\mathrm{i}}\left[\frac{\mathrm{n}_{1}}{\mathrm{n}_{2}}\left(\sin \theta_{1}\right)\right]=\sin ^{-\mathrm{i}}\left[\sin 59.5^{\circ} / 1.526\right]=34.4^{\circ}
$$

Likewise, the reflection components $r_{\perp}$ and $r_{\|}$are evaluated from the equations below:

$$
\left.\begin{array}{c}
r_{\perp}=\frac{\sin ^{2}\left(\theta_{2}-\theta_{1}\right)}{\sin ^{2}\left(\theta_{2}+\theta_{1}\right)}=\frac{\sin ^{2}(34.4-59.5)}{\sin ^{2}(34.4+59.5)}=0.181 \\
r_{\|}=\frac{\tan ^{2}(34.4-59.5)}{\tan ^{2}(34.4+59.5)}=0.001
\end{array}\right\}
$$

The transmittance components are

$$
\left.\begin{array}{l}
\tau_{\perp}=\frac{\left(1-\tau_{\perp}\right)}{\left(1+\tau_{\perp}\right)}=\frac{1-0.181}{1+0.181}=0.693 \\
\tau_{\|}=\frac{\left(1-\tau_{\|}\right)}{\left(1+\tau_{\|}\right)}=\frac{1-0.001}{1+0.001}=0.998
\end{array}\right\}
$$

The average transmittance is $\tau_{\mathrm{r}}=0.5\left(\tau_{\perp}+\tau_{\|}\right)=0.693+0.998=0.8455$

Accounting for cover absorptance,

$$
\begin{gathered}
\tau_{\mathrm{a}}=\mathrm{e}^{-\mathrm{kL} / \cos \theta_{2}} \\
=\mathrm{e}^{-0.0125 / \cos 34.4}=0.985
\end{gathered}
$$

Hence, the resultant transmittance for diffuse radiation $\tau_{d}$ is determined from the following equation [19]:

$$
\tau_{\mathrm{d}}=\tau_{\mathrm{r}} \cdot \tau_{\mathrm{a}}=0.985 \times 0.8455=0.833
$$

Solar absorptance of the selective absorber plate $(\alpha)_{\mathrm{p}}=0.9$; hence, the transmittance-absorptance product for diffuse radiation is

$$
(\tau \alpha)_{\mathrm{d}}=1.01(0.833)(0.9)=0.757
$$




\subsection{Absorption of radiation}

Evaluating all necessary optical properties of the glass glazing, the amount of solar radiation actually absorbed by the collector can be easily deduced. The total incident radiation aimed at each wing of the collector is

$$
\mathrm{I}_{\mathrm{ci}}=\forall \mathrm{I}_{\mathrm{b}} \mathrm{R}_{\mathrm{bi}}+2\left[0.5 \mathrm{I}_{\mathrm{d}}+0.1\left(\mathrm{I}_{\mathrm{d}}+\mathrm{I}_{\mathrm{b}}\right)\right]
$$

the total absorbed solar radiation of each wing is

$$
\begin{aligned}
\mathrm{S}_{\mathrm{i}} & =(\tau \alpha)_{\mathrm{b}} \forall \mathrm{I}_{\mathrm{b}} \mathrm{R}_{\mathrm{bi}}+2(\tau \alpha)_{\mathrm{b}}\left[0.5 \mathrm{I}_{\mathrm{d}}+0.1\left(\mathrm{I}_{\mathrm{d}}+\mathrm{I}_{\mathrm{b}}\right)\right] \\
& =(\tau \alpha)_{\mathrm{b}} \forall \mathrm{I}_{\mathrm{b}} \mathrm{R}_{\mathrm{bi}}+(\tau \alpha)_{\mathrm{b}}\left[\mathrm{I}_{\mathrm{d}}+0.2\left(\mathrm{I}_{\mathrm{d}}+\mathrm{I}_{\mathrm{b}}\right)\right]
\end{aligned}
$$

The mean absorbed solar radiation, $\mathrm{S}$, of the whole collector plate is evaluated by the relation

$$
\mathrm{S}=1 / 3\left[\mathrm{~S}_{1}+\mathrm{S}_{2}+\mathrm{S}_{3}\right]
$$

Applying the above expressions with other expressions for optical properties for calculating the absorbed radiation, the values calculated are tabulated as shown in Table 5.

\begin{tabular}{ccccccccccc}
\hline Time & $\mathbf{7 - 8}$ & $\mathbf{8 - 9}$ & $\mathbf{9 - 1 0}$ & $\mathbf{1 0 - 1 1}$ & $\mathbf{1 1 - 1 2}$ & $\mathbf{1 2 - 1}$ & $\mathbf{1 - 2}$ & $\mathbf{2 - 3}$ & $\mathbf{3 - 4}$ & $\mathbf{4 - 5}$ \\
\hline $\mathrm{I}_{\mathrm{b}}\left(\mathrm{MJ} / \mathrm{m}^{2}\right)$ & 0.0246 & 0.2423 & 0.0371 & 1.0621 & 1.1144 & 1.1992 & 1.2452 & 1.1076 & 0.7478 & 0.3078 \\
\hline $\mathrm{I}_{\mathrm{d}}\left(\mathrm{MJ} / \mathrm{m}^{2}\right)$ & 0.1086 & 0.2239 & 0.2287 & 0.2255 & 0.2242 & 0.2216 & 0.2200 & 0.2244 & 0.2290 & 0.2250 \\
\hline $\mathrm{S}_{1}\left(\mathrm{MJ} / \mathrm{m}^{2}\right)$ & 0.136 & 0.384 & 0.418 & 0.389 & 0.240 & 0.507 & 0.505 & 0.464 & 0.380 & 0.275 \\
\hline$\forall_{1}$ & 1 & 1 & 1 & 1 & 1 & 0.4260 & 0.1870 & 0.1010 & 0.0590 & 0.0320 \\
\hline $\mathrm{R}_{\mathrm{b} 1}$ & 1.7480 & 0.8260 & 0.3940 & 0.1030 & 0.1400 & 0.3800 & 0.6540 & 1.0200 & 1.6200 & 2.993 \\
\hline$(\tau \alpha)_{\mathrm{b} 1}$ & 0.774 & 0.720 & 0.572 & 0.214 & 0.302 & 0.640 & 0.768 & 0.808 & 0.820 & 0.823 \\
\hline$(\tau \alpha)_{\mathrm{d} 1}$ & 0.757 & 0.757 & 0.700 & 0.757 & 0.757 & 0.757 & 0.757 & 0.757 & 0.757 & 0.757 \\
\hline $\mathrm{S}_{2}\left(\mathrm{MJ} / \mathrm{m}^{2}\right)$ & 0.124 & 0.377 & 0.593 & 0.793 & 0.797 & 0.840 & 0.889 & 0.873 & 0.743 & 0.516 \\
\hline$\forall_{2}$ & 1 & 1 & 1 & 1 & 1 & 1 & 1 & 1 & 1 & 1 \\
\hline $\mathrm{R}_{\mathrm{b} 2}$ & 1.247 & 0.795 & 0.627 & 0.551 & 0.520 & 0.520 & 0.551 & 0.627 & 0.795 & 1.247 \\
\hline$(\tau \alpha)_{\mathrm{b} 2}$ & 0.691 & 0.709 & 0.722 & 0.730 & 0.733 & 0.733 & 0.730 & 0.722 & 0.709 & 0.691 \\
\hline$(\tau \alpha)_{\mathrm{d} 2}$ & 0.757 & 0.757 & 0.757 & 0.757 & 0.757 & 0.757 & 0.757 & 0.757 & 0.757 & 0.757 \\
\hline $\mathrm{S}_{3}\left(\mathrm{MJ} / \mathrm{m}^{2}\right)$ & 0.104 & 0.259 & 0.357 & 0.465 & 0.488 & 0.434 & 0.416 & 0.621 & 0.766 & 0.667 \\
\hline$\forall_{3}$ & 0.032 & 0.059 & 0.101 & 0.187 & 0.426 & 1 & 1 & 1 & 1 & 1 \\
\hline $\mathrm{R}_{\mathrm{b} 3}$ & 2.993 & 1.620 & 1.020 & 0.654 & 0.380 & 0.140 & 0.103 & 0.394 & 0.826 & 1.748 \\
\hline$(\tau \alpha)_{\mathrm{b} 3}$ & 0.823 & 0.820 & 0.808 & 0.768 & 0.640 & 0.302 & 0.214 & 0.572 & 0.720 & 0.774 \\
\hline$(\tau \alpha)_{\mathrm{d} 3}$ & 0.757 & 0.757 & 0.757 & 0.757 & 0.757 & 0.757 & 0.757 & 0.757 & 0.757 & 0.757 \\
\hline $\mathrm{S}\left(\mathrm{MJ} / \mathrm{m}^{2}\right)$ & 0.121 & 0.430 & 0.466 & 0.549 & 0.568 & 0.594 & 0.603 & 0.653 & 0.630 & 0.486 \\
\hline
\end{tabular}

Table 5. Measured insolation data for each of the absorbers 


\subsection{The collector efficiency factor and the collector loss coefficient}

Despite the unusual configuration of the tri-wing absorber plate, a section of it reduces to a vertical flat-plate collector over both sides of the plate without back insulation. This implies that a wing of the absorber can be treated as a flat-plate air heater with flow over both sides of the plate. To conform to the performance equation of a flat-plate collector, the configuration of the chimney collector is transformed to suit the equation. Criteria for the transformation are as follows:

1. The total area of the tri-wing absorber plate is equal to the total area of the flat absorber plate.

2. The height of the chimney collector is the same as the height of the resulting flat absorber plate.

3. The area of the circular inlet column of the chimney collector and the rectangular area inlet column of the resulting flat-plate collector are equal throughout the height of the collector.

4. The resulting flat-plate absorber is positioned within the rectangular column such that the flow is halved.

5. Size difference of the glass glazing of the two cases is neglected. The resulting flat-plate collector has an absorber plate $5.3 \mathrm{~m}$ in height and $2.4 \mathrm{~m}$ in breadth enclosed by a rectangular channel of glass glazing measuring $2.46 \mathrm{~m}$ by $0.8587 \mathrm{~m}$ in length and breadth. Thus, the flow width on either side of the plate is about $43 \mathrm{~cm}$.

\section{Heat transfer and collector performance analysis}

Considering a vertical absorber plate of one wing of the collector heated by insolation to a temperature $T_{p}$, a free convection boundary layer is formed [20, 21]. The boundary layer is such that at the wall of the plate, the velocity of air stream is zero. This increases to some maximum value and then decreases to zero due to free stream conditions, provided the gap between the plate and the cover is much greater than the boundary layer thickness.

From the prevailing conditions of the system, temperature $T=T_{p}$ at $y=0, T=T_{\infty}$ at $y=\delta$ and $\frac{\mathrm{dt}}{\mathrm{dy}}=0$ at $\mathrm{y}=\delta$, a parabolic temperature function can be assumed to represent the temperature profile of the system with respect to $y$.

The expressions for the overall collector heat loss coefficient $U_{L}$ and the collector efficiency factor $\mathrm{F}^{\prime}$, which are very important performance parameters, were applied in the evaluation of useful energy rate extracted from the collector. To incorporate the flow rate and express the system energy equation using the collector inlet temperature, another performance parameter is introduced as the collector heat removal factor $F_{R}$. The collector heat removal factor is defined as the ratio of actual useful heat collector rate to useful heat collector rate attainable with the entire collector surface at the inlet fluid temperature. This is stated mathematically as 


$$
F_{R}=\frac{m_{p}\left(T_{o}-T_{1}\right)}{A_{c}\left[S-U_{L}\left(T_{1}-T_{a}\right)\right]}=\left[\frac{m_{p}}{A_{c} U_{L}}\right]\left[1-e^{-\frac{A_{c} U_{L} F}{m C_{p}}}\right]
$$

Thus, the energy equation of the system becomes

$$
\mathrm{Q}_{\mathrm{u}}=2 \mathrm{~A}_{\mathrm{c}} \mathrm{F}_{\mathrm{R}}\left[\mathrm{S}-\mathrm{U}_{\mathrm{L}}\left(\mathrm{T}_{1}-\mathrm{T}_{\mathrm{a}}\right)\right]
$$

The efficiency of the whole collector system $\eta$ defined as the ratio of the useful heat extracted from the collector $Q_{u}$ to the total incident solar radiation on the collector is mathematically expressed as

$$
\eta=\frac{Q_{u}}{A_{c} I_{T}}=2 F_{R}\left[(\tau \alpha)_{c}-\frac{U_{L}}{I_{T}}\left(T_{1}-T_{a}\right)\right]
$$

where $(\tau \alpha)$ is the effective transmittance-absorptance product of the collector glazing expressed by equation (24)

$$
(\tau \alpha)_{\mathrm{c}}=\frac{\mathrm{S}_{\mathrm{T}}}{\mathrm{I}_{\mathrm{T}}}
$$

where $\mathrm{T}_{1}$ and $\mathrm{T}_{\mathrm{a}}$ are the collector's inlet and outlet temperatures, respectively.

\section{Results and discussions}

The derived expressions were utilized in evaluating the performance of the chimney, and the results were tabulated in Table 6 . The outcome of the resulting parameters modelled from the analysis was graphically plotted to illustrate the performance efficiency of the chimney. This analysis is based on the use of a selective surface; in practice, the use of a non-selective absorbing surface with known properties is recommended for durability and economy.

\begin{tabular}{ccccccccccc}
\hline Time & 7.30 & $\mathbf{8 . 3 0}$ & $\mathbf{9 . 3 0}$ & $\mathbf{1 0 . 3 0}$ & $\mathbf{1 1 . 3 0}$ & $\mathbf{1 2 . 3 0}$ & $\mathbf{1 . 3 0}$ & $\mathbf{2 . 3 0}$ & $\mathbf{3 . 3 0}$ & $\mathbf{4 . 3 0}$ \\
\hline $\mathrm{T}_{\mathrm{a}}\left({ }^{\circ} \mathrm{C}\right)$ & 29.30 & 30.10 & 31.85 & 32.65 & 33.20 & 33.35 & 33.80 & 34.90 & 35.90 & 36.80 \\
\hline $\mathrm{I}_{\mathrm{T}}\left(\mathrm{MJ} / \mathrm{m}^{2}\right)$ & 0.1334 & 0.4662 & 0.8658 & 1.2876 & 1.3386 & 1.4208 & 1.4652 & 1.332 & 0.9768 & 0.5328 \\
\hline $\mathrm{I}_{1}\left(\mathrm{MJ} / \mathrm{m}^{2}\right)$ & 0.121 & 0.340 & 0.466 & 0.549 & 0.568 & 0.594 & 0.603 & 0.653 & 0.630 & 0.486 \\
\hline $\mathrm{S}\left(\mathrm{MJ} / \mathrm{m}^{2}\right)$ & 2.593 & 3.306 & 3.546 & 3.676 & 3.702 & 3.735 & 3.744 & 3.809 & 3.772 & 3.553 \\
\hline $\mathrm{a} \mathrm{h}\left(w / \mathrm{m}^{2}{ }^{\circ} \mathrm{C}\right)$ & 41.260 & 58.67 & 68.36 & 70.13 & 75.78 & 77.98 & 79.09 & 82.53 & 82.30 & 74.80 \\
\hline $\mathrm{T}_{\mathrm{p}}\left({ }^{\circ} \mathrm{C}\right)$ & 29.31 & 32.80 & 35.48 & 37.69 & 37.57 & 38.35 & 38.95 & 39.85 & 40.67 & 40.50 \\
\hline $\mathrm{U}_{\mathrm{t}}\left(w / \mathrm{m}^{2 \circ} \mathrm{C}\right)$ & 13.95 & 14.12 & 14.25 & 14.35 & 14.37 & 14.41 & 14.45 & 14.50 & 14.56 & 14.60 \\
\hline
\end{tabular}




\begin{tabular}{ccccccccccc}
\hline Time & 7.30 & 8.30 & $\mathbf{9 . 3 0}$ & $\mathbf{1 0 . 3 0}$ & $\mathbf{1 1 . 3 0}$ & $\mathbf{1 2 . 3 0}$ & $\mathbf{1 . 3 0}$ & $\mathbf{2 . 3 0}$ & $\mathbf{3 . 3 0}$ & $\mathbf{4 . 3 0}$ \\
\hline $\mathrm{h}_{\mathrm{r}}\left(\mathrm{w} / \mathrm{m}^{2 \circ} \mathrm{C}\right)$ & 0.6554 & 0.7252 & 0.7690 & 0.7980 & 0.8039 & 0.8150 & 0.8214 & 0.8380 & 0.8400 & 0.8105 \\
\hline $\mathrm{F}^{\prime}$ & 0.835 & 0.859 & 0.862 & 0.863 & 0.863 & 0.862 & 0.862 & 0.862 & 0.861 & 0.856 \\
\hline $\mathrm{U}_{\mathrm{L}}\left(\mathrm{w} / \mathrm{m}^{2 \circ} \mathrm{C}\right)$ & 6.100 & 7.116 & 7.395 & 7.711 & 7.754 & 7.819 & 7.848 & 7.959 & 7.933 & 7.640 \\
\hline $\mathrm{T}_{\mathrm{F}}\left({ }^{\circ} \mathrm{C}\right)$ & 31.70 & 38.66 & 42.94 & 50.32 & 46.24 & 47.26 & 47.90 & 48.31 & 49.82 & 47.88 \\
\hline $\mathrm{U}(\mathrm{m} / \mathrm{s})^{-1}$ & 0.261 & 0.360 & 0.407 & 0.255 & 0.436 & 0.446 & 0.450 & 0.464 & 0.459 & 0.421 \\
\hline $\mathrm{m}(\mathrm{kg} / \mathrm{s})$ & 0.384 & 0.518 & 0.577 & 0.353 & 0.612 & 0.623 & 0.628 & 0.644 & 0.637 & 0.588 \\
\hline $\mathrm{Q}_{\mathrm{u}}(\mathrm{w})$ & 227.71 & 751.25 & 1041.35 & 365.36 & 1275.77 & 1558.17 & 1374.99 & 1500.80 & 1448.91 & 1123.48 \\
\hline $\mathrm{F}_{\mathrm{R}}$ & 0.7670 & 0.7970 & 0.8024 & 0.7660 & 0.8048 & 0.8050 & 0.8047 & 0.8054 & 0.8035 & 0.797 \\
\hline $\mathrm{T}_{\mathrm{t}}\left({ }^{\circ} \mathrm{C}\right)$ & 31.53 & 38.30 & 42.48 & 50.05 & 45.71 & 45.41 & 47.34 & 48.71 & 49.24 & 47.40 \\
\hline$(\tau \alpha) \mathrm{c}$ & 0.9084 & 0.7293 & 0.5382 & 0.4264 & 0.4243 & 0.4181 & 0.4116 & 0.4902 & 0.6450 & 0.9122 \\
\hline $\mathrm{H}$ & 0.577 & 0.444 & 0.332 & 0.079 & 0.263 & 0.303 & 0.260 & 0.311 & 0.410 & 0.582 \\
\hline
\end{tabular}

Table 6. Results of modelled parameters from experimental analysis

The graph of temperatures versus diurnal hours, as shown in Figure 4, illustrates that peak values of the chimney air temperature are in the range $31.7^{\circ} \mathrm{C}-50.32{ }^{\circ} \mathrm{C}$ compared with peak values of ambient air temperature in the range $26.20^{\circ} \mathrm{C}-28.30{ }^{\circ} \mathrm{C}$. This gives a minimum temperature elevation of $3.4^{\circ} \mathrm{C}$ and a maximum temperature elevation of $17.67^{\circ} \mathrm{C}$. It has been earlier stated that an effective design of the solar chimney is that which maintains the chimney air temperature consistently above the ambient air temperature.

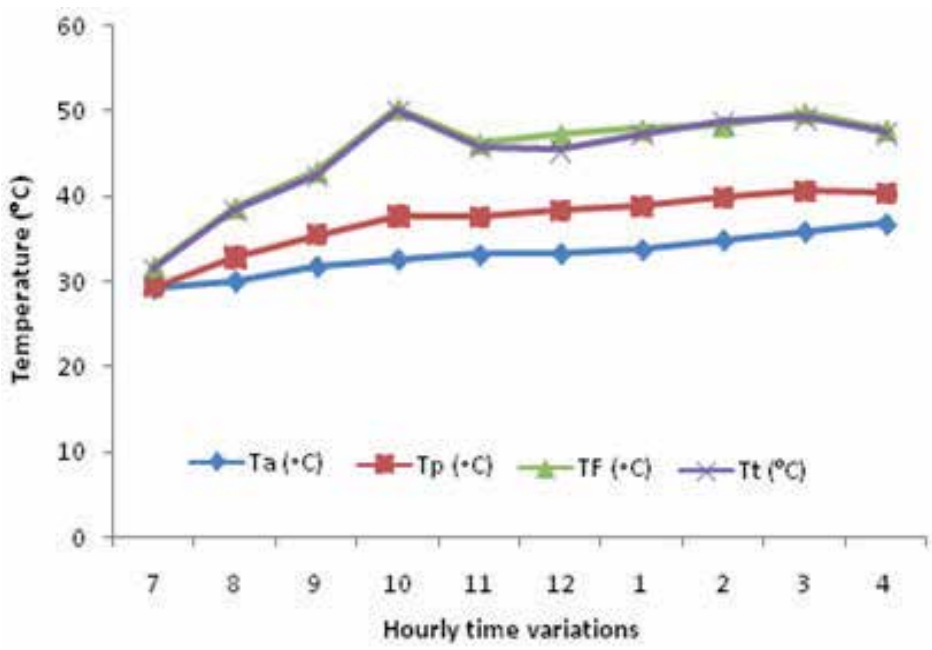

Figure 5. Diurnal variation of chimney and ambient temperatures 
The graph showed that chimney air temperature is always within the range of absorber plate and glass cover temperatures. This indicated that the chimney air is heated by the collector plate which is at a higher temperature but loses heat to the glazing which is at a lower temperature.

Figure 5 shows the values of direct beam radiation $R_{b}$ and diffuse radiation $S$ for all hours of insolation on each wing. It is evident from the figure that the components of radiation are lower at near noon due to low values of $R_{b}$ at this time. This is a result of the collector standing in a vertical position and the location near the equator. Highest components of direct beam radiation may be obtained for locations farther away from the equator. The diffuse solar radiation component absorbed by the collector will be evidently greater.

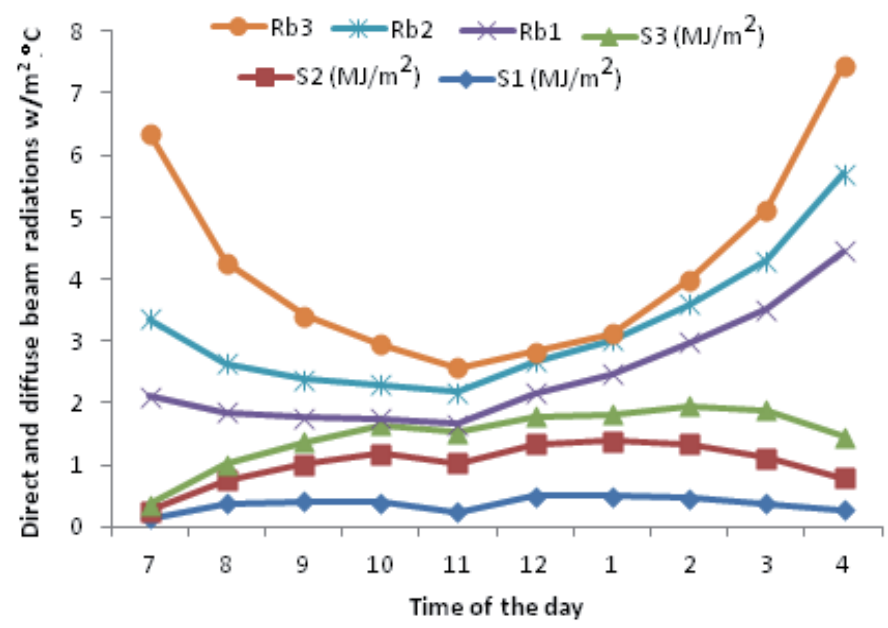

Figure 6. The values of direct beam radiation $\mathrm{Rb}$ for all hours of insolation on each wing

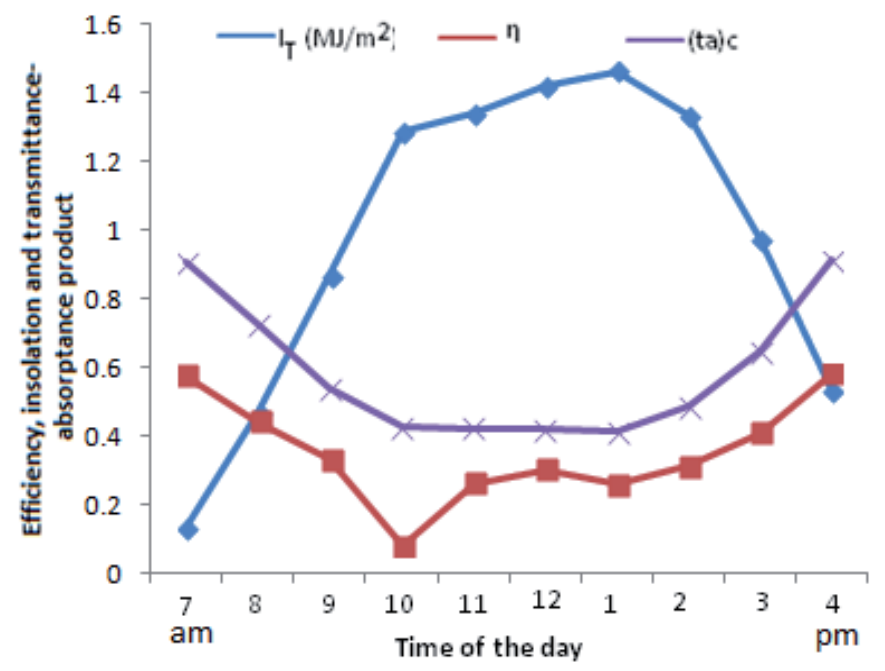

Figure 7. Graph of efficiency, insolation and transmittance-absorptance product 
The graph of efficiency versus insolation shown in Figure 6 indicates that higher efficiencies of the collector are obtained during early and late hours despite high insolations available at near-noon hours. This is mainly due to lower values of the effective transmittance-absorptance product prevailing at near-noon hours.

\section{Adaptation to wood drying}

Mechanical wood drying processes have included forced air or fan drying or dehumidification processes using a kiln [22]. These processes involve very high operating costs to power the fan. High-rise solar chimneys had been widely used in solar updraft power plants (SUPP) to updraft heated air to the atmosphere; however, this heat can be redirected back to the room for the purpose of heating the room under natural convection. Applying this principle, depending on outside temperature and humidity, the solar heated air within the chimney can be conventionally forced back to the room space where lumbers were stacked by covering the top of the chimney from where the exhaust air escapes. By so doing, the hot air displaces the cooler air from the air duct causing hot air down-draft into the chamber, and the process repeats itself. The analyses of thermal exchange air conditioning, air circulation in drying products and drying efficiency are still under investigation.

\section{Conclusion}

From the computed parameters of the collector presented in the tables, it is observed that low variance is exhibited for $\mathrm{U}_{t}, \mathrm{U}_{\mathrm{L}}, \mathrm{F}^{\prime}$ and $\mathrm{F}_{\mathrm{R}}$. This indicates that the characteristics of the solar chimney are uniform over a wide range of operations. The result shows that buoyant airflow within the chimney is possible and the variation of air temperature elevation with insolation is minimal while the chimney has better efficiency at lower values of solar radiation. Thus, the aim of this work, which was to devise a method of analysis of thermal performance for this type of solar chimney, has been accomplished.

Nevertheless, a method of complete analytical evaluations that will give satisfactory results can be achieved by obtaining a table of correlation factor from experimental data values to analytical values of this kind.

\section{Author details}

R. S. Bello ${ }^{1^{*}}$, C. N. Ezebuilo ${ }^{1}$, K. A. Eke ${ }^{1}$ and T. A. Adegbulugbe ${ }^{2}$

*Address all correspondence to: segemi2002@yahoo.com

1 Federal College of Agriculture, Ishiagu, Nigeria

2 Federal College of Agriculture, Moor Plantation, Ibadan, Nigeria 


\section{References}

[1] Hirunlabh, J. Study of natural ventilation of houses by a metallic solar wall under tropical climate. Renewable Energy 1999: Vol. 18 No. 1, pp. 109-119. http://en.wikipedia.org/wiki/Solar_chimney (assessed on September 2012).

[2] Shiv, L., Kaushik, S.C. and Bhargav, P.K. Solar chimney: A sustainable approach for ventilation and building space conditioning. International Journal of Development and Sustainability 2013: Vol. 2 No. 1, pp. 277-297.

[3] Gan, G. A parametric study of Trombe wall for passive cooling of buildings. Energy and Buildings 1998: Vol. 27, pp. 37-43.

[4] Bello, R. S. and Mohammed, A. S. Simulation of performance equations of passive integral solar water heating and storage system (ICS). Science Academy Transactions on Renewable Energy Systems Engineering and Technology (SATRESET) 2012: Vol. 2 No. 3 (September 2012 ISSN: 2046-6404). URL: http://www.sciacademypublisher.com/journals/index.php/SATRESET.

[5] Bello, R. S. and Odey, S. O. Development of hot water solar oven for low temperature thermal processes. Leonardo Electronic Journal of Practices and Technologies 2009: No. 14, 73-84 Romania. ISSN: 1583-1078. URL: www.lejpt.academicdirect.org/ A14/073_084.pdf.

[6] Bello, R. S., Odey, S. O., Eke, K. A., Mohammed, A. S., Balogun, R. B., Okelola, O. and Adegbulugbe, T. A. Application of Asphalt bonded solar thermogenerator in small scale agroforesty based industry. In Elisha, B. Babatunde (Ed). Solar Radiation. Reijeka: InTech 2012. pp 459-484. ISBN: 978-953-51-0384-4. URL:http://www.intechopen.com/books/solar-radiation.

[7] Hirunlabh, J. New configurations of a roof solar collector maximizing natural ventilation. Building and Environment 2001: Vol. 36 No. 3, pp. 383-391.

[8] Bansal, N.K., Mathur, J. and Bhandari, M.S. Solar chimney for enhanced stack ventilation. Building and Environment 1993: Vol. 28 No. 3, pp. 373-377.

[9] Ong, K. S. A Mathematical Model of a Solar Chimney. Monash University Malaysia 46150 Petaling Jaya, Malaysia: 2001.

[10] Alter, L. The Trombe wall: Low tech solar design makes a comeback 2011. available at:http://www.treehugger.com/sustainable-product-design/the-trombe-wall-lowtech-solar-design-makes-a-comeback.html/ (assesses October 2012).

[11] Khedari, J. Ventilation impact of a solar chimney on indoor temperature fluctuation and air change in a school building. Energy and Buildings 2000: Vol. 32 No. 1, pp. 89-93. 
[12] Zhai, X., Dai, Y. and Wang, R. Comparison of heating and natural ventilation in a solar house induced by two roof solar collectors. Applied Thermal Engineering 2005: Vol. 25 No. 5-6, pp. 741-757.

[13] Hirunlabh, J. Khedari, J. and Bunnag T. Experimental study of a roof solar collector towards the natural ventilation of new houses. Energy and Buildings 1997: Vol. 26 No. 2, pp. 159-164. International Journal of Development and Sustainability 2013: Vol. 2 No. 1, pp. 277-297. ISDS www.isdsnet.com 295.

[14] Ekechukwu, O. V. and Norton, B. Design and measured performance of a solar chimney for natural circulation solar-energy dryers. Renewable energy 1997: Vol. 10, pp. 81-90.

[15] Mathur, J. and Mathur, S. Summer-performance of inclined roof solar chimney for natural ventilation. Energy and Buildings 2006: Vol. 38 No. 10, pp. 1156-1163.

[16] Lee, K.H. and Strand, R.K. Enhancement of natural ventilation in buildings using a thermal chimney. Energy and Buildings 2009: Vol. 41 No. 6, pp. 615-621.

[17] Wikipedia. Mach number. 2014 http://en.wikipedia.org/wiki/Mach_number.

[18] Wikipedia. Nsukka. 2014 http://en.wikipedia.org/w/index.php?title=Nsukka\&action=history.

[19] Duffie, J. A. and Beckman, W. A. Solar Energy Thermal Processes. John and Sons Pub NY. 2003.

[20] McAdams, W. H. Heat Transmission, 3rd edition. McGraw-Hill, New York 1954.

[21] Holman, J. P. Heat Transfer. National students' edition, McGraw-Hill, Inc 1976.

[22] Bello, R. S. Workshop Technology \& Practice. Pub by Createspace 7290 B. Investment Drive Charl US. 2012. ISBN-13: 978-147-928-308-8. URL: https://www.createspace.com/3982311. 

Photo-Degradation \& Instrumentation 

Chapter 4

\title{
Solar-Light-Assisted Photo-degradation of Azo Dyes Using Some Transition Metal Oxides
}

\author{
A.V. Salker \\ Additional information is available at the end of the chapter \\ http://dx.doi.org/10.5772/59962
}

\section{Introduction}

Heterogeneous photo-catalysis through illumination by solar light on a semiconductor surface is an attractive advanced oxidation process. Several works have been done on various semiconductor photo-catalysts such as $\mathrm{TiO}_{2}, \mathrm{ZnO}, \mathrm{Fe}_{2} \mathrm{O}_{3}, \mathrm{MnO}_{2}, \mathrm{CeO}_{2}$, etc., for the degradation of organic and inorganic dye pollutants [1-4]. The photo-catalytic activity of a catalyst depends on crystal structure, oxidation state, surface area, band gap, etc. The activity can be enhanced by proper choice of semiconductors and also by incorporating active metal in it. $\mathrm{SnO}_{2}$ is a wideband-gap semiconductor and is successfully employed as a photo-catalyst for the treatment of various organic compounds as well as dye pollutants. $\mathrm{CeO}_{2}$ and $\mathrm{MnO}_{2}$ are low-cost and relatively harmless materials which are present in the Earth's crust. These materials present several characteristics and potential advantages for photo-catalytic applications [2].

Numerous hazardous organic compounds are discharged into the environment as a result of man-made activities. Waste water from different industries and laboratories pose great hazards to the environment. These wastes are harmful to microorganisms, aquatic lives and men. Rigorous research is being carried out to develop advanced physico-chemical methods for the detoxification of these toxic wastes from water and soil. Photo-catalysis process has received a high attention in breaking of organic compounds due to complete mineralization ability and also applicable to water pollution control employing solar light. The solar light is a renewable energy, cost effective and completely free for the photo-degradation of organic as well as inorganic dyes.

Photo-degradation of pollutants using solar light is very economically viable process since solar energy is an abundant natural energy source. The photo-catalysts chosen for the present discussion are some transition metal oxides and mixed metal oxides. The transition metal oxide materials are of interest to many due to less expensive in comparison to the precious metal 
catalysts such as platinum, palladium, etc. Transition metal doping improves trapping of electrons and inhibiting electron-hole recombination during the photolysis process. The oxides catalysts are thermally stable and increase the life span of the catalyst. Insertion of transition metal ions in the photo-catalyst structure can significantly enhance the photonic efficiency by widening the light absorption range and modifying the redox potential of the photo-produced radicals. $\mathrm{SnO}_{2}$ has been used in a wide range of applications in science, technology and industries such as catalysts, semiconductor material, gas sensing, ceramics, plastics and biomedical applications [5]. A. Pandurangan et al. [6] has studied the photocatalytic degradation of Auramine $\mathrm{O}$ using $\mathrm{ZnO}$ as a photo-catalyst and sunlight as an illuminant. The description of the present work is about photocatalytic degradation of Auramine $\mathrm{O}$ and Naphthol Blue Black dyes over $\mathrm{SnO}_{2}$ and $\mathrm{CeO}_{2}$ doped $\mathrm{Mn}$ compounds using solar light.

\section{Experimental}

$\mathrm{SnO}_{2}$ and $\mathrm{CeO}_{2}$ doped $\mathrm{Mn}$ samples have been prepared by adopting co-precipitation method. The stoichiometric quantities of pure grade metal nitrates chemicals were taken in proportions and dissolved in distilled water. To this added $10 \%$ sodium hydroxide solution with stirring till precipitation was complete. This precipitate was digested on a water bath with the addition of $30 \% \mathrm{H}_{2} \mathrm{O}_{2}$ with stirring. The precipitate was filtered and dried at $100{ }^{\circ} \mathrm{C}$. It was then fired at $400{ }^{\circ} \mathrm{C}$ for $4 \mathrm{~h} . \mathrm{CeO}_{2}$ doped samples were then sintered in a furnace at $700{ }^{\circ} \mathrm{C}$ for $7-10 \mathrm{~h}$ to form solid solutions.

Photo-catalysts prepared by co-precipitation method were characterized by XRD, FTIR and band gap measurements. Surface area of the sample was measured using BET nitrogen adsorption method. The magnetic susceptibility was determined by Gouy method at room temperature in air employing a field of 800 Gauss and using $\left\{\mathrm{Hg}\left[\mathrm{Co}(\mathrm{SCN})_{4}\right]\right\}$ as a standard material. The electrical resistivity (Q) of the $\mathrm{SnO}_{2}$ sample was measured by two probe method using sintered pellet from $250{ }^{\circ} \mathrm{C}$ to room temperature during cooling cycle. The diffuse reflectance spectra of all the samples were recorded at room temperature in the $200-800 \mathrm{~nm}$ range using $\mathrm{BaSO}_{4}$ as a reference material.

The photo-catalytic degradation of azo dyes was performed in a simple glass reactor. Aqueous solution of dye $10^{-5} \mathrm{M}$ concentration was placed in the reactor; the solution was aerated with oxygen for 5 to 10 minutes then added the solid semiconductor catalyst and closed with cork or stopper to prevent loss due to evaporation. The photolysis of Auramine O dye was performed out using sunlight and $\mathrm{SnO}_{2}$ as the photo-catalyst. The Naphthol blue black dye (NBB) degradation was carried out using $\mathrm{CeO}_{2}$ doped compounds. The study was performed between 10.00 am to $4.00 \mathrm{pm}$ during all sunny days. The reaction was studied for various experimental conditions such as $\mathrm{pH}$, presence of oxygen, amount of catalyst, absence of catalyst, etc. The $100 \mathrm{ml}$ of $10^{-5} \mathrm{M}$ aqueous solution of the respective dye was aerated with $\mathrm{O}_{2}$ and kept in sunlight with $100 \mathrm{mg}$ of the photo-catalyst sample in a glass reactor. The photodegradation rate was measured by taking the absorbance $\left(\lambda_{\max }\right)$ of the dye with periodic interval of time employing UV-Visible spectrophotometer. 


\section{Results and discussion}

$\mathrm{SnO}_{2}$ was characterized by recording the $\mathrm{X}$-ray diffraction pattern and the $\mathrm{d}_{\mathrm{hkl}}$ and $2 \theta$ values obtained were checked with the reported values in the literature (ICDD-PDF data files). Figure 1 shows the XRD pattern of $\mathrm{SnO}_{2}$ sample prepared at $400{ }^{\circ} \mathrm{C} . \mathrm{SnO}_{2}$ is having tetrahedral structure. Particle size determined by Debye Scherer's equation was found to be from $20-50 \mathrm{~nm}$.

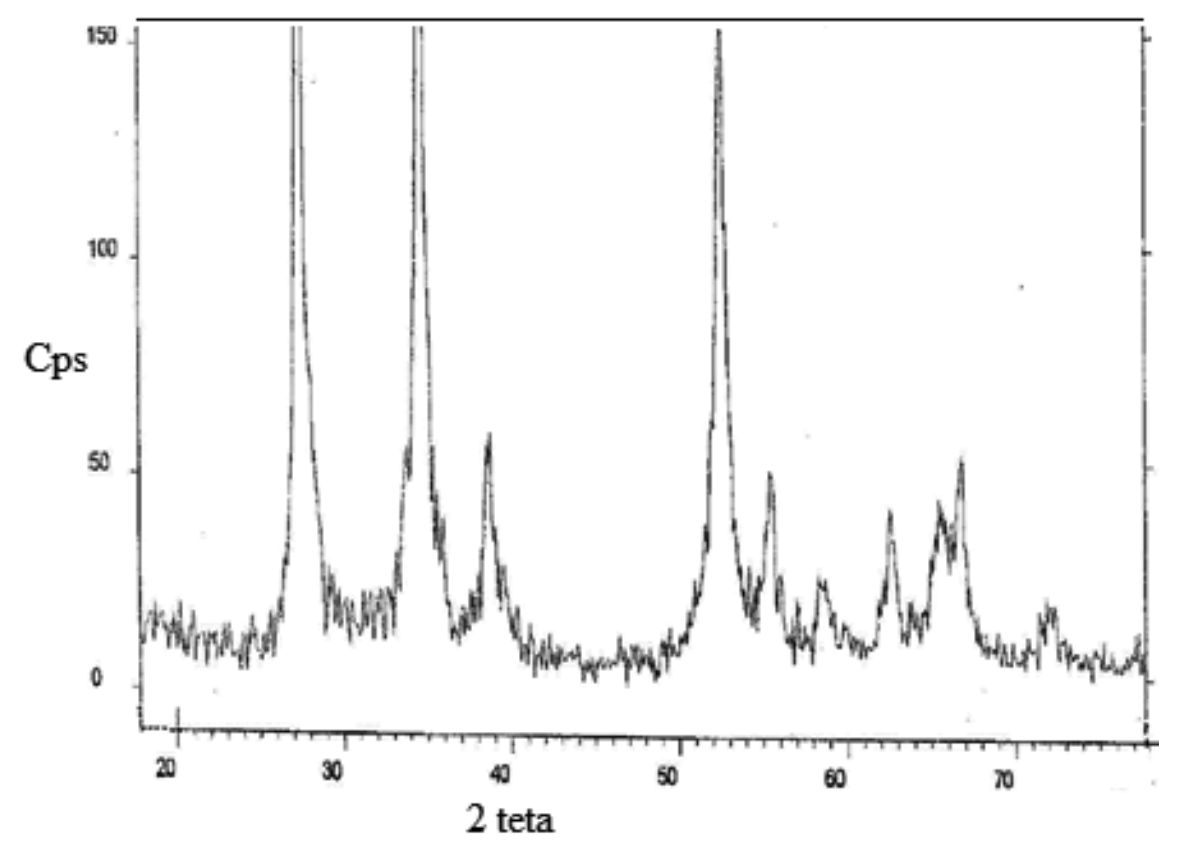

Figure 1. XRD pattern of $\mathrm{SnO}_{2}$.

Thermal study of dried hydroxide sample shows that $\mathrm{Sn}(\mathrm{OH})_{4}$ decompose at around $120^{\circ} \mathrm{C}$ which is indicated by endothermic peak in thermal analysis. The surface area measured by using BET nitrogen adsorption method is found to be $8.05 \mathrm{~m}^{2} / \mathrm{g}$. The FTIR study was performed aiming to ascertain the metal oxygen bond in $\mathrm{SnO}_{2}$ sample. The two broad bands were observed at 610 and $680 \mathrm{~cm}^{-1}$ assigned to Sn-O stretching vibrational modes, which is in agreement with literature data [7]. Magnetic study performed at room temperature indicates that $\mathrm{SnO}_{2}$ is diamagnetic in nature as reported earlier.

The electrical resistivity of the sample was measured by two probe method during cooling cycle from $250^{\circ} \mathrm{C}$ to room temperature. Variation in electrical resistivity with temperature for $\mathrm{SnO}_{2}$ sample is shown in Figure 2. The electrical resistivity decreases with increase in temperature showing semiconductor behaviour. $\mathrm{SnO}_{2}$ is n-type semiconductor, since oxygen vacancies or interstitial $\mathrm{Sn}^{+4}$ is donor site [8]. Figure 3 shows UV-Visible reflectance spectra of $\mathrm{SnO}_{2}$ sample. The spectrum consists of single, broad intense absorption in visible region 
ascribed to a charge transfer process from the valence band to the conduction band. The DRS spectrum provides the band gap of $\mathrm{SnO}_{2}$ equal to $3.5 \mathrm{eV}$ which is in good agreement to the reported value.

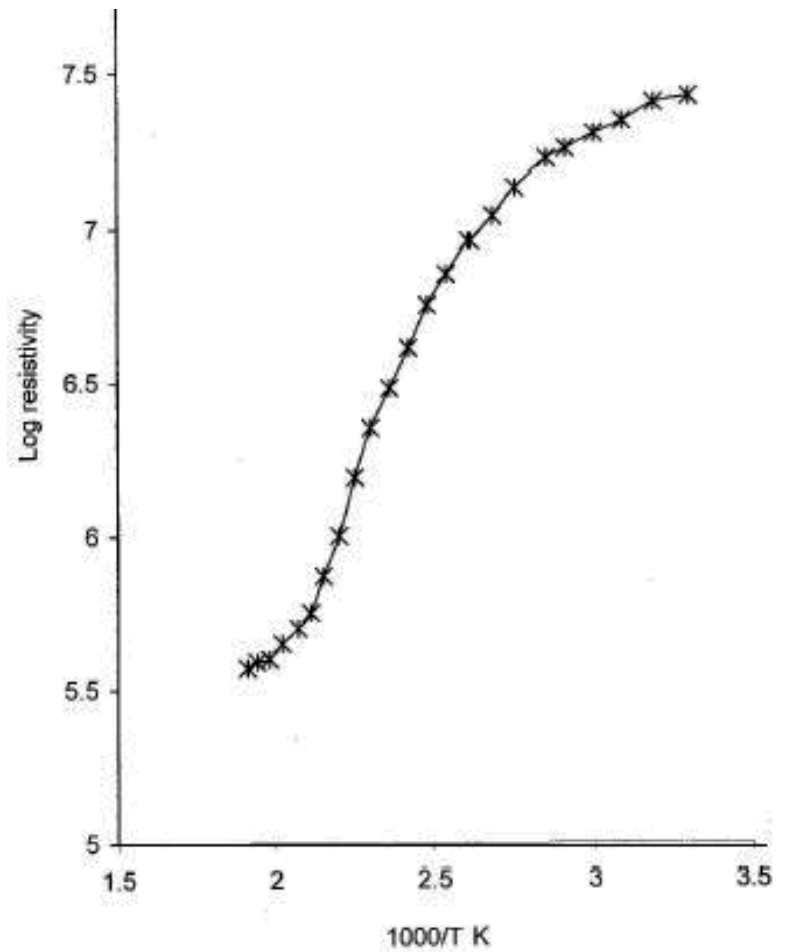

Figure 2. Variation of electrical resistivity with temperature of $\mathrm{SnO}_{2}$.

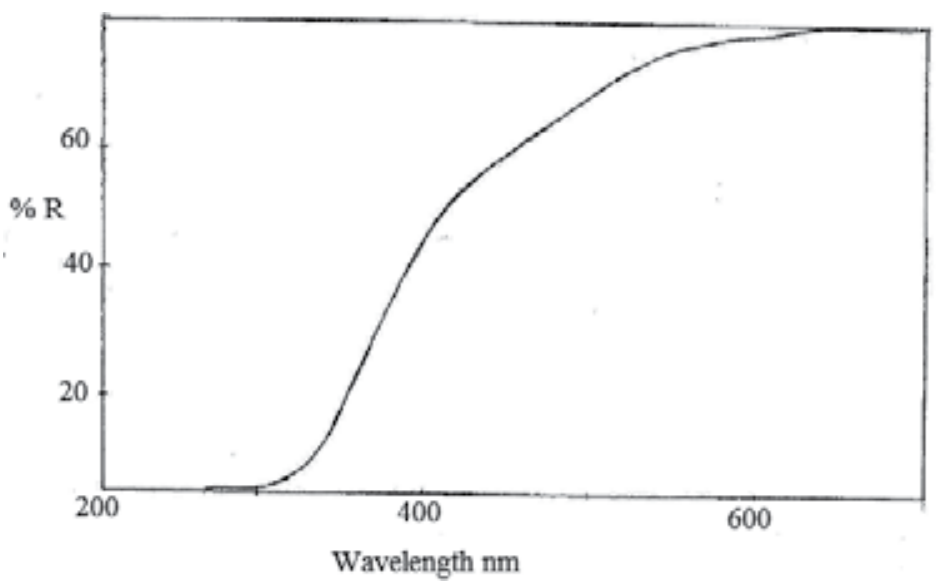

Figure 3. UV-Visible diffuse reflectance spectra of $\mathrm{SnO}_{2}$. 
The photo-catalytic degradation of the Auramine $\mathrm{O}$ dye was performed using prepared $\mathrm{SnO}_{2}$ photo-catalyst. The complete UV-Visible spectrum of the dye is shown in Figure 4 . The dye has absorption in the visible region at $\lambda_{\max } 432 \mathrm{~nm}$. The progress of photo-catalytic degradation is monitored by measuring the absorbance of the solution at this wavelength.

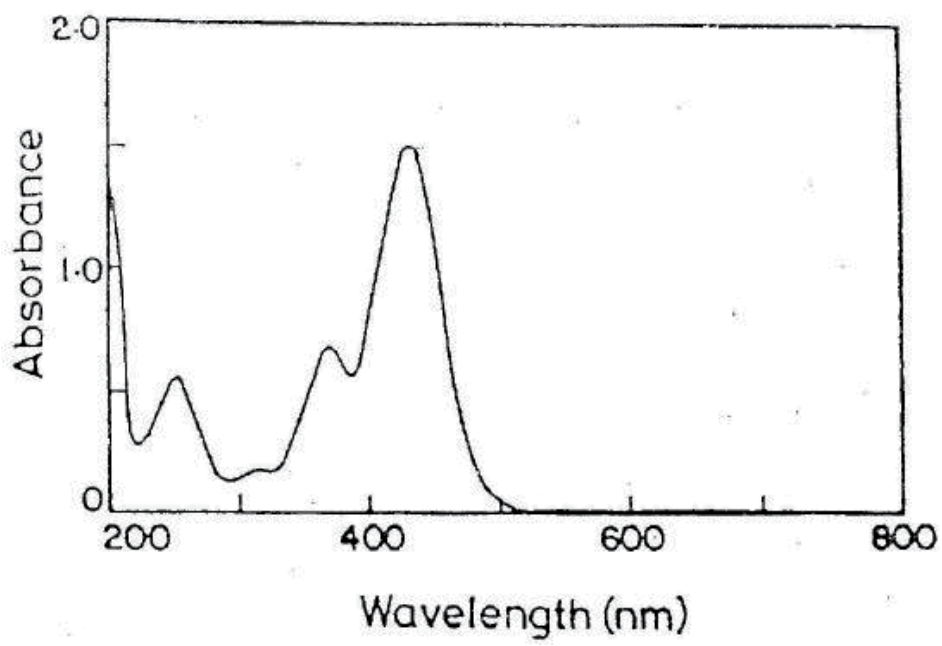

Figure 4. UV-Visible spectrum of Auramine O dye.

The optimum amount of the catalyst for photo-catalytic degradation of Auramine O dye was found to be $100 \mathrm{mg}$ for $100 \mathrm{ml}$ of the solution as shown in Figure 5. The reaction was studied with different experimental conditions like $\mathrm{pH}$, amount of catalyst, oxygen, etc. The rate of dye degradation increases with the amount of the photo-catalyst, but after a certain limit if the amount is increased further, there will be a saturation point. The amount of photo-catalyst affects both the number of active sites on the photo-catalyst and the penetration of light through the suspension [9]. Also increased amount of photo-catalyst increases the rate of deactivation of activated molecules by collision with ground state photo-catalyst.

In the absence of oxygen, the photo-catalytic degradation of the dye was negligible. Oxygen is an electron scavenger [10] which traps the photo-generated electrons from the conduction band and thus preventi the electron-hole recombination. Dissolved oxygen traps the conduction band electrons forming superoxide ion $\left(\mathrm{O}^{2-}\right)$. Also the dye degradation is negligible in absence of sunlight. Figure 6 shows the photo-catalytic degradation of Auramine O dye with time under different conditions over $\mathrm{SnO}_{2}$ photo-catalyst. Figure 7 shows the Auramine $\mathrm{O}$ dye degradation over photo-catalyst at neutral $\mathrm{pH}$ and at different interval period. The absorption spectra obtained after complete degradation suggest that degradation products are colourless. It has been observed that degradation of dye is faster in alkaline $\mathrm{pH}$, i.e. at $\mathrm{pH} 10$. At higher $\mathrm{pH}$, the hydroxyl radical and $\mathrm{O}_{2}^{-}$can be easily diffuse from the negative surface of the semiconductor into the bulk of the reaction solution. At $\mathrm{pH} 4$, the degradation activity is lower than neutral $\mathrm{pH}$. 


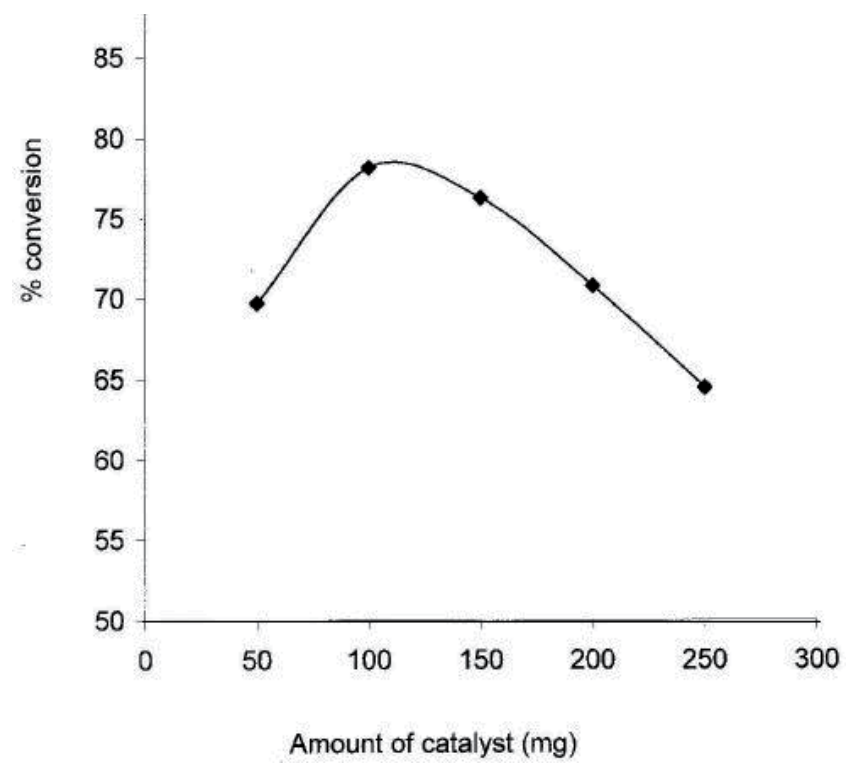

Figure 5. Optimization of catalyst amount.

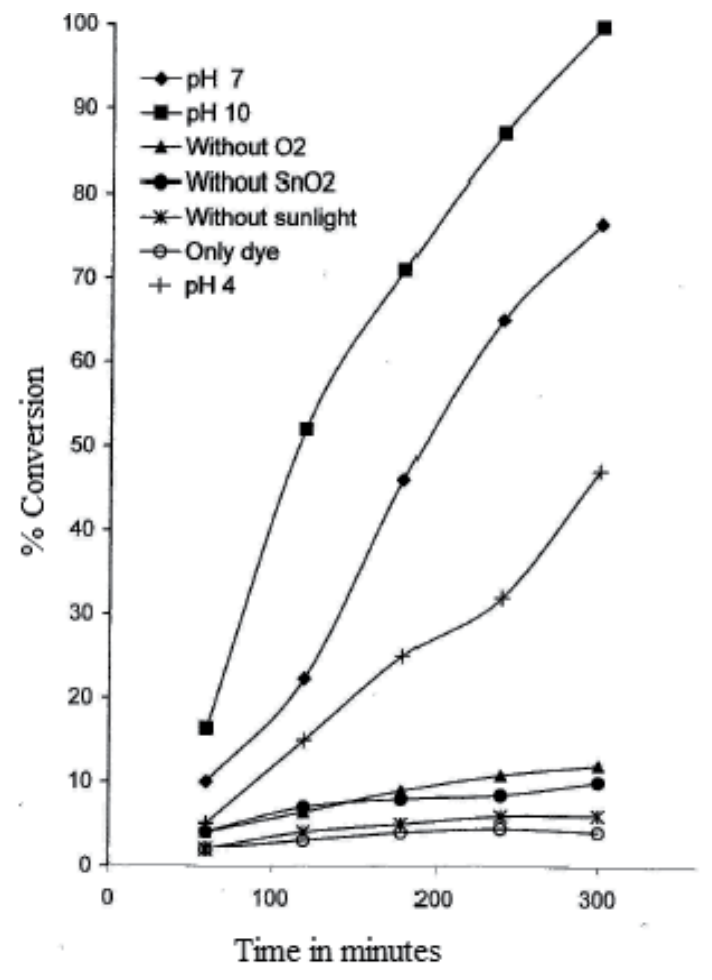

Figure 6. Percentage conversion of Auraamine O dye with time using $\mathrm{SnO}_{2}$ photo-catalyst. 


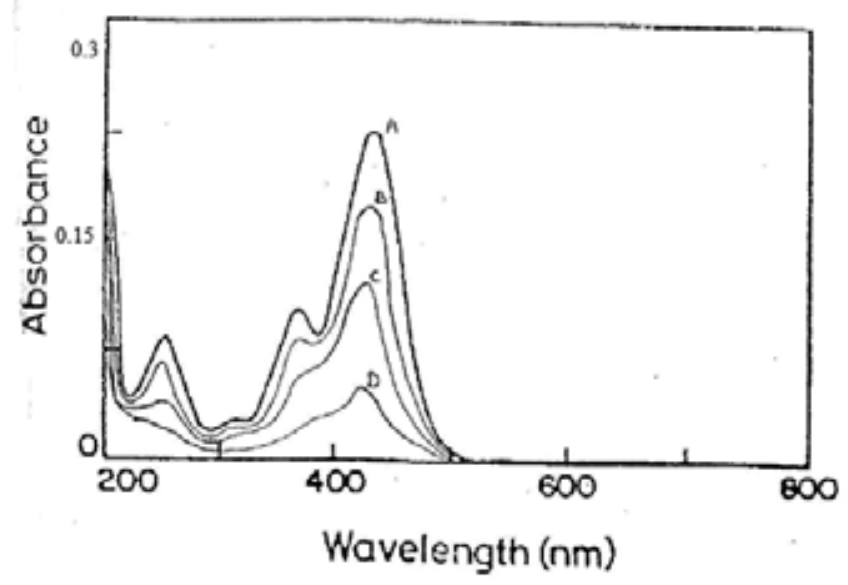

Figure 7. Auramine O dye degradation over the photo-catalyst at neutral pH with time (A) $60 \mathrm{~min}$, (B) $120 \mathrm{~min}$, (C) 180 min and (D) $240 \mathrm{~min}$.

Photo-catalytic degradation of Naphthol Blue Black dye (NBB) was studied using $\mathrm{CeO}_{2}$ doped $\mathrm{Mn}$ compounds. The Figure 8 shows the X-ray diffraction pattern of $\mathrm{CeO}_{2}$ and some doped compounds. The NBB dye in aqueous solution has $\lambda_{\max }$ at $618 \mathrm{~nm}$ in the visible region. The absorbance of the dye solution at $618 \mathrm{~nm}$ monitors the progress of photo-catalytic degradation process. The photo-catalytic process was carried out at varying experimental parameters such as quantum of the catalyst, with and without aeration, with and without catalyst, with and without solar radiation and varying the $\mathrm{pH}$ from neutral, acidic to basic. Figure 9 depicts the representative spectra of NBB through $\lambda_{\max }$ in the range 400 to $700 \mathrm{~nm}$ with different irradiation time using $\mathrm{CeO}_{2}$ doped $\mathrm{Mn}$ sample $\left(\mathrm{Ce}_{.7} \mathrm{Mn}_{0.3} \mathrm{O}_{2}\right)$ as photo-catalyst at neutral $\mathrm{pH}$. The lowering of optical density or absorbance was observed with time by sun light irradiation. This conveys that the rupturing of conjugation bonds of the dye take place due to solar radiation with the photo-catalyst, giving colourless product. It was found that $100 \mathrm{mg}$ was the optimum weight of catalyst required in this photo-catalytic reaction for $100 \mathrm{ml}$ of the dye solution. Normally the rate of dye degradation reaction goes up with the amount of catalyst mainly due to the increase in the exposed surface area of the catalyst. If the weight of the photo-catalyst increases beyond a certain weight $(100 \mathrm{mg})$, there will be a saturation point. As per Kartal et al. [9], the quantum of photo-catalyst influences both the number of active sites and the passage of light through the suspension. Oxygen takes the electron which was migrated to conduction band due to photon irradiation, and if there is no oxygen, electron-hole recombination takes place lowering the dye degradation rate. Therefore, oxygen is very essential in photo-degradation process. Oxygen scavenges the photo-generated electrons from the conduction band generating $\mathrm{O}_{2}^{-}$ions $\left(\mathrm{O}_{2}+\mathrm{e}^{-} \rightarrow \mathrm{O}_{2}^{-}\right)$[11].

Dye degradation was studied at different $\mathrm{pH}$ conditions, which is one of the important factors. It has been observed that photo-degradation rate is higher in alkaline $\mathrm{pH}$, i.e. at $\mathrm{pH} 10$. At higher alkaline $\mathrm{pH}$ there is more possibility for the formation of hydroxyl radical $\left(\mathrm{OH}^{-}\right)$, which helps photo-degradation process of the dye. Hydroxyl radical acts as an oxidant thereby 


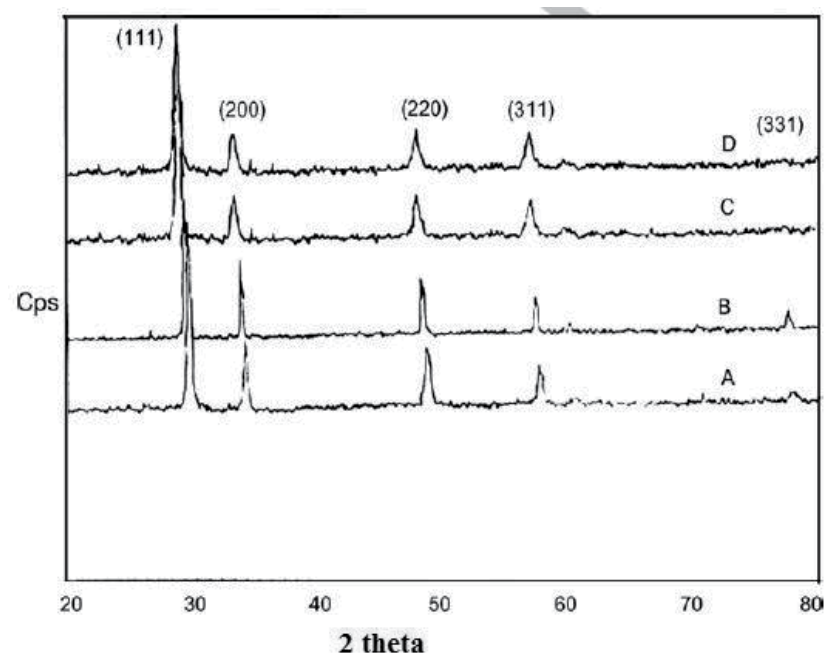

Figure 8. $\mathrm{XRD}$ powder pattern of $\mathrm{CeO}_{2}$ doped $\mathrm{Mn}$ : (A) $\mathrm{CeO}_{2}$, (B) $\mathrm{Ce}_{0.9} \mathrm{Mn}_{0.1} \mathrm{O}_{2},(\mathrm{C}) \mathrm{Ce}_{0.8} \mathrm{Mn}_{0.2} \mathrm{O}_{2}$ and (D) $\mathrm{MnO}_{2}$.

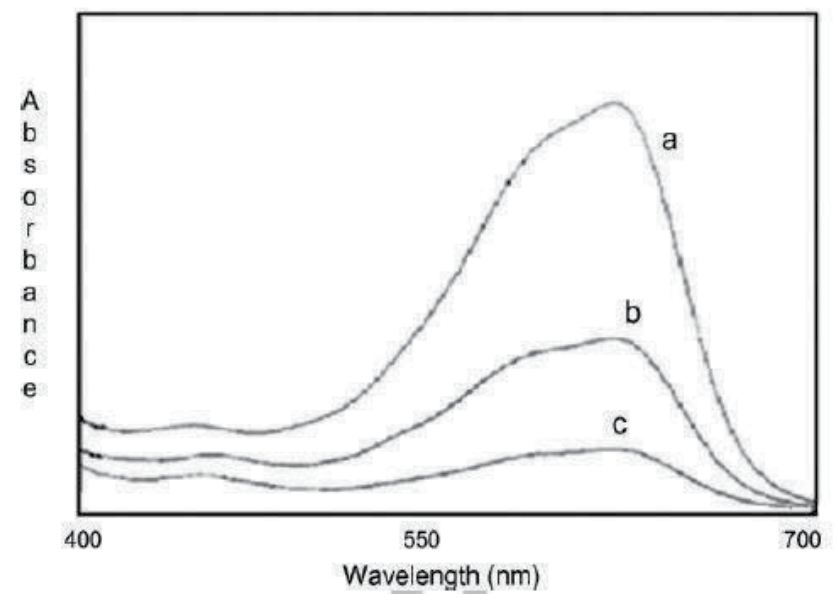

Figure 9. Absorption spectra of NBB dye degradation at $\lambda_{\max }$ range with time over $\mathrm{Ce}_{0.7} \mathrm{Mn}_{0.3} \mathrm{O}$ : (a) after $1 \mathrm{~h}$, (b) $3 \mathrm{~h}$ and (c) $4 \mathrm{~h}$ irradiation.

increasing the rate of degradation. By increasing the $\mathrm{pH}$ of the dye solution from 4 to 10 enhances the photo-catalytic process. The photo-catalytic degradation reaction was higher in alkaline $\mathrm{pH}$ than in acidic $\mathrm{pH}$. In alkaline $\mathrm{pH}$ the number of hydroxyl ions are more, the negative surface of the photo-catalyst with $\mathrm{OH}^{-}$ions behaves as an efficient trap for the photogenerated holes to produce hydroxyl radicals. Besides, the hydroxyl radical and $\mathrm{O}_{2}^{-}$ions can easily diffuse from the negative surface of the photo-catalyst into the bulk solution easily at higher $\mathrm{pH}$. Therefore, hydroxyl radical is main species for dye degradation. $\mathrm{CeO}_{2}$ showed low activity for the degradation of NBB dye. But after doping with Mn, it showed increased photocatalytic activity as seen in Figure 10 at $\mathrm{pH} 7$. As the dopant (x) increases, the photo-catalytic 
activity increases. Table 1 shows the calculated band gap energies of the samples. The solid solution samples showed lower band gap energies than $\mathrm{CeO}_{2}$ and these samples of lower band gap have helped to propagate the electron from valence band to conduction band initiating photolysis reaction. Also increased magnetic susceptibility of these solid solutions is an indication of more free electrons availability than $\mathrm{CeO}_{2}$. These are some of the factors responsible for the photo-activity besides others. Figure 11 shows the photo-catalytic degradation of NBB dye over $\mathrm{Ce}_{1-\mathrm{x}} \mathrm{Mn}_{\mathrm{x}} \mathrm{O}_{2}$ with time at $\mathrm{pH} 10$. Here also solid solutions showed higher photocatalytic activity than $\mathrm{CeO}_{2}$ and $\mathrm{MnO}_{2}$, respectively.

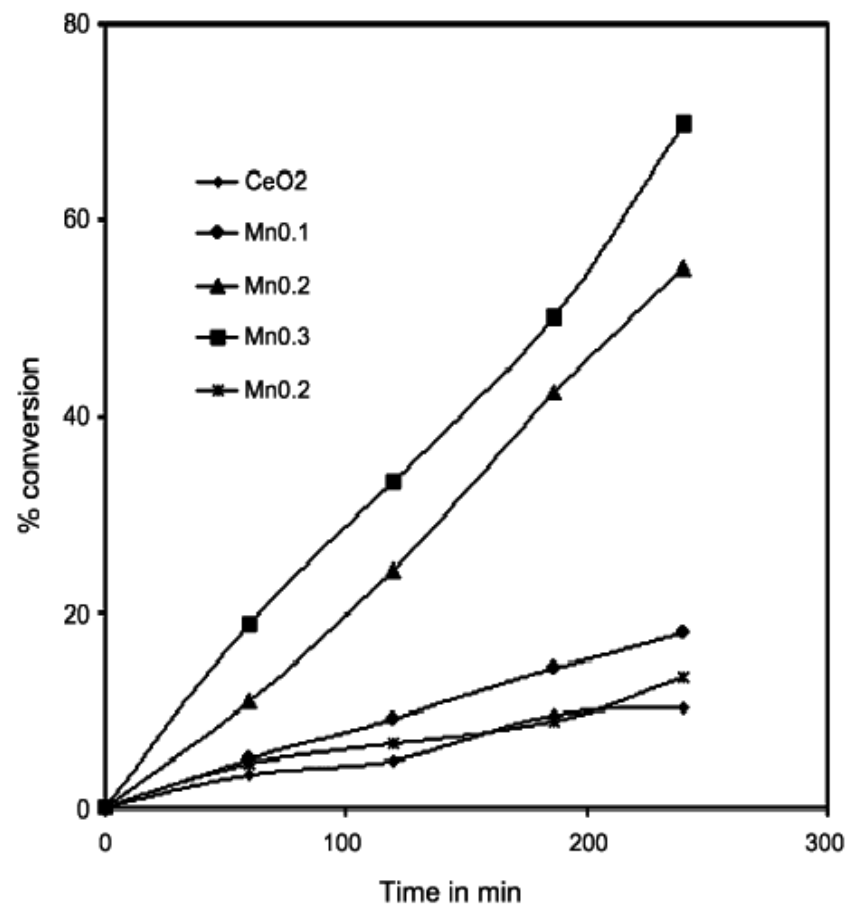

Figure 10. Photo-catalytic degradation of NBB dye with time using $\mathrm{CeO}_{2}$ doped $\mathrm{Mn}$ at $\mathrm{pH} 7$.

\begin{tabular}{ccccc}
\hline Sample & $\begin{array}{c}\text { Magnetic } \\
\text { susceptibility } \\
\left(\chi_{\mathbf{g}} \text { cgs units }\right)\end{array}$ & $\boldsymbol{\mu}_{\text {eff }}(\mathbf{B M})$ & $\begin{array}{c}\text { Surface area } \\
\mathbf{B E T}\left(\mathbf{m}^{\mathbf{2}} \mathbf{g}^{-1}\right)\end{array}$ & $\begin{array}{c}\text { Band gap energy } \\
(\mathbf{e V})\end{array}$ \\
\hline $\mathrm{CeO}_{2}$ & $2.94 \times 10^{-6}$ & 1.06 & 7.36 & 3.64 \\
\hline $\mathrm{Ce}_{0.9} \mathrm{Mn}_{0.1} \mathrm{O}_{2}$ & $4.06 \times 10^{-6}$ & 1.21 & 2.75 & 3.20 \\
\hline $\mathrm{Ce}_{0.8} \mathrm{Mn}_{0.2} \mathrm{O}_{2}$ & $4.98 \times 10^{-6}$ & 1.30 & 6.52 & 3.26 \\
\hline $\mathrm{Ce}_{0.7} \mathrm{Mn}_{0.3} \mathrm{O}_{2}$ & $6.84 \times 10^{-6}$ & 1.48 & 8.34 & 3.50 \\
\hline $\mathrm{MnO}_{2}$ & $84.98 \times 10^{-6}$ & 3.84 & 16.07 & 3.66 \\
\hline
\end{tabular}

Table 1. Magnetic susceptibility, surface area and band gap energy of $\mathrm{Ce}_{1-\mathrm{x}} \mathrm{Mn}_{\mathrm{x}} \mathrm{O}_{2}$ samples. 


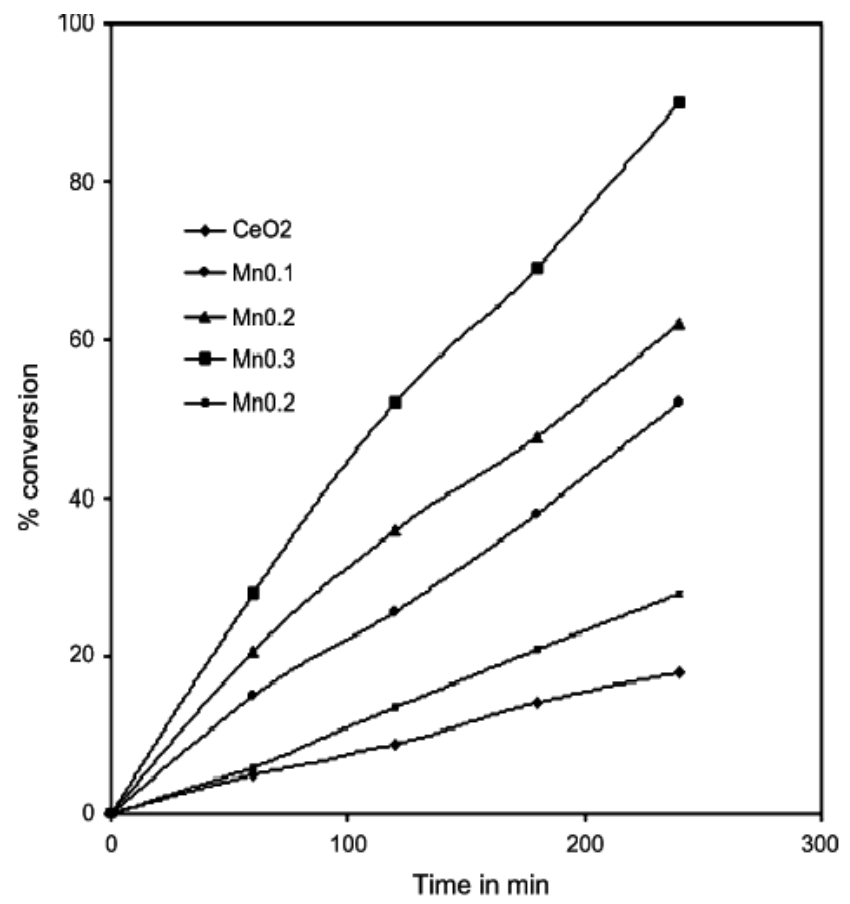

Figure 11. Photo-catalytic degradation of NBB dye with time using $\mathrm{CeO}_{2}$ doped $\mathrm{Mn}$ at $\mathrm{pH} 10$.

The electrons are excited when photo-catalyst is illuminated by sunlight and electrons are promoted to conduction band leaving holes in the valence band. These electrons are trapped by $\mathrm{O}_{2}$ forming $\mathrm{O}_{2}^{-}$ions. The valence band holes generate hydroxyl radicals $(\mathrm{OH})$ from $\mathrm{OH}^{-}$ ions and these $\mathrm{HO}^{\prime}$ radicals attack the dye leading to complete mineralization. Scheme I suggests one of the photo-catalytic degradation path way, which is in some agreement with the literature [10] by taking photo-catalyst $\mathrm{SnO}_{2}$ as an example.

$$
\begin{aligned}
& \mathrm{SnO}_{2}+\mathrm{hv} \rightarrow \mathrm{SnO}_{2}{ }^{*} \\
& \mathrm{SnO}_{2}{ }^{*} \rightarrow \mathrm{e}_{\mathrm{CB}}^{-}+\mathrm{h}^{+}{ }_{\mathrm{VB}} \rightarrow \text { recombination } \rightarrow \text { heat } \\
& \mathrm{O}_{2}+\mathrm{e}_{\mathrm{CB}}^{-} \rightarrow \mathrm{O}_{2}^{-} \\
& \mathrm{O}_{2}^{-}+\mathrm{H}_{2} \mathrm{O} \rightarrow \mathrm{OH}^{-}+\mathrm{HO}_{2}{ }^{\times} \\
& \mathrm{HO}_{2}{ }^{\times}+\mathrm{HO}_{2}{ }^{\times} \rightarrow \mathrm{H}_{2} \mathrm{O}_{2} \\
& \mathrm{~h}^{+}{ }_{\mathrm{VB}}+\mathrm{OH}^{-} \rightarrow \mathrm{OH}^{\times} \\
& \mathrm{OH}^{\times}+\text {Dye } \rightarrow \text { Degraded products } \\
& \left(\mathrm{e}_{\mathrm{CB}}^{-} \text {is the electron in conduction band and } \mathrm{h}_{\mathrm{VB}}^{+}\right. \text {is hole in valence band) }
\end{aligned}
$$


Heterogeneous photo-catalysis through illumination by solar light on semiconductor surface is an attractive advance oxidation process. Photo-degradation of pollutants using semiconductor photo-catalyst with solar light can make it an economically viable process since solar energy is an abundant and inexpensive natural energy source. Solar energy has been successfully used for photo-catalytic degradation of pollutants. The main advantage of the photocatalytic process is its mild operation conditions.

It is often suggested that surface hydroxyl group play an important role in determining the photo-catalytic activity, since these species act as a traps for photo-generated holes to form hydroxyl radicals and reduce electron-hole recombination. In the photo-degradation of reactive dyes, the azo group was attached by hydroxyl group at two positions, one at the single bond $\mathrm{C}-\mathrm{N}$ of the azo group and other at the double bond of the azo group. The photo-catalytic activity is influenced by several factors such as the crystal structure of the semiconductor, surface area, size distribution, band gap and surface hydroxyl group density.

\title{
4. Conclusions
}

Nano size $\mathrm{SnO}_{2}$ and $\mathrm{CeO}_{2}$ doped compounds were prepared by co-precipitation precursor method. $\mathrm{SnO}_{2}$ is diamagnetic in nature and shows semiconductor behaviour. $\mathrm{SnO}_{2}$ has band gap of $3.5 \mathrm{eV}$, which help in preventing the electron-hole recombination. It is found that azo dye Auramine $\mathrm{O}$ can be degraded efficiently using $\mathrm{SnO}_{2}$ semiconductor photo-catalyst with solar light. $\mathrm{CeO}_{2}$ has low photo-catalytic activity for the degradation of Naphthol Blur Black. Increase in photo-catalytic activity was noticed by incorporation of $\mathrm{Mn}$ in $\mathrm{CeO}_{2}$ lattice. This is mainly due to the increase of the redox couple $\mathrm{Ce}^{4+}-\mathrm{Ce}^{3+}$ and improvement of the band gap energy. The mechanism involves the formation of $\mathrm{OH}^{\cdot}$ radicals which are active oxidizing agents for the degradation of dyes. Also oxygen prevents the recombination of electron-hole pairs hence increasing the reaction rate. The dye degrades to a colourless solution after irradiation.

\section{Acknowledgements}

Dr. P. Borker is greatly acknowledged for her contribution in this investigation.

\section{Author details}

\author{
A.V. Salker \\ Department of Chemistry, Goa University, Goa, India
}




\section{References}

[1] Muruganandham M, Swaminathan M. Solar photocatalytic degradation of a reactive azo dye in $\mathrm{TiO}_{2}$ suspension. Solar Energy Material Solar Cells 2004; 81: 439 - 457.

[2] Borker P, Salker A V. Solar assisted photocatalytic degradation of Napthol Blue Black dye using $\mathrm{Ce}_{1-\mathrm{x}} \mathrm{Mn}_{\mathrm{x}} \mathrm{O}_{2}$. Material Chemistry and Physics 2007; 103: 366 - 370.

[3] Borker P, Salker A V. Photocatalytic degradation of textile azo dye over $\mathrm{Ce}_{1-\mathrm{x}} \mathrm{Sn}_{\mathrm{x}} \mathrm{O}_{2}$ series. Material Science \& Engg. B 2006; 133: 55 - 60.

[4] Zhang M, An T, Hu X, Wang C, Shang G, Fu J. Preparation and photocatalytic properties of a nanometer $\mathrm{ZnO}-\mathrm{SnO}_{2}$ coupled oxide. Applied Catalysis A 2004; 260: 215 222.

[5] Antonio J A T, Gutierrez-Baez R, Sebastian P J, Vazquez A. Thermal stability and structural deformation of rutile $\mathrm{SnO}_{2}$ nanoparticles. Journal of Solid State Chemistry 2003; 174: 241 - 248.

[6] Pandurangan A, Kamala P, Uma S, Palanichamy M, Murugesan V. Degradation of basic yellow auramine $\mathrm{O}-\mathrm{A}$ textile dye by semiconductor photocatalysis. Indian Journal of Chemical Technoly 2001; 8: 496 - 499.

[7] Mihaiu S, Postole G, Carata M, Caldarau M, Crisan D, Dragan N, Zaharescu M. The structure properties correlation in the Ce doped $\mathrm{SnO}_{2}$ materials obtained by different synthesis route. Journal of European Ceramic Society 2004; 24: 963 - 967.

[8] Morais E A, Scalvi L U A, Geraldo V, Scalvi R M F, Ribeiro S J L, Santilli C V, Pulcinelli S H. Electro-optical properties of Er doped $\mathrm{SnO}_{2}$ thin films. Journal of European Ceramic Society 2004; 24: 1857 - 1860.

[9] Kartal O E, Erol M, Oguze H. Photocatalytic destruction of phenol by $\mathrm{TiO}_{2}$ powders. Chemical Engineering Technology 2001; 24: 645 - 649.

[10] Hasnat M A, Siddiquey I A, Saiful I S M. Photodegradation of malachite green in the aqueous media. Indian Journal of Chemitry 2003; 42(8): 1865 - 1867.

[11] Piscopo A, Robert D, Weber J V. Influence of $\mathrm{pH}$ and chloride anion on the photocatalytic degradation of organic compounds Part I Effect on the benzamide and parahydroxybenzoic acid in $\mathrm{TiO}_{2}$ aqueous solution. Applied Catalysis B 2001; 35: 117 124. 
Chapter 5

\title{
Applications of Mesoporous Ordered Semiconductor Materials - Case Study of $\mathrm{TiO}_{2}$
}

\author{
Antonio E. H. Machado, Karen A. Borges, Tatiana A. Silva, \\ Lidiaine M. Santos, Mariana F. Borges, Werick A. Machado, \\ Bruno P. Caixeta, Marcela Dias França, Samuel M. Oliveira, \\ Alam G. Trovó and Antonio O.T. Patrocínio
}

Additional information is available at the end of the chapter

http://dx.doi.org/10.5772/59602

\section{Introduction}

\subsection{Titanium dioxide $\left(\mathrm{TiO}_{2}\right)$}

$\mathrm{TiO}_{2}$ is a promising material for technological applications for its versatility [1-4], abundance, low toxicity, good chemical stability, photosensitivity and photostability [5-8]. In nature, it is found mainly in the mineral ilmenite [9], that can be processed industrially by two different routes [10]: The first, involves the reaction of the concentrate of ilmenite with hot sulphuric acid, resulting in the formation of sulphates of titanium, $\mathrm{Fe}(\mathrm{II})$ and $\mathrm{Fe}(\mathrm{III})$, being these last eliminated by centrifugation, after cooling. The final solution is then purified and hydrolyzed to produce pure $\mathrm{TiO}_{2}$ [11]. The other usual way of obtaining consists in combining the ore with coke and gaseous chlorine under heating, resulting in $\mathrm{CO}_{2}$ and a spongy material rich in $\mathrm{TiCl}_{4}$. The reaction product is subjected to successive fractional distillation, with the formation of $\mathrm{TiCl}_{2}$ and $\mathrm{TiCl}_{3}$, due to stability of titanium in other degrees of oxidation. The different precursors of titanium are hydrolyzed, forming titanium dioxide [12].

In 1972, [13], obtained, for the first time, success in decomposition of water under irradiation with light and without application of any electric potential. They reported that, in trials where they employed n-type $\mathrm{TiO}_{2}$ as anode and Platinum as cathode, when $\mathrm{TiO}_{2}$ electrode illuminated under short-circuit conditions, hydrogen evolved from the Platinum electrode, while oxygen evolved from the anode. Since then, studies aimed at discovering and exploring different possibilities of technological application for $\mathrm{TiO}_{2}$ have been given great importance [14-22]. 
As technological applications for $\mathrm{TiO}_{2}$ can be cited its use in ultraviolet radiation absorbing filters [3, 23], in chemical sensors for gases [24-26], as a bactericide [27], in biomaterials for bone implants [28], in environmental photocatalysis [8, 24, 29, 30], in the photocatalytic hydrogen evolution [17, 31-36], in dye-sensitized solar cells [21, 37-44], among other.

The photocatalytic efficiency of $\mathrm{TiO}_{2}$ depends on its structural and morphological characteristics, which are related to the method of synthesis used in the preparation of nanoparticles [18, $21,29,45]$. To be photoactive, favoring the photocatalysis process, besides being mainly consisting of anatase crystalline phase, the $\mathrm{TiO}_{2}$ must possess high specific surface area, good porosity, with high sized pores $[35,45,46]$. In this context, the search for $\mathrm{TiO}_{2}$ particles that have differentiated features, with catalytic properties potentiated, constitutes a field of intense activity [19, 20, 47-50].

\section{Porosity and porous materials}

The porosity, related to the presence of cavities, channels or interstices is of great importance since it is related to the ability of materials to interact with atoms, ions, molecules, and nanoparticles not only at their surfaces but also throughout the bulk [51,52]. Thus, the control of porosity is very important if the objective is the development of new materials [53, 54].

The pores are classified as closed or open, considering the ability of porous materials to interact with their neighborhoods. Figure 1 shows various types of closed (a) or opened (b, c, f) pores.

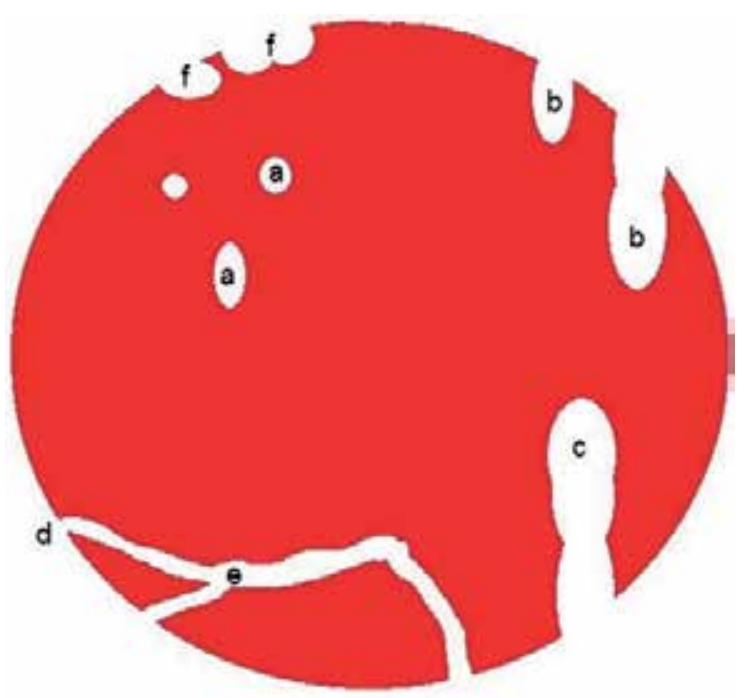

Figure 1. Schematic representation of a porous solid, presenting the most common types of pores: (a) closed; (b, c, d) opened; (e) interconnected; (f) surface roughness. Font: [55].

Open pores have continuous channels that communicate to the outer surface of the material, generating a cross-linked structure. Closed pores are inactive for the flow of liquids, gases and 
other substrates, being totally isolated from their neighborhood. These pores are related to macroscopic properties such as mechanical resistance and thermal conductivity [55]. The pores can also be interconnected, (e). Otherwise used to classify the pores takes into account its format: bottleneck, (b), cylindrical, (c), and funnel type, (d). The surface roughness, represented by (f), is also a type of porosity [55].
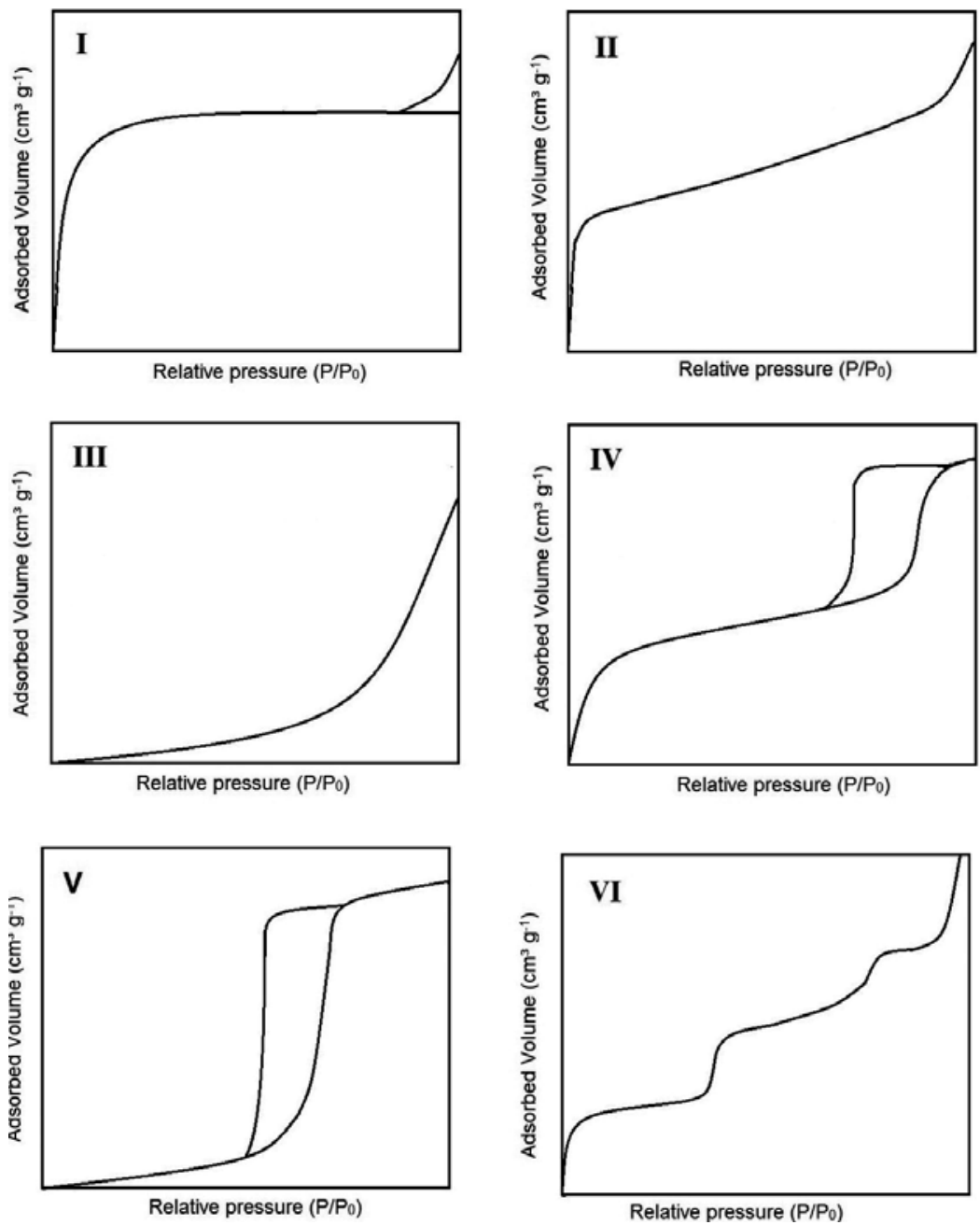

Figure 2. Representation of the six main types of isotherm: I, microporous solids; II, non-porous solids; III, macroporous solids; IV and V, mesoporous solids; VI, non-porous solids with uniform surface.

IUPAC recommends a quantitative division of the pores in three classes according to their mean diameter: micropores, lower than $2 \mathrm{~nm}$; mesopores, between 2 and $50 \mathrm{~nm}$; macropores, higher than $50 \mathrm{~nm}$ [56]. This pore size classification is based on measurements of adsorptiondesorption of $\mathrm{N}_{2}$ in boiling temperature and in the statistical width of layers of $\mathrm{N}_{2}$ adsorbed. 
The analysis of these data is usually done by using the Brunauer/Emmett/Teller method (BET), proposed by Stephen Brunauer, Paul Hugh Emmett e Edward Teller [57-59]. Applying BET, it is possible to describe the form of the adsorption and desorption isotherms for a specific solid. Knowing the format of the isotherm it is possible to define its porosity [60], Figure 2.

Microporous solids usually present a type I isotherm, whereas the isotherms II and III are related to non-porous solids finely divided or macroporous solids. Already the isotherms type IV and V present a hysteresis loop, a characteristic of mesoporous materials. The type IV hysteresis represents materials with uniform porosity, while type $\mathrm{V}$ hysteresis is referred to pores with non-defined forms and sizes. Finally, the type VI hysteresis is related to non-porous solids with almost uniform surface [60,61].

\section{Mesoporous nanostructured $\mathrm{TiO}_{2}$}

Organized mesoporous nanostructured titanium dioxide $\left(\mathrm{TiO}_{2}\right)$ is one of the most promising semiconductor materials, considering its current technological applications [19-21, 44, 60, 62-70]. The presence of pores in nanostructured materials tends to enhance their physical and chemical properties. Compared with bulk $\mathrm{TiO}_{2}$, the uniform channels in mesoporous $\mathrm{TiO}_{2}$ do not only increase the density of active sites with high accessibility but also facilitate the diffusion of reactants and products; the high surface area and large pore volume provides enhanced capability for dye loading and pollutant adsorption [60]. It is also possible to produce mesoporous $\mathrm{TiO}_{2}$ using template-free methods. However, these materials usually present disordered mesostructures as a result of the irregular packing of building blocks [60].

\section{Surfactants as drive agents in obtaining mesoporous ordered materials}

Certain surfactants are capable to act as drive agents, as structural templates, in the synthesis of a semiconductor oxide, promoting its organization. This process occurs due to the spontaneous organization of the critical nuclei of the oxide formed around the structures defined by the surfactant, which control the growth of the microstructures initially formed, resulting in ordered mesoporous materials. The structural control and manipulation of the physical characteristics of a mesoporous material depends on the nature and concentration of the surfactant employed in the synthesis process [21, 71].

For a well-succeeded action of the directing agent in the synthesis, the model and the inorganic species need to interact [71]:

1. $\mathrm{S}^{+} \mathrm{I}^{-}$: cationic surfactants are used as structural drivers for inorganic species negatively charged;

2. $\mathrm{S}^{-} \mathrm{I}^{+}$: anionic surfactants are used as structural drivers for positively charged inorganic species; 
3. $\mathrm{S}^{+} \mathrm{X}^{-} \mathrm{I}^{+}$: the surfactant and inorganic species are positively charged in the presence of species of opposite charge acting as counter ion;

4. $S^{-} X^{+} I^{-}$: the surfactant and inorganic species are negatively charged in the presence of a species of opposite charge, which acts as a counter ion;

5. $\quad S^{0} I^{0}$ : the surfactant has no load and the medium favors the neutrality of the inorganic species. In this case, the interaction between the species occurs through hydrogen bonds or dipole.

The concentration of surfactant in the reaction medium must be higher than the critical micelle concentration (CMC), which favors the auto mounting of micelles, originating bi and threedimensional arrays responsible for empty spaces that will produce thenanoporous material [71].

\section{Synthesis of mesoporous $\mathrm{TiO}_{2}$}

Among the methodologies of synthesis, the methods of sol-gel and homogeneous precipitation best favor the control of morphology $[58,72,73]$. The term sol-gel involves several synthetic methodologies based on hydrolytic processes [19, 20, 59, 74]. Hydrolysis and condensation reactions involving the precursor allows the formation of colloidal particles (sol) and subsequent formation of three-dimensional networks (gel). This process ensures a good homogeneity for the reaction product, leading, in general, to metastable phases, amorphous or not [50]. In the case of amorphous materials, a step of crystallization for oxides formed is required.

The use of solvothermal conditions is an alternative for conversion of the amorphous material to crystalline without the use of high temperatures [60, 73]. The solvothermal method consists in the dissolution of a metallic precursor in anhydrous benzyl alcohol and heating at temperatures above $423 \mathrm{~K}$. Under these conditions, the alcoholic hydroxyl group connects partially to the metal ion starting a polycondensation reaction. The steric hindrance, due to the greater volume of the organic group, tends to control the formation of nanoparticles which tend to stabilize in smaller sizes and narrower size dispersions than the obtained in the sol-gel process [75].

The hydrothermal method is a particularity of the solvothermal method in which the solvent is water. Under hydrothermal conditions the solubility of the amorphous particles increases significantly and the crystallization can occur concurrently with processes of re-dissolution and re-precipitation in the crystalline core $[50,76,77]$. This method has been widely used, since small variations in the main synthesis parameters $(\mathrm{pH}$, concentration of precursor, among others) can cause significant changes in morphology, size, chemical constitution, between other properties of the synthesized nanostructures.

The homogeneous precipitation method has also been studied enough due to its great versatility. In this case, chlorinated precursors of titanium or even titanium tetraisopropoxide react with a base (sodium or ammonium hydroxide) forming titanium hydroxide. This compound is converted through the loss of water in amorphous $\mathrm{TiO}_{2}$, which, under different thermal treatments, gives rise to the three known crystalline forms [78]. 
The combination between these strategies of synthesis and the use of molecular templates warrants a better control in obtaining ordered mesoporous materials. In this sense, two approaches can be highlighted: the soft template and hard template methods [60].
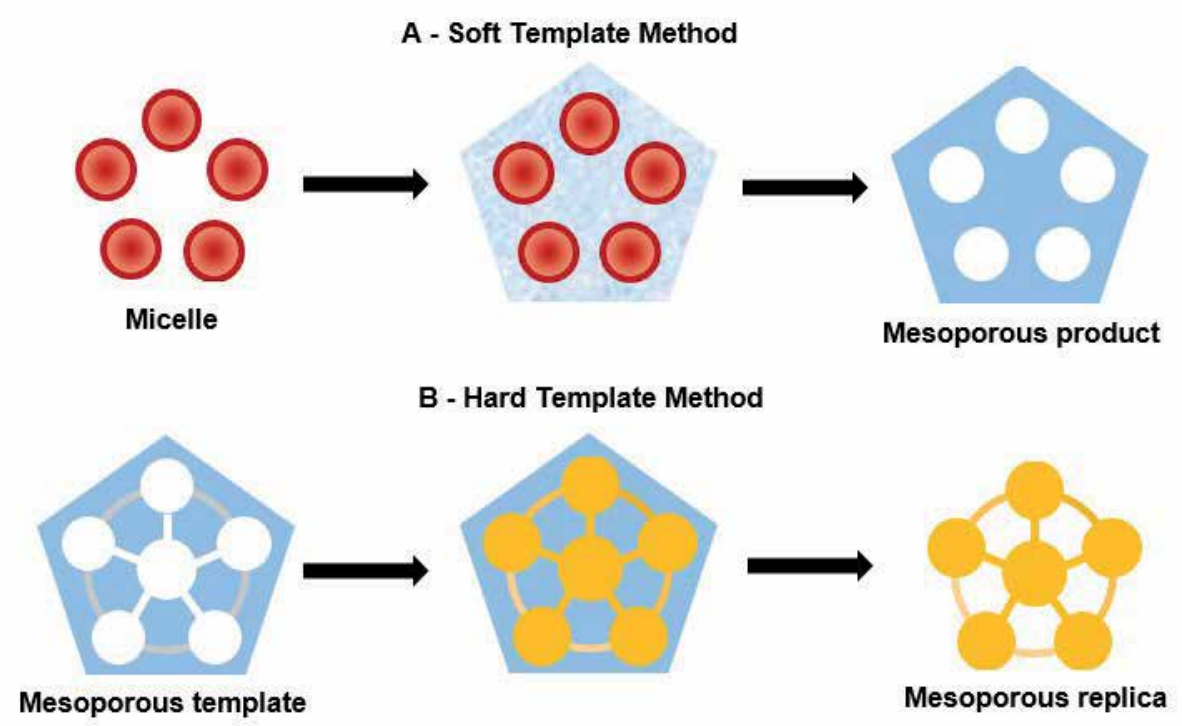

Figure 3. Representative scheme of the Soft-templating (A) and Hard-templating (B) methods, used in the synthesis of mesoporosos materials.

The soft-templating method consists in the use of a template in the liquid phase, being widely used in the sol-gel processes based on titanium precursors. Due to its high chemical reactivity these precursors tend to suffer hydrolysis, giving rise to dense precipitates very quickly. The self-structuration of surfactants can produce mesostructures at the sol particle. This occurs by the spontaneous organization of molecules around automounted micelle structures, usually in aqueous medium, giving rise to colloidal nanocrystals.

Studies have suggested that two mechanisms are related to the formation of mesoporous materials via soft-templating method [71, 79-81]. The first, known as Cooperative SelfAssembly (CSA), and the second Liquid Crystal Template (LCT). In CSA, there is a simultaneous aggregation between the inorganic precursor and the surfactant, with the formation of a liquid crystal-like phase with cubic, hexagonal or lamellar arrangement, containing both micelles and the inorganic precursor. On the other hand, in the LCT mechanism the concentration of surfactant is so high that a liquid-crystalline phase is formed without the presence of inorganic precursors. In both mechanisms, after formation of the material is necessary to remove the template for the obtaining of porosity. For this, the procedure most commonly used is the calcination [71].

Chiola, Ritsko and coworkers, reported in 1971 the obtaining of mesoporous silica [82]. However, the special characteristics of the produced materials did not were at first explained 


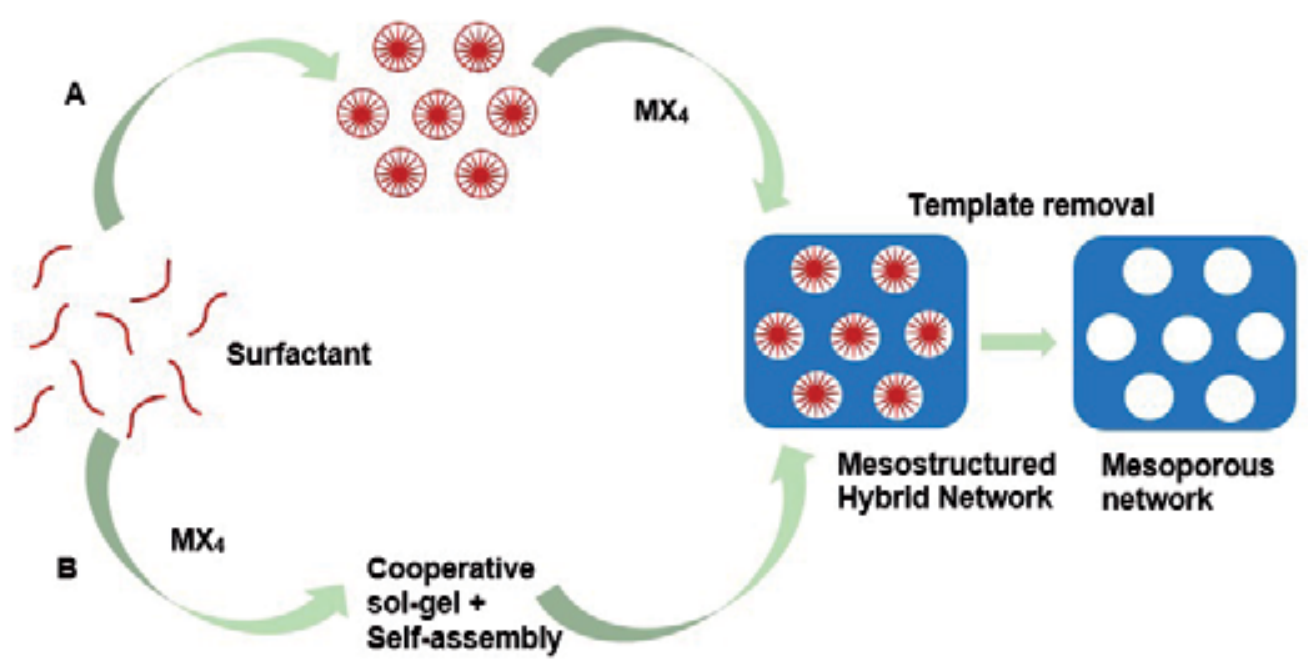

Figure 4. Formation of mesoporous structures: (A) Cooperative self-assembly process (CSA), and (B) Liquid-crystal templating process (LCT).

because the absence of adequate methods of analysis. In 1990, scientists from Mobil Oil Corporation [83], reported obtaining of mesoporous silicate molecular sieves, denoted by M41s, synthesized using a supramolecule-templating process, giving rise to a new and fascinating research field. Subsequently, efforts have been concentrated in studies related to synthesis and applications of mesoporous materials [9, 72, 84-91].

In 1995, the preparation of mesoporous $\mathrm{TiO}_{2}$ using sol-gel method associated with a surfactant as structural template were at first reported [92]. Since then, efforts have been spent on the proposition of methods of synthesis of ordered mesoporous $\mathrm{TiO}_{2}$, aiming to contribute to the improvement of the photocatalytic activity of this material, aiming its different applications [93-96].

Nanometric structures of mesoporous $\mathrm{TiO}_{2}$ were produced using the sol-gel methodology, under acidic ( $\mathrm{pH} 3$ to 4) and alkaline ( $\mathrm{pH} 7$ to 9) media, using cetyl trimethyl ammonium bromide (CTAB), sodium dodecyl benzenesulphonate (DBS) and nonylphenol ethoxylate as surfactants (NPE) [72]. The effect of the surfactant and pH on morphology, particle size, surface area, and pore size distribution was studied being the synthesized oxides evaluated considering the degradation of naphthalene. Using CTAB under acidic $\mathrm{pH}$ the nanometric material is $100 \%$ anatase, while under alkaline $\mathrm{pH}$ the material was produced in two crystalline phases, anatase $(84.7 \%)$ and brookite $(15.3 \%)$. In the presence of DBS, under acidic $\mathrm{pH}, 83 \%$ of the crystalline phase was anatase and $17 \%$ rutile, while under alkaline $\mathrm{pH}, 100 \%$ was anatase. However, using NPE a mixture $94.7 \%$ anatase and $5.3 \%$ rutile was produced under acidic $\mathrm{pH}$, while under alkaline $\mathrm{pH}$ the phases are anatase and brookite (8.28\%).The authors suggested that the good result obtained for the degradation of naphthalene ( $97 \%$ up to $4 \mathrm{~h}$ under irradiation in the visible $-\lambda>400 \mathrm{~nm}$ ) using the mesoporous material obtained in the presence 
of $\mathrm{CTAB}$ in acidic medium is due to the surface area $\left(86.7 \mathrm{~cm}^{3} \mathrm{~g}^{-1}\right)$ and to the mean pore volume $\left(0.0569 \mathrm{~cm}^{3} \mathrm{~g}^{-1}\right)$.

A variant of the Soft Templating method is the Evaporation Induced Self Assembly (EISA) [97, 98]. It was originally designed for the preparation of fine films of mesostructured silica [79], and has been successful in obtaining different mesoporous materials $\left(\mathrm{TiO}_{2}, \mathrm{ZrO}_{2}, \mathrm{Al}_{2} \mathrm{O}_{3}\right.$, $\mathrm{Nb}_{2} \mathrm{O}_{5}, \mathrm{Ta}_{2} \mathrm{O}_{5}, \mathrm{WO}_{3}, \mathrm{HfO}_{2}, \mathrm{SnO}_{2}$, etc) $[79,80]$. In this method, organic solvents such as ethanol, propanol, etc, are used as reaction medium. By virtue of the use of non-aqueous medium and block copolymer surfactants, the rate of hydrolysis well as redox reactions and phase transformation are minimized. EISA presents advantages when compared to aqueous sol-gel reaction, such as more control and homogeneity in the formation of particles, high crystallinity in reaction temperatures between 373 and $573 \mathrm{~K}$.

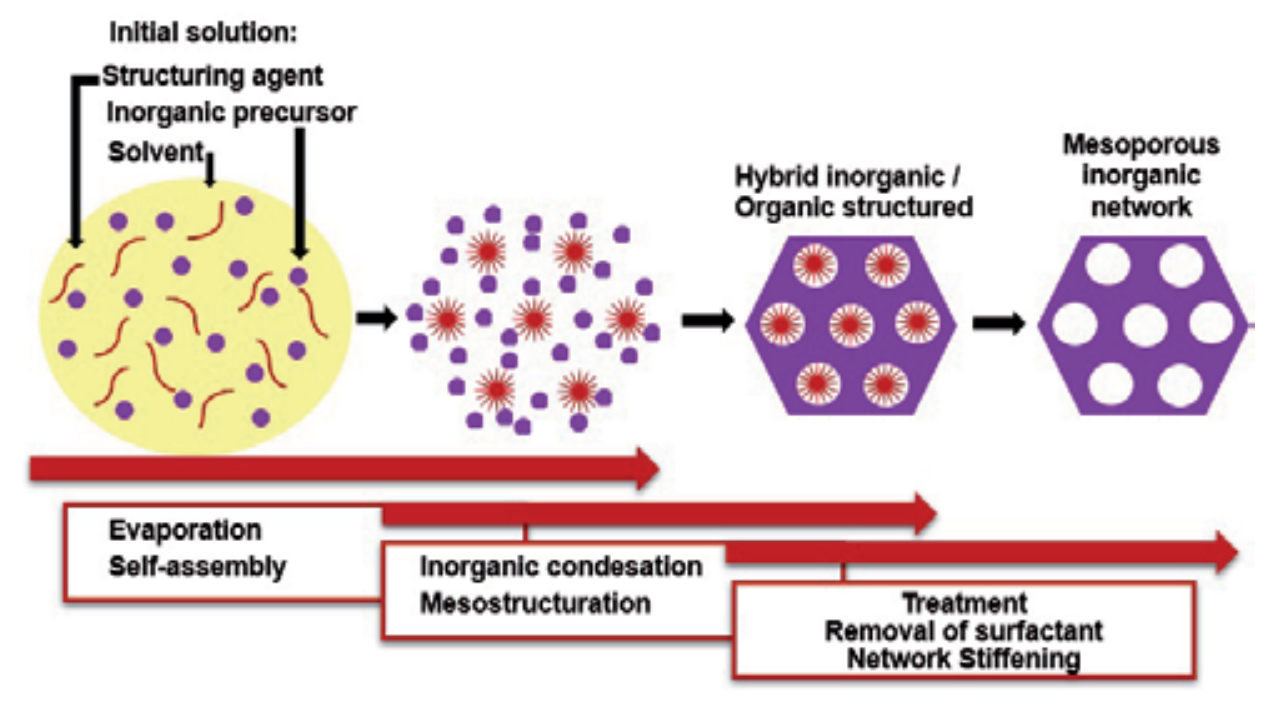

Figure 5. Scheme presenting the most representative steps of Evaporation Induced Self-Assembly (EISA).

A methodology capable of producing monodisperse spheres of $\mathrm{TiO}_{2}$ at room temperature, using titanium (IV) butoxide (TBT) mixed to ethylene glycol, used as template, was proposed in [99]. The mixture was subsequently subjected to a conventional hydrothermal treatment. Thus, it was possible to obtain nanoparticles with surface area up to $233.2 \mathrm{~m}^{2} \mathrm{~g}^{-1}$ and mean pore volume of $0.27 \mathrm{~cm}^{3} \mathrm{~g}^{-1}$. The photocatalytic activity of the synthesized material was evaluated by degradation of methylene blue, Red MX-5B and phenolphthalein under UV irradiation, when were obtained kinetic constants of degradation of $6.7,13.2$, and $14.7 \mathrm{w} \%$ $\mathrm{min}^{-1}$, respectively, attributed to the greater surface area of the catalyst. The synthesis of 
$\mathrm{TiO}_{2}$ spheres based on EISA, using titanium (IV) tetra isopropoxide and Triton X-100 has been also reported, aiming their application in DSSCs [100]. The particle size could be controlled changing the $\mathrm{Ti} / \mathrm{H}_{2} \mathrm{O}$ molar ratio and adjusted between 500 and $1100 \mathrm{~nm}$, with a surface area of $56-151 \mathrm{~cm}^{2} \mathrm{~g}^{-1}$.

Using the EISA strategy excellent catalysts based on $\mathrm{CeO}_{2}$, capable to oxidize harmful gases, as $\mathrm{CO}, \mathrm{NO}_{x}$ and hydrocarbons, in non-toxic gases, were synthesized [81]. The tribloc copolymer P123 and polyvinyl pyrrolidone (PVP) were used as templates. In this way, were obtained catalysts with different pore sizes (about $40 \mu \mathrm{m}, 2 \mu \mathrm{m}$ and $<0.3 \mu \mathrm{m}$ ) and specific surface area of $32.5 \mathrm{~m}^{2} \mathrm{~g}^{-1}$.

Damages to the mesoporous structure can occur due to the presence of residual templates, as for example the blocking of pores or even poisoning of catalytic sites on the surface of the mesoporous material. Calcination has been pointed as a way to promote the elimination of some surfactants [101]. Non-ionic surfactants, as Triton X-100, can be easily removed by washing of the oxide formed [102].

In the hard-templating method the solid is formed around a template, usually zeolites and meso and macroporous silica, via interactions between the template and the precursor [60]. This methodology is more complex when compared to the soft-templating method. However, it is highly effective in obtaining mesoporous structures [103]. By applying this methodology nanostructures are formed on surface of the templates [104].

The obtaining of uniform nanospheres of $\mathrm{TiO}_{2}$ based on hard-templating methodology, using silica as template and $\left(\mathrm{NH}_{4}\right)_{2} \mathrm{TiF}_{6}$ as precursor, has been proposed [105]. This material presented surface area of $54.2 \mathrm{~m}^{2} \mathrm{~g}^{-1}$ and pore volume of $0.15 \mathrm{~cm}^{3} \mathrm{~g}^{-1}$. The photocatalytic activity of this material was evaluated regarding the degradation of the dyes methylene blue, rhodamine B and methyl-orange. The levels of degradation were respectively $95 \%, 95 \%$ and $90 \%$. This result was attributed to the high surface area and charge separation in these monodisperse materials.

In reference [106] the obtaining of mesoporous $\mathrm{TiO}_{2}$ is proposed using the combination of hard-and soft-tamplating methods. Using mesoporous silica in the first step (hard-templating) and Pluronic P123 as driver agent in the soft-templating stage, to control of morphology of the particles, was possible the production of three-dimensionally ordered mesopores with surface area of $145 \mathrm{~m}^{2} \mathrm{~g}^{-1}$ and pore volume of $0.246 \mathrm{~cm}^{3} \mathrm{~g}^{-1}$. Due to the porous of the material obtained and the three-dimensional periodicity of the spheres, the authors highlight the possible applications that these materials can have, as in environmental photocatalysis, solar cells and in lithium rechargeable batteries. Finally, the authors highlight the ease with which this methodology can be extended for the synthesis of other mesoporous metal oxides.

Figure 6 presents the main differences between the hard and soft template methods, while Table 1 presents the structure of the main surfactants suggested as driver agents for the synthesis of mesoporous materials. 


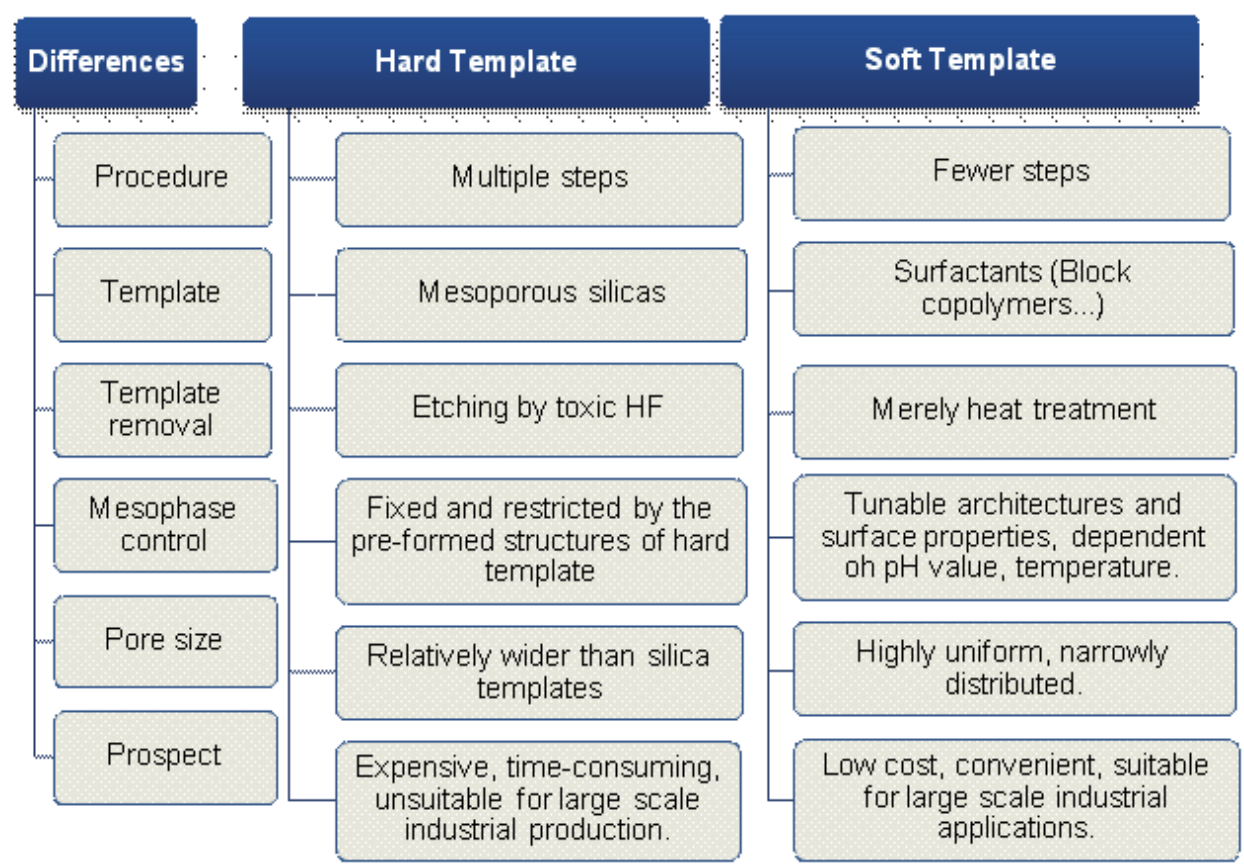

Figure 6. Comparison between hard and soft templating [107].

$\begin{array}{llll}\text { Surfactant } & \text { References } \\ \text { Priton X-100 } & \text { [108, 109] } \\ \text { Ethyl cellulose } & \text { [109-112] }\end{array}$




\begin{tabular}{|c|c|c|}
\hline Surfactant & Structure & References \\
\hline 1-hexadecyl & $\mathrm{H}_{2} \mathrm{~N}^{\dagger}$ & [115] \\
\hline Acetylacetone & & [115] \\
\hline Isopropanol & & [115] \\
\hline Sodium dodecyl sulfate & & [116] \\
\hline $\begin{array}{l}\text { Cetyltrimethyl } \\
\text { ammonium bromide }\end{array}$ & & {$[5,110,117,118]$} \\
\hline $\begin{array}{l}\text { Cetyltrimethyl } \\
\text { ammonium chloride }\end{array}$ & & {$[5]$} \\
\hline $\begin{array}{l}\text { Hexamethylene } \\
\text { tetramine }\end{array}$ & & [118] \\
\hline Benzalkonium chloride & $10,12,1$ & [5] \\
\hline $\begin{array}{l}\text { Polyvinyl } \\
\text { pyrrolidone }\end{array}$ & & [118] \\
\hline Pluronic P123 & & [62] \\
\hline
\end{tabular}

Table 1. Main surfactants suggested as driver agents for the synthesis of mesoporous materials and their chemical structures. 


\section{Technological applications of mesoporous $\mathrm{TiO}_{2}$}

\subsection{Environmental photocatalysis}

One of the potential applications of heterogeneous photocatalysis is the environmental remediation [8, 20,74, 119-122]. Different semiconductor oxides have shown to be capable of triggering photocatalytic, highlighting the $\mathrm{TiO}_{2}[19,20,123]$. In this context, nanostructured materials tend to favor the photocatalytic applications of these materials [60].

Kim and Kwak reported studies where the photocatalytic activity of a mesoporous $\mathrm{TiO}_{2}$ prepared using di-block copolymers via sol-gel synthesis was evaluated, using methylene blue as oxidizable substrate [50]. The materials with small crystallite size (about $5.1 \mathrm{~nm}$ ), high surface area (about $210 \mathrm{~m}^{2} \mathrm{~g}^{-1}$ ) and small pore size distribution were the ones who exhibited the best photocatalytic activities, using ultraviolet radiation, with apparent constants of degradation around $0.093 \mathrm{~min}^{-1}$. The particles synthesized presented spherical morphology with surface areas dependent on the type of di-block copolymer used.

In [58] is related a sol-gel synthesis of a $\mathrm{TiO}_{2}$ with intermediate porosity, under hydrothermal conditions using a water-soluble cationic surfactant, obtaining a mesoporous $\mathrm{TiO}_{2}$ with maximum pore size of $6.9 \mathrm{~nm}$ and maximum surface area of $284 \mathrm{~m}^{2} \mathrm{~g}^{-1}$. The synthesized material had its photocatalytic activity evaluated on degradation of methylene blue. The synthesized product showed to be superior (95\%) to $\mathrm{TiO}_{2}$ P25 (24\%), using irradiation with UV radiation under the same reaction conditions. The greater photocatalytic efficiency was attributed to the higher surface area, when compared to this parameter measured to $\mathrm{TiO}_{2} \mathrm{P} 25$ $\left(50 \mathrm{~m}^{2} \mathrm{~g}^{-1}\right)$, and the ordination of the synthesized material, attributed to the use of the surfactant.

The synthesis of $\mathrm{a} \mathrm{TiO}_{2}$ supported on SBA-15 mesoporous silica, reported in [124], resulted in materials efficient to degrade photocatalytic phenols. SBA-15 silica presents hexagonal arrangement and bi-dimensional pores with diameter up to $30 \mathrm{~nm}$. The materials obtained have surface area of $361.4 \mathrm{~m}^{2} \mathrm{~g}^{-1}$ and pore volume of $1.217 \mathrm{~cm}^{3} \mathrm{~g}^{-1}$.

\subsection{Hydrogen production}

Hydrogen production via heterogeneous photocatalysis based in the electronic excitation of a semiconductor material using UV-Visible radiation is promising for the production of clean and sustainable energy $[19,54,125]$. Generally speaking, this process is based on the electronic excitation of the photocatalyst. From there, the photo-generated hole at the valence band reacts readily with a sacrificial reagent, while in conduction band electrons are trapped by a cocatalyst, being used in the reduction of $\mathrm{H}^{+}$ions, with the production of hydrogen [126].

Mesoporous $\mathrm{TiO}_{2}$ of intermediate porosity have generally high surface area and high density of active sites, which tends to facilitate the diffusion of reagents, favoring the conversion of solar energy in photocatalytic reactions [41, 93, 127].

A porous composite based on $\mathrm{TiO}_{2}$ incorporated to silica MCM-48 (Mobil Crystalline Materials $\mathrm{n}^{\circ} 48$ ) was proposed as photocatalyst for hydrogen production [128]. The authors reported that the tetrahedrically coordinated $\mathrm{TiO}_{2}$ act as active sites on photocatalysis of water reducing 
the potential, facilitating the formation of gaseous hydrogen, even in the absence of a cocatalyst.

Microspheres of $\mathrm{TiO}_{2}$ doped with carbonates has also been proposed for hydrogen production under visible $(\lambda>400 \mathrm{~nm})$ irradiation [129]. A rate of $\mathrm{H}_{2}$ production of $0.2 \mathrm{mmol} \mathrm{h}^{-1} \mathrm{~g}^{-1}$ was achieved using the photocatalyst charged with $1 \mathrm{wt} \% \mathrm{Pt}$. The photocatalytic performance was attributed to the characteristics of the mesoporous structure such as the diameter of the microspheres, between 0.5 and $4 \mu \mathrm{m}$, pore size in the range between 3 and $11 \mathrm{~nm}$ and high surface area $\left(500 \mathrm{~m}^{2} \mathrm{~g}^{-1}\right)$.

A mesoporous $\mathrm{TiO}_{2}-\mathrm{SiO}_{2}$ mixed oxide with molar ratio of $97: 3$, calcined at $773 \mathrm{~K}$ was also proposed for hydrogen production [66]. It produced hydrogen at a rate of $0.27 \mathrm{~cm}^{3} \mathrm{~h}^{-1} \mathrm{~g}^{-1}$, an expressive value when compared to the rate achieved using $\mathrm{TiO}_{2} \mathrm{P} 25\left(0.17 \mathrm{~cm}^{3} \mathrm{~h}^{-1} \mathrm{~g}^{-1}\right)$. This mixed oxide has characteristics that favored its photocatalytic activity, such as a surface area of $162 \mathrm{~m}^{2} \mathrm{~g}^{-1}$, pore diameter of $4.3 \mathrm{~nm}$ and pore volume of $0.24 \mathrm{~cm}^{3} \mathrm{~g}^{-1}$.

\subsection{Electrodes in Lithium ion batteries}

Mesoporosos materials have been used in the production of electrodes for Lithium ion batteries. Physical properties such as particle size, porosity and pore size determine the performance of this class of batteries [127]. The mesoporous structure favors the transport of electrolyte, facilitating the contact between the surface of the electrode and the electrolyte and shortening the path of diffusion of the $\mathrm{Li}^{+}$ions.

These batteries have a long life cycle, rapid loading and unloading capacity, being capable to store high energy densities in a compact and lightweight container. Because of this, it has been used as power sources for portable electronic devices [127, 130, 131].

Mesoporous $\mathrm{TiO}_{2}$ is a promising material in this kind of battery by offering numerous advantages, such as high potential of ions insertion, low cost, low toxicity, easy synthesis and stability to $\mathrm{pH}$ variation [60]. Anatase is generally regarded as the most suitable polymorph of $\mathrm{TiO}_{2}$ for $\mathrm{Li}^{+}$insertion, superior to rutile and with more stable structure than brookite. However, anatase with large particle sizes present poor performance due to its low capabilities to promote ionic diffusion and electronic conductivity [132, 133]. Thus, the control of particle size and porosity during its synthesis is imperative for obtaining materials with desirable characteristics.

The particle size influence on the dynamic process of storage of $\mathrm{Li}^{+}$ions, ensuring a significant increase on battery performance when the particle size is reduced. For example, the discharge capacity of $\mathrm{TiO}_{2}$ rutile with particles of $300 \mathrm{~nm}$ is $110 \mathrm{mAh} \mathrm{g}^{-1}$, while this same parameter for particle sizes of 30 and $15 \mathrm{~nm}$ is, respectively, 338 and $378 \mathrm{mAh} \mathrm{g}^{-1}$ [134].

Studies involving the application of mesoporous microspheres of anatase with regular porosity showed that pore structure significantly influences on specific capacity, speed capability and performance cycle of the batteries [60]. The materials with higher surface area had the best performance. It was also observed that when the pore size was very small, the transport of $\mathrm{Li}$ ${ }^{+}$in the electrolyte was heavily restricted. 


\subsection{Solar cells}

Solar cells have a great advantage when compared to conventional power generation systems, since in these solar energy can be directly converted into electric. The traditional solar cells are basically constituted by two layers of semiconductor materials, an n-p type pair. When photons with appropriate energy reach the semiconductor pair, electrons are excited producing electricity [135].

The first solar cells were based on crystalline silicon. Actually, studies are being conducted with the goal of developing efficient photovoltaic cells and low cost, since the crystalline silicon-based cells are of very high cost.

The solar cells can be classified as:

a. First generation solar cells, where are the silicon solar cells used commercially, which today correspond to about $86 \%$ of the solar cells market [136];

b. Second generation solar cells. More profitable than the first generation solar cells, but still less efficient;

c. Third generation solar cells, where are the dye-sensitized organic cells;

d. Hybrid solar cells [137].

In the organic solar cells are used semiconductor organic polymers or small and medium organic molecules, such as phthalocyanines, fullerenes, poly-(p-phenylenevinylene) (PPV). These cells can be produced on flexible substrates, and are promising in terms of production costs. On the other hand, they still have low efficiency, as well as some limitations, such as the possibility of degradation of the organic component.

In 2009, Park and co-workers developed an organic solar cell based on a polymer-fullerene composite, with a reasonable energetic efficiency (6.5\%) [138].

Dye-sensitized solar cells, DSCs, Figure 7, are devices constituted by a semiconductor material, a sensitizer (dye), a conductive glass, an electrolyte and a platinum counter-electrode. Unlike conventional systems, where semiconductor assumes both the task of absorbing light as the charge carriage, in DSCs such functions are separated: the light is absorbed by a dye anchored to the surface of a semiconductor, and the charge separation occurs at the semiconductorelectrolyte interface [139].

A great leap in this area was given by [140] by using mesoporous nanocristalline $\mathrm{TiO}_{2}$ films in place of single crystals of oxide semiconductor as substrates for the adsorption of the sensitizer dye. The use of mesoporous films resulted in a significant increase in the conversion efficiency of incident light in current, $\mathrm{I}_{\mathrm{PCE}}$, which went from 0.13 to $88 \%$ [141]. The principal reason for this was the increase in the amount of dye adsorbed due to the greater surface area in general available in the mesoporous films. Using mesoporous films, the overall efficiency of conversion of solar cells sensitized by dye reached $7 \%$ in the decade of 90 [140]. Actually, the best cells exceed the $13 \%[142,143]$, confirming the feasibility of commercial applications of these devices. 


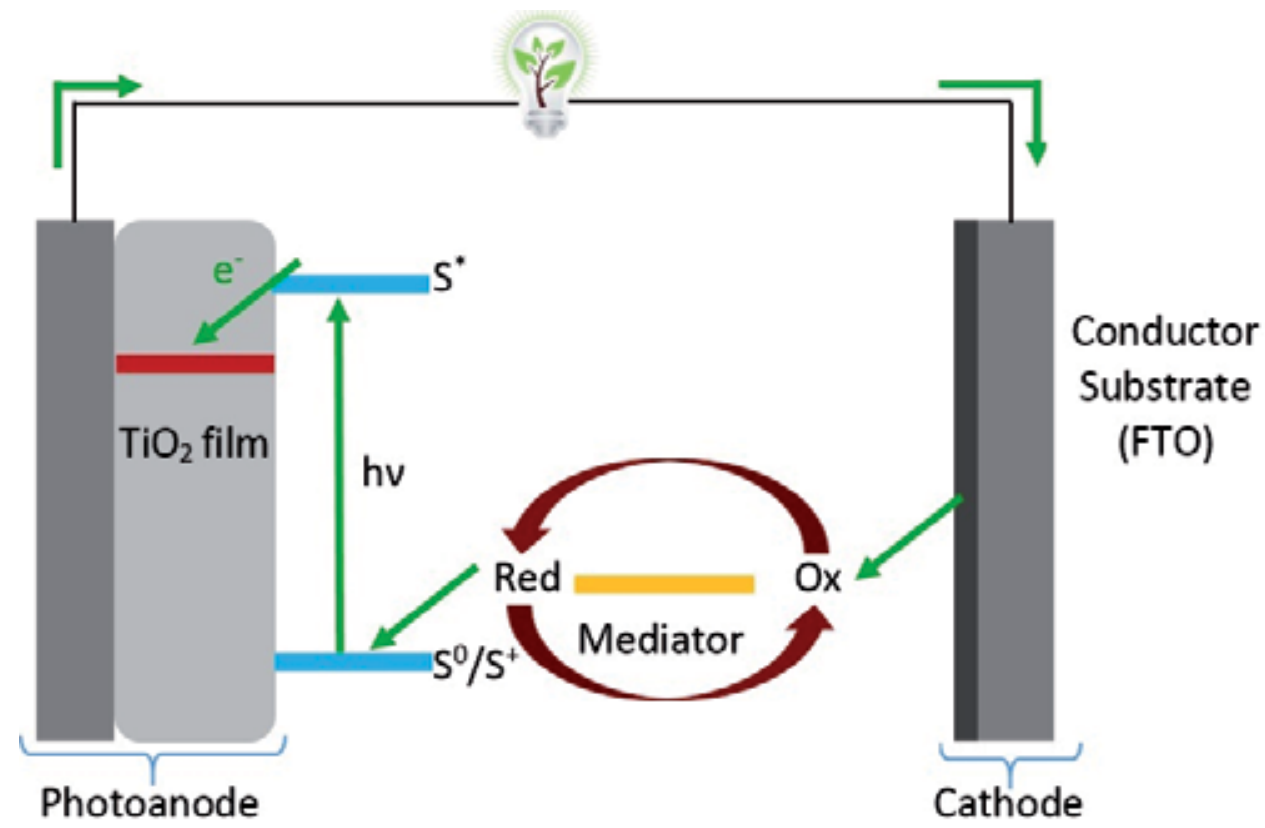

Figure 7. Simplified diagram showing the functioning of DSCs.

The $\mathrm{I}^{-} / \mathrm{I}_{3}$ redox pair dissolved in nitriles is thermodynamically capable to reduce the photo oxidized dye on the surface of $\mathrm{TiO}_{2}$. The difference between the energy of the semiconductor conduction band and the redox potential of the electrolyte determines the maximum opencircuit potential than a DSC can achieve. Additionally, the kinetics of reduction is one or two orders of magnitude faster than the process of recombination between the electron in the conduction band of the oxide and the photo oxidized dye [144]. This difference makes the charge separation process in the $\mathrm{TiO}_{2}$-sensitizer-electrolyte interface to be very efficient. The disadvantages of using liquid electrolytes based on $\mathrm{I}^{-} / \mathrm{I}_{3}$ redox pair include the toxicity of species of iodine and the inner filter effect caused by the strong absorption of light in the visible region by $\mathrm{I}_{3}{ }^{-}$, which makes DSCs efficiency dependent on the exposed face.

The system $\mathrm{TiO}_{2} / \mathrm{Ru}(\mathrm{II})$ complex/(I- $\left./ \mathrm{I}_{3}^{-}\right)$is relatively simple and efficient, allowing a considerable advance in the understanding of the charge separation process from absorption of sunlight in sensitized semiconductors. However, this system presents challenges to be overcome, to its large-scale implementation. There stands out the high cost of the $\mathrm{Ru}(\mathrm{II})$ complexes, the high toxicity of the electrolyte and the and the need for an efficient sealing of the device in order to prevent the leakage of the electrolyte and the consequent loss of activity. Even so, modules up to $6000 \mathrm{~cm}^{2}$ have been produced [145].

Alternatively, several other materials have been proposed to build DSCs. Organic compounds, such as indole and anthocyanins derivatives also have been proposed as sensitizers [146-150]. Recently, [151] described DSCs possessing efficiencies higher than $12 \%$ using a $\mathrm{Zn}$ (II) porphyrine as sensitizer and $\mathrm{Co}(\mathrm{II}) /(\mathrm{III})$ complexes as redox pair. Another approach that has 
attracted much attention involves the use of solid systems that, at first, dispense step of sealing and increase solar cell stability in real conditions of operation [152-155].

A major breakthrough in the development of solid DSCs has been achieved with the use of perovskites, as the $\mathrm{CH}_{3} \mathrm{NH}_{3} \mathrm{PbI}_{3}$, as sensitizers [156-158]. These compounds are chemically very stable and can be produced in situ from precursors solutions and have a wide range of absorption, from visible to near infrared. When adsorbed on surface of $\mathrm{TiO}_{2}$ films, $\mathrm{CH}_{3} \mathrm{NH}_{3} \mathrm{PbI}_{3}$ is capable of injecting electrons efficiently and be regenerated by hole transporter materials (HTM) as spiro-MeOTAD (2,2',7,7'-tetraquis [N,N-di(4-metoxyphenyl)amino]-9,9'-spirobifluorene). DSCs with efficiencies higher than $14 \%$ have been described using this approach [156]. It is interesting that the use of this same material in DSCs with $\mathrm{Ru}(\mathrm{II})$ complexes results in conversion efficiencies between 2 and 3\% [159, 160]. This makes clear that it is not enough to simply replace one or another component in the DSCs to achieve greater efficiencies. It is necessary a good understanding of the characteristics of each part of the interfaces of the device and of the different processes of electron transfer that occur between the components.

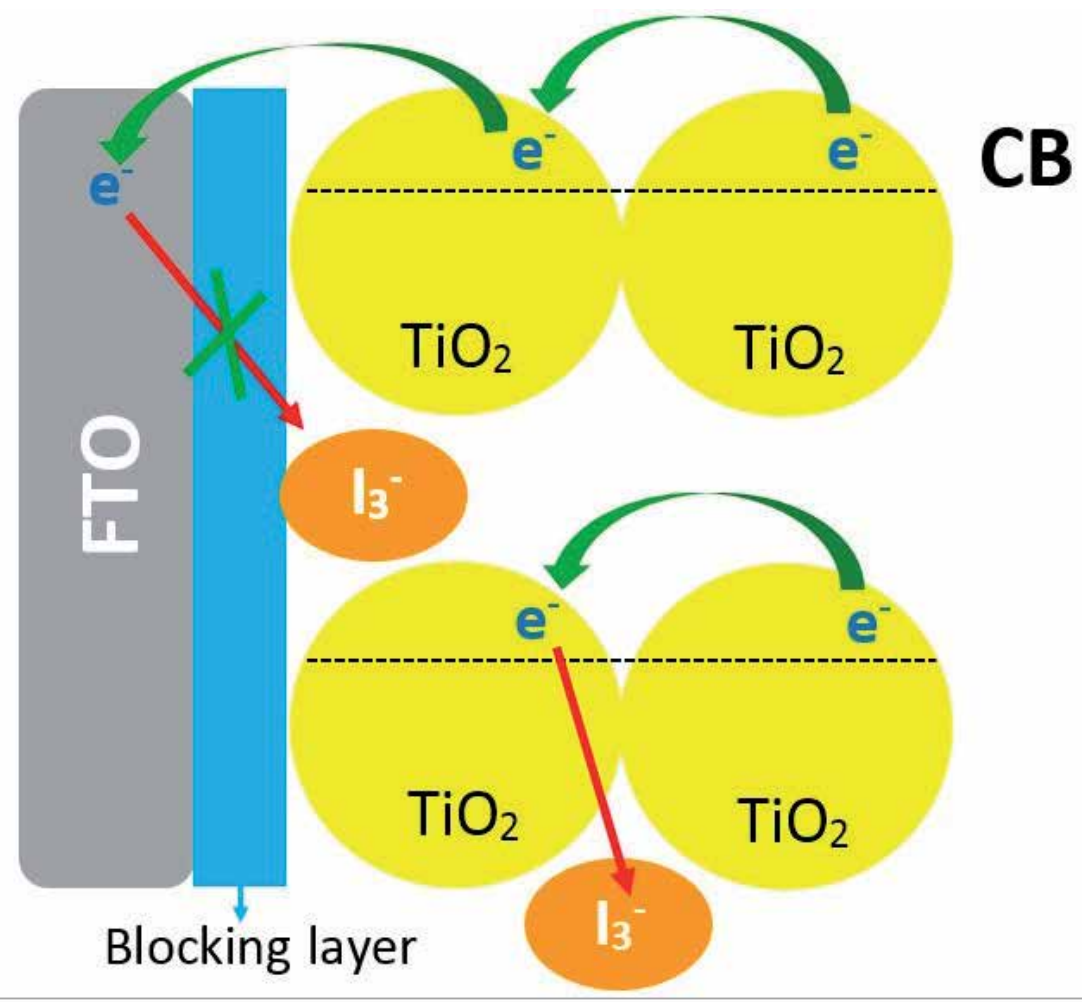

Figure 8. Decrease of electronic recombination on the FTO/electrolyte interface due to the application of the blocking layer. 
In all approaches described above, it is common the need to deposit multiple layers of semiconductor oxides with different functions. Besides the nanoporous layer, responsible for dye adsorption and transport of electrons, there is the blocking layer deposited on the surface of the substrate which is responsible for reduction of the electronic recombination on the substrate-electrolyte interface, Figure 8.

Additionally, scattering layers, composed of particles with size between 400 and $700 \mathrm{~nm}$ can be deposited, which contributes to a greater use of the incident light. Several proposals can be found in the literature in relation to different layers of metal oxides in DSCs. In these are included the use of different techniques of deposition and also various materials. The research groups working in this area agree that the deposition of different semiconductor oxide layers with different morphologies is indispensable for production of high efficiency DSCs [143, 161]. However, there is still no consensus on the best deposition technique to be employed and what better composition to be used for the different electrolytes.

Recently, we reported the production of contact-blocking layers using the layer-by-layer (LbL) technique, which showed excellent performance in DSCs based on liquid electrolytes [162-164]. This technique stands out for its low cost, possibility of control of composition, thickness and morphology of films and the possibility to be employed on a large scale. It was noted, for example, that the use of a mixture between $\mathrm{TiO}_{2}$ and more insulating oxides as $\mathrm{Nb}_{2} \mathrm{O}_{5}$ results in an increase of all the photoelectrochemical parameters of the DSCs [165].

\section{Conclusion}

In this chapter, aspects related to obtaining and application of mesoporous nanostructured materials in photocatalytic processes had been addressed, emphasizing its application in advanced oxidative processes, increasing the overall efficiency of conversion in dye sensitized solar cells, manufacturing of electrodes for lithium-ion batteries and hydrogen production, with focus on $\mathrm{TiO}_{2}$. Although many advances have occurred, some challenges still needed to be overcome so that these materials become more efficient and economically viable. On the other hand, the potential that mesoporous materials demonstrated and the improvements already achieved promote the study and development of what is a promising source of technological applications.

\section{Acknowledgements}

To Fundação de Amparo à Pesquisa do Estado de Minas Gerais (FAPEMIG), Coordenação de Aperfeiçoamento de Pessoal de Nível Superior (CAPES), and Conselho Nacional de Desenvolvimento Científico e Tecnológico (CNPq), Brazilian agencies for research funding and grants, by the support and funding. 


\section{Author details}

Antonio E. H. Machado ${ }^{1 *}$, Karen A. Borges ${ }^{1}$, Tatiana A. Silva ${ }^{1}$, Lidiaine M. Santos ${ }^{1}$,

Mariana F. Borges ${ }^{1}$, Werick A. Machado ${ }^{1}$, Bruno P. Caixeta ${ }^{1}$, Marcela Dias França ${ }^{2}$,

Samuel M. Oliveira ${ }^{1}$, Alam G. Trovó ${ }^{1}$ and Antonio O.T. Patrocínio ${ }^{1}$

*Address all correspondence to: aehmachado@gmail.com

1 Universidade Federal de Uberlândia, Instituto de Química, Laboratório de Fotoquímica e Ciência de Materiais, Minas Gerais, Brazil

2 Instituto Federal Goiano, Goiás, Brazil

\section{References}

[1] Bahng SH, Kwon NH, Kim HC, Siddique A, Kang HJ, Lee JY, et al. Simple Synthesis of Water-Dispersible and Photoactive Titanium Dioxide Nanoparticles Using Functionalized Poly(ethylene oxide)s. Macromolecular Research 2014;22(4) 445-456. DOI: 10.1007/s13233-014-2062-5.

[2] Hidalgo D, Messina R, Sacco A, Manfredi D, Vankova S, Garrone E, et al. Thick mesoporous $\mathrm{TiO}_{2}$ films through a sol-gel method involving a non-ionic surfactant: Characterization and enhanced performance for water photo-electrolysis. International Journal of Hydrogen Energy 2014. DOI: 10.1016/j.ijhydene.2014.02.163.

[3] Sanchez-Quiles D, Tovar-Sanchez A. Sunscreens as a source of hydrogen peroxide production in coastal waters. Environmental Science \& Technology 2014;48(16) 9037-9042. DOI: 10.1021/Es5020696.

[4] Xi BJ, Chu XN, Hu JY, Bhatia CS, Danner AJ, Yang H. Preparation of $\mathrm{Ag} / \mathrm{TiO}_{2} / \mathrm{SiO}_{2}$ films via photo-assisted deposition and adsorptive self-assembly for catalytic bactericidal application. Applied Surface Science 2014;311 582-592. DOI: 10.1016/j.apsusc. 2014.05.112.

[5] Yeh SW, Ko HH, Chiang HM, Chen YL, Lee JH, Wen CM, et al. Characteristics and properties of a novel in situ method of synthesizing mesoporous $\mathrm{TiO}_{2}$ nanopowders by a simple coprecipitation process without adding surfactant. Journal of Alloys and Compounds 2014;613 107-116. DOI: 10.1016/j.jalicom.2014.05.227.

[6] Wang $\mathrm{ZY}$, Yao N, Hu X. Single material $\mathrm{TiO}_{2}$ double layers antireflection coating with photocatalytic property prepared by magnetron sputtering technique. Vacuum 2014;108 20-26. DOI: 10.1016/j.vacuum.2014.05.009. 
[7] Chen KC, Wang $\mathrm{YH}$. The effects of Fe-Mn oxide and $\mathrm{TiO}_{2} /$ alpha- $\mathrm{Al}_{2} \mathrm{O}_{3}$ on the formation of disinfection by-products in catalytic ozonation. Chemical Engineering Journal 2014;253 84-92. DOI: 10.1016/j.cej.2014.04.111.

[8] A. Oliveira, E. M. Saggioro, T. Pavesi, J. C. Moreira, L. F. V. Ferreira. Solar photochemistry for environmental remediation-advanced oxidation processes for industrial wastewater treatment. In: Saha S (ed.) Molecular Photochemistry-Various Aspects. Rijeka: InTech; 2012. p. 195-223.

[9] Wu MM, Shen Y, Gu F, Xie YA, Zhang JC, Wang LJ. Preparation and photoelectric properties of mesoporous ZnO films. Journal of Sol-Gel Science and Technology 2010;53(2) 470-474. DOI: 10.1007/s10971-009-2099-7.

[10] Xiong XH, Wang ZX, Wu FX, Li XH, Guo HJ. Preparation of $\mathrm{TiO}_{2}$ from ilmenite using sulfuric acid decomposition of the titania residue combined with separation of $\mathrm{Fe}^{3+}$ with EDTA during hydrolysis. Advanced Powder Technology 2013;24(1) 60-67. DOI: 10.1016/j.apt.2012.02.002.

[11] Sasikumar C, Rao DS, Srikanth S, Ravikumar B, Mukhopadhyay NK, Mehrotra SP. Effect of mechanical activation on the kinetics of sulfuric acid leaching of beach sand ilmenite from Orissa, India. Hydrometallurgy 2004;75(1-4) 189-204. DOI: 10.1016/ j.hydromet.2004.08.001.

[12] El-Hazek N, Lasheen TA, El-Sheikh R, Zaki SA. Hydrometallurgical criteria for $\mathrm{TiO}_{2}$ leaching from Rosetta ilmenite by hydrochloric acid. Hydrometallurgy 2007;87(1-2) 45-50. DOI: 10.1016/j.hydromet.2007.01.003.

[13] Fujishima A, Honda K. Eletrochemical photolysis of water at semiconductor electrode. Nature 1972(238) 37-38.

[14] He LF, Wang CD, Yao XL, Ma RG, Wang HK, Chen PR, et al. Synthesis of carbon nanotube/mesoporous $\mathrm{TiO}_{2}$ coaxial nanocables with enhanced lithium ion battery performance. Carbon 2014;75 345-352. DOI: 10.1016/j.carbon.2014.04.013.

[15] Hu LY, Wang JY, Zhang JX, Zhang QY, Liu ZH. An N-doped anatase/rutile $\mathrm{TiO}_{2}$ hybrid from low-temperature direct nitridization: enhanced photoactivity under UV-/ visible-light. Rsc Advances 2014;4(1) 420-427. DOI: 10.1039/C3ra44421j.

[16] Lan X, Wang LZ, Zhang BY, Tian BZ, Zhang JL. Preparation of lanthanum and boron co-doped $\mathrm{TiO}_{2}$ by modified sol-gel method and study their photocatalytic activity. Catalysis Today 2014;224 163-170. DOI: 10.1016/j.cattod.2013.10.062.

[17] Liu GQ, Liu LC, Song JR, Liang JD, Luo QZ, Wang DS. Visible light photocatalytic activity of $\mathrm{TiO}_{2}$ nanoparticles hybridized by conjugated derivative of polybutadiene. Superlattices and Microstructures 2014;69 164-174. DOI: 10.1016/j.spmi.2014.02.013.

[18] Neubert S, Ramakrishnan A, Strunk J, Shi HY, Mei B, Wang LD, et al. Surface-Modified $\mathrm{TiO}_{2}$ Photocatalysts Prepared by a Photosynthetic Route: Mechanism, Enhancement, and Limits. Chempluschem 2014;79(1) 163-170. DOI: 10.1002/cplu.201300277. 
[19] A. E. H. Machado, A. O. T. Patrocinio, M. D. França, L. M. Santos, K. A. Borges, L. F. Paula. Metal oxides for photoinduced hydrogen production and dye-sensitized solar cell applications. In: Méndez-Vilas A. (ed.) Materials and processes for energy: communicating current research and technological developments. Badajoz: Formatex; 2013. p. 867-879.

[20] A. E. H. Machado, L. M. Santos, K. A. Borges, P. S. Batista, V. A. B. Paiva, P. S. Müller Jr., et al. Potential Applications for Solar Photocatalysis: From Environmental Remediation to Energy Conversion. In: Babatunde E. B. (ed.) Solar Radiation. Rijeka: InTech; 2012. p. 339-378.

[21] F. Sordello, V. Maurino, C. Minero. Improved photochemistry of $\mathrm{TiO}_{2}$ inverse opals and some examples. In: Saha S (ed.) Molecular Photochemistry-Various Aspects. Rijeka: InTech; 2012. p. 63-87.

[22] M. Valenzuela. Photocatalytic deposition of metal oxides on semiconductor particles: a review. In: Saha S (ed.) Molecular Photochemistry-Various Aspects. Rijeka: InTech; 2012. p. 25-41.

[23] Jaroenworaluck A, Pijarn N, Kosachan N, Stevens R. Nanocomposite $\mathrm{TiO}_{2}-\mathrm{SiO}_{2}$ gel for UV absorption. Chemical Engineering Journal 2012;181 45-55. DOI: 10.1016/j.cej. 2011.08.028.

[24] Affam AC, Chaudhuri M. Degradation of pesticides chlorpyrifos, cypermethrin and chlorothalonil in aqueous solution by $\mathrm{TiO}_{2}$ photocatalysis Journal of Environmental Management 2013;130 160-165. DOI: 10.1016/j.jenvman.2013.08.058.

[25] Chen JW, Shi JW, Wang X, Ai HY, Cui HJ, Fu ML. Hybrid metal oxides quantum dots $/ \mathrm{TiO}_{2}$ block composites: Facile synthesis and photocatalysis application. Powder Technology 2013;246 108-116. DOI: 10.1016/j.powtec.2013.05.014.

[26] Hirakawa T, Sato K, Komano A, Kishi S, Nishimoto CK, Mera N, et al. Specific properties on $\mathrm{TiO}_{2}$ photocatalysis to decompose isopropyl methylphosphonofluoridate and dimethyl methylphosphonate in Gas Phase. Journal of Photochemistry and Photobiology a-Chemistry 2013;264 12-17. DOI: 10.1016/j.jphotochem.2013.04.012.

[27] A. Eremenko, N. Smirnova, I. Gnatiuk, O. Linnik, N. Vityuk, Y. Mukha, et al. Silver and gold nanoparticles on sol-gel $\mathrm{TiO}_{2}, \mathrm{ZrO}_{2}, \mathrm{SiO}_{2}$ surfaces: optical spectra, photocatalytic activity, bactericide properties. In: Cuppoletti J (ed.) Nanocomposites and Polymers with Analytical Methods. Rijeka: InTech; 2011. p. 51-83.

[28] V. S. Viteri, E. Fuentes. Titanium and Titanium Alloys as Biomaterials. In: Gegner J (ed.) Tribology-Fundamentals and Advancements. Rijeka: InTech; 2013. p. 155-181.

[29] Grcic I, Vujevic D, Zizek K, Koprivanac N. Treatment of organic pollutants in water using $\mathrm{TiO}_{2}$ powders: photocatalysis versus sonocatalysis. Reaction Kinetics Mechanisms and Catalysis 2013;109(2) 335-354. DOI: 10.1007/s11144-013-0562-5.

[30] Machado AEH, França MD, Velani V, Magnino GA, Velani HMM, Freitas FS, et al. Characterization and evaluation of the efficiency of $\mathrm{TiO}_{2} /$ zinc phthalocyanine nano- 
composites as photocatalysts for wastewater treatment using solar irradiation. International Journal of Photoenergy 2008;2008. DOI: 10.1155/2008/482373.

[31] Fujishima A, Honda K. Electrochemical Photolysis of Water at a Semiconductor Electrode. Nature 1972;238(5358) 37-+. DOI: 10.1038/238037a0.

[32] Gao P, Sun DD. Hierarchical sulfonated graphene oxide- $\mathrm{TiO}_{2}$ composites for highly efficient hydrogen production with a wide $\mathrm{pH}$ range. Applied Catalysis B-Environmental 2014;147 888-896. DOI: 10.1016/j.apcatb.2013.10.025.

[33] Melian EP, Suarez MN, Jardiel T, Rodriguez JMD, Caballero AC, Arana J, et al. Influence of nickel in the hydrogen production activity of $\mathrm{TiO}_{2}$. Applied Catalysis B-Environmental 2014;152 192-201. DOI: 10.1016/j.apcatb.2014.01.039.

[34] Mendez JAO, Lopez CR, Melian EP, Diaz OG, Rodriguez JMD, Hevia DF, et al. Production of hydrogen by water photo-splitting over commercial and synthesised $\mathrm{Au} / \mathrm{TiO}_{2}$ catalysts. Applied Catalysis B-Environmental 2014;147 439-452. DOI: 10.1016/j.apcatb.2013.09.029.

[35] Taboada E, Angurell I, Llorca J. Dynamic photocatalytic hydrogen production from ethanol-water mixtures in an optical fiber honeycomb reactor loaded with $\mathrm{Au} / \mathrm{TiO}_{2}$. Journal of Catalysis 2014;309 460-467. DOI: 10.1016/j.jcat.2013.10.025.

[36] Wu ZF, Zhang WH, Xiong F, Yuan Q, Jin YK, Yang JL, et al. Active hydrogen species on $\mathrm{TiO}_{2}$ for photocatalytic $\mathrm{H}_{2}$ production. Physical Chemistry Chemical Physics 2014;16(15) 7051-7057. DOI: 10.1039/C4cp00697f.

[37] Hagfeldt A, Gratzel M. Light-Induced Redox Reactions in Nanocrystalline Systems. Chemical Reviews 1995;9549-68.

[38] Hagfeldt A, Gratzel M. Molecular photovoltaics. Accounts Chemistry Reserarch 2000(33) 269-277.

[39] Jayaweera PVV, Perera AGU, Tennakone K. Why Gratzel`s cells works so well. Inorganica Chimica Acta 2008(361) 707-711.

[40] Peter LM. Dye-sensitized nanocristalline solar cells. Physical Chemistry Chemical Physics 2007;9 2630-2642.

[41] Chang HM, Yang YJ, Li HC, Hsu CC, Cheng IC, Chen JZ. Preparation of nanoporous $\mathrm{TiO}_{2}$ films for DSSC application by a rapid atmospheric pressure plasma jet sintering process. Journal of Power Sources 2013;234 16-22. DOI: 10.1016/j.jpowsour. 2013.01.113.

[42] Sannino D, Vaiano V, Ciambelli P, Zama I, Gorni G. Evaluation of N719 amount in $\mathrm{TiO}_{2}$ films for DSSC by thermogravimetric analysis. Journal of Thermal Analysis and Calorimetry 2013;111(1) 453-458. DOI: 10.1007/s10973-012-2436-x.

[43] Zeng Z, Zhang B, Liu XJ, Peng X, Meng SX, Feng YQ. The impact of porphyrin mesoposition steric effect on porphyrin density on $\mathrm{TiO}_{2}$ surface of DSSC. Advanced Mate- 
rials and Engineering Materials Ii 2013;683 522-525. DOI: 10.4028/www.scientific.net/ AMR.683.522.

[44] Paula LF, Amaral RC, Iha NYM, Paniago RM, Machado AEH, Patrocinio AOT. New layer-by-layer $\mathrm{Nb}_{2} \mathrm{O}_{5}-\mathrm{TiO}_{2}$ film as an effective underlayer in dye-sensitised solar cells. Rsc Advances 2014;4(20) 10310-10316. DOI: 10.1039/C4ra00058g.

[45] Zhu XD, Wang YJ, Zhou DM. $\mathrm{TiO}_{2}$ photocatalytic degradation of tetracycline as affected by a series of environmental factors. Journal of Soils and Sediments 2014;14(8) 1350-1358. DOI: 10.1007/s11368-014-0883-7.

[46] Kumar N, Maitra U, Hegde VI, Waghmare UV, Sundaresan A, Rao CNR. Synthesis, Characterization, Photocatalysis, and Varied Properties of $\mathrm{TiO}_{2}$ Cosubstituted with Nitrogen and Fluorine. Inorganic Chemistry 2013;52(18) 10512-10519. DOI: 10.1021/ Ic401426q.

[47] Gupta SK, Singh J, Anbalagan K, Kothari P, Bhatia RR, Mishra PK, et al. Synthesis, phase to phase deposition and characterization of rutile nanocrystalline titanium dioxide $\left(\mathrm{TiO}_{2}\right)$ thin films. Applied Surface Science 2013;264 737-742. DOI: 10.1016/ j.apsusc.2012.10.113.

[48] Idigoras J, Berger T, Anta JA. Modification of Mesoporous $\mathrm{TiO}_{2}$ Films by Electrochemical Doping: Impact on Photoelectrocatalytic and Photovoltaic Performance. Journal of Physical Chemistry C 2013;117(4) 1561-1570. DOI: 10.1021/Jp306954y.

[49] Ji YF, Zhou L, Ferronato C, Salvador A, Yang X, Chovelon JM. Degradation of sunscreen agent 2-phenylbenzimidazole-5-sulfonic acid by $\mathrm{TiO}_{2}$ photocatalysis: Kinetics, photoproducts and comparison to structurally related compounds. Applied Catalysis B-Environmental 2013;140 457-467. DOI: 10.1016/j.apcatb.2013.04.046.

[50] Kim DS, Kwak SY. The hydrothermal synthesis of mesoporous $\mathrm{TiO}_{2}$ with high crystallinity, thermal stability, large surface area, and enhanced photocatalytic activity. Applied Catalysis a-General 2007;323 110-118. DOI: 10.1016/j.apcata.2007.02.010.

[51] Davis ME. Ordered porous materials for emerging applications. Nature 2002;417(6891) 813-821. DOI 10.1038/Nature00785.

[52] Lee ES, Lee KM, Yoon SI, Ko YG, Shin DH. Influence of CNT incorporation on the photovoltaic behavior of $\mathrm{TiO}_{2}$ films formed by high-voltage electrophoretic deposition. Current Applied Physics 2013;13 S26-S29. DOI: 10.1016/j.cap.2013.01.013.

[53] Kondo JN, Domen K. Crystallization of mesoporous metal oxides. Chemistry of Materials 2008;20(3) 835-847. DOI: 10.1021/Cm702176m.

[54] Zheng XL, Kuang Q, Yan KY, Qiu YC, Qiu JH, Yang SH. Mesoporous $\mathrm{TiO}_{2}$ Single Crystals: Facile Shape-, Size-, and Phase-Controlled Growth and Efficient Photocatalytic Performance. Acs Applied Materials \& Interfaces 2013;5(21) 11249-11257. DOI: 10.1021/Am403482g. 
[55] Ferreira OP, Alves OL, Macedo JD, Gimenez ID, Barreto LS. Ecomaterials: Development and application of functional porous materials for environmental protection. Química Nova 2007;30(2) 464-467. DOI: 10.1590/S0100-40422007000200039.

[56] McCusker LB, Liebau F, Engelhardt G. Nomenclature of structural and compositional characteristics of ordered microporous and mesoporous materials with inorganic hosts-(IUPAC recommendations 2001). Pure and Applied Chemistry 2001;73(2) 381-394. DOI: 10.1351/pac200173020381.

[57] Guo SY, Han S, Chi B, Pu J, Li J. Synthesis of shape-controlled mesoporous titanium phosphate nanocrystals: The hexagonal titanium phosphate with enhanced hydrogen generation from water splitting. International Journal of Hydrogen Energy 2014;39(6) 2446-2453. DOI: 10.1016/j.ijhydene.2013.12.007.

[58] Kao LH, Hsu TC, Cheng KK. Novel synthesis of high-surface-area ordered mesoporous $\mathrm{TiO}_{2}$ with anatase framework for photocatalytic applications. Journal of Colloid and Interface Science 2010;341(2) 359-365. DOI: 10.1016/j.jcis.2009.09.058.

[59] Yang XH, Fu HT, Yu AB, Jiang XC. Large-surface mesoporous $\mathrm{TiO}_{2}$ nanoparticles: Synthesis, growth and photocatalytic performance. Journal of Colloid and Interface Science 2012;38 774-783. DOI 10.1016/j.jcis.2012.06.080.

[60] Li W, Wu ZX, Wang JX, Elzatahry AA, Zhao DY. A Perspective on Mesoporous $\mathrm{TiO}_{2}$ Materials. Chemistry of Materials 2014;26(1) 287-298. DOI: 10.1021/Cm4014859.

[61] Kim DS, Han SJ, Kwak SY. Synthesis and photocatalytic activity of mesoporous $\mathrm{TiO}_{2}$ with the surface area, crystallite size, and pore size. Journal of Colloid and Interface Science 2007;316(1) 85-91. DOI: 10.1016/j.jcis.2007.07.037.

[62] Blin JL, Stebe MJ, Roques-Carmes T. Use of ordered mesoporous titania with semicrystalline framework as photocatalyst. Colloids and Surfaces a-Physicochemical and Engineering Aspects 2012;407 177-185. DOI: 10.1016/j.colsurfa.2012.05.029.

[63] Crossland EJW, Noel N, Sivaram V, Leijtens T, Alexander-Webber JA, Snaith HJ. Mesoporous $\mathrm{TiO}_{2}$ single crystals delivering enhanced mobility and optoelectronic device performance. Nature 2013;495(7440) 215-219. DOI: 10.1038/Nature11936.

[64] Herrero C, Quaranta A, Leibl W, Rutherford AW, Aukauloo A. Artificial photosynthetic systems. Using light and water to provide electrons and protons for the synthesis of a fuel. Energy \& Environmental Science 2011;4(7) 2353-2365. DOI: 10.1039/ C0ee00645a.

[65] Kandiel TA, Ivanova I, Bahnemann DW. Long-term investigation of the photocatalytic hydrogen production on platinized $\mathrm{TiO}_{2}$ : an isotopic study. Energy \& Environmental Science 2014;7(4) 1420-1425. DOI: 10.1039/C3ee41511b.

[66] Rungjaroentawon N, Onsuratoom S, Chavadej S. Hydrogen production from water splitting under visible light irradiation using sensitized mesoporous-assembled $\mathrm{TiO}_{2}$ - 
$\mathrm{SiO}_{2}$ mixed oxide photocatalysts. International Journal of Hydrogen Energy 2012;37(15) 11061-11071.

[67] Taffa DH, Kathiresan M, Arnold T, Walder L, Erbacher M, Bauer D, et al. Dye sensitized membranes within mesoporous $\mathrm{TiO}_{2}$ Photocurrents in aqueous solution. Journal of Photochemistry and Photobiology a-Chemistry 2010;216(1) 35-43. DOI: 10.1016/j.jphotochem.2010.09.003.

[68] Tan HQ, Zhao Z, Niu M, Mao CY, Cao DP, Cheng DJ, et al. A facile and versatile method for preparation of colored $\mathrm{TiO}_{2}$ with enhanced solar-driven photocatalytic activity. Nanoscale 2014;6(17) 10216-10223. DOI: 10.1039/C4nr02677b.

[69] Zhang RY, Elzatahry AA, Al-Deyab SS, Zhao DY. Mesoporous titania: From synthesis to application. Nano Today 2012;7(4) 344-366. DOI: 10.1016/j.nantod.2012.06.012.

[70] Zhou XF, Lu J, Jiang JJ, Li XB, Lu MN, Yuan GT, et al. Simple fabrication of N-doped mesoporous $\mathrm{TiO}_{2}$ nanorods with the enhanced visible light photocatalytic activity. Nanoscale Research Letters 2014;9 DOI: 10.1186/1556-276x-9-34.

[71] Pal N, Bhaumik A. Soft templating strategies for the synthesis of mesoporous materials: Inorganic, organic-inorganic hybrid and purely organic solids. Advances in Colloid and Interface Science 2013;189 21-41. DOI: 10.1016/j.cis.2012.12.002.

[72] Abdel-Azim SM, Aboul-Gheit AK, Ahmed SM, El-Desouki DS, Abdel-Mottaleb MSA. Preparation and Application of Mesoporous Nanotitania Photocatalysts Using Different Templates and pH Media. International Journal of Photoenergy 2014;2014. DOI: $10.1155 / 2014 / 687597$.

[73] Song HJ, Chen T, Sun YL, Zhang XQ, Jia XH. Controlled synthesis of porous flowerlike $\mathrm{TiO}_{2}$ nanostructure with enhanced photocatalytic activity. Ceramics International 2014;40(7) 11015-11022. DOI: 10.1016/j.ceramint.2014.03.108.

[74] Patrocinio AOT, El-Bacha AS, Paniago EB, Paniago RM, Iha NYM. Influence of the Sol-Gel $\mathrm{pH}$ Process and Compact Film on the Efficiency of $\mathrm{TiO}_{2}$-Based Dye-Sensitized Solar Cells. International Journal of Photoenergy 2012. DOI: $10.1155 / 2012 / 638571$.

[75] Niederberger M, Garnweitner G, Buha J, Polleux J, Ba JH, Pinna N. Nonaqueous synthesis of metal oxide nanoparticles: Review and indium oxide as case study for the dependence of particle morphology on precursors and solvents. Journal of Sol-Gel Science and Technology 2006;40(2-3) 259-266. DOI: 10.1007/s10971-006-6668-8.

[76] Ribeiro C, Malagutti, A. R., Mendonça, V. R. E Mourão, A. J. L. Nanoestruturas em fotocatálise: uma revisão sobre estratégias de síntese de fotocatalisadores em escala nanométrica. Química Nova 2009;32(8).

[77] Muniz EC, Goes MS, Silva JJ, Varela JA, Joanni E, Parra R, et al. Synthesis and characterization of mesoporous $\mathrm{TiO}_{2}$ nanostructured films prepared by a modified sol-gel 
method for application in dye solar cells. Ceramics International 2011;37(3) 1017-1024. DOI: 10.1016/j.ceramint.2010.11.014.

[78] Kojima T, Sugimoto T. Formation Mechanism of Amorphous $\mathrm{TiO}_{2}$ Spheres in Organic Solvents 3. Effects of Water, Temperature, and Solvent Composition. Journal of Physical Chemistry C 2008;112(47) 18445-18454. DOI: 10.1021/Jp802957e.

[79] Mahoney L, Koodali RT. Versatility of evaporation-induced self-assembly (EISA) method for preparation of mesoporous $\mathrm{TiO}_{2}$ for energy and environmental applications. Materials 2014;7(4) 2697-2746. DOI: 10.3390/Ma7042697.

[80] Arconada N, Castro Y, Duran A, Hequet V. Photocatalytic oxidation of methyl ethyl ketones over sol-gel mesoporous and meso-structured $\mathrm{TiO}_{2}$ films obtained by EISA method. Applied Catalysis B-Environmental 2011;107(1-2) 52-58. DOI: 10.1016/ j.apcatb.2011.06.036.

[81] Ouyang J, Li XY, Jin J, Yang HM, Tang AD. Surface status and reduction behavior of porous ceria $\left(\mathrm{CeO}_{2}\right)$ via amended EISA method. Journal of Alloys and Compounds 2014;606 236-241. DOI: 10.1016/j.jallcom.2014.04.048.

[82] Chiola V, Ritsko JE, Vanderpool CD, Process for producing low-bulk density silica. Patent: US 3556725D A. US; 19/01/1971.

[83] Yanagisawa T, Shimizu T, Kuroda K, Kato C. Trimethylsilyl derivatives of alkyltrimethylammonium-kanemite complexes and their conversion to microporous $\mathrm{SiO}_{2}$ materials. The Bulletin of the Chemical Society of Japan 1990;63(5) 1535-1537 DOI: 10.1246/bcsj.63.1535.

[84] Badawy MI, Ghaly MY, Ali MEM. Photocatalytic hydrogen production over nanostructured mesoporous titania from olive mill wastewater. Desalination 2011;267(2-3) 250-255. DOI: 10.1016/j.desal.2010.09.035.

[85] Bian YR, Wang XH, Hu ZY. Synthesis of mesoporous titania thin films by a simple route at low-temperature via plasma treatment. Journal of Materials Science 2013;48(11) 4088-4096. DOI: 10.1007/s10853-013-7221-0.

[86] Zhou W, Li W, Wang JQ, Qu Y, Yang Y, Xie Y, et al. Ordered Mesoporous Black $\mathrm{TiO}_{2}$ as Highly Efficient Hydrogen Evolution Photocatalyst. Journal of the American Chemical Society 2014;136(26) 9280-9283. DOI: 10.1021/Ja504802q.

[87] Xiang P, Li X, Wang H, Liu GH, Shu T, Zhou ZM, et al. Mesoporous nitrogen-doped $\mathrm{TiO}_{2}$ sphere applied for quasi-solid-state dye-sensitized solar cell. Nanoscale Research Letters 2011;6. DOI: 10.1186/1556-276X-6-606.

[88] Wu ZY, Tao YF, Lin Z, Liu L, Fan XX, Wang Y. Hydrothermal Synthesis and Morphological Evolution of Mesoporous Titania-Silica. Journal of Physical Chemistry C 2009;113(47) 20335-20348. DOI: 10.1021/jp9037842. 
[89] Wen ZH, Wu W, Liu Z, Zhang H, Li JH, Chen JH. Ultrahigh-efficiency photocatalysts based on mesoporous $\mathrm{Pt}_{-} \mathrm{WO}_{3}$ nanohybrids. Physical Chemistry Chemical Physics 2013;15(18) 6773-6778. DOI: 10.1039/c3cp50647a.

[90] Wang YZ, Zhu SP, Chen XR, Tang YG, Jiang YF, Peng ZG, et al. One-step templatefree fabrication of mesoporous $\mathrm{ZnO} / \mathrm{TiO}_{2}$ hollow microspheres with enhanced photocatalytic activity. Applied Surface Science 2014;307 263-271. DOI: 10.1016/j.apsusc. 2014.04.023.

[91] Shamaila S, Khan A, Sajjad L, Chen F, Zhang JL. Mesoporous titania with high crystallinity during synthesis by dual template system as an efficient photocatalyst. Catalysis Today 2011;175(1) 568-575. DOI: 10.1016/j.cattod.2011.03.041.

[92] Antonelli DM, Ying JY. Synthesis of Hexagonally Packed Mesoporous $\mathrm{TiO}_{2}$ by a Modified Sol-Gel Method. Angewandte Chemie-International Edition in English 1995;34(18) 2014-2017. DOI: 10.1002/anie.199520141.

[93] Joo JB, Lee I, Dahl M, Moon GD, Zaera F, Yin YD. Controllable Synthesis of Mesoporous $\mathrm{TiO}_{2}$ Hollow Shells: Toward an Efficient Photocatalyst. Advanced Functional Materials 2013;23(34) 4246-4254. DOI: 10.1002/adfm.201300255.

[94] Lopez A, Acosta D, Martinez AI, Santiago J. Nanostructured low crystallized titanium dioxide thin films with good photocatalytic activity. Powder Technology 2010;202(1-3) 111-117. DOI: 10.1016/j.powtec.2010.04.025.

[95] Ramasamy E, Jo C, Anthonysamy A, Jeong I, Kim JK, Lee J. Soft-template simple synthesis of ordered mesoporous titanium nitride-carbon nanocomposite for high performance dye-sensitized solar cell counter electrodes. Chemistry of Materials 2012;24(9) 1575-1582. DOI: 10.1021/Cm203672g.

[96] Tran TH, Nosaka AY, Nosaka Y. Adsorption and decomposition of a dipeptide (AlaTrp) in $\mathrm{TiO}_{2}$ photocatalytic systems. Journal of Photochemistry and Photobiology aChemistry 2007;192(2-3) 105-113. DOI: 10.1016/j.jphotochem.2007.05.011.

[97] Lu YF, Fan HY, Stump A, Ward TL, Rieker T, Brinker CJ. Aerosol-assisted self-assembly of mesostructured spherical nanoparticles. Nature 1999;398(6724) 223-226. DOI:10.1038/18410.

[98] Yang H, Coombs N, Sokolov I, Ozin GA. Free-standing and oriented mesoporous silica films grown at the air-water interface. Nature 1996;381(6583) 589-592. DOI: 10.1038/381589a0.

[99] Yang XH, Fu HT, Yu AB, Jiang XC. Large-surface mesoporous $\mathrm{TiO}_{2}$ nanoparticles: Synthesis, growth and photocatalytic performance. Journal of Colloid and Interface Science 2012;387 74-83. DOI: 10.1016/j.jcis.2012.06.080.

[100] Wu MT, Chow $\mathrm{TJ} \mathrm{TiO}_{2}$ particles prepared by size control self-assembly and their usage on dye-sensitized solar cell. Microporous and Mesoporous Materials 2014;196 354-358. DOI: 10.1016/j.micromeso.2014.05.035. 
[101] Gao J, Li HR, Rong H, Dai YH. Large pore nanocrystalline $\mathrm{TiO}_{2}$ films for quasi-solid state dye-sensitized solar cells. Nanotechnology and Precision Engineering, Pts 1 and 2 2013;662 177-181. DOI: 10.4028/www.scientific.net/AMR.662.177.

[102] Wang Y, Jiang ZH, Yang FJ. Preparation and photocatalytic activity of mesoporous $\mathrm{TiO}_{2}$ derived from hydrolysis condensation with TX-100 as template. Materials Science and Engineering B-Solid State Materials for Advanced Technology 2006;128(1-3) 229-233. DOI: 10.1016/j.mseb.2005.12.004.

[103] Rodriguez-Abreu C, Vilanova N, Solans C, Ujihara M, Imae T, Lopez-Quintela A, et al. A combination of hard and soft templating for the fabrication of silica hollow microcoils with nanostructured walls. Nanoscale Research Letters 2011;6. DOI: 10.1186/1556-276x-6-330.

[104] Hu CY, Xu YJ, Duo SW, Li WK, Xiang JH, Li MS, et al. Preparation of Inorganic Hollow Spheres Based on Different Methods. Journal of the Chinese Chemical Society 2010;57(5A) 1091-1098. DOI: 10.1002/jccs.201000154.

[105] Tang H, Zhang D, Tang GG, Ji XR, Li CS, Yan XH, et al. Low temperature synthesis and photocatalytic properties of mesoporous $\mathrm{TiO}_{2}$ nanospheres. Journal of Alloys and Compounds 2014;591 52-57. DOI: 10.1016/j.jallcom.2013.12.176.

[106] Chen JF, Hua ZJ, Yan YS, Zakhidov AA, Baughman RH, Xu LB. Template synthesis of ordered arrays of mesoporous titania spheres. Chemical Communications 2010;46(11) 1872-1874. DOI: 10.1039/B915706a.

[107] Ma TY, Liu L, Yuan ZY. Direct synthesis of ordered mesoporous carbons. Chemical Society Reviews 2013;42(9) 3977-4003. DOI: 10.1039/C2cs35301f.

[108] Wan J, Lei Y, Zhang YR, Leng Y, Liu J. Study on $\mathrm{TiO}_{2}$ photoelectrode to improve the overall performance of dye-sensitized solar cells. Electrochimica Acta 2012;59 75-80. DOI: 10.1016/j.electacta.2011.10.040.

[109] Wyrwas B, Chrzanowski L, Lawniczak L, Szulc A, Cyplik P, Bialas W, et al. Utilization of Triton X-100 and polyethylene glycols during surfactant-mediated biodegradation of diesel fuel. Journal of Hazardous Materials 2011;197 97-103. DOI: 10.1016/ j.jhazmat.2011.09.060.

[110] Batigoc C, Akbas H, Boz M. Thermodynamics of non-ionic surfactant Triton X-100cationic surfactants mixtures at the cloud point. Journal of Chemical Thermodynamics 2011;43(12) 1800-1803. DOI: 10.1016/j.jct.2011.06.005.

[111] Patel V, Ray D, Aswal VK, Bahadur P. Triton X-100 micelles modulated by solubilized cinnamic acid analogues: The $\mathrm{pH}$ dependant micellar growth. Colloids and Surfaces a-Physicochemical and Engineering Aspects 2014;450 106-114. DOI: 10.1016/ j.colsurfa.2014.03.015. 
[112] Xu S, Zhou CH, Yang Y, Hu H, Sebo B, Chen BL, et al. Effects of Ethanol on Optimizing Porous Films of Dye-Sensitized Solar Cells. Energy \& Fuels 2011;25(3) 1168-1172. DOI: 10.1021/Ef101546a.

[113] Dhungel SK, Park JG. Optimization of paste formulation for $\mathrm{TiO}_{2}$ nanoparticles with wide range of size distribution for its application in dye sensitized solar cells. Renewable Energy 2010;35(12) 2776-2780. DOI: 10.1016/j.renene.2010.04.031.

[114] Li Y, Wang WN, Zhan ZL, Woo MH, Wu CY, Biswas P. Photocatalytic reduction of $\mathrm{CO}_{2}$ with $\mathrm{H}_{2} \mathrm{O}$ on mesoporous silica supported $\mathrm{Cu} / \mathrm{TiO}_{2}$ catalysts. Applied Catalysis B-Environmental 2010;100(1-2) 386-392. DOI: 10.1016/j.apcatb.2010.08.015.

[115] Nguyen-Phan TD, Pham HD, Kim S, Oh ES, Kim EJ, Shin EW. Surfactant removal from mesoporous $\mathrm{TiO}_{2}$ nanocrystals by supercritical $\mathrm{CO}_{2}$ fluid extraction. Journal of Industrial and Engineering Chemistry 2010;16(5) 823-828. DOI: 10.1016/j.jiec. 2010.05.005.

[116] Spataru T, Preda L, Osiceanu P, Munteanu C, Anastasescu M, Marcu M, et al. Role of surfactant-mediated electrodeposited titanium oxide substrate in improving electrocatalytic features of supported platinum particles. Applied Surface Science 2014;288 660-665. DOI: 10.1016/j.apsusc.2013.10.092.

[117] Mali SS, Kim H, Shim CS, Patil PS, Kim JH, Hong CK. Surfactant free most probable $\mathrm{TiO}_{2}$ nanostructures via hydrothermal and its dye sensitized solar cell properties. Scientific Reports 2013;3. DOI: 10.1038/Srep03004.

[118] Rahman MYA, Umar AA, Roza L, Salleh MM. Effect of optical property of surfactant-treated $\mathrm{TiO}_{2}$ nanostructure on the performance of $\mathrm{TiO}_{2}$ photo-electrochemical cell. Journal of Solid State Electrochemistry 2012;16(5) 2005-2010. DOI: 10.1007/ s10008-011-1605-3.

[119] Hashimoto K, Irie H, Fujishima $\mathrm{A} \mathrm{TiO}_{2}$ photocatalysis: A historical overview and future prospects. Japanese Journal of Applied Physics Part 1-Regular Papers Brief Communications \& Review Papers 2005;44(12) 8269-8285. DOI: 10.1143/Jjap.44.8269.

[120] Hoffmann MR, Martin ST, Choi WY, Bahnemann DW. Environmental Applications of Semiconductor Photocatalysis. Chemical Reviews 1995;95(1) 69-96. DOI: 10.1021/ Cr00033a004.

[121] Ibhadon AO, Fitzpatrick P. Heterogeneous Photocatalysis: Recent Advances and Applications. Catalysts 2013;3(1) 189-218. DOI: 10.3390/Catal3010189.

[122] Oregan B, Gratzel M. A Low-Cost, High-Efficiency Solar-Cell Based on Dye-Sensitized Colloidal $\mathrm{TiO}_{2}$ Films. Nature 1991;353(6346) 737-740. DOI: 10.1038/353737a0.

[123] Khataee AR, Zarei M, Ordikhani-Seyedlar R. Heterogeneous photocatalysis of a dye solution using supported $\mathrm{TiO}_{2}$ nanoparticles combined with homogeneous photoelectrochemical process: Molecular degradation products. Journal of Molecular Catalysis a-Chemical 2011;338(1-2) 84-91. DOI: 10.1016/j.molcata.2011.01.028. 
[124] Zhao S, Su D, Che J, Jiang BY, Orlov A. Photocatalytic properties of $\mathrm{TiO}_{2}$ supported on SBA-15 mesoporous materials with large pores and short channels. Materials Letters 2011;65(23-24) 3354-3357. DOI 10.1016/j.matlet.2011.07.053.

[125] Feng CG, Li YZ, Liu X. Photocatalytic Degradation of Imidacloprid by Phosphotungstic Acid Supported on a Mesoporous Sieve MCM-41. Chinese Journal of Chemistry 2012;30(1) 127-132. DOI: 10.1002/cjoc.201180453.

[126] Schneider J, Bahnemann DW. Undesired Role of Sacrificial Reagents in Photocatalysis. Journal of Physical Chemistry Letters 2013;4(20) 3479-3483.

[127] Shin JY, Samuelis D, Maier J. Sustained Lithium-Storage Performance of Hierarchical, Nanoporous Anatase $\mathrm{TiO}_{2}$ at High Rates: Emphasis on Interfacial Storage Phenomena. Advanced Functional Materials 2011;21(18) 3464-3472. DOI: 10.1002/adfm. 201002527.

[128] Zhao D, Budhi S, Rodriguez A, Koodali RT. Rapid and facile synthesis of Ti-MCM-48 mesoporous material and the photocatalytic performance for hydrogen evolution. International Journal of Hydrogen Energy 2010;35(11) 5276-5283. DOI: 10.1016/j.ijhydene.2010.03.087.

[129] Liu B, Liu LM, Lang XF, Wang HY, Lou XW, Aydil ES. Doping high-surface-area mesoporous $\mathrm{TiO}_{2}$ microspheres with carbonate for visible light hydrogen production. Energy \& Environmental Science 2014;7(8) 2592-2597. DOI: 10.1039/C4ee00472h.

[130] Armand M, Tarascon JM. Building better batteries. Nature 2008;451(7179) 652-657. DOI: $10.1038 / 451652 a$.

[131] Dunn B, Kamath H, Tarascon JM. Electrical Energy Storage for the Grid: A Battery of Choices. Science 2011;334(6058) 928-935. DOI: 10.1126/science.1212741.

[132] Guo YG, Hu YS, Maier J. Synthesis of hierarchically mesoporous anatase spheres and their application in lithium batteries. Chemical Communications 2006;2006(26) 2783-2785. DOI: 10.1039/B605090e.

[133] Wang Y, Liu SQ, Huang KL, Fang D, Zhuang SX. Electrochemical properties of freestanding $\mathrm{TiO}_{2}$ nanotube membranes annealed in Ar for lithium anode material. Journal of Solid State Electrochemistry 2012;16(2) 723-729. DOI: 10.1007/ s10008-011-1417-5.

[134] Deng D, Kim MG, Lee JY, Cho J. Green energy storage materials: Nanostructured $\mathrm{TiO}_{2}$ and $\mathrm{Sn}$-based anodes for lithium-ion batteries. Energy \& Environmental Science 2009;2(8) 818-837. DOI: 10.1039/B823474d.

[135] Dimroth F, Kurtz S. High-efficiency multijunction solar cells. Mrs Bulletin 2007;32(3) 230-235. DOI: 10.1557/Mrs2007.27.

[136] Peter LM. Dye-sensitized nanocrystalline solar cells. Physical Chemistry Chemical Physics 2007;9(21) 2630-2642. DOI: 10.1039/B617073k. 
[137] Ito S, Nazeeruddin MK, Liska P, Comte P, Charvet R, Pechy P, et al. Photovoltaic characterization of dye-sensitized solar cells: Effect of device masking on conversion efficiency. Progress in Photovoltaics 2006;14(7) 589-601. DOI: 10.1002/Pip.683.

[138] Park SH, Roy A, Beaupré S, Cho S, Coates N, Moon JS, et al. Bulk heterojunction solar cells with internal quantum efficiency approaching $100 \%$. Nature Photonics 2009;3 297-302. DOI:10.1038/nphoton.2009.69.

[139] Gratzel M. Solar energy conversion by dye-sensitized photovoltaic cells. Inorganic Chemistry 2005;44(20) 6841-6851. DOI: 10.1021/Ic0508371.

[140] O'Regan B, Grätzel M. A Low-Cost, High-Efficiency Solar-Cell Based on Dye-Sensitized Colloidal TiO2 Films. Nature 1991;353(6346) 737-740. 10.1038/353737a0.

[141] Gratzel M. Photoelectrochemical cells. Nature 2001;414(6861) 338-344. DOI: $10.1038 / 35104607$.

[142] Chiba Y, Islam A, Watanabe Y, Komiya R, Koide N, Han LY. Dye-sensitized solar cells with conversion efficiency of $11.1 \%$. Japanese Journal of Applied Physics, Part 2: Letters \& Express Letters 2006;45(24-28) L638-L640.

[143] Kroon JM, Bakker NJ, Smit HJP, Liska P, Thampi KR, Wang P, et al. Nanocrystalline dye-sensitized solar cells having maximum performance. Progress in Photovoltaics 2007;15(1) 1-18. DOI: 10.1002/Pip.707.

[144] Kalyanasundaram K, Gratzel M. Applications of functionalized transition metal complexes in photonic and optoelectronic devices. Coordination Chemistry Reviews 1998;177 347-414. DOI: 10.1016/S0010-8545(98)00189-1.

[145] Hinsch A, Veurman W, Brandt H, Loayza Aguirre R, Bialecka K, Flarup Jensen K. Worldwide first fully up-scaled fabrication of $60 \times 100 \mathrm{~cm}^{2}$ dye solar module prototypes. Progress in Photovoltaics 2012;20(6) 698-710. DOI: 10.1002/pip.1213.

[146] Higashijima S, Miura H, Fujita T, Kubota Y, Funabiki K, Yoshida T, et al. Highly efficient new indoline dye having strong electron-withdrawing group for zinc oxide dye-sensitized solar cell (vol 67, pg 6289, 2011). Tetrahedron 2011;67(43) 8421-8421. DOI: 10.1016/j.tet.2011.08.092.

[147] Kuang D, Uchida S, Humphry-Baker R, Zakeeruddin SM, Grätzel M. Organic dyesensitized ionic liquid based solar cells: Remarkable enhancement in performance through molecular design of indoline sensitizers. Angewandte Chemie-International Edition 2008;47(10) 1923-1927.

[148] Patrocinio AOT, Murakami Iha NY. Em busca da sustentabilidade: Células solares sensibilizadas por extratos naturais. Quimica Nova 2010;33(3) 574-578.

[149] Patrocinio AOT, Mizoguchi SK, Paterno LG, Murakami Iha NY. Efficient and low cost devices for solar energy conversion: efficiency and stability of some natural dye 
sensitized solar cells. Synthetic Metals 2009;159 2342-2344. DOI: 10.1016/j.synthmet. 2009.08.027.

[150] Shahid M, Shahid ul I, Mohammad F. Recent advancements in natural dye applications: a review. Journal of Cleaner Production 2013;53(0) 310-331. DOI: http:// dx.doi.org/10.1016/j.jclepro.2013.03.031.

[151] Yella A, Lee H-W, Tsao HN, Yi C, Chandiran AK, Nazeeruddin MK, et al. PorphyrinSensitized Solar Cells with Cobalt (II/III)-Based Redox Electrolyte Exceed 12 Percent Efficiency. Science 2011;334(6056) 629-634. 10.1126/science.1209688.

[152] Adithi U, Thomas S, Uma V, Pradeep N. Electrical Characterization of Dye sensitized Nano Solar cell using Natural Pomegranate juice as Photosensitizer. In: Chauhan AK, Murli C, Gadkari SC (ed.) Solid State Physics 2013. p. 208-209.

[153] Zhang Q, Liu X. Dye-Sensitized Solar Cell Goes Solid. Small 2012;8(24) 3711-3713. 10.1002/smll.201201759.

[154] Bach U, Daeneke T. A Solid Advancement for Dye-Sensitized Solar Cells. Angewandte Chemie-International Edition 2012;51(42) 10451-10452. DOI: 10.1002/anie. 201205437.

[155] Yanagida S, Yu YH, Manseki K. Iodine/Iodide-Free Dye-Sensitized Solar Cells. Accounts of Chemical Research 2009;42(11) 1827-1838. DOI: 10.1021/Ar900069p.

[156] Park N-G. Organometal Perovskite Light Absorbers Toward a 20\% Efficiency LowCost Solid-State Mesoscopic Solar Cell. Journal of Physical Chemistry Letters 2013;4(15) 2423-2429. DOI: 10.1021/jz400892a.

[157] Burschka J, Pellet N, Moon SJ, Humphry-Baker R, Gao P, Nazeeruddin MK, et al. Sequential deposition as a route to high-performance perovskite-sensitized solar cells. Nature 2013;499(7458) 316-+. DOI: 10.1038/Nature12340.

[158] Bisquert J. The Swift Surge of Perovskite Photovoltaics. Journal of Physical Chemistry Letters 2013;4(15) 2597-2598. DOI: 10.1021/jz401435d.

[159] Krüger J, Plass R, Cevey L, Piccirelli M, Grätzel M, Bach U. High efficiency solid-state photovoltaic device due to inhibition of interface charge recombination. Applied Physics Letters 2001;79(13) 2085-2087. DOI: http://dx.doi.org/10.1063/1.1406148.

[160] Krüger J, Plass R, Grätzel M, Matthieu H-J. Improvement of the photovoltaic performance of solid-state dye-sensitized device by silver complexation of the sensitizer cis-bis(4,4'-dicarboxy-2,2'bipyridine)-bis(isothiocyanato) ruthenium(II). Applied Physics Letters 2002;81(2) 367-369. DOI: http://dx.doi.org/10.1063/1.1490394.

[161] Ito S, Murakami TN, Comte P, Liska P, Grätzel C, Nazeeruddin MK, et al. Fabrication of thin film dye sensitized solar cells with solar to electric power conversion efficiency over 10\%. Thin Solid Films 2008;516(14) 4613-4619. DOI: 10.1016/j.tsf.2007.05.090.

[162] Patrocinio AOT, El-Bacha AS, Paniago EB, Paniago RM, Murakami Iha NY. Influence of the Sol-Gel pH Process and Compact Film on the Efficiency of $\mathrm{TiO}_{2}$-Based Dye- 
Sensitized Solar Cells. International Journal of Photoenergy 2012;638 5711-5717. DOI: $10.1155 / 2012 / 638571$.

[163] Patrocinio AOT, Paterno LG, Murakami Iha NY. Role of Polyelectrolyte for Layer-byLayer Compact $\mathrm{TiO}_{2}$ Films in Efficiency Enhanced Dye-Sensitized Solar Cells. Journal of Physical Chemistry C 2010;114(41) 17954-17959. DOI: 10.1021/jp104751g.

[164] Patrocinio AOT, Paterno LG, Murakami Iha NY. Layer-by-layer $\mathrm{TiO}_{2}$ films as efficient blocking layers in dye-sensitized solar cells. Journal of Photochemistry and Photobiology a-Chemistry 2009;20 523-527. DOI: 10.1016/j.jphotochem.2009.04.008.

[165] Paula LF, Amaral RC, Murakami Iha NY, Paniago RM, Machado AEH, Patrocinio AOT. New layer-by-layer $\mathrm{Nb}_{2} \mathrm{O}_{5}-\mathrm{TiO}_{2}$ film as an effective underlayer in dye-sensitised solar cells. Rsc Advances 2014;4(20) 10310-10316. DOI: 10.1039/C4RA00058G. 
Chapter 6

\title{
Instrumentation and Measurement of Ground-Level Ultraviolet Irradiance and Spectral Composition in Estonia
}

\author{
Kalju Eerme, Margit Aun and Uno Veismann \\ Additional information is available at the end of the chapter \\ http://dx.doi.org/10.5772/59615
}

\section{Introduction}

Solar radiation sustains and affects all forms of life on Earth and is relevant to a variety of technological applications. The effects of solar radiation depend strongly on its spectral composition in which the influence of ultraviolet radiation (UVR) is the largest. Natural factors like geographical latitude, Earth-Sun distance, and solar zenith angle (SZA) strongly influence the UVB (wavelengths 280-315 nm) irradiance and to a somewhat lesser extent the UVA $(315-400 \mathrm{~nm})$ radiation. The exposure of organisms to UVR is characterized by annual and diurnal cycles of solar irradiance's availability and by the variance (anomalies) of biologicallyweighted irradiances within seasons.

Variations and trends in the availability and spectral composition of UVR are having various effects on atmospheric chemistry, plant health, litter decomposition and the carbon cycle, as well as on human health [1-10]. The effects of UV are mostly cumulative and depend on the spectral composition of received radiation energy. UVR is a globally important abiotic factor influencing ecosystem structure and functions in multiple ways [11]. The most influential UVB part of incident solar radiation is capable of breaking connections between atoms in organic molecules and exerts destructive effects on different materials. The net effect of UV radiation at the cellular level is a balance of damage and repair cellular key structures like DNA [5]. UVB radiation causes many biological and chemical processes, which are generally damaging to living organisms.

The impact of UVB radiation on vegetation changes with species and crops [6]. The effects of $\mathrm{UVB}$ radiation must be considered together with other climatic factors such as an increase in temperature and $\mathrm{CO}_{2}$ levels, which can modify the response to UVB radiation. Irradiation at 
wavelengths below $300 \mathrm{~nm}$ is extremely harmful to DNA. The ratio of irradiances in the UVB and UVA spectral ranges is one of the key factors for estimating its possible harmful influence.

Many important consequences can arise from the indirect effects of high UVB radiation through changes in the chemical composition and shape of the plants, or through changes in the abiotic environment. These indirect effects can include changes in the sensitivity of plants to being attacked by insects and pathogenic elements. The effects of UV radiation and those of other environmental factors at the ecosystem level are poorly known, as well as are those at molecular and organism levels.

Plants possess a number of defence systems against environmental stress factors in nature. Among such protection mechanisms is the altered synthesis of antioxidant substances as well as other secondary metabolites. Without repairs, the harmful photoproducts ultimately lead to cell death. To avoid this catastrophic effect, all organisms possess DNA repair systems that are able to recognize and remove UV photoproducts. The ultraviolet (UV) index is a standard vehicle for informing the public about the level of UV radiation reaching the Earth's surface and its potential harmful effects on human health. Although the received energy in the UVB band is only a small fraction of the extra-terrestrial solar radiation, it accounts for $80 \%$ of the harmful effects of sun exposure.

In most applications of the UVR data quantification of the received spectral doses a understanding of the mechanisms of influence on the cell, organism and ecosystem levels are needed. The variations of total incoming solar radiation as well as spectral composition, especially in the UVB range, beside geographical factors depend strongly on atmospheric factors, such as clouds, total ozone, aerosols and precipitable water vapour. Spectral energy is necessary to estimate over days, parts of days and over longer time intervals.

Despite there being different broadband and narrowband UV sensors in use, spectral UV measurements are still considered the irreplaceable, ultimate reference in a variety of applications. Spectral measurements allow the data to be applied to any biological process or chemical photoreaction with a known action spectrum. Weather conditions prescribing the availability and spectral composition of ground-reaching UV irradiance in key phenological phases of ecosystem development manifest significant year-to-year and longer-term periodic changes. These changes are reflected in ecosystem health and productivity. For sustainable agriculture and environmental management both the changes in quality of received irradiance and in ecosystem responses need to be investigated on a quantitative level. The present study financed by a programme of research and development of environmental technology is one of those attempts.

In the present chapter, the major features of systematic changes and the variability in groundlevel UVR at subpolar latitude are considered. The work is based on ground-level UVR spectra recorded at a research institute, Tartu Observatory, $\left(58^{\circ} .16^{\prime} \mathrm{N}, 26^{\circ} .28^{\prime} \mathrm{E}, 70 \mathrm{~m}\right.$ a.s.l.) since 2004 together with the auxiliary information on broadband solar radiation and weather conditions recorded by the Tartu-Tõravere meteorological station of the Estonian Environmental Agency at the same site. The homogeneous datasets of the broadband solar radiation and weather conditions for the site extend back to the beginning of 1955 [12-17]. The total number of 
broadband solar radiation and weather characterizing factors increased in the 1990s and 2000s. During the period of recording UV spectra the spectral dataset was well supplied with the necessary auxiliary information.

\section{Data and methods}

\subsection{Solar radiation research in Estonia}

Attempts at quantitative measurements of solar radiation have been made in Tartu since 1904 and increased in the 1930s after acquiring a modern Ångström pyrheliometer to quite a high level [18]. The instrument was lost during World War II, and new efforts initiated by Juhan Ross began in the early 1950s. The results of regular studies have been published in several publications and in monographs. General climatic features of the broadband solar radiation in Estonia are presented in the Handbook of Estonian Solar Radiation Climate [19].

Major results on interannual and intraseasonal variations of broadband solar radiation in Estonia are presented as a chapter in the previous edition of the InTech book Solar Radiation [15]. The longest and most complete dataset on solar radiation in Estonia [20, 21] has been collected at a typical Estonian rural site at the Tartu-Tõravere Meteorological Station $\left(58^{\circ} .16^{\prime} \mathrm{N}\right.$, $26^{\circ} .28^{\prime} \mathrm{E}, 70 \mathrm{~m}$ a.s.l.). The site, as well as that used before 1965, being located closer to Tartu town can be considered typical for Northern Europe. The landscape pattern around the location consists of arable fields, grassland areas and patches of mostly coniferous forest.

Between 1950 and 1965 the station was a part of the present research institute of Tartu Observatory and since 1965 it was operated by the Estonian Meteorological and Hydrological Institute, recently reorganized to part of the Estonian Environmental Agency as a State Meteorological Service. In 1996 the station was included to the system of Baseline Surface Radiation Network (BSRN) stations. Until 1996 the Yanishevski AT-50 actinometers and Savinov-Yanishevski M-115 pyranometers were used and then replaced by the Eppley Labor. Inc. pyrheliometers and Kipp \& Zonen pyranometers. The absolute accuracy of the ventilated Kipp \& Zonen pyranometers is about $\pm 2 \%$ and that of the pyrheliometers $\pm 1 \%$.

In the past, inter-calibration of sensors was regularly performed in Voeikov Main Geophysical Observatory (St. Petersburg, Russia), whereas it is now done in the World Radiation Center (Davos, Switzerland). Regular meteorological observations were performed at the site, including the hourly visual cloud detection, at all three basic levels. The long-term record of traditional broadband solar radiation and weather conditions helps the understanding of the regular changes and variations of UVR, which is the main objective of the present chapter.

\subsection{UV broadband, narrowband and spectral measurements}

Studies of atmospheric column ozone and UV radiation in Estonia were initiated by the Tartu Observatory in 1993 to consider the possibilities of studying relationships between the UVR and broadband irradiance characteristics. Regular direct sun column ozone measurements have been carried out between 1994-1999 using an especially suited laboratory spectrometer 
SDL-1 supplied with a mirror system and applying the Dobson retrieval algorithm [22, 23]. Since 2003, direct sun column ozone measurements were performed using a MICROTOPS-II instrument. Mostly, the satellite data were used for atmospheric column ozone [23]. Since summer 2002, a sun photometer of the NASA AERONET network measuring column aerosol optical depth (AOD) and precipitable water vapour operates there, and the aerosol studies group of the University of Tartu performs ground-level atmospheric aerosol-size distribution measurements. For the years before 2002 only pyrheliometer-measured broadband AOD data are available.

Solar UV radiation measurements with filter instruments were performed at the TartuTõravere Meteorological Station under scientific supervision by research scientists of Tartu Observatory [19]. The erythemally-weighted sensors UV-SET had been in operation since January 1998 [12-14]. A Kipp \& Zonen narrowband filter instrument CUVB1 with an effective wavelength $306 \pm 0.2 \mathrm{~nm}$ and bandwidth $2 \pm 0.5 \mathrm{~nm}$ operates at Tartu-Tõravere meteorological station since 2002 [16]. Similar UVB instruments were installed at two other meteorological stations Tallinn-Harku (59 $26^{\prime}$ N, 244' E) and Pärnu (58 $23^{\prime}$ N, $24^{\circ} 38^{\prime}$ E). A Kipp \& Zonen broadband UVA sensor as well as a YES broadband UVB sensor was installed at the site in 2005.

Spectral measurements of solar UVR were performed at the same site by Tartu Observatory. Since 2004, UVR spectra in the range 280-400 nm were collected using Avantes Inc. simple array spectrometer AvaSpec-256 with a 15-minute interval [24]. In 2009 these measurements were stopped due to the significant drop of array sensitivity. In 2008, the purchase of a spectrometric system based on the Bentham Instruments Ltd. DMc150F-U double monochromator was realized by funding from the EC REGPOT project EstSpacE. The system was installed in Spring 2009. Spectra in the wavelength range $280-400 \mathrm{~nm}$ are recorded by this instrument, also every 15 minutes.

In both systems the radiation-collecting diffuser is placed on the roof and connected with a quartz fibre to the spectrometer installed in the special weather box in the building. Calibration of optical instruments has been performed at Tartu Observatory for several decades. It was based on the $1000 \mathrm{~W}$ quartz halogen standard lamp FEL calibrated by Oriel traceable to the USA National Institute for Standards and Technology (NIST) [25-27]. Spectrometer AvaSpec-256 needed recalibration after at least two months. The second disadvantage was a relatively high stray light level within this compact instrument and the necessity of the removal of its contribution in the recorded spectra.

A programme for the compensatory calculation of the stray light influence of the array spectrometer AvaSpec-256 was applied. The slit-scattering function of the spectrometer was measured directly using a $450 \mathrm{~W}$ xenon arc source and monochromator at the Metrology Research Institute, Aalto University, Finland. The stray light level of the AvaSpec-256 spectrometer was rather high $(0.1-1 \%)$, but the slit-scattering function is symmetrical and without noticeable artefacts. The uncertainty estimation of the stray light correction is based on the empirical comparison of the simplified algorithm and deconvolution over the set of measured spectra. For the Bentham double monochromator, a calibrator CL 6 belonging to the set of 
spectrometer auxiliary instruments was regularly used for checking the instruments' sensitivity, and the calibrator itself was regularly compared with a certificated FEL lamp.

\subsection{Spectra collection}

The spectral data collection system including software for the AvaSpec-256 spectrometer was designed at the Tartu Observatory. UVR spectra were recorded as separate files but were also grouped automatically on the calendar day level. This allows relatively easy selection of all spectra recorded during each day for further treatment and analysis. One of the main procedures in data treatment is calculating the received energy within different wavelength ranges and time intervals. The ratios of UVA/UVB irradiances were calculated automatically for each spectrum, allowing the ease of obtaining the same ratios in daily or part-day doses. In the case of the Bentham DMc150F-U spectrometer, the producers' software BenWin+ was used for instrument control and data recording.

The measured spectra were recorded in the memory of the control computer as separate files. The name of the file contains information on the time of recording (year, month, date, hour and minute of the beginning of spectrum record). Later the files were transformed to the Excel environment and organized as workbooks for each month and sheets for each day. Around the summer solstice, the amount of informative spectra per day was about 75 and around winter solstice it was about 25 .

The database of spectra was supported by two other databases useful for grouping spectra on the bases of different seasonal and weather conditions. One of them contains all supporting daily data, such as the daily doses of direct, diffuse and global broadband radiation, daily sunshine duration, daily erythemally-weighted and UVB narrowband doses, atmospheric column ozone, AOD, cloud and snow cover data. Direct and global irradiance relative to assumed normal clear conditions for each day are included. Normal clear conditions mean those for a typical column ozone and AOD for that calendar day.

Smoothed annual cycles of daily normal clear daily sums of global and direct irradiance have been composed empirically using the respective data since 1955 and have been used as the reference in the reconstruction of erythemally-weighted daily doses back to 1955 [16]. The other auxiliary database contains hourly sums of broadband direct, diffuse and global irradiance useful for studying relationships between broadband and UV radiation in a day. The hours are accounted from local noon in real solar time to both sides.

The dataset of UV spectral irradiance allows performing of integration of spectral energy by wavelength ranges and time. For example, it allows easy calculation of UVB and UVA spectral energy for different time intervals. Often, there arose a necessity to integrate different action spectra-weighted energies over days, parts of days and over longer intervals like weeks or months. Those products are useful in making comparison of received spectral energy in various conditions. One possible application is a study of relationships between UV doses in different wavelength ranges and the hourly sums of the pyranometer-measured broadband irradiance. 


\section{Main features of annual and daily regular changes in UV irradiance in cloudless conditions}

Environmental effects of UV irradiance at any site depend strongly on the availability of direct sunshine and on solar elevation during the sunshine episodes. Solar elevation modulates the UV irradiance and its spectral composition in the absence of sunshine. Solar elevation changes regularly from sunrise to sunset, reaching the highest value at noon in real solar time. Noon solar elevation manifests a regular annual cycle, being the smallest at winter solstice and the largest at summer solstice. Usually SZA is used instead of solar elevation for characterization of solar position on the celestial sphere. At the Tartu Observatory site the extreme values of noon SZA are $81.7^{\circ}$ (solar elevation $8.3^{\circ}$ ) and $34.8^{\circ}$ (solar elevation $55.2^{\circ}$ ), respectively. The most influential part of the UVR ground-level spectrum is the UVB range.

In the days around summer solstice, the threshold of the Bentham double monochromator's sensitivity is $294 \mathrm{~nm}$ at noon in sunshine conditions. In early mornings and late evenings, the threshold of sensitivity drops to approximately $310 \mathrm{~nm}$. In cloudy weather, the irradiance levels may be somewhat lower and the threshold of sensitivity can be several nanometres larger than in clear conditions. At an SZA above $80^{\circ}$, the accuracy of spectral irradiance measurements is significantly lower than at higher sun conditions and the influence of column ozone and AOD on its spectral composition is less clear. In Figure 1 the diurnal cycles of threshold UVB wavelength and SZA during a nearly clear midsummer day are illustrated.

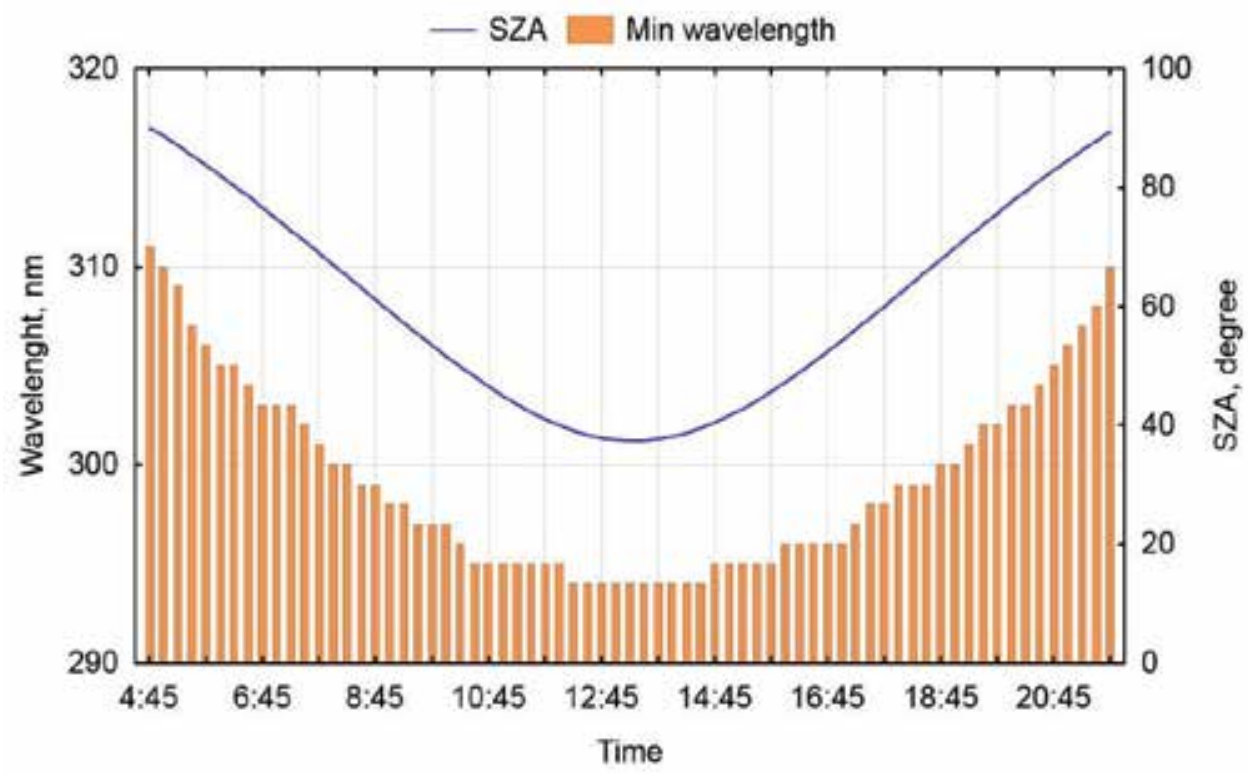

Figure 1. Diurnal cycles of SZA and shortwave threshold for UVB irradiance in midsummer cloudless conditions 
The recorded UVB range in recorded spectrum is much shorter than the UVA range. The width of the first varies during the day from 5 to $20 \mathrm{~nm}$. In the UVA range, it is constant and much larger, $85 \mathrm{~nm}$. Due to the small and varying contribution of the UVB range, the ratio of the received irradiance energy or power also varies across a wide range. To avoid very small numbers, it is better to use the version UVA/UVB for presenting this ratio instead of UVB/ UVA.

It is commonly known that the spectral composition of the UVB irradiance depends on stratospheric column ozone. At a large SZA the optical path of incoming solar rays is long, and diffuse radiation dominates. In those conditions much of the UVB radiation is absorbed by tropospheric ozone and attenuation reaches longer wavelengths than at high sun conditions. As a result the UVB day is seemingly shorter than the UVA day. In the UVA spectral range the level of irradiance is higher, and radiation is not absorbed by ozone. Beside the atmospheric column ozone another modulating factor of UVR is AOD. Its influence also tends be larger in the UVB range.

In Figure 2 the diurnal cycles of irradiance at some UVB and UVA wavelengths are presented. The selected day, 12 July 2010, was almost clear. Only a very small amount of cumulus (Cu) clouds between 13 and 17 in local time were met. Total ozone was 299 DU and the AOD at the UV wavelength $340 \mathrm{~nm}$ was relatively large, at 0.428 . In cases of good atmospheric transparency it is around 0.1 and its median and trimean values in 2002-2012 have been close to 0.2. The conventional mean is not a relevant characteristic of the AOD due to a strong asymmetry of distribution.
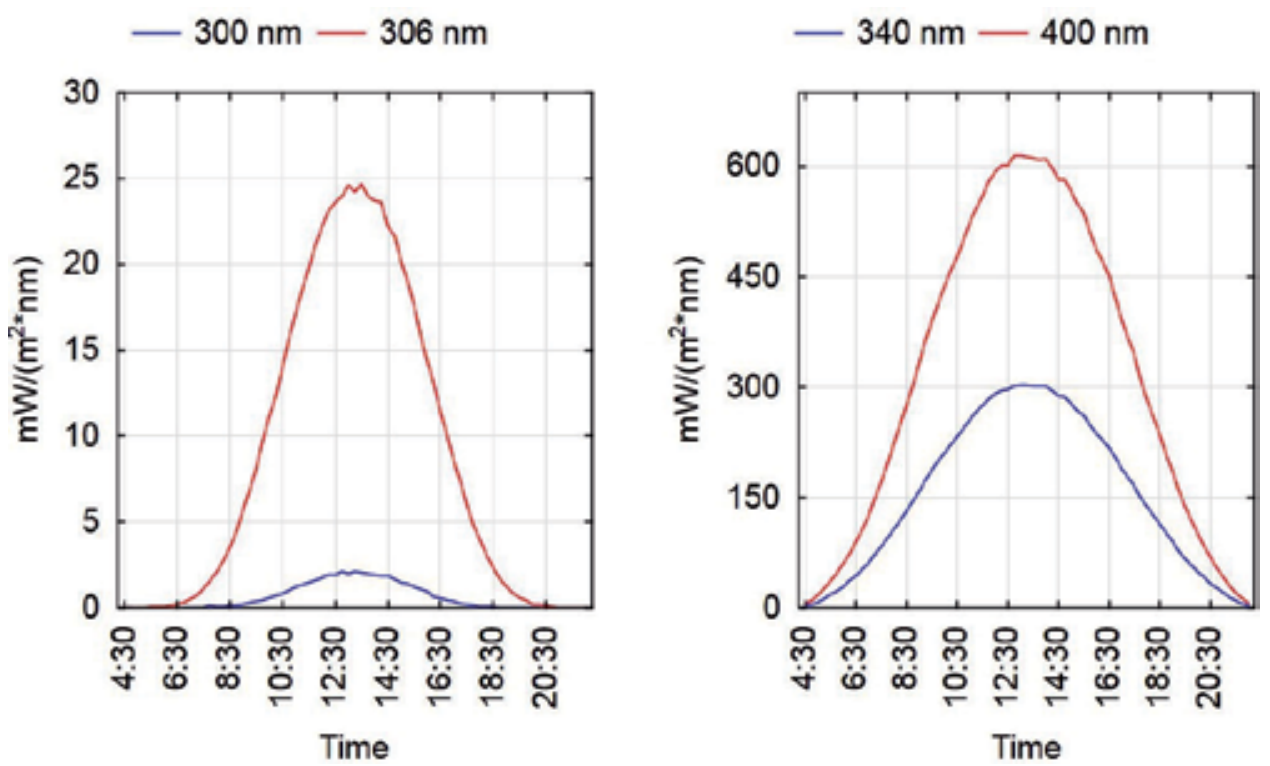

Figure 2. Diurnal cycles of spectral irradiance at selected UVB (left) and UVA (right) wavelengths on an almost clear summer day 12 July 2010 
Finding of relevant data is restricted by the deficit of cloudless days. The ratio UVA/UVB in the received daily spectral energy accumulates from the recorded spectra. The contribution from the spectra recorded at smaller SZA is larger in it. Immediately after sunrise and before sunset the UVB irradiance is strongly suppressed and the value of the UVA/UVB ratio often reaches 500 to 600 at SZA around $87^{\circ}$. At an SZA above that value the UVA/UVB ratio manifests strong instability due to the low reliability of recording UVB irradiance and is not presented in the figures. With the decreasing SZA the relative contribution of UVB irradiance increases.

In Figure 3 the average dependence of UVA/UVB ratio on SZA is presented in almost cloudless weather conditions for the abovementioned full day. In Figure 4 the same is presented for another almost clear day on 13 April when noon SZA reaches only $62^{\circ}$ and column ozone, 376 $\mathrm{DU}$, is close to its normal spring level. The value of AOD at $340 \mathrm{~nm}$ is once again quite large, at 0.493 .

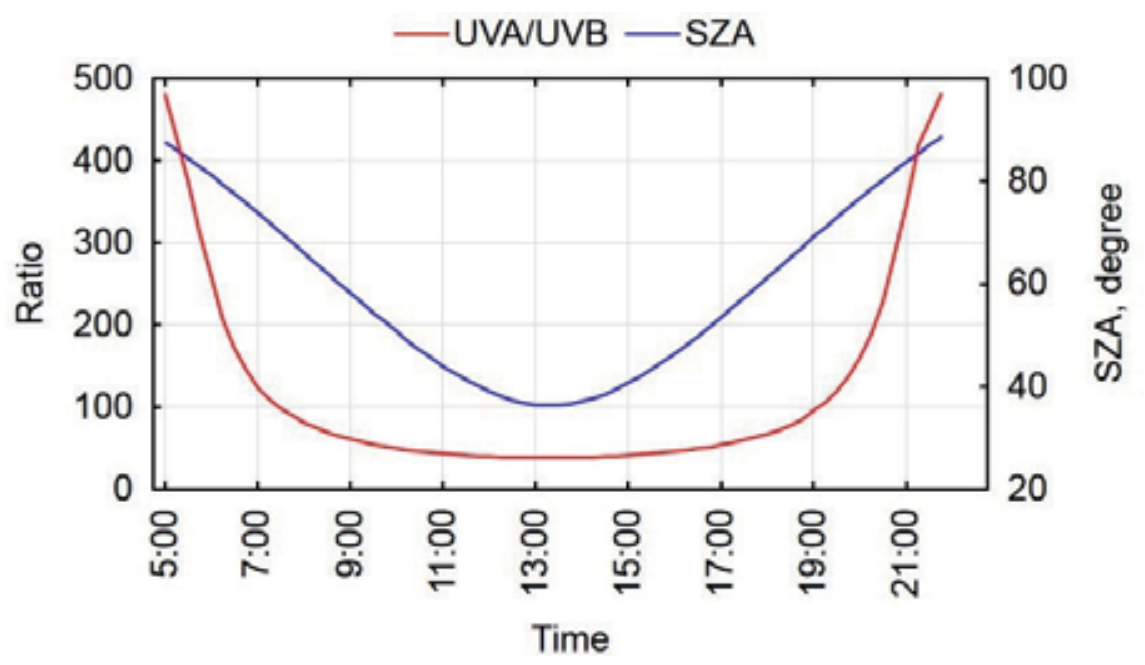

Figure 3. Diurnal cycles of UVA/UVB irradiance ratio in almost clear summer day 12 July 2010

The smallest of UVA/UVB values are met around the daily smallest SZA. Around summer solstice the range of diurnal changes in the UVA/UVB ratio reaches 15 times, but in some cases is only eight to ten times. With the decrease of SZA to $70^{\circ}$ the ratio UVA/UVB drops to about 100 and after reaching SZA $50^{\circ}$ to about 50 . In the Northern European summer conditions most of the UV radiation is received during six hours around noon.

An example of relative contribution from these six hours in the full day dose is presented in Figure 5 at wavelengths 300 to $400 \mathrm{~nm}$ for clear day in July.

One can see that at wavelengths around $300 \mathrm{~nm}$ the contribution from these six hours is 85 to $90 \%$ of the daily total, and decreases with increasing wavelength due to decrease of ozone absorption. Around wavelength $330 \mathrm{~nm}$ the noon six hours contribution reaches a $60 \%$ level and remains at an almost constant level. 


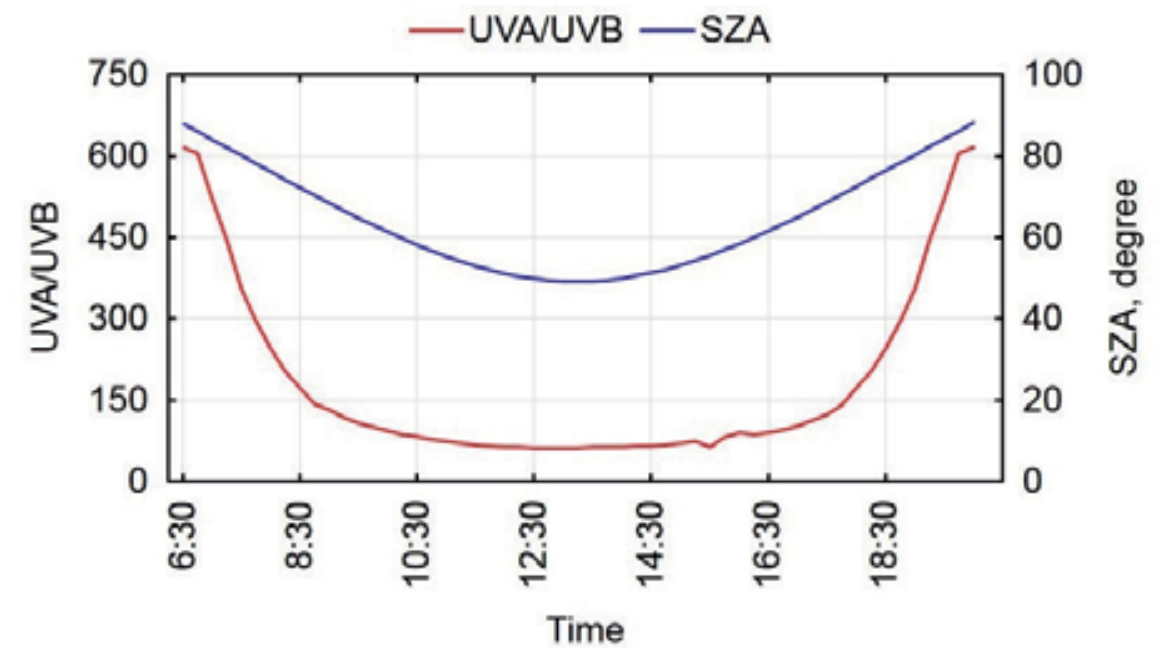

Figure 4. Diurnal cycles of UVA/UVB irradiance ratio in almost clear spring day 13 April 2010

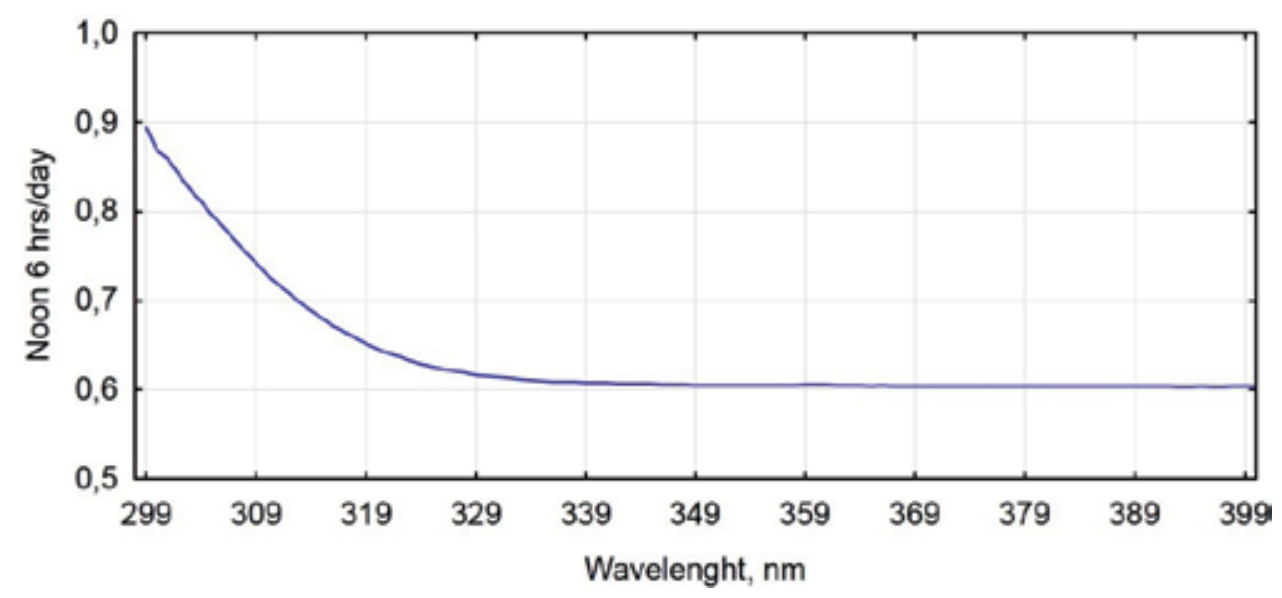

Figure 5. Dependence of the ratio of UV irradiances from six noon hours and full day on wavelength

On cloudy days the ratio manifests variations due to attenuation and enhancement of irradiance by clouds. The contribution from six hours around noon is a useful indicator only from May to August when the outdoor activities of the population take place frequently in sunshine.

During sunshine episodes the ground-level UVR and its spectral composition are modulated by atmospheric column ozone and aerosols. Atmospheric column ozone manifests an annual cycle with the maximum around 390 Dobson Units (DU) in March-April and a minimum of around 270-280 DU in October-November [23]. From the first half of May until the middle of September the column ozone decreases quite linearly and the variations around this linear decrease are mostly moderate, within \pm 20 DU. Larger variations were recorded in spring, from February until the middle of May, and also in October-November. Within that period, 
prolonged episodes reaching a week or even more in length were recorded when column ozone was even more than 50 DU lower of its normal seasonal level.

Aerosol-size distribution is characterized by the fine mode fraction, e.g., how much the submicronic particles contribute to the AOD at $500 \mathrm{~nm}$. Smoke often contributes more than $90 \%$ of small particles' influence in AOD, reducing radiation more strongly at shorter wavelengths [28-31]. Smoke was a major reason for a large AOD in years when there were prolonged dry periods in summer. The major season of forest fires in the region is in July-August and that of landscape burnings in late April to early May.

In most of the years, the dryness and frequency of fire outbreak are moderate. In 2002-2012 the AERONET system recorded AOD values above the threefold and twofold median were met at Tartu-Tõravere meteorological station in about $6 \%$ and $17 \%$, respectively, out of all 1500 days of the AERONET measurement data. The influence of the landscape fire episode in AprilMay 2006 on the UV spectrum is described in [32]. In conditions of seasonal normal ozone between 379 and 391 DU three almost clear days with AOD values at $340 \mathrm{~nm}$ between 0.979 and 1.299 were found.

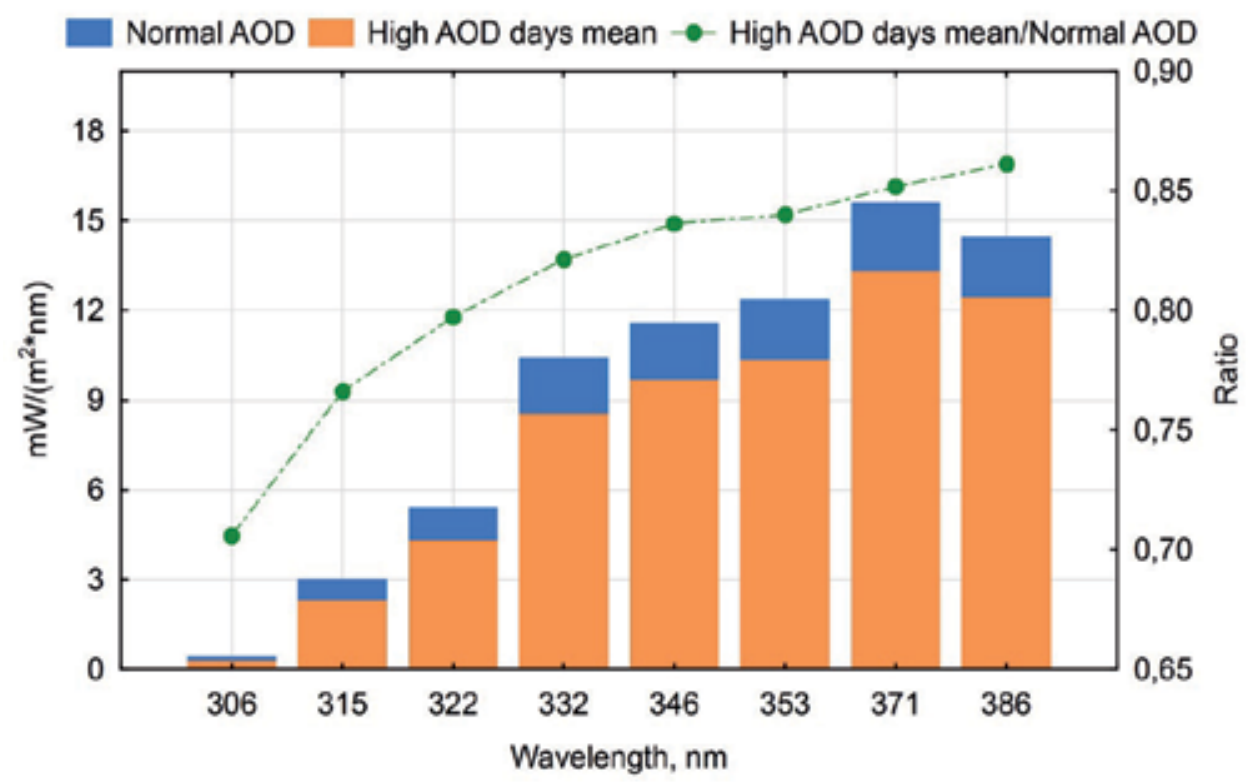

Figure 6. Comparison of mean daily spectral doses for the group of days manifesting smoke induced large AOD and a clear day with almost equal noon SZA, similar column ozone $384 \mathrm{DU}$ and moderate AOD $(0.16$ at $340 \mathrm{~nm})$

The cloud influence is often described by the cloud modification factor (CMF). CMF is defined as a ratio of measured cloudy irradiance to that of normal conditions of clear sky. Here we use a similar aerosol modification factor (AMF) to compare total influence on the UVR. The AMF in daily irradiance totals was found to be 0.84 in UVA and 0.75 in UVB ranges. It is comparable to the CMF of middle-level clouds. The major difference is that the AMF decreases with 
wavelength decrease in the whole UV range while CMF manifests in the UVA range decrease with the increase of wavelength. Comparison of mean spectral daily doses for the mentioned days manifesting smoke-induced large AOD and a clear day with almost equal noon SZA, similar column ozone $384 \mathrm{DU}$ and moderate AOD $(0.16$ at $340 \mathrm{~nm})$ is presented in Figure 6.

\section{Variations of UV irradiance and spectral composition in cloudy conditions}

Clear skies are not common at the study site or in the neighbouring Northern European area. The clear conditions are met most frequently in March. In April to September the number of cloudless days in a month is only one to two on average [33]. Most of the solar radiation energy is received in May to August. In broadband solar radiation the relative contribution of direct sunshine energy is highest on average in May, reaching $45 \%$ to its assumed clear value. By August it steadily decreases to $40.5 \%$ [15].

Similarly a change of the global radiation energy takes place, from $70 \%$ of the assumed clear in May to $66 \%$ in August, on average. The lowest direct irradiance energy relative to the assumed clear, $13 \%$, is received in November when the average global irradiance relative to clear is the lowest, at $20 \%$. In low sun conditions during October to February, the overcast conditions prevail and the received UVR energies are small. The aerosol and total ozone contributions in their variability are much less than those from cloudiness. Overcast skies in the summer half-year are also met less frequently than the partly cloudy days, which are typical for the climatic region of study. Clouds may significantly reduce the ground-level irradiance but also enhance it by reflections from bright clouds. A key question is in what conditions the UVR level is reduced or enhanced [34-37].

The Cloud Modification Factor (CMF) is defined as a ratio of measured cloudy irradiance to that of normal conditions of clear sky. When the Sun is shaded by clouds the irradiance is reduced and CMF is below 1 . When the Sun is not shaded the reflection from clouds near the Sun may enhance the irradiance, and CMF may exceed 1. In Figure 7 an example of both effects is presented in the case of SZA $36^{\circ}$ when fortunately both situations occurred during the same day in conditions of variable $\mathrm{Cu}, \mathrm{Cb}$ and Ac cloudiness.

The data for the cloudless background were taken from spectral dataset of another day. One can see that both enhancement and attenuation increase the relative contribution of UVA radiation in the UVR spectrum. Daily total cloud effect depends much on the cloudiness characteristics during noon hours when the received energy is the largest. In dry summers there are fewer clouds in that time period and less influence on the UVR spectra. In wetter summers, both the attenuation and enhancement are stronger due to the convection of moist air. Total effect depends on the cloud amount and on their vertical extent. Most of the daily variations in UV irradiance in May to August occur during three hours before and after the midday. Statistical relationships between broadband solar irradiance and dose, and those of UVA are stronger than between broadband solar irradiance and UVB radiation. 


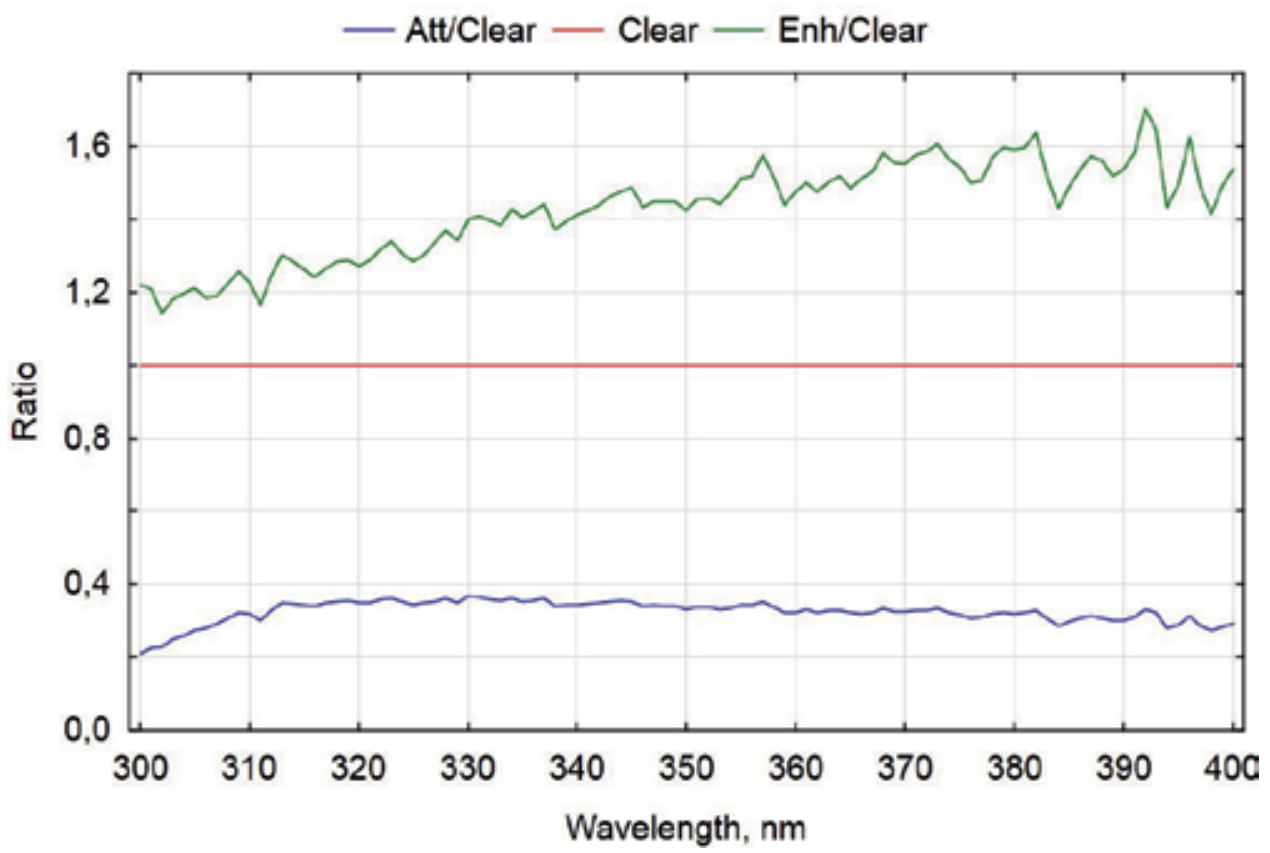

Figure 7. Example of enhancement and attenuation of UV spectral irradiance by clouds at SZA $36^{\circ}$
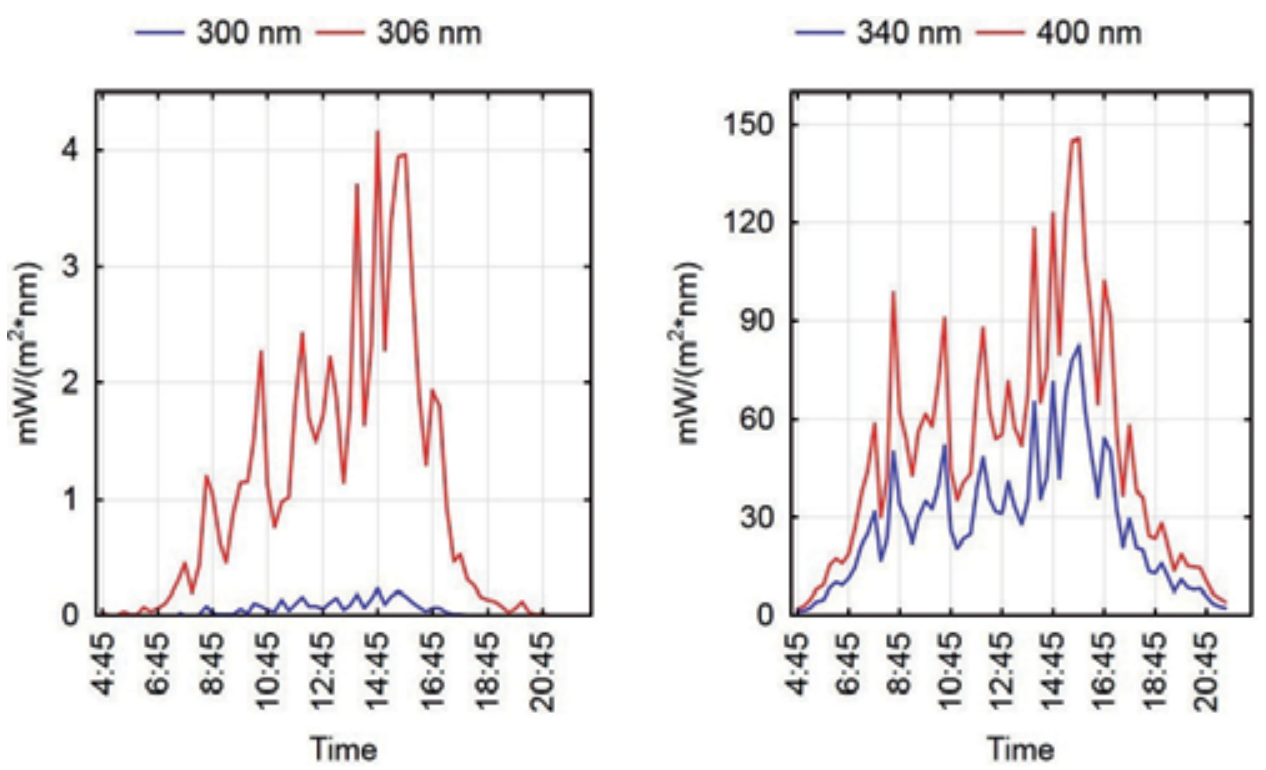

Figure 8. Diurnal cycles of spectral irradiance in overcast by thick Frnb cloudiness at selected UVB (left) and UVA (right) wavelengths, 21 June 2010 
Some examples of variable diurnal cycles of UV irradiance spectral density at selected wavelengths are presented in this section. In our work [38] it was noted that in seemingly uniform overcast conditions the recorded ground-level UV irradiance varies across a wide range.

In Figure 8 diurnal cycles of the UVB irradiance at wavelengths 300 and $306 \mathrm{~nm}$ and of the UVA irradiance at wavelengths 340 and $400 \mathrm{~nm}$ are presented in the case of thick fractusnimbus (Frnb) cloudiness. One can see strong variations over the relatively low irradiance level.

In Figure 9 diurnal cycles at the same wavelengths are presented in conditions of almost no direct sunshine but close to three times more global irradiance. The cloud cover on that day (5 July 2012) consisted of bright and more transparent altocumuli (Ac), stratocumuli (Sc) and cumulonimbus $(\mathrm{Cb})$ clouds.
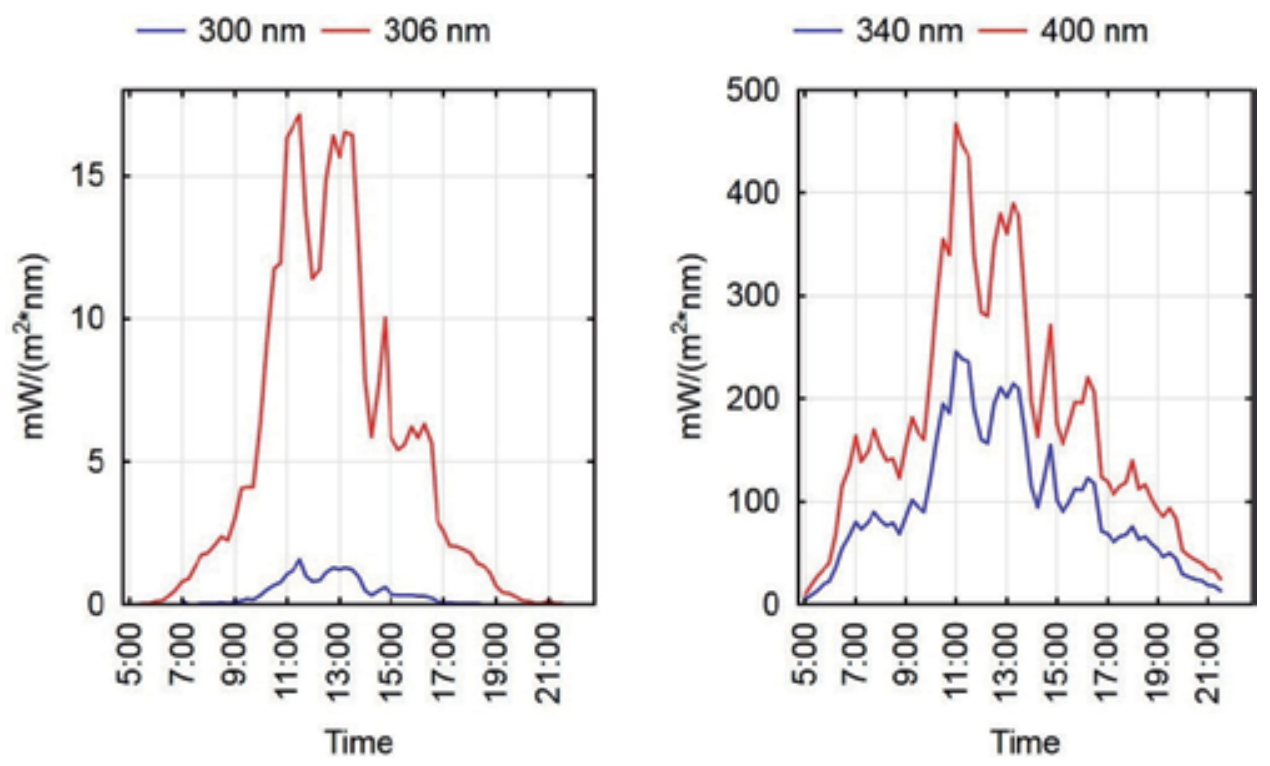

Figure 9. Diurnal cycles of spectral irradiance in overcast by thinner $A c, S c, C b$ cloudiness at selected UVB (left) and UVA (right) wavelengths, 5 July 2012

The UV irradiance levels were significantly larger than in the previous thick cloudiness case. In Figure 10 to Figure 12 the daily cycles of spectral irradiance at the same selected wavelengths were presented in partly cloudy conditions. In Figure 10 the daily broadband direct irradiance relative to clear was 0.29; in Figure 11 it was 0.49 and in Figure 12 the largest 0.82.

The relative global irradiances in these selected days were $0.67,0.75$ and 0.92 , respectively. The selected days were 8 July, 9 July in 2012 and 17 July in 2009. Clouds were typical combinations of cirrus $(C i), C b, C u$, and $A c$ in two first cases. Only two cloud types, $C i$ and $C u$, were met in the third case. 

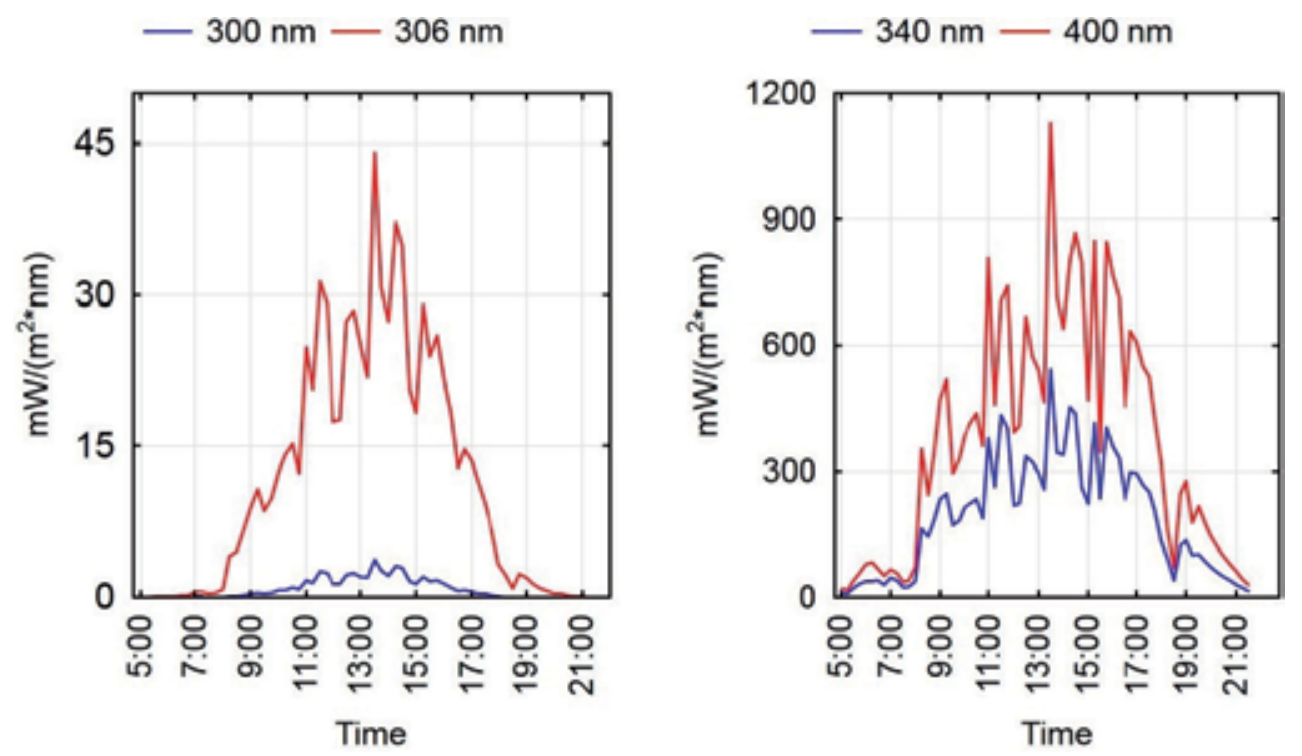

Figure 10. Diurnal cycles of spectral irradiance at selected UVB (left) and UVA (right) wavelengths at relatively large amounts of partial cloudiness, 8 July 2012

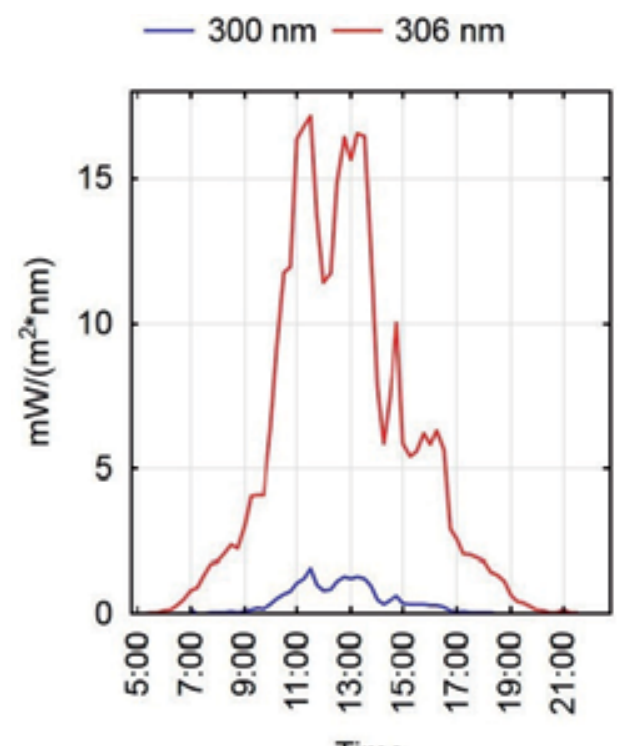

Time

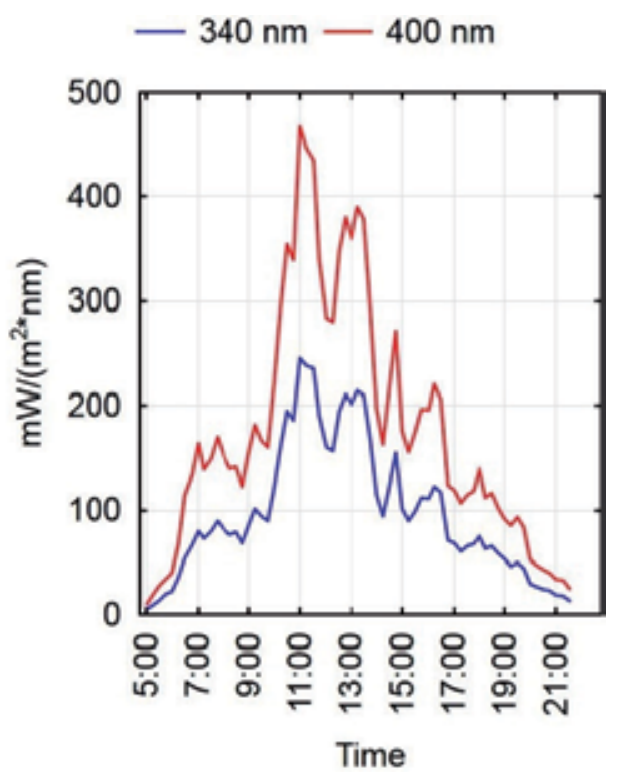

Figure 11. Diurnal cycles of spectral irradiance at selected UVB (left) and UVA (right) wavelengths at mean amounts of partial cloudiness, 9 July 2012

All of these cases might be considered as typical good weather cloud situations in summer months. A common feature is that in morning and evening the change of UVR with time is relatively smooth. 

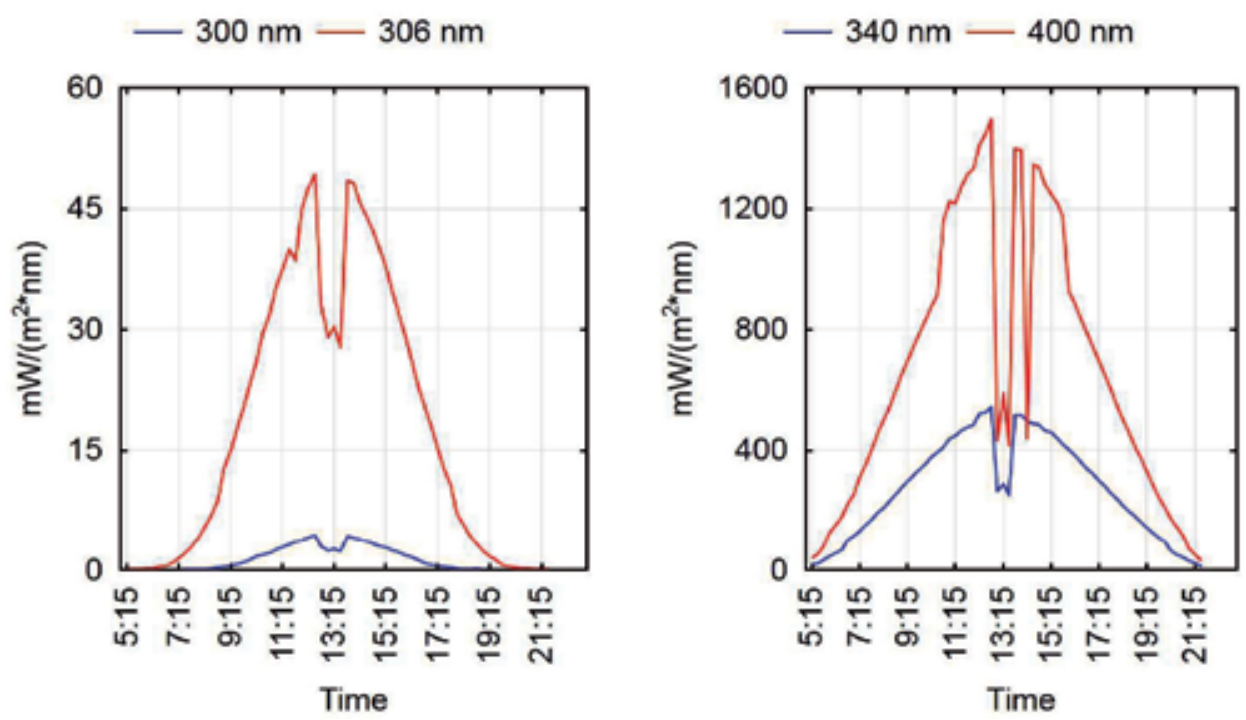

Figure 12. Diurnal cycles of spectral irradiance at selected UVB (left) and UVA (right) wavelengths at small amounts of partial cloudiness, 17 July 2009

Contrasting variations begin after heating the surface to the ability of initiating convection, producing $\mathrm{Cu}$ and $\mathrm{Cb}$ clouds. Locally produced convective clouds are the major factor causing variability in ground-level solar irradiance. There also exists background cloudiness, often consisting of $C i, A c, S c$ clouds and contributing to the variability of ground-level spectral irradiance. Frontal clouds are also frequent in some years, manifesting high cyclonic activity. Then full days or parts of days are overcast. Usually the attenuation of solar radiation in those conditions is larger [39]. Generally, the attenuation by clouds in the UV range is somewhat less than in the whole incoming solar radiation. In the UVA range the attenuation decreases with the decrease in wavelength and is the smallest reaching UVB spectral range where the increasing absorption by tropospheric ozone leads to an increase of attenuation.

\section{Summary and conclusions}

Environmental effects of UV irradiance at any site depend on the received radiation energy and its spectral composition. The availability of the most efficient UVB irradiance depends on the presence of direct sunshine and on solar elevation. Geographical site and time-dependent regular daily cycle of solar elevation reaches its highest value at noon in real solar time. Noon solar elevation manifests a regular annual cycle, being the smallest at winter solstice and the largest at summer solstice. The highest levels of solar irradiance including UVR in clear weather conditions are recorded at noon.

At summer solstice the shortwave threshold at the study site in the UVB range is $294 \mathrm{~nm}$ in normal column ozone and atmospheric transparency conditions. In early morning and late 
evening the shortwave threshold drops to approximately $310 \mathrm{~nm}$. The UVA spectral range of recorded irradiance is always equal to 316 to $400 \mathrm{~nm}$. In the UVB range it is much shorter, and varies during the day from $5 \mathrm{~nm}$ to $20 \mathrm{~nm}$. Due to absorption by tropospheric ozone and partly by aerosols the UVA/UVB ratio of irradiances in the UVA and UVB spectral ranges changes during a year and during a day in wide range.

Immediately after sunrise and before sunset it may reach about 500-600 nm, and decreases to less than 50 in summer noon hours. In cloudless conditions the major modulators of the ground-level UV irradiance are column ozone and spectral aerosol optical depth. Variations in both may result in comparable effects in irradiance levels and spectral composition. The influence of these factors is important to consider in the presence of sunshine. Cloudless UV irradiance may vary more than twice at the same SZA in the UVB spectral range. In most of the UVA range the influence of column ozone is negligible and variations in irradiance result from AOD variations. At solar elevations below $10^{\circ}$ (SZA above $80^{\circ}$ ) the accuracy of spectral irradiance measurements is lower than at higher sun conditions and the spectral influence of column ozone and AOD is less clear.

The regular annual cycle of the atmospheric column ozone with the maximum (380-390 DU) in March-April and minimum (270-280 DU) in October-November is a reason for the differences in UVB irradiance levels in spring and autumn. These differences become obvious during sunshine episodes, which tend to be less frequent in autumn and in some years are extended in spring. On the contrary, in spring episodes when column ozone drops to close to usual levels, autumnal ones are met.

Snow conditions at the study site contributing significantly to the surface albedo have been variable in recent decades. In spring in some years snow persists until the middle of April (noon SZA around $48^{\circ}$ ) but in other years the presence of snow remains episodic during the whole winter. In autumn there have been separate years when snow cover appeared for some time in October (noon SZA around $69^{\circ}$ ). In other cases there had been almost no snow by January. Albedo of snow is high, sometimes close to 0.90 , for fresh snow and much smaller for wet and dirty snow. Reflection from the fresh clean snow increases the recorded irradiance significantly. In autumnal period the irradiance level is low before reflecting from surface and its UVB part very small. Since the beginning of November, snow does not increase vitamin D synthesizing irradiance to necessary level. Without snow the surface albedo is only a few percent.

A major contributor to variations of both UVB and UVA irradiance in Northern Europe and Estonia is cloudiness. In cloudy weather the irradiance levels tend to be somewhat lower and the threshold of sensitivity several nanometres larger than in cloudless conditions. Cloud influence on the UVR spectra is related to attenuation and enhancement of irradiance.

Attenuation of solar irradiance happens when the Sun is shaded by cloud. When the Sun shines and bright clouds are close to the visible solar disk, reflection and scattering by these clouds often leads to larger irradiances than in cloudless conditions. A cloudy sky background is a significant irradiance modulating factor. Daily total cloud effect depends much on the cloudiness characteristics during noon hours when the received energy is the largest. In dry 
summers there are less clouds in that time period and less influence on the UVR spectra. In wetter summers, both the attenuation and enhancement are stronger due to the convection of moist air.

The largest daily doses of UVR spectral density are recorded in the presence of medium cloud amounts. At small cloud amounts, clouds are less frequently located close to the Sun. At large cloud amounts shading of the Sun by clouds and attenuation of irradiance dominates. In moderate cloud amounts sunshine episodes are relatively frequent and related to the enhancement of irradiance. Both enhancement and attenuation increase the relative contribution of UVA radiation in the UVR spectrum. Daily total cloud effect depends much on the cloudiness characteristics during noon hours when the received energy is the largest. Total effect depends on the cloud amount and on their vertical extent. Deep convective clouds attenuate the UVB range of incoming irradiance significantly more than shallow stratiformed clouds. The CMF of stratiform clouds like $S c$ does not necessarily decrease with decreasing wavelength, as is commonly considered for cloudy atmospheres.

\section{Acknowledgements}

This work has been supported by the project 3.2.0801.11-0041 'Estonian radiation climate' funded by the European Regional Development Fund. In previous years the work has been supported by several ETF grants. The authors thank the AERONET team and Weather Service of the Estonian Environment Agency for the data collected at the Tartu-Tõravere meteorological station.

\section{Author details}

Kalju Eerme*, Margit Aun* and Uno Veismann

*Address all correspondence to: kalju.eerme@to.ee

Tartu Observatory, Tõravere, Estonia

\section{References}

[1] Caldwell M M, Bormann J F, Ballare C L, Flint S D, and Kulandaveilu G. Terrestrial ecosystems, increased ultraviolet radiation, and interactions with other climate change factors. Photochemical \& Photobiological Sciences 2007; 6 252-266. 
[2] den Outer P N, Slaper H, and Tax R B. UV radiation in the Netherlands: Assessing long-term variability and trends in relation to ozone and clouds. Journal of Geophysical Research 2005; 110 D02203, doi:10.1029/2004JD004824.

[3] Häder D-P, Kumar H D, Smith R C, and Worrest R C. Effects of solar UV radiation on aquatic ecosystems and interactions with climate change. Photochemical and Photobiological Sciences 2007; 6 267-285.

[4] Boa H, Xinghua Z, and Yuesi W. Variability in UVB radiation in Beijing, China. Photochemistry and Photobiology 2013; 89 745-750.

[5] Jackson S P and Bartek J. The DNA-damage response in human biology and disease. Nature 2009; 461(7267) 1071-1078.

[6] Kakani V G, Reddy K R, Zhao D, and Sailaja K. Field crop responses to ultraviolet-B radiation: A review. Agricultural and Forest Meteorology 2003; 120 191-218.

[7] Martinez-Lozano J A, Utrillas M P, Nunez J A, Esteve A R, Gomez-Amo J L, Estelles $\mathrm{V}$ and Pedros R. Measurement and analysis of broadband UVB solar radiation in Spain. Photochemistry and Photobiology 2012; 88 1489-1496.

[8] Meleti, C, Bais A F, Kazadzis S, Kouremeti N, Garane K, Zerefos C. Factors affecting solar ultraviolet irradiance measured since 1990 at Thessaloniki, Greece. International Journal of Remote Sensing 2009; 30(15-16) 4167-4179.

[9] Sabburg J M, Parisi A V, and Kimlin M G. Enhanced spectral UV irradiance: a 1 year preliminary study. Atmospheric Research 2003; 66(4) 261-272

[10] Sandmann H, and Stick C. Spectral and spatial UV sky radiance measurements at a seaside resort under clear sky and slightly overcast conditions. Photochemistry and Photobiology 2014; 90 225-232.

[11] Lindfors A, Heikkilä A, Kaurola J, Koskela T, Lakkala K. Reconstruction of solar spectral surface UV irradiance using radiative transfer simulations. Photochemistry and Photobiology 2009; 85(5) 1233-1239.

[12] Veismann U, Eerme K, and Koppel R. Solar erythemal ultraviolet radiation in Estonia in 1998. Proceedings of the Estonian Academy of Sciences. Physics. Mathematics 2000; 49 122-132.

[13] Eerme K, Veismann U, and Koppel R. Ultraviolet irradiance in meteorologically contrasting summers of 1998 and 1999 in Estonia. Proceedings of the Estonian Academy of Sciences. Physics. Mathematics 2000; 49 251-265.

[14] Eerme K, Veismann U, and Koppel R. Variations of erythemal ultraviolet radiation and dose at Tartu-Tõravere, Estonia. Climate Research 2002; 22 245-253.

[15] Eerme, K. Interannual and intraseasonal variations of the available solar radiation. Solar radiation. Croatia: InTech; 2012. 
[16] Eerme K, Veismann U, Ansko I, and Lätt S. Year-to-year variations of the vitamin D synthesis related UV-B radiation in Estonia. In: Slusser J R, Schäfer K, Comerón A. Remote Sensing of Clouds and the Atmosphere XI, proceedings of SPIE 6362, 11-14 September 2006, Stockholm, Sweden. Doi:10.1117/12.688976.

[17] Eerme K, Kallis A, Veismann U, and Ansko I. Long-term variations of available solar radiation on seasonal timescales in 1955-2006 at Tartu-Tõravere meteorological station, Estonia. Theoretical and Applied Climatology 2010; 101 371-379.

[18] Kallis A, Russak V, and Ohvril H. 100 years of solar radiation measurements in Estonia. In: World Climate Research Programme. Report of the Eighth Session of the Baseline Surface Radiation Network (BSRN), Workshop and Scientific Review, 26-30 July 2004, Exeter, UK. WCRP Informal Report No. 4/2005, C1.C4

[19] Russak V, and Kallis A. Handbook of Estonian solar radiation climate. Tallinn: EMHI; 2003.

[20] Russak V. Changes in solar radiation in Estonia during the last half-century. In: EMS Annual Meeting Abstracts: proceedings of the Sixth Annual Meeting of the European Meteorological Society. Sixth European Conference on Applied Climatology, 2006, Ljubljana, Slovenia; ISSN 1812-7053.

[21] Russak V. Changes in solar radiation and their influence on temperature trend in Estonia (1955-2007). Journal of Geophysical Research 2009; 114 1-6, doi: 10.1029/2008JD010613.

[22] Eerme K, Veismann U, Koppel R, and Pehk M. First four years of atmospheric total ozone measurements in Estonia. Proceedings of the Estonian Academy of Sciences, Biology and Ecology 1998; 47 188-202.

[23] Eerme K, Veismann U, and Koppel R. Estonian total ozone climatology. Annales Geophysicae 2002; 20 247-255.

[24] Ansko I, Eerme K, Lätt S, Noorma M, and Veismann U. Study of suitability of AvaSpec array spectrometer for solar UV field measurements. Atmospheric Chemistry and Physics 2008; 8 3247-3253.

[25] Veismann U, Graf R, Kolk R, Kattai K, Märtin L, Tõnnisson T. The determination of the main characteristics of the spaceborne teleradiometer 'Faza'. In: Remote sensing of the atmosphere from space station 'Salyut 7' - 'Cosmos 1686' - 'Soyuz T4'(in Russian). Tartu: Academy of Sciences of the Estonian SSR, Institute of Astrophysics and Atmospheric Physics; 1989. p67-90.

[26] Tõnnisson T, Graf R, and Märtin L. The test facility 'Spectrum' for radiometric calibration of spaceborne radiometers in the spectral region 0.3-2.5 $\mu \mathrm{m}$. The determination of the main characteristics of the spaceborne teleradiometer 'Faza'. In: Remote sensing of the atmosphere from space station 'Salyut 7' - 'Cosmos 1686' - 'Soyuz T4' 
(in Russian). Tartu: Academy of Sciences of the Estonian SSR, Institute of Astrophysics and Atmospheric Physics; 1989. p54 -66.

[27] Veismann U, Pehk M, Kübarsepp T. Standards for radiometric calibrations of electrooptical devices in Estonia, In: Baltic Electronic Conference: Proceedings of the $4^{\text {th }} \mathrm{Bi}^{-}$ ennial Conference, 9-14 October, Tallinn, Estonia. Tallinn; 1994 p187-194.

[28] Barnaba F, Angelini F, Curci G, and Gobbi G P. An important fingerprint of wildfires on the European aerosol load. Atmospheric Chemistry and Physics 2011; 11 10487-10501.

[29] Krzyscin J W, Eerme K, and Janouch M. Long-term variations of the UV-B radiation over Central Europe as derived from the reconstructed UV time series, Annales Geophysicae 2004; 22(5) 1473-1485, doi:10.5194/angeo-22-1473-2004.

[30] Witte J C, Douglass A R, da Silva A, Torres O, Levy R, and Duncan B N. NASA ATrain and Terra observations of the 2010 Russian wildfires. Atmospheric Chemistry and Physics 2011; 11 9287-9301.

[31] Jaroslavski J P and Krzyścin J W. Importance of aerosol variations for surface UV-B level. Analysis of ground based data taken at Belsk, Poland, 1992-2004. Journal of Geophysical Research 2005; 110 D16201, doi: 10.1029/2005JD005951.

[32] Aun M, Eerme K, Ansko I, Veismann U, Lätt S. Modification of spectral ultraviolet doses by different types of overcast cloudiness and atmospheric aerosol. Photochemistry and Photobiology 2011; 87 461-469.

[33] Schwander H, Koepke P, Kaifel A, and Seckmeyer G. Modification of spectral UV irradiance by clouds. Journal of Geophysical Research 2002; 107(D16) AAC 7-1-AAC 7-12, doi:10.1029/2001JD001297.

[34] Seckmeyer G, Glandorf M, Wickers C, McKenzie R, Henriques D, Carvalho F, Webb A, Siani A M, Bais A, Kjeldstad B, Brogniez C, Werle P, Koskela T, Lakkala K, Gröbner J, Slaper H, den Outer P, and Feister U. Europe's darker atmospheres in the UVB. Photochemical and Photobiological Sciences 2008; 7 925-930.

[35] Staiger H, den Outer P N, Bais A F, Feister U, Johnsen B, and Vuilleumier L. Hourly resolved cloud modification factors in the ultraviolet. Atmospheric Chemistry and Physics 2008; 8 2493-2508.

[36] Thiel S, Ammannato L, Bais A, Bandy B, Blumthaler M, Bohn B, Engelsen O, Gobbi G P, Gröbner J, Jäkel E, Junkermann W, Kazadzis S, Kift R, Kjeldstad B, Kouremeti N, Kylling A, Mayer B, Monks P S, Reeves C E, Shallhart B, Scheirer R, Schmidt S, Schmitt R, Schreder J, Silbernagl R, Topaloglou C, Thorseth T M, Webb A R, Wendisch $\mathrm{M}$, and Werle P. Influence of clouds on the spectral actinic flux density in the lower troposphere (INSPECTRO): Overview of field campaigns. Atmospheric Chemistry and Physics 2008; 8 1789-1812. 
[37] Mayer B, Kylling A, Madronich S, and Seckmeyer G. Enhanced absorption of UV radiation due to multiple scattering in clouds: Experimental evidence and theoretical explanation. Journal of Geophysical Research 1998; 103(D3) 31241-31254.

[38] Eerme K, and Aun M. A review of the variations of optical remote sensing conditions over Estonia in 1958-2011. International Journal of Remote Sensing Applications 2012; 2(3) 12-19.

[39] Josefsson W, and Landelius T. Effect of clouds on UV radiance: As estimated from cloud amount, cloud type, precipitation, global radiation and sunshine duration. Journal of Geophysical Research 2000; 105 4927-4935. 



\section{Section 3}

\section{Solar Applications in Architecture}



Chapter 7

\title{
Development of Novel Building-Integrated Photovoltaic (BIPV) System in Building Architectural Envelope
}

\author{
Wen-Sheng Ou \\ Additional information is available at the end of the chapter \\ http://dx.doi.org/10.5772/60574
}

\section{Introduction}

The saving and usage of green energy have been an emphasized research topic in various nations including Taiwan: an island nation located in a subtropical zone with $90 \%$ of the population living in regions with mean sea-level elevations of $400 \mathrm{~m}$ or lower. Limitations of some geological factors and climatic conditions cause a large population to be crowded in buildings that are concentrated in metropolitan areas.

Hence, large buildings cover by a glass shell which must rely heavily on artificial central air conditioning systems to resist outside heat loadings had become popular. Such a building takes a heavy toll on energy consumption. These buildings experience the problems of poor indoor air circulation, an inefficient cooling system in maintaining a comfortable indoor environment, as well as excessive energy consumption. Ninety-eight percent the energy consumed in Taiwan is imported.

Recent worldwide concerns on global warming and emphases on environmental protection have made it urgently necessary to develop sustainable energy sources for replacing conventional petroleum energy. Solar energy [1-4] is renewable, inexhaustible and abundant. The Earth receives an incredible supply of solar energy. It provides enough energy in one minute to supply the world's energy needs for one year [5]. Hence how to effectively use solar energy is becoming an active research topic in various nations today.

Solar energy can be utilized as either heat or light, with the majority of the research and application focusing on photoelectrical conversion of light into electricity. Using solar cells made of special materials of semi-conductance, the incident solar beam can be directly converted into electricity. The efficiency of electricity generation depends on the clarity of the solar panel. Additionally, storage of the electricity generated for later use must be considered. 
In recent years, the booming semi-conductor industry had led to rapid advances in manufacturing and implementing solar energy projects more cost effectively. Hence, solar energy is expected to be an important and a major source of energy in the future.

In Taiwan, central air conditioning systems are used in large buildings that accommodate offices, hotels, department stores and hospitals. These buildings, which are considered as "airconditioned buildings", have fixed office hours, similar occupants and application modes, and hence comparable heat generated from illumination and occupants. Additionally, these buildings adopt a glass shell to shield the structure so that natural lighting is available during daytime for saving electricity.

The expected benefits of using solar panels on buildings include lowering building costs, reducing energy consumption, and providing a more comfortable indoor environment. The greenhouse effectiveness in glass buildings is also applied in cold zones for saving heating energy. Additionally, large glass windows also provide excellent views for occupants to assist in improving their moods and work efficiency. Hence, in recent years, buildings covered in glass panels are becoming popular in the US and some European nations. Influenced by the global trend, the architecture in Taiwan has adopted this type of buildings. However, when irradiated under direct sunlight, this type of building is considered to be badly insulated, so that a huge quantity of energy is needed to provide adequate air conditioning for resisting the outdoor heat loadings.

More intensive solar radiation causes either higher indoor temperatures, heavier loading on the air-conditioning unit, or higher consumption of electric energy. If solar energy is available, more intensive solar rationing means that more electricity can be generated. Hence, if the building is covered with solar panels instead of glass windows, the incoming solar radiation can be intercepted for generating electricity that will provide building cooling in addition to reducing the indoor air temperature caused by direct sunshine. The excess electricity can be sold back to the power company to offset the peak loading period. Hence, in this research, the energy audit for the buildings covered with glass panels and cooled with central air conditioners will be carried out for developing three types of "integrated solar panel" systems.

In this research, the results of analysing indigenous climates and examining building materials are used to propose the replacement of conventional glass plate by solar photoelectric panels to be an integrated part of the building shell proposed as the BIPV (Building-Integrated Photovoltaic) system in building architecture. Results of laboratory studies proved that in addition to providing electrical energy to the building, the BIPV building shell is also effective in thermally shielding and isolating the building.

The BIPV system proposed in this research will greatly alleviate the electricity burden during peak hours; its application will promote the development of sustainable energy sources. Comparisons of these solar panels to be used on buildings will be conducted based on their material, angle, temperature, and panel clarity. The results will be used to access the actual cost-effectiveness of installing and using these solar panels on existing buildings. 


\section{Development of integrated sunshading board and Building-Integrated Photovoltaic (BIPV)}

Previous research results published in literature [6-8] shows that if based on the total $\mathrm{CO}_{2}$ emission from a building with 50 -year life cycle, about $80 \%$ of $\mathrm{CO}_{2}$ emission is caused by the air conditioning. The energy saving regulations enforced in Taiwan stipulated that the building shell energy consumption index be used for designing an energy-saving building. In other words, the annual thermal loadings is the thermal loading for providing air conditioning to maintain a healthy and comfortable room; the loading is based on the outdoor thermal environment adjacent to windows, walls, and wall openings.

The thermal flow caused by "difference between outdoor and indoor temperatures" and "solar radiation" is the major factor causing air conditioning energy loadings. Hence, the technology of insulating the building and shading the solar radiation is an important factor for designing the energy-saving features of a building. The effectiveness of solar panels is affected by environmental factors such as solar illumination and temperature, among many others, which affect the voltage and current of the electricity produced, causing unusual movement of Flyback Converters.

A solar panel combined with a shading board is proposed in this research to increase the building shading effect so that the cost-effectiveness of the solar panel can be augmented. A current convertor to convert the produced DC (direct current) into AC (alternate current) and electricity storage to overcome the inherited problem of unstable energy source for solar panels are also integrated into the BIPV building in order to raise the cost-effectiveness of the proposed system.

\subsection{Design of external shading}

Taiwan is located in subtropical region; research results indicate that the major factors affecting the air conditioning energy consumption for buildings in the hot and humid environment are the "percentage of window opening" and "window shielding factor" About $62-85 \%$ of the building's air conditioning energy is affected by these two factors whereas only $10-15 \%$ depends on the orientation of the building in question. Among these factors, the "opening percentage" is the most influential factor; buildings with higher opening percentage will waste more energy on air conditioning.

Regardless of the type of glass used for windows, a 1\% increase of the glass window area will cause the energy consumption to rise by $1.0 \%$. In contrast, the "window shielding factor" will save energy consumed for air conditioning in addition to preventing reflective light to ensure good natural lighting and views. The studies in this research were conducted in South Taiwan. Based on local climatic and geographic conditions, and incident angle of solar radiation, the outside window shielding system will be designed as blinds with 1:4 horizontal to vertical ratio (the horizontal shielding depth is $60 \mathrm{~cm}$ for a $240 \mathrm{~cm}$ French window) to evaluate its thermal insulating efficient. 


\subsection{Solar photoelectrical system}

The integrated system consists of several modules: including the solar electricity-generating module, an integrated parallel connection module to connect to the municipal power system, an emergency power supply module to convert direct and alternate currents, and a battery module to store excess energy produced during the daytime.

\subsubsection{Solar photoelectrical system}

The basic principle of solar electricity generation is to convert solar light with wavelengths between 0.7 to 0.9 micrometer irradiating on a semiconductor. Inside the semiconductor, negatively charged electron and positively charged electron holes will be generated and accumulated at the P-type and N-type layer regions, respectively, thus producing an electromotive difference depending on their unique characteristics. If connected to an external loading, the semiconductor cell produces electricity that can be used for a variety application in the building

2.2.2. Integrated parallel connection to municipal power system and exchanger to provide emergency direct and alternate electric currents

The electricity produced by solar panels and batteries is direct current (DC) whereas the general appliances use alternate current (DC). Hence, the solar generated DC must be converted into $\mathrm{AC}$ with an electric converter so that the electric energy can be widely supplied to household appliances. Additionally, solar electricity generation depends on the solar intensity and angle that the output electrical current and voltage are unstable. If used as an independent electric source, the energy system lacks stability and will not provide a reliable source of energy. Hence, a converter must be used to change the pattern of electricity; in addition to converting the solar generated DC into AC, the solar electricity generation module will be connected to municipal power system to maintain a steady supply of electricity. When the solar energy becomes insufficient, the municipal power system will kick in to provide the needed electricity. If the solar energy is greater than the loading, the excess electricity can be sent back to other consumers through the municipal power system. This arrangement will greatly elevate the stability of solar energy generation system to fully extend it cost-effectiveness.

\subsubsection{Battery module}

When the electric system is operated steadily, changes in the solar electricity generated and the system operation in response to variations of external conditions will be compensated by using the battery module. If the solar system produces more electricity than is needed, the excess electricity will charge the battery model, or it will be sent back to the municipal power system.

When the solar electricity is insufficient (such as at night) to meet the building's demands, the electricity stored in the battery module will supply the needed power before obtaining power from the municipal system. Thus, the battery module will allow the solar system to be flexible 
in response to various conditions. Additionally, when the solar power system malfunctions, or the electrical voltage becomes $10 \%$ higher or $15 \%$ lower than the normal level, the battery can temporarily kick in to make the adjustment so that the solar power system combined with the battery module will depend less on the municipal system to provide steady electricity to meet the loadings.

\subsection{Integrated Photovoltaic (BIPV)}

The integrated photoelectrical solar panels used in this experiment have $30 \mathrm{~kW}$ capacity consisting of $8.58 \mathrm{~kW}, 8.82 \mathrm{~kW}$, and $12.6 \mathrm{~kW}$ panels. Figure 1 shows the system (System I) equipped with multiple crystal silica arrays.

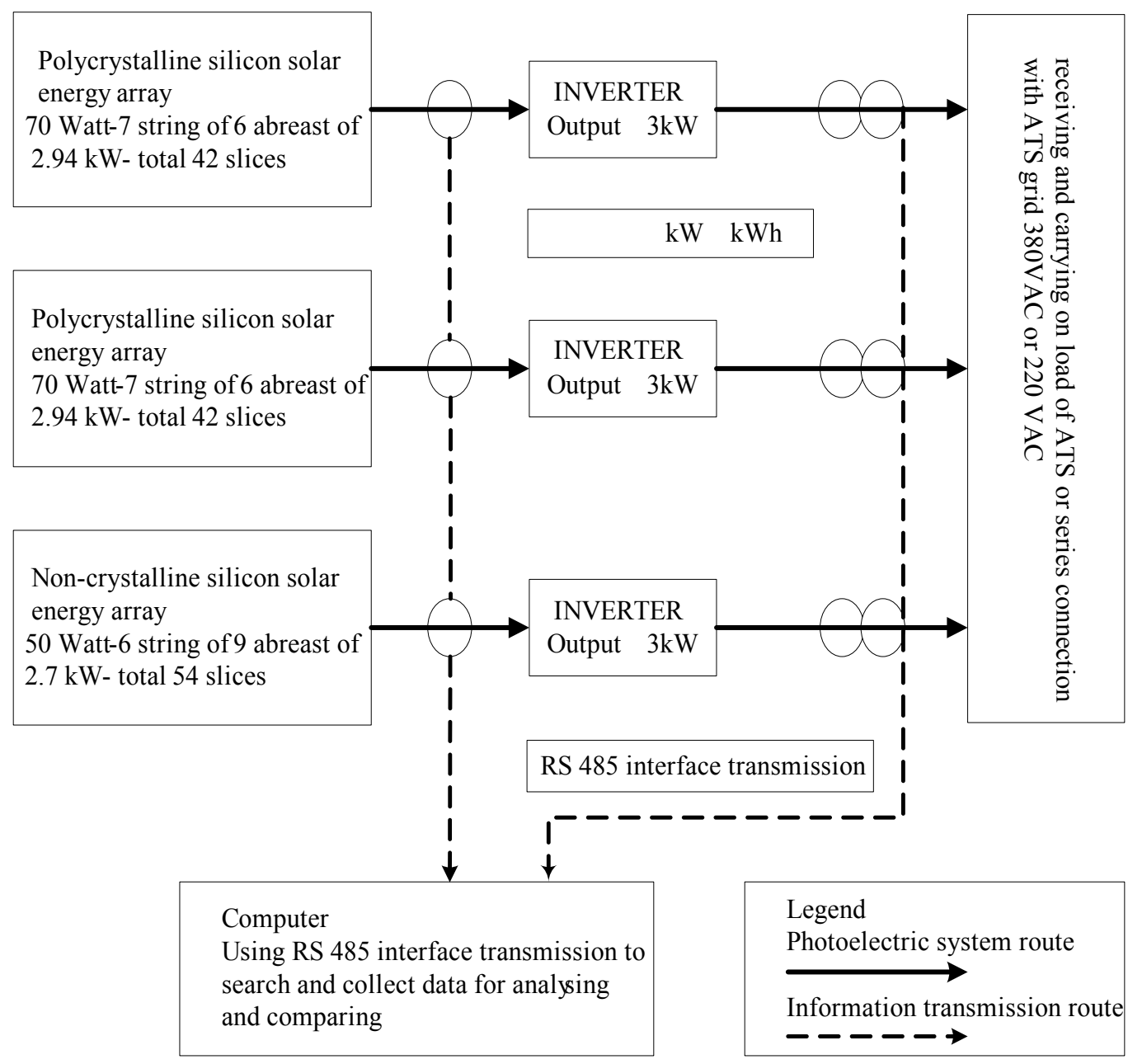

Figure 1. Integrated photoelectrical solar panel System I of $8.58 \mathrm{~kW}$ 
Figure 2 shows the system (System II) equipped with multiple silica and single silica solar energy photoelectrical panels.

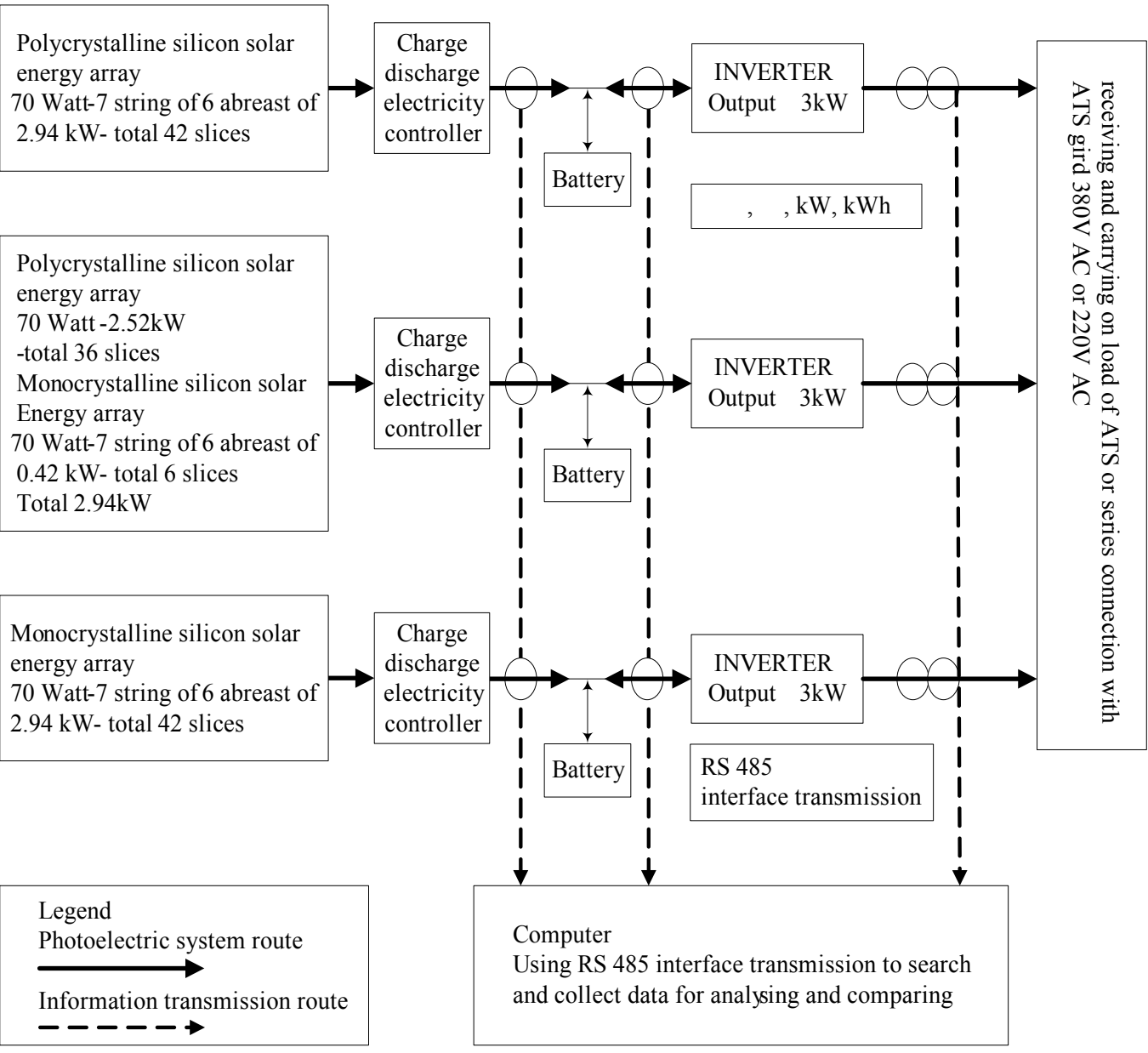

Figure 2. Integrated photoelectrical solar panel System II of $8.82 \mathrm{~kW}$

Figure 3 shows the system (System III) with single silica solar photoelectrical panels only installed.

In each system, the panel faces south, and is $25^{\circ}$ inclined that can be manually adjusted $10^{\circ}$ up and down. These systems were used to investigate the influence of solar panel material, angle of inclination, ambient temperature and panel clarity on the effectiveness of solar energy generation. 


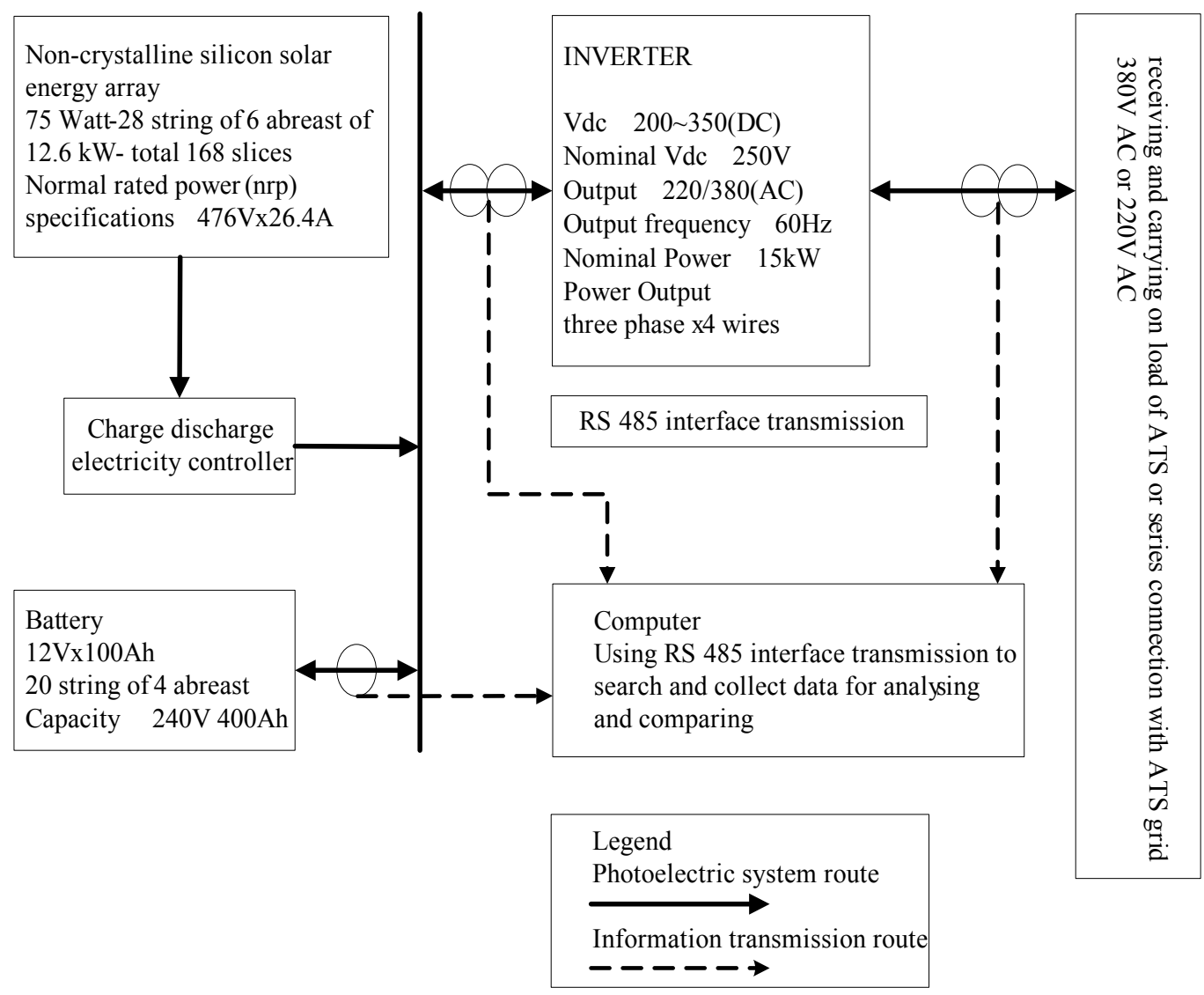

Figure 3. Integrated photoelectrical solar panel System III of $12.6 \mathrm{~kW}$

\section{Installation of experimentalequipment}

The integrated solar energy panel proposed in this research consists of shielding and solar panels. Initially, the experimental room is only equipped with the proposed shielding panels for comparing variations of the room temperature, humidity, and energy consumption of air conditioning before and after installing the shield panels. Solar energy panels are then installed for studying the performance and efficiency of solar photocells made of different materials under various environmental conditions, comparing the effectiveness of solar photoelectrical systems equipped with or without the battery module, analysing the various methods to connect the current converters, studying the influence of solar panel installation angles on the efficiency under direct sunshine or solar radiation.

The experimental site is located in Tainan City, Taiwan; the experimental installations are shown in Figures 4 and 5. The solar panel system is mounted on an existing building in order to evaluate on-site the system's efficiency under natural solar illumination conditions. The evaluation is also carried out using a system facing east, south, and west so that annual performance and efficiency of the solar system proposed in this research can be assessed. 


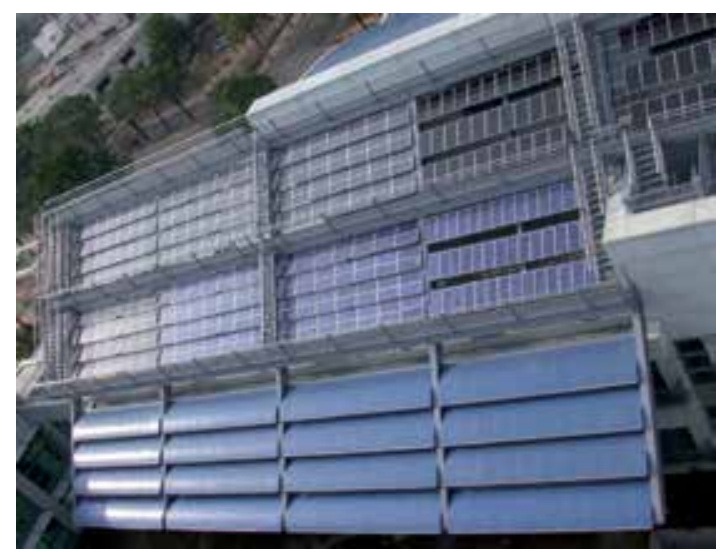

Figure 4. Final Photo of experimental installations in test filed

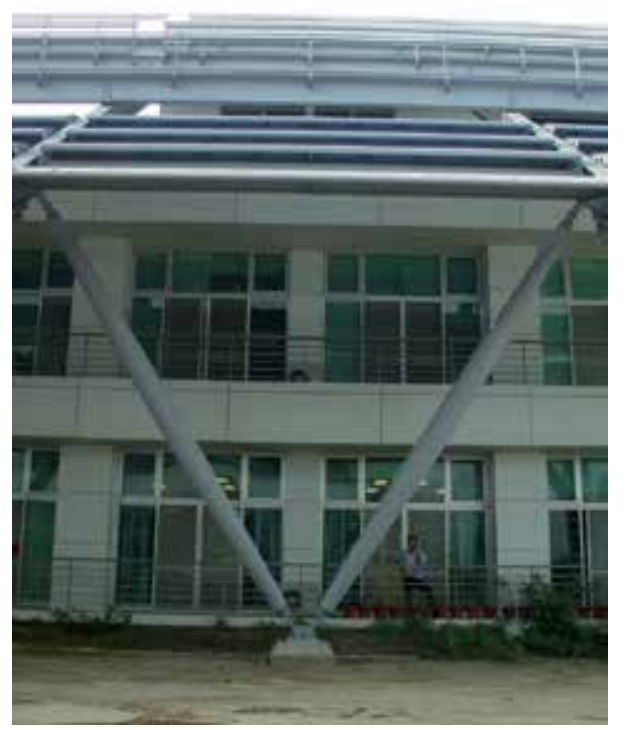

Figure 5. Final Photo of experimental installations with Integrated Photovoltaic and Sunshading Board

\section{Results and discussions}

\subsection{Advantages of sunshading board for energy-saving of building}

Temperature differences of the experimental building before and after installing sunshading board and then the solar panel were recorded. The actual effectiveness of shading board 
was evaluated by comparing the indoor room temperature and the shaded spot temperature with the outside temperature in order to monitor the savings on air conditioning energy consumption.

The temperature monitoring programme started one year before the installation of shading boards and lasted for three years; the results obtained during the hottest August and September were used for evaluating the cooling effectiveness. The temperature sensors were installed on the balcony of the building so that the temperature measurement was not affected by direct sunshine or precipitation.

Energy consumption for cooling was recorded with three digital wattmeters from 8:00 am till 5:00 pm. The daily energy consumption was accumulated to yield the monthly consumption, and the following formula was used to estimate the energy savings:

$$
\text { Percent of Energy Savings }=\frac{\text { Reduction of Watts }}{\text { Yearly Watts }} \%
$$

The on-site experimental results obtained with three experimental rooms are shown in Figure 6. The room equipped with a shading board shows lower temperature of $2.6^{\circ} \mathrm{C}$ to $2.7^{\circ} \mathrm{C}$ in August and $1.8^{\circ} \mathrm{C}$ to $2.1^{\circ} \mathrm{C}$ in September.

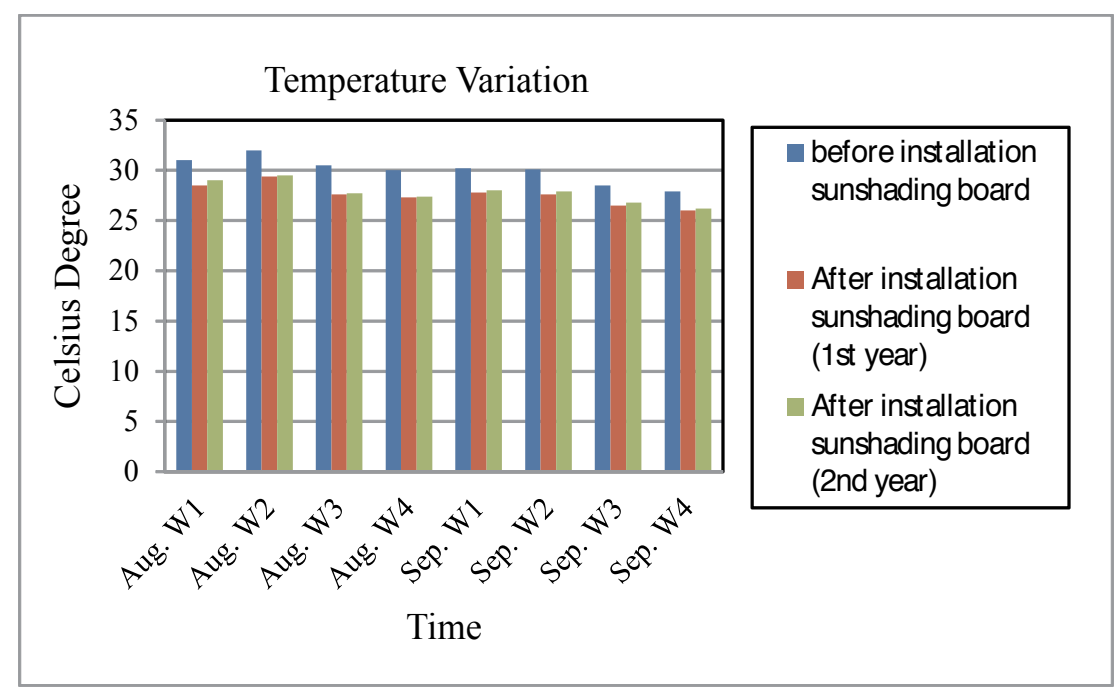

Figure 6. The temperature variation of various test rooms before and after they were equipped with a shading board

Figure 7 shows the analyses on energy consumption in August and September for the three rooms. Savings on air conditioning energy air consumptions for the two-year study period were $9.17 \%$ to $31.95 \%$ in August and $18.30 \%$ to $29.05 \%$ in September. 


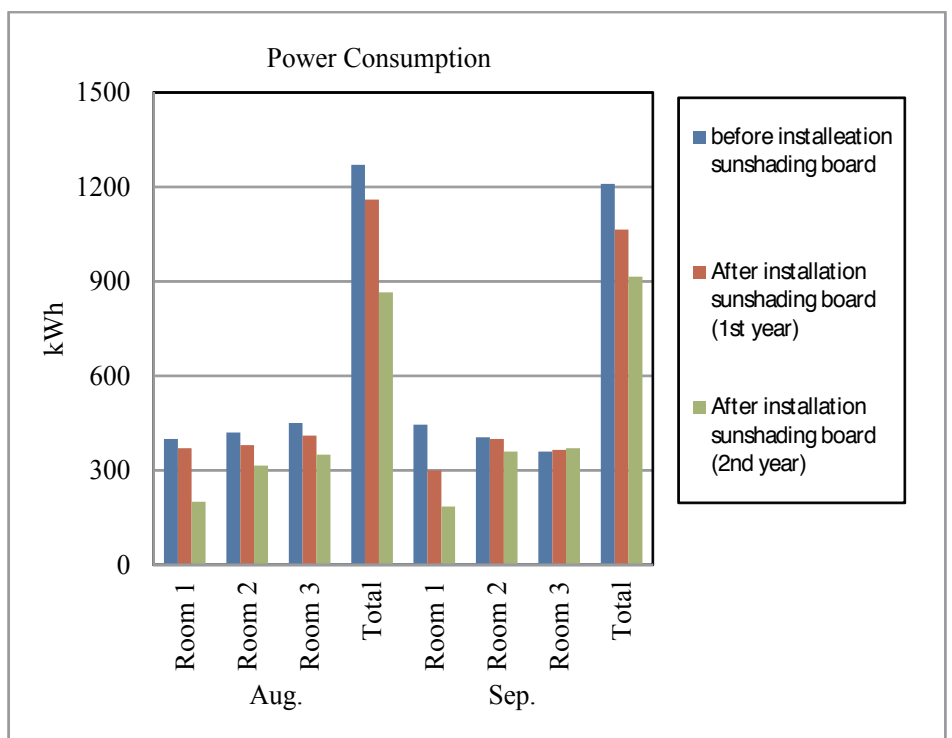

Figure 7. The power consumption in August and September for the three rooms before and after they were equipped with a shading board

\subsection{Energy efficiency for solar panels installed at various angles}

The efficiency of solar panels in stalled at various angles $-15^{\circ}, 25^{\circ}$ and $30^{\circ}$, - was carried out using the polycrystalline silicon and monocrystalline silicon panels in Systems I and III. These panels have different output rated values, so that the results are normalized by dividing the data by the output rated value of individual solar panels. As shown by the results in Figure 8 , the solar panel with a $25^{\circ}$ inclination has better energy output efficiencies than those $15^{\circ}$ and $30^{\circ}$ inclinations. Additionally, the performance of monocrystalline silicon panel is not significantly influenced by the angle of installation.

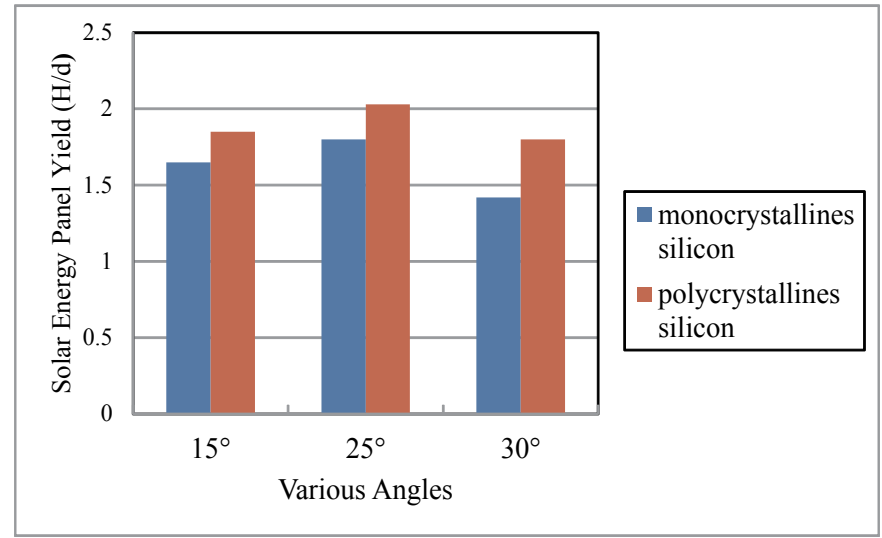

Figure 8. The comparison of the rated output efficiency of polycrystalline silicon and monocrystalline silicon panels 


\subsection{Solar panel surface clarity and energy efficiency}

Improving the solar panel energy efficiency by cleaning the solar panel was undertaken to study the energy output efficiency for the non-crystalline, monocrystalline, and polycrystalline solar panel with and without the emulated rainfall. The weather in Taiwan is rather humid; the dust in the air is thus easily moistened, adhered to and accumulated on the solar panel,s surface to interfere with the solar panel's energy efficiency. On-site observations reveals that raindrops were somewhat effective in cleaning the solar panel surface. Hence, a water spraying system was installed above the solar panel and operated once every week to study the effectiveness of cleaning by rainwater. The results are shown in Figure 9.

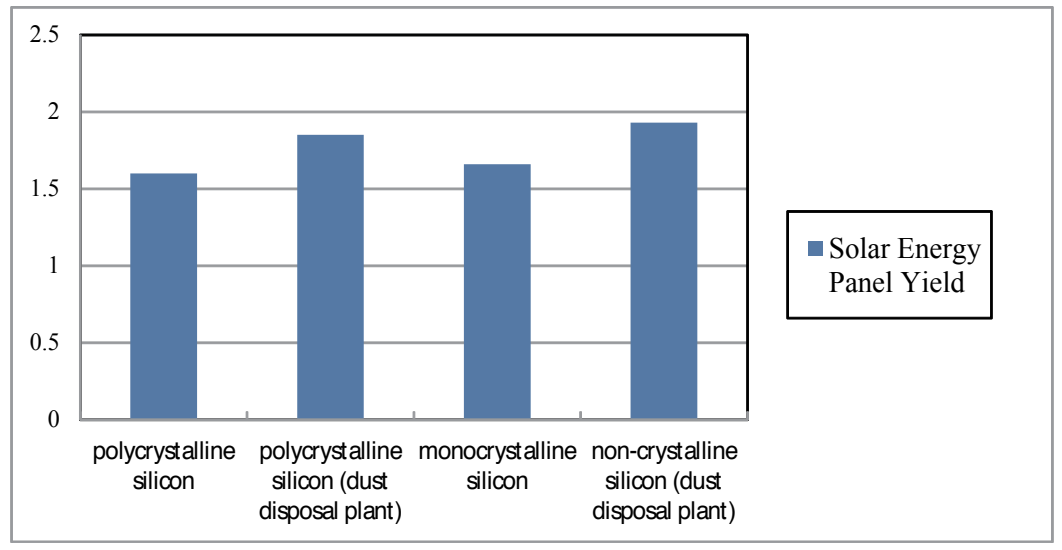

Figure 9. The comparison of the energy output efficiency for the non-crystalline, monocrystalline, and polycrystalline solar panel

Without the water spray cleaning system, the polycrystalline solar panel produces $3.7 \%$ more energy than the monocrystalline solar panel. Providing the water spray cleaning system, however, causes the solar panels to produce more energy: $17.72 \%$ for the polycrystalline solar panel, and $5.38 \%$ for the non-crystalline solar panel.

A BIPV building will lower the indoor temperature by $1.8-2.7^{\circ} \mathrm{C}$ during summer to save $9.17 \%$ to $31.95 \%$ of energy in cooling the building. The solar panel used in the BIPV building is made of monocrystalline silicon with a $25^{\circ}$ inclination oriented westerly in order to obtain the maximum energy generating efficiency. The variation of ambient temperature may cause the electricity generation to vary by $0.07-4.5 \%$; clear ambient air will assist in elevating the power generation by $3.7 \%$ to $29 \%$. The overall experimental results revealed that the order of improved energy efficiency using water spray cleaning is monocrystalline solar panel, noncrystalline solar panel, then polycrystalline solar panel.

The energy output for solar panels before and after cleaning at various ambient temperatures are listed in Tables 1 and 2. The results in each table indicated that the clarity of solar panels affects the efficiency of solar panels made of different materials; dirty solar panels will lower the efficiency of producing electricity by $3.7 \%$ (Table 1) to $29.29 \%$ (Table 2). 


\begin{tabular}{ccccccc}
\hline & \multicolumn{5}{c}{ Generated power output $(\mathrm{kW})$} \\
\cline { 2 - 5 } & $\begin{array}{c}\text { Before } \\
\text { cleaning } \\
\text { Item }\end{array}$ & $\begin{array}{c}\text { During } \\
\text { cleaning }\end{array}$ & $\begin{array}{c}\text { After cleaning } \\
\text { stage } \\
\left(30^{\circ} \mathrm{C}\right)\end{array}$ & $\begin{array}{c}\text { Later } \\
\text { stage } \\
\left(44^{\circ} \mathrm{C}\right)\end{array}$ & $\begin{array}{c}\text { Clear } \\
\text { degree } \\
(\%)\end{array}$ & $\begin{array}{c}\text { Real } \\
\text { temperature } \\
\text { variation }(\%)\end{array}$ \\
\hline System & 1.31 & 1.59 & 1.64 & 1.48 & 12.98 & 1.44 \\
\cline { 1 - 5 } $\begin{array}{c}\text { Polycrystalline } \\
\text { silicon }\end{array}$ & 1.08 & 1.13 & 1.09 & 1.12 & 3.70 & 0.07 \\
$\begin{array}{c}\text { Non-crystalline } \\
\text { silicon }\end{array}$ & 1.08 & & & & \\
\hline
\end{tabular}

Table 1. Solar panel energy output for panel before and after cleaning.

\begin{tabular}{|c|c|c|c|c|c|c|}
\hline \multicolumn{7}{|c|}{ Generated power output (kW) } \\
\hline & & & After cleaning & & & \\
\hline$\frac{\text { Item }}{\text { System }}$ & $\begin{array}{l}\text { Before } \\
\text { cleaning } \\
\left(38^{\circ} \mathrm{C}\right)\end{array}$ & $\begin{array}{l}\text { During } \\
\text { cleaning }\end{array}$ & $\begin{array}{l}\text { Earlier } \\
\text { stage } \\
\left(34^{\circ} \mathrm{C}\right)\end{array}$ & $\begin{array}{l}\text { Later } \\
\text { stage } \\
\left(38^{\circ} \mathrm{C}\right)\end{array}$ & $\begin{array}{c}\text { Clear } \\
\text { degree } \\
(\%)\end{array}$ & $\begin{array}{c}\text { Real } \\
\text { temperature } \\
\text { variation (\%) }\end{array}$ \\
\hline $\begin{array}{l}\text { Polycrystalline } \\
\text { silicon }\end{array}$ & 1.40 & 1.63 & 1.71 & 1.81 & 29.29 & 4.53 \\
\hline $\begin{array}{l}\text { Non-crystalline } \\
\text { silicon }\end{array}$ & 1.20 & 1.21 & 1.29 & 1.29 & 7.17 & 1.74 \\
\hline
\end{tabular}

Table 2. Solar panel surface clarify and temperature before and after cleaning.

Hence, maintaining a clear solar panel surface by washing with natural raindrops or artificial water spraying system will assist in promoting the energy efficiency of the solar panel. The cleaning will lower the surface temperature of solar panels; but the temperature variation caused by cleaning the solar panel will result in decreasing energy efficiency slightly of only $0.07 \%$ (Table 1 ) to $4.53 \%$ (Table 2 ).

\section{Conclusions}

Various factors such as the solar panel's material, inclination angle, natural cleaning by rainwater and climatic conditions, among many others, may affect the solar panel's energy efficiency. Additionally, how the solar panel can be integrated with the shell of a building so that the combination will become a reliable source for cheap energy to provide air conditioning for the building is also the ultimate goal of this research.

The research results confirm that installing solar heat shading boards will lower the indoor temperature by $1.8^{\circ} \mathrm{C}$ to $2.7^{\circ} \mathrm{C}$, save about $9.17 \%$ to $31.95 \%$ of energy consumption. As far as 
the solar panel's material is concerned, the monocrystalline panel is better than non-crystalline solar panel, which is better than polycrystalline panel. The order of magnitude for the panel installing angles is $25^{\circ}>20^{\circ}>30^{\circ}$ with west-orientation being the most favorable for energy production, followed by south-orientation and east-orientation.

Maintaining a clean solar panel surface by washing will reduce the panel surface temperature to lower the energy output by $0.07 \%$ to $4.57 \%$; however, this action will improve the energy output by $3.7 \%$ to $29 \%$. In summary, installing the shading board will reduce the energy consumption for air conditioning. Raising the energy efficiency of solar panels, and developing new solar panel technology and implementation methods will effectively alleviate the peak power demand, improve the balance of power consumption, and promote the development and reuse of renewable energy sources.

\section{Acknowledgements}

This work was partially supported by CPAMI of R.O.C. The authors wish to thank Professor Chen Jiann-Fuh form NCKU for many helpful suggestions during the course of this work.

\section{Author details}

Wen-Sheng Ou

Address all correspondence to: wsou@ncut.edu.tw

Department of Landscape Architecture, National Chin-Yi University of Technology, Taichung, Taiwan

\section{References}

[1] R. Thomas, Photovoltaic and Architecture. London: Taylor and Francis; 2001.

[2] D. Prasad, M. Snow, Designing with Solar Power: A Source Book for Building Integrated Photovoltaics (BIPV). Sydney: Earthscan Publications Ltd; 2005.

[3] German Solar Energy Society, Planning and Installing Photovoltaic Systems: A Guide for Installers, Architects and Engineers. Sydney: Earthscan Publications Ltd; 2005.

[4] M. K. Nazeeruddin, E. Baranoff, M. Grätzel, Solar Energy. 2011; 85(6) 1172-1178.

[5] Alternative Energy: Solar Energy. http://www.altenergy.org/renewables/solar.html/ (accessed 3 June 2011). 
[6] H. T. Lin, Evaluation Manual for Green Building Renovation. Taipei: Architecture and Building Research Institute; 2010.

[7] H. T. Lin, Evaluation Manual for Green Buildings in Taiwan. Taipei: Architecture and Building Research Institute; 2009.

[8] H. T. Lin, Ecology, Energy Saving, Waste Reduction and Health, National Cheng Kung University. Taipei: Architecture and Building Research Institute; 2011. 


\title{
Chapter 8
}

\section{New Computational Techniques for Solar Radiation in Architecture}

\author{
Jose M. Cabeza-Lainez, Jesus A. Pulido Arcas, Carlos Rubio Bellido, \\ Manuel-Viggo Castilla, Luis Gonzalez-Boado and \\ Benito Sanchez-Montanes Macias
}

Additional information is available at the end of the chapter

http://dx.doi.org/10.5772/60017

\section{Introduction}

Many architectural examples rank among masterpieces for its beautiful and harmonious use of solar radiation. However, their creation had to rely solely on intuition because they possessed a curvilinear nature. As the necessary tools required for evaluating shapes derived from the sphere or the circle were not available, such forms could not be assessed.

Circular emitters represent an important issue not merely in architecture but in the field of configuration factors calculation. The circle form is present in a variety of devices and emitters that find ample application in the realms of thermal engineering, daylighting in architecture and artificial light, amongst others. In the past, several factors have been found for specific positions of the unit area in relation to the sources of such surface, centered with respect to the circle, but not for a generic location whether parallel or inclined. In this respect, perpendicular semicircles have been totally disregarded. As a result, calculation for the said configuration factors was sustained by iterative methods, which do not provide the desired accuracy in every situation and also require considerable effort and time in terms of computational capacity.

In previous researches, new configuration factors have been devised for complex forms and shapes, such as the paraboloid, the ellipsoid, the sphere and the straight cone, which are ever present in architecture and engineering. What is more, several configurations of volumes that include similar elements could also be assessed by virtue of adroit mathematical deduction. As a result, researchers and designers were provided with new configuration factors, so that the design process is entirely freed from iterative methods. 
In this chapter, an exact analytical solution derived from complex double integration is presented. The expression obtained significantly soothes the calculation of the configuration factor between a circular emitter and a point that lies in a plane located at any position to the former, not only in an axis perpendicular to its center. Those results were checked against more conventional formulas. Based on such calculus procedures, an entirely new factor for the semicircle to a perpendicular plane that contains the straight edge has been deducted. Likewise, the solution has been converted into an original algorithm and programmed in simulation software developed by the authors so that interactive maps of the radiative field can be visualized in a consistent and accurate way. Thus, computer simulation techniques, engineering and image applications will be greatly enhanced and benefitted.

\section{Outline of the problem \& objectives}

The reciprocity principle enunciated by Lambert in his paramount book Photometria, written in Latin (Lambert, 1760), yields the following well-known integral equation:

$$
\varnothing_{1-2}=\left(E_{b 1}-E_{b 2}\right) \iint_{A_{1} A_{2}} \cos \theta_{1} \cdot \cos \theta_{2} \cdot \frac{d A_{1} \cdot d A_{2}}{\pi \cdot r^{2}}
$$

Relevant terms in equation (1) are depicted in figure 1.

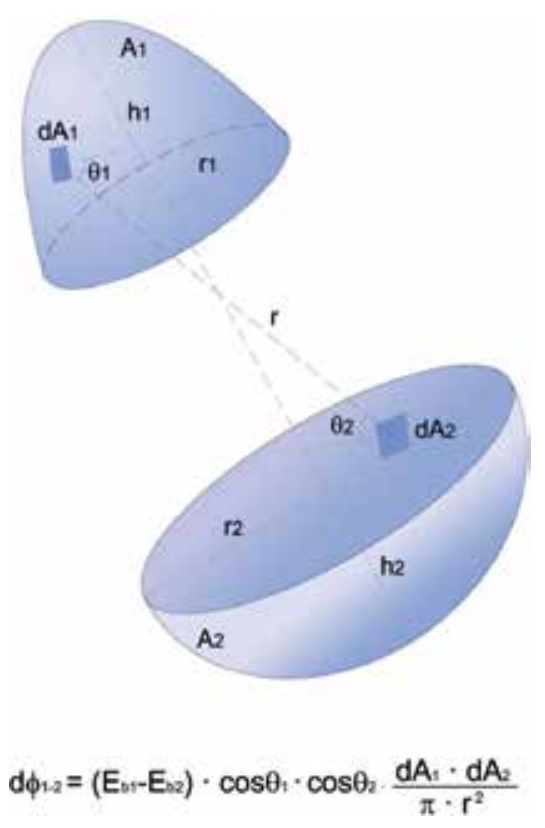

Figure 1. The reciprocity principle and quantities' significance for surfaces $A_{1}$ and $A_{2}$ 
From the times of Lambert to our days, researchers and scientists in the fields of Geometric Optics and Radiative Transfer have striven to provide solutions for the canonical equation 1. This is no minor feat, since the said equation will lead in most cases to a quadruple integration and to be sure the fourth degree primitive of even simple mathematical expressions implies lengthy calculations. For this reason, direct mathematical calculation of circular emitters was avoided, and only expressions for some particular position with respect to the emitter were available. In this sense, a detailed catalogue of configuration factors is provided online in [1], but with respect to circular emitters, only specific ones where the receiving point location is restricted to an axis passing through the center of the emitting circle are included[2],[3].

Considering the importance of these emitters and its wide application in architectural design and engineering, the objectives of the research aimed at establishing precise mathematical expressions for the required configuration factors. Such procedure entails exact analytical solutions of the quadruple integral, in order to yield expressions that barely include geometric parameters.

That said, a circular source that emits with constant power has been considered; receiving points are located freely in any parallel or inclined plane. Starting from canonical equation (1) and following mathematical procedures, new configuration factors are developed for these surfaces.

\section{Integration process for circular emitters}

\subsection{Direct integration for a differential element to a circular disk on a plane parallel to that of the element}

Let us consider the proposed figure. In order to determine the radiant interchange between an emitting circle, which lies in the plane $\mathrm{ZX}$, and a point $\mathrm{P}$ situated in another parallel plane $\mathrm{XY}$, the following coordinate system is proposed (Figure 2).

Terms depicted in figure 2 are:

$\mathrm{d}$ : vertical distance between the center of the emitting circle and the plane XY.

$\mathrm{b}$ : horizontal distance between differential element $\mathrm{dA}_{1}$ and the plane $\mathrm{ZX}$ that contains the said circle.

r: Emitting surface radius.

S: Distance between differential elements (in the canonical equation (1) of the configuration factor, it is denoted as $r$, but in order to differentiate it from radius of the disk (emitting surface, r), we shift to this denomination).

According to figure 2, the differential element $\mathrm{dA}_{2}$ is expressed in terms of $\mathrm{r}$ and $\theta$. Thus, to receive a proper integral, the rest of elements inside the integration sign of the canonical equation (1) should be expressed using the said variables. Basic construction for this expression 


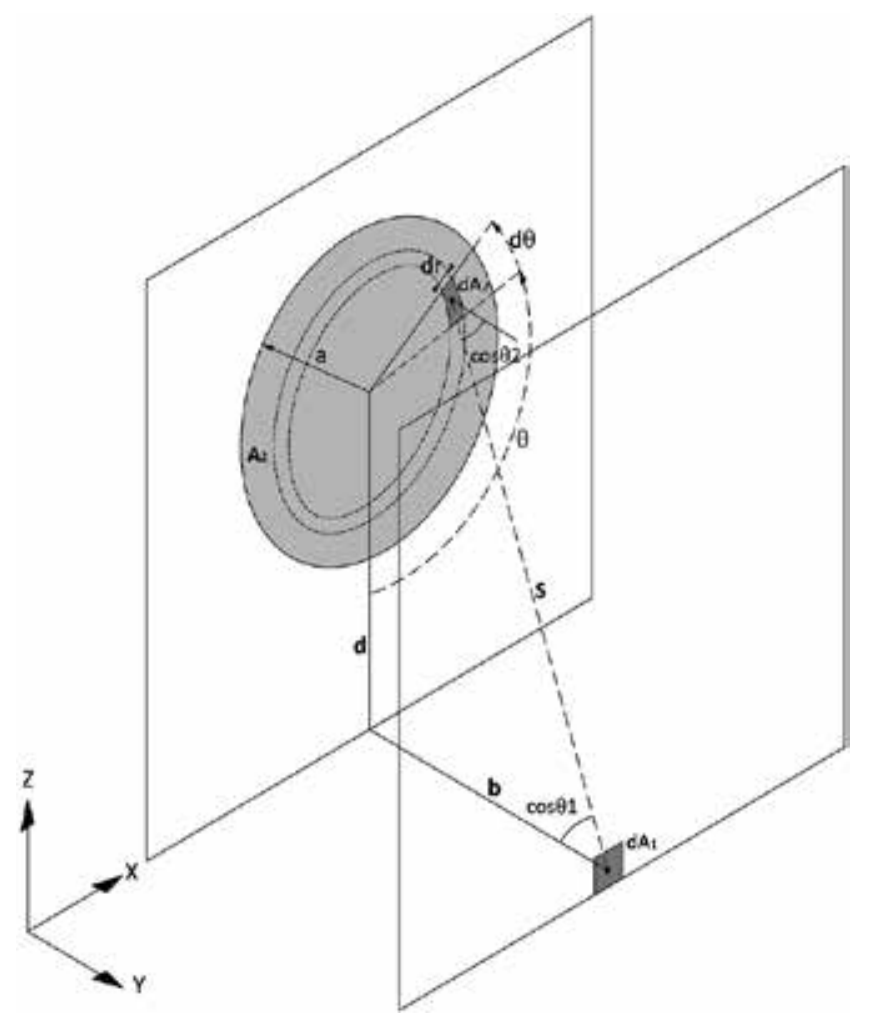

Figure 2. Calculation parameters for the parallel plane.

can be found in numerous manuals of radiative transfer [4]. Furthermore, mathematical support for the integration process is described in references [5]

$d A_{1}$ represents the point source

$$
\begin{gathered}
d A_{2}=r d r d \theta \\
\cos \theta_{1}=\frac{(d+r \cos \theta)}{S} \\
\cos \theta_{2}=\frac{b}{S} \\
S=r^{2}+d^{2}+b^{2}-2 d r \cdot \cos \theta
\end{gathered}
$$

Substituting terms from (2) in accordance to figure 2, in the canonical equation of radiative transfer (1), the main integral that we need to solve is, 


$$
\iint_{A_{1} A_{2}} \cos \theta_{1} \cdot \cos \theta_{2} \cdot \frac{d A_{1} \cdot d A_{2}}{\pi \cdot r^{2}}=\int_{0}^{a} \int_{0}^{2 \pi} \frac{b r \cdot(b-r \cdot \cos \theta)}{\left(r^{2}+d^{2}+b^{2}-2 d r \cdot \cos \theta\right)^{2}} d \theta d r
$$

Operating in the numerator we can decompose this integral in two parts:

$$
\int_{0}^{a 2 \pi} \int_{0}^{b^{2} r} \frac{b r^{2} \cdot \cos \theta}{\left(r^{2}+d^{2}+b^{2}-2 d r \cdot \cos \theta\right)^{2}} d \theta d r-\int_{0}^{a} \int_{0}^{2 \pi} \frac{b^{2}}{\left(r^{2}+d^{2}+b^{2}-2 d r \cdot \cos \theta\right)^{2}} d \theta d r
$$

The limits for inner and outer integral are, respectively: from 0 to $2 \pi$, and from 0 to a, that is, the whole extension of the radius of the emitting circle.

In order to solve this double integral, we first integrate with respect to $\theta$. Proceeding with the first integral implies taking out all the constants that are independent of $\theta$, and this yields:

$$
b^{2} r \cdot d r \int_{0}^{2 \pi} \frac{d \theta}{\left(r^{2}+d^{2}+b^{2}-2 d r \cdot \cos \theta\right)^{2}}
$$

Such expression corresponds to a type, which yields the solution:

$$
\int \frac{d x}{(B+C \cdot \cos (A x))^{2}}=\frac{C \cdot \sin (A x)}{A\left(B^{2}-C^{2}\right) \cdot(B+C \cos (A x))}-\frac{B}{\left(C^{2}-B^{2}\right)} \int \frac{d x}{B+C \cdot \cos (A x)}
$$

The change of variables is defined thus:

$$
d \theta=d x \quad B=r^{2}+d^{2}+b^{2} \quad C=-2 d r \quad A=1
$$

Before operating, and in order to simplify the otherwise tedious calculations, this expression can be put in simpler form by applying logical deductions. Focusing our attention in the first term of (9):

$$
\frac{C \cdot \sin (A x)}{A\left(B^{2}-C^{2}\right) \cdot(B+C \cos (A x))}
$$

It can be observed that $\sin (\mathrm{Ax})$ is in the numerator; if $\mathrm{A}=1$ the former means that we have $\sin (\mathrm{X})$; but we need to bear in mind that the limits for our defined integral are $2 \pi$ and 0 , thus, $\sin (2 \pi)$, $\sin (0)$, equal nil and so does the integral,

$$
\left.\frac{C \cdot \sin (A x)}{A\left(B^{2}-C^{2}\right) \cdot(B+C \cos (A x))}\right]_{0}^{2 \pi}=0-0=0
$$


Subsequently, we focus our attention in the second term of equation (9);

$$
-\frac{B}{\left(C^{2}-B^{2}\right)}=-\frac{r^{2}+d^{2}+b^{2}}{4 d^{2} r^{2}-\left(r^{2}+d^{2}+b^{2}\right)^{2}}=+\frac{r^{2}+d^{2}+b^{2}}{\left(r^{2}+d^{2}+b^{2}\right)^{2}-4 d^{2} r^{2}}
$$

So far, we have solved all terms outside the integration sign of equation (9). What remains inside the integral admits this change:

$$
\int \frac{d x}{B+C \cdot \cos (A x)}=\frac{2}{A \sqrt{B^{2}+C^{2}}} \cdot \arctan \frac{(B-C) \cdot \tan (A x / 2)}{\sqrt{B^{2}-C^{2}}}
$$

Therefore, substituting all terms we receive:

$$
\frac{r^{2}+d^{2}+b^{2}}{\left(r^{2}+d^{2}+b^{2}\right)-4 d^{2} r^{2}}\left[\frac{2}{\sqrt{\left(r^{2}+d^{2}+b^{2}\right)^{2}-4 d^{2} b^{2}}} \cdot \arctan \frac{\left(\left(r^{2}+d^{2}+b^{2}\right)+2 d r\right) \cdot \tan (\theta / 2)}{\sqrt{\left(r^{2}+d^{2}+b^{2}\right)^{2}-4 d^{2} b^{2}}}\right]
$$

Once more, some logics were employed in order to compact the calculations; concentrating on the third term of (15), we find an the arctangent and a tangent expression. Bearing in mind that the limits of integration are $(2 \pi, 0)$, the result of arctangent is obviously $\pi$, and that produces:

$$
\frac{r^{2}+d^{2}+b^{2}}{\left(r^{2}+d^{2}+b^{2}\right)-4 d^{2} r^{2}} \cdot \frac{2 \pi}{\sqrt{\left(r^{2}+d^{2}+b^{2}\right)^{2}-4 d^{2} b^{2}}}
$$

The value of $\pi$ is taken out of the integration mark and eliminated by means of the canonical equation of the configuration factor. That yields:

$$
2 b^{2} \int_{0}^{a} \frac{r \cdot\left(r^{2}+d^{2}+b^{2}\right)}{\left(\left(r^{2}+d^{2}+b^{2}\right)^{2}-4 d^{2} r^{2}\right)^{3 / 2}} \cdot d r
$$

Again making some arrangements to these elements to produce an expression that enables easy integration, let us multiply the numerator and denominator by 4 and add and subtract a new term, $-2 \mathrm{rd}^{2}$, always bearing in mind to reproduce the original expression in (17); that gives the following equation.

$$
2 b^{2} \int_{0}^{a} \frac{4\left(r \cdot\left(r^{2}+d^{2}+b^{2}\right)-2 r d^{2}+2 r d^{2}\right)}{4\left(\left(r^{2}+d^{2}+b^{2}\right)^{2}-4 d^{2} r^{2}\right)^{3 / 2}} \cdot d r
$$

Decomposing and operating again: 


$$
\begin{gathered}
2 b^{2} \int_{0}^{a} \frac{4\left(r^{2}+d^{2}+b^{2}\right)-8 r d^{2}+8 r d^{2}}{4\left(\left(r^{2}+d^{2}+b^{2}\right)-4 d^{2} r^{2}\right)^{3 / 2}} \cdot d r= \\
2 b^{2} \int_{0}^{a} \frac{4\left(r^{2}+d^{2}+b^{2}\right)-8 r d^{2}}{4\left(\left(r^{2}+d^{2}+b^{2}\right)-4 d^{2} r^{2}\right)^{3 / 2}}+\frac{8 r d^{2}}{4\left(\left(r^{2}+d^{2}+b^{2}\right)-4 d^{2} r^{2}\right)^{3 / 2}} \cdot d r= \\
2 b^{2} \int_{0}^{a} \frac{4 r \cdot\left(r^{2}+d^{2}+b^{2}\right)-8 r d^{2}}{4\left(\left(r^{2}+d^{2}+b^{2}\right)-4 d^{2} r^{2}\right)^{3 / 2}} \cdot d r+\int_{0}^{a} \frac{2 r d^{2}}{\left(\left(r^{2}+d^{2}+b^{2}\right)-4 d^{2} r^{2}\right)^{3 / 2}} \cdot d r
\end{gathered}
$$

The integral of a sum is given, which can be treated as the sum of integrals. Dealing with the first term of (19) the following expression is received:

$$
2 b^{2} \int_{0}^{a} \frac{4 r \cdot\left(r^{2}+d^{2}+b^{2}\right)-8 r d^{2}}{4\left(\left(r^{2}+d^{2}+b^{2}\right)-4 d^{2} r^{2}\right)^{3 / 2}} \cdot d r=2 b^{2} \int_{0}^{a} \frac{4 r \cdot\left(r^{2}+b^{2}-d^{2}\right)}{4\left(\left(r^{2}+d^{2}+b^{2}\right)-4 d^{2} r^{2}\right)^{3 / 2}} \cdot d r
$$

That offers the solution:

$$
-b^{2}\left[\frac{1}{\left.\left(\left(r^{2}+d^{2}+b^{2}\right)^{2}-4 d^{2} r^{2}\right)\right)^{1 / 2}}\right]_{0}^{a}=\frac{b^{2}}{d^{2}+b^{2}}-\frac{b^{2}}{\left(\left(a^{2}+d^{2}+b^{2}\right)^{2}-4 d^{2} a^{2}\right)^{1 / 2}}
$$

Now it is time to proceed to the remaining term of (19)

$$
\int_{0}^{a} \frac{2 r d^{2}}{\left(\left(r^{2}+d^{2}+b^{2}\right)-4 d^{2} r^{2}\right)^{3 / 2}} \cdot d r
$$

Expanding the denominator and rearranging its terms with reference to the variable r:

$$
2 b^{2} d^{2} \int_{0}^{a} \frac{2 r d r}{\left(r^{4}+2 r^{2}\left(b^{2}-d^{2}\right)+\left(b^{2}+d^{2}\right)^{2}\right)^{3 / 2}}
$$

Introducing the change of variable $\mathrm{r}^{2}=\mathrm{t}$, that yields: 


$$
2 b^{2} d^{2} \int_{0}^{a^{2}} \frac{d t}{\left(t^{2}+2 t \cdot\left(b^{2}-d^{2}\right)+\left(b^{2}+d^{2}\right)^{2}\right)^{3 / 2}}
$$

This integral responds to the following model with the solution:

$$
\int \frac{d x}{X \sqrt{X}}=\frac{2(2 a x+b)}{\Delta \sqrt{X}} \text { for } X=a x^{2}+b x+c \text { and } \Delta=4 a c-b^{2}
$$

Making the substitution:

$$
a=1 ; \quad b=2\left(b^{2}-d^{2}\right) ; \quad c=\left(b^{2}+d^{2}\right)^{2} ; \Delta=4\left(b^{2}+d^{2}\right)^{2}-\left(b^{2}-d^{2}\right)^{2}=16 b^{2} d^{2}
$$

The ensuing outcome is given:

$2 b^{2} d^{2}\left[\frac{2\left(2 t+2 b^{2}-2 d^{2}\right)}{16 b^{2} d^{2} \sqrt{\left(t^{2}+2 t \cdot\left(b^{2}-d^{2}\right)+\left(b^{2}+d^{2}\right)^{2}\right)}}\right]_{0}^{a^{2}}=\frac{a^{2}+b^{2}-d^{2}}{2 \sqrt{\left(\left(a^{2}+d^{2}+b^{2}\right)^{2}-4 d^{2} a^{2}\right)}}-\frac{b^{2}-d^{2}}{2\left(d^{2}+b^{2}\right)}$

Finally, adding both terms, from (21) and (27), in order to obtain the final result:

$$
\begin{aligned}
& \frac{b^{2}}{d^{2}+b^{2}}-\frac{b^{2}}{\sqrt{\left(\left(a^{2}+d^{2}+b^{2}\right)^{2}-4 d^{2} a^{2}\right)}}+\frac{a^{2}+b^{2}-d^{2}}{2 \sqrt{\left(\left(a^{2}+d^{2}+b^{2}\right)^{2}-4 d^{2} a^{2}\right)}}-\frac{b^{2}-d^{2}}{2\left(d^{2}+b^{2}\right)}= \\
& \frac{-2 b^{2}+a^{2}+b^{2}-d^{2}}{2 \sqrt{\left(\left(a^{2}+d^{2}+b^{2}\right)^{2}-4 d^{2} a^{2}\right)}}+\frac{2 b^{2}-b^{2}+d^{2}}{2\left(d^{2}+b^{2}\right)}= \\
& \frac{a^{2}-b^{2}-d^{2}}{2 \sqrt{\left(\left(a^{2}+d^{2}+b^{2}\right)^{2}-4 d^{2} a^{2}\right)}}+\frac{b^{2}+d^{2}}{2\left(d^{2}+b^{2}\right)}= \\
& \frac{1}{2}-\frac{b^{2}+d^{2}-a^{2}}{2 \sqrt{\left(\left(a^{2}+d^{2}+b^{2}\right)^{2}-4 d^{2} a^{2}\right)}}
\end{aligned}
$$

\subsection{Direct integration for a differential element to a circular disk on a plane perpendicular to that of element}

In the perpendicular plane, that is, the $\mathrm{ZX}$ plane, according to the defined coordinate reference system, the main equation to be solved is: 


$$
\int_{0}^{a} \int_{0}^{2 \pi} \frac{b r(d-r \cos \theta)}{\left(r^{2}+d^{2}+b^{2}-2 d r \cos \theta\right)^{2}} \cdot d \theta d r
$$

This can be decomposed into two terms

$$
\int_{0}^{a} \int_{0}^{2 \pi} \frac{b r d}{\left(r^{2}+d^{2}+b^{2}-2 d r \cos \theta\right)^{2}} \cdot d \theta d r-\int_{0}^{a} \int_{0}^{2 \pi} \frac{b r^{2} \cos \theta}{\left(r^{2}+d^{2}+b^{2}-2 d r \cos \theta\right)^{2}} \cdot d \theta d r
$$

The first part of this expression has already been solved, but with $\mathrm{b}^{2}$ instead of $\mathrm{b} d$ as a constant. The first term was solved in two parts, which were expressed in equations (21) and (27). From equation (21):

$$
-b \cdot d\left[\frac{1}{\left.\left(\left(r^{2}+d^{2}+b^{2}\right)^{2}-4 d^{2} r^{2}\right)\right)^{1 / 2}}\right]_{0}^{a}=\frac{b d}{d^{2}+b^{2}}-\frac{b d}{\sqrt{\left(\left(a^{2}+d^{2}+b^{2}\right)^{2}-4 d^{2} a^{2}\right)}}
$$

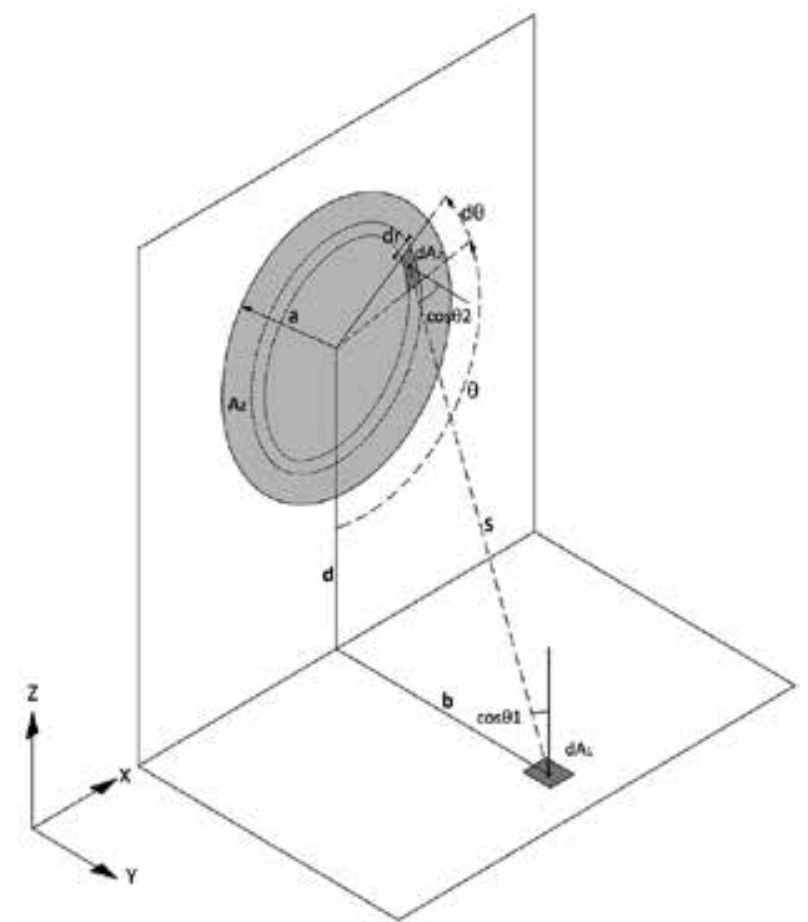

Figure 3. Calculation parameters for the perpendicular plane 
Now, equation (27) is rearranged as follows:

$$
\begin{gathered}
2 b d^{3}\left[\frac{2\left(2 t+2 b^{2}-2 d^{2}\right)}{16 b^{2} d^{2} \sqrt{\left(t^{2}+2 t \cdot\left(b^{2}-d^{2}\right)+\left(b^{2}+d^{2}\right)^{2}\right)}}\right]_{0}^{a^{2}}= \\
=2 b d^{3}\left[\frac{\left(a^{2}+b^{2}-d^{2}\right)}{4 b^{2} d^{2} \sqrt{\left(\left(a^{2}+d^{2}+b^{2}\right)^{2}-4 d^{2} a^{2}\right)}}-\frac{\left(b^{2}-d^{2}\right)}{4 b^{2} d^{2}\left(d^{2}+b^{2}\right)}\right] \\
\frac{d \cdot\left(a^{2}+b^{2}-d^{2}\right)}{2 b \sqrt{\left(\left(a^{2}+d^{2}+b^{2}\right)^{2}-4 d^{2} a^{2}\right)}}-\frac{d\left(b^{2}-d^{2}\right)}{2 b\left(d^{2}+b^{2}\right)}
\end{gathered}
$$

Next, assemble equations (31) and (32), group terms by common denominator and operate:

$$
\begin{aligned}
& \frac{b d}{d^{2}+b^{2}}-\frac{b d}{\sqrt{\left(\left(a^{2}+d^{2}+b^{2}\right)^{2}-4 d^{2} a^{2}\right)}}+\frac{d \cdot\left(a^{2}+b^{2}-d^{2}\right)}{2 b \sqrt{\left(\left(a^{2}+d^{2}+b^{2}\right)^{2}-4 d^{2} a^{2}\right)}}-\frac{d\left(b^{2}-d^{2}\right)}{2 b\left(d^{2}+b^{2}\right)} \\
& \frac{d \cdot\left(a^{2}+b^{2}-d^{2}\right)-2 b^{2} d}{2 b \sqrt{\left(\left(a^{2}+d^{2}+b^{2}\right)^{2}-4 d^{2} a^{2}\right)}}+\frac{2 b^{2} d-d \cdot\left(b^{2}-d^{2}\right)}{2 b\left(d^{2}+b^{2}\right)}=\frac{a^{2} d-b^{2} d-d^{3}}{2 b \sqrt{\left(\left(a^{2}+d^{2}+b^{2}\right)^{2}-4 d^{2} a^{2}\right)}}+\frac{b^{2} d+d^{3}}{2 b\left(d^{2}+b^{2}\right)}= \\
& =\frac{-d\left(-a^{2}+b^{2}+d^{2}\right)}{2 b \sqrt{\left(\left(a^{2}+d^{2}+b^{2}\right)^{2}-4 d^{2} a^{2}\right)}}+\frac{d\left(b^{2}+d^{2}\right)}{2 b\left(d^{2}+b^{2}\right)}=\frac{-d\left(b^{2}+d^{2}-a^{2}\right)}{2 b \sqrt{\left(\left(a^{2}+d^{2}+b^{2}\right)^{2}-4 d^{2} a^{2}\right)}}+\frac{d}{2 b}= \\
& \frac{1}{2} \cdot \frac{d}{b}\left[1-\frac{\left(b^{2}+d^{2}-a^{2}\right)}{\sqrt{\left(\left(a^{2}+d^{2}+b^{2}\right)^{2}-4 d^{2} a^{2}\right)}}\right]
\end{aligned}
$$

Also, the second term from equations (30): 


$$
\int_{0}^{a} \int_{0}^{2 \pi} \frac{b r^{2} \cos \theta}{\left(r^{2}+d^{2}+b^{2}-2 d r \cos \theta\right)^{2}} \cdot d \theta d r
$$

Again, integrating with respect to $\theta$ we receive:

$$
\int_{0}^{a} \frac{4 b d r^{2}}{\left(\left(r^{2}+d^{2}+b^{2}\right)^{2}-4 d^{2} r^{2}\right)^{3 / 2}} \cdot d r
$$

Employing the change $\mathrm{r}^{2}=\mathrm{t}$ in equation (35),

$$
2 b d \int_{0}^{a^{2}} \frac{t}{\left(\left(t^{2}+2 t\left(b^{2}-d^{2}\right)\right)+\left(b^{2}+d^{2}\right)^{2}\right)^{3 / 2}} \cdot d t
$$

An integral that admits the immediate solution:

$$
\begin{aligned}
& \int \frac{x d x}{X \sqrt{X}}=-\frac{2(2 b x+2 c)}{\Delta \sqrt{X}} \text { for } \\
& X=a x^{2}+b x+c \text { and } \Delta=4 a c-b^{2}
\end{aligned}
$$

Making the following substitutions:

$$
\begin{aligned}
& a=1 ; b=2\left(b^{2}-d^{2}\right) ; c=\left(b^{2}+d^{2}\right)^{2} \\
& \Delta=4\left(b^{2}+d^{2}\right)^{2}-\left(b^{2}-d^{2}\right)^{2}=16 b^{2} d^{2}
\end{aligned}
$$

Equation (36) becomes:

$$
2 b d\left[\frac{\left(b^{2}-d^{2}\right) t+\left(b^{2}+d^{2}\right)^{2}}{4 b^{2} d^{2} \sqrt{t^{2}+2 t\left(b^{2}-d^{2}\right)+\left(b^{2}+d^{2}\right)^{2}}}\right]_{0}^{a^{2}}=\frac{a^{2}\left(b^{2}-d^{2}\right)+\left(b^{2}+d^{2}\right)^{2}}{2 b d \sqrt{\left(a^{2}+b^{2}+d^{2}\right)^{2}-4 d^{2} a^{2}}}-\frac{b^{2}+d^{2}}{2 b d}
$$

Finally, in order to produce the final solution for the perpendicular plane, it is required to assemble equations (33) and (39). Grouping and rearranging by common denominators it yields: 


$$
\begin{gathered}
\frac{d}{2 b}-\frac{d\left(b^{2}+d^{2}-a^{2}\right)}{2 b \sqrt{\left(\left(a^{2}+d^{2}+b^{2}\right)^{2}-4 d^{2} a^{2}\right)}}+\frac{a^{2}\left(b^{2}-d^{2}\right)+\left(b^{2}+d^{2}\right)^{2}}{2 b d \sqrt{\left(a^{2}+b^{2}+d^{2}\right)^{2}-4 d^{2} a^{2}}}-\frac{b^{2}+d^{2}}{2 b d} \\
\frac{a^{2} b^{2}-a^{2} d^{2}+b^{4}+d^{4}-2 b^{2} d^{2}-b^{2} d^{2}-d^{4}+a^{2} d^{2}}{2 b d \sqrt{\left(a^{2}+b^{2}+d^{2}\right)^{2}-4 d^{2} a^{2}}}+\frac{d^{2}-b^{2}-d^{2}}{2 b d} \\
\frac{b^{2}\left(a^{2}+b^{2}+d^{2}\right)}{2 b d \sqrt{\left(a^{2}+b^{2}+d^{2}\right)^{2}-4 d^{2} a^{2}}}-\frac{b^{2}}{2 b d} \\
\frac{b}{2 d}\left[\frac{a^{2}+b^{2}+d^{2}}{\sqrt{\left(a^{2}+b^{2}+d^{2}\right)^{2}-4 d^{2} a^{2}}}-1\right]
\end{gathered}
$$

Again, this result can be checked against usual formulas that appear in numerous configuration factor catalogues, although those do not completely solve the problem. Only they work when the element is in a plane that passes through the center of the circle. A more general solution of a vector nature had been presented by the authors in other texts [6],[7]. In this chapter a sound relationship between the two fundamentals expressions has been found.

\subsection{Resolution of the integral for the third coordinate plane}

Being radiation a vector, the resolution for a third coordinate plane that obviously cuts the emitting circle in two halves is required; the outline of the integral in this case yields:

$$
\int_{0}^{a} \int_{0}^{\pi} \frac{b r^{2} \sin \theta}{\left(r^{2}+d^{2}+b^{2}-2 d r \cos \theta\right)^{2}} \cdot d \theta \cdot d r
$$

In this particular case, the limits of the integral cannot be extended to $2 \pi$, as the value would be nil. If (41) is integrated with respect to $\theta$, in the numerator the derivatives of $\cos \theta,-\sin \theta$ could be found. Therefore by making this change:

$$
t=\cos \theta \quad d t=-\sin \theta d \theta
$$

Integral (41) can therefore be expressed as:

$$
\int_{0}^{a} \int_{-1}^{1} \frac{-b r^{2}}{\left(r^{2}+d^{2}+b^{2}-2 d r t\right)^{2}} \cdot d t \cdot d r
$$




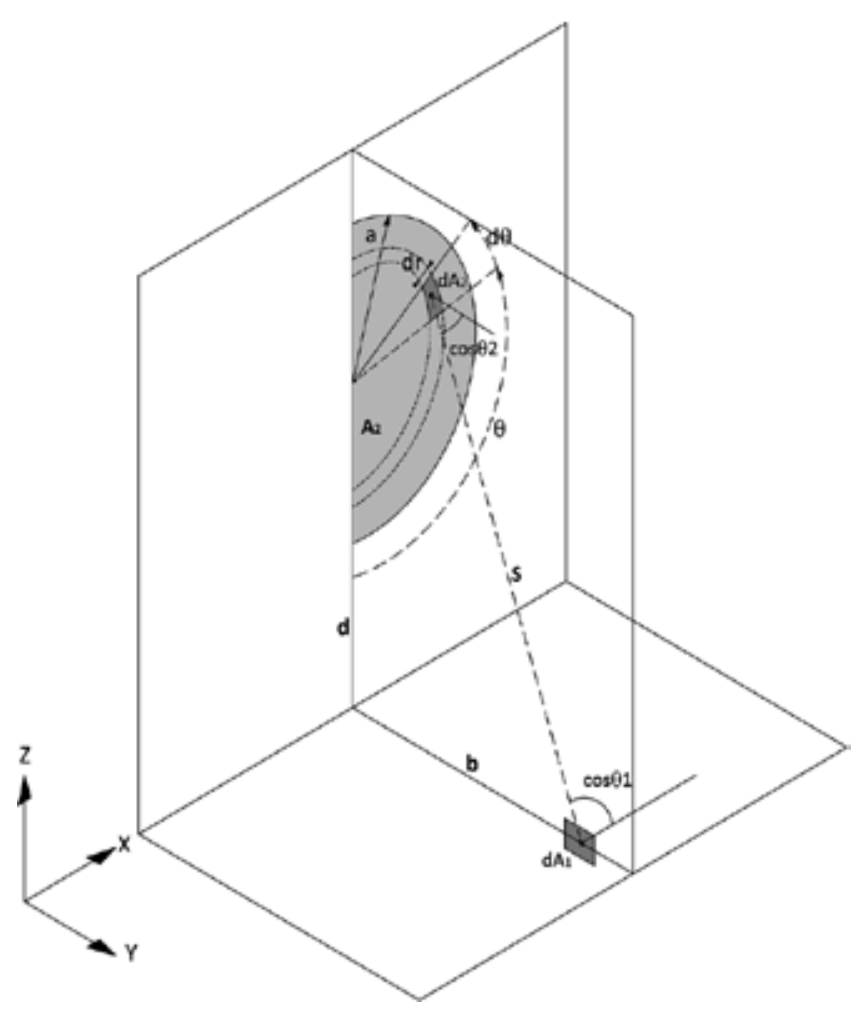

Figure 4. Calculation parameters for the semicircle

Taking out all the constants, and integrating with respect to $r$, the primitive is just the quotient of the numerator:

$$
\frac{-b r^{2}}{2 d r}\left[\frac{1}{r^{2}+d^{2}+b^{2}-2 d r t}\right]_{1}^{-1}=\frac{b r}{2 d}\left(\frac{1}{r^{2}+d^{2}+b^{2}-2 d r}-\frac{1}{r^{2}+d^{2}+b^{2}+2 d r}\right)
$$

Integrating (44) with respect to $r$; the last integral to solve is:

$$
\int_{0}^{a} \frac{r}{r^{2}+d^{2}+b^{2}-2 d r} \cdot d r+\int_{0}^{a} \frac{r}{r^{2}+d^{2}+b^{2}+2 d r} \cdot d r
$$

That responds to the form:

$$
\int \frac{x \cdot d x}{X}=\frac{1}{2 a} \cdot \ln X-\frac{b}{2 a} \int \frac{d x}{X} \quad X=a x^{2}+b x+c \quad \Delta=4 a c-b^{2}
$$




$$
\int \frac{d x}{X}=\frac{2}{\sqrt{\Delta}} \cdot \arctan \frac{2 a x+b}{\sqrt{\Delta}}
$$

Substituting in (46) yields for both terms:

$$
\begin{array}{r}
a=1 ; b= \pm 2 d ; c=\left(d^{2}+b^{2}\right) \\
X=r^{2} \pm 2 d r+\left(d^{2}+b^{2}\right) \Delta=4 b^{2}
\end{array}
$$

Now, substituting in the first term of (45):

$$
\frac{1}{2}\left[\ln \left(r^{2}+d^{2}+b^{2}-2 d r\right)\right]_{0}^{a}+\frac{d}{b}\left[\arctan \left(\frac{r-d}{b}\right)\right]_{0}^{a}
$$

And bringing equation (48) to the limits of the integral $[a, 0]$ :

$$
\frac{1}{2}\left(\ln \left(a^{2}+d^{2}+b^{2}-2 d a\right)\right)-\ln \left(d^{2}+b^{2}\right)+\frac{d}{b}\left(\arctan \frac{a-d}{b}+\arctan \frac{d}{b}\right)
$$

In a similar way, for the second term of equation (45):

$$
-\frac{1}{2}\left(\ln \left(a^{2}+d^{2}+b^{2}+2 d a\right)\right)+\ln \left(d^{2}+b^{2}\right)+\frac{d}{b}\left(\arctan \frac{a+d}{b}-\arctan \frac{d}{b}\right)
$$

Finally, multiplying by ${ }^{b} / 2 \pi d$ and grouping, the final result can be expressed as:

$$
\frac{1}{2 \pi}\left(\arctan \frac{a+d}{b}+\arctan \frac{a-d}{b}\right)+\frac{b}{4 \pi d} \ln \frac{a^{2}+b^{2}+d^{2}-2 a d}{a^{2}+b^{2}+d^{2}+2 a d}
$$

It can be demonstrated that the former equates the area subtended by a circular sector that encompasses the diameter of the emitting disk and the corresponding sector of a hyperbola defined by the intersection of the unit sphere and the cone [7].

If $\mathrm{a}=\mathrm{d}$, the factor is,

$$
\frac{1}{2 \pi} \arctan \frac{2 a}{b}-\frac{b}{4 \pi d} \ln \frac{4 a^{2}+b^{2}}{b^{2}}
$$


Where the former assert is more easily visualized.

If $d=0$ the expression is undetermined and the limit is passed with l'Hôpital's rule, obtaining the familiar result.

$$
\frac{1}{\pi}\left(\arctan \frac{a}{b}-\frac{a b}{a^{2}+b^{2}}\right)
$$

Equation (51) is entirely new and has never been mentioned in literatures; equation (52) constitutes a particular case of the former, that is, when a equals $\mathrm{d}$, meaning that the receiving point lies on the edge of the emitting semicircle; equation (53) is the particular case in which the receiving point is aligned with the center of the half-disk.

\subsection{Extension to three dimensional emitters - Configuration factor between a sphere and a differential element placed at a random position}

After analyzing the previous form factors for the circle, a new question can be deducted. A sphere can be considered, in terms of radiative transfer as a circle [7], as the viewed area of the said sphere from a distant point equals always a circle, because only half of the emitter is visible. Let us consider as emitting source a sphere of radius $r$, and a differential element, placed randomly in space at a distance $(x, y, z)$, referenced to the three coordinate directions as shown in figure 5 :

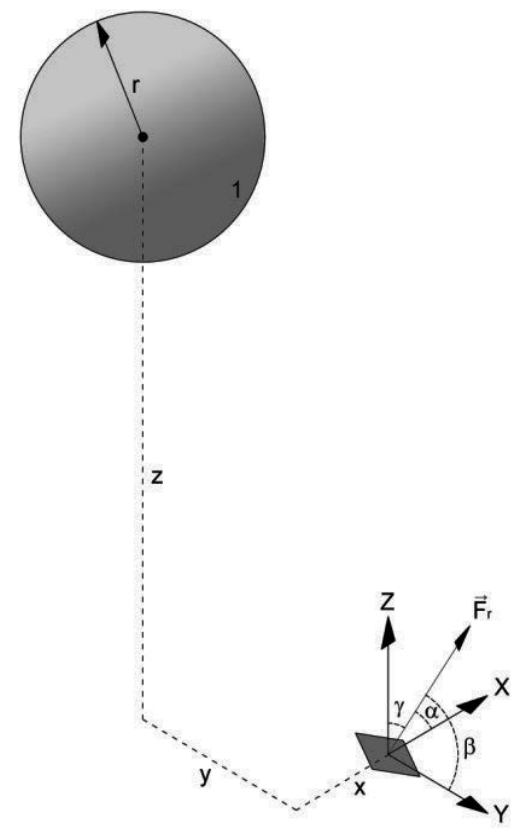

Figure 5. Calculations parameters for the sphere and a differential element at a random position 
The differential element, as in former cases, is defined by its normal, and it is necessary to find the radiation vector $\vec{F}_{r}$ impinging on it. Obtaining the modulus (configuration factor) is a direct operation, the angles formed by the unit element are already known:

$$
\left|\bar{F}_{r}\right|=F_{d 1-x} \cdot \cos \alpha+F_{d 1-y} \cdot \cos \beta+F_{d 1-z} \cdot \cos \gamma
$$

And expanding each of them,

$$
\begin{gathered}
F_{d 1-x}=\frac{r^{2} \cdot x}{\sqrt{\left(x^{2}+y^{2}+z^{2}\right)^{3}}} \\
F_{d 1-y}=\frac{r^{2} \cdot y}{\sqrt{\left(x^{2}+y^{2}+z^{2}\right)^{3}}} \\
F_{d 1-z}=\frac{r^{2} \cdot z}{\sqrt{\left(x^{2}+y^{2}+z^{2}\right)^{3}}}
\end{gathered}
$$

\subsection{Configuration factor between a sphere and a plane.}

Extending the previous deduction to a finite rectangle located at a certain distance to the sphere in a random position (figure 6), a new unknown factor has been deducted:

$$
F_{A 1-A 2}=\frac{1}{4 \pi}\left(\arctan \frac{x_{2} y_{2}}{z \sqrt{x_{2}^{2}+y_{2}^{2}+z^{2}}}-\arctan \frac{x_{2} y_{1}}{z \sqrt{x_{2}^{2}+y_{1}^{2}+z^{2}}}-\arctan \frac{x_{1} y_{2}}{z \sqrt{x_{1}^{2}+y_{2}^{2}+z^{2}}}-\arctan \frac{x_{1} y_{1}}{z \sqrt{x_{1}^{2}+y_{1}^{2}+z^{2}}}\right)
$$

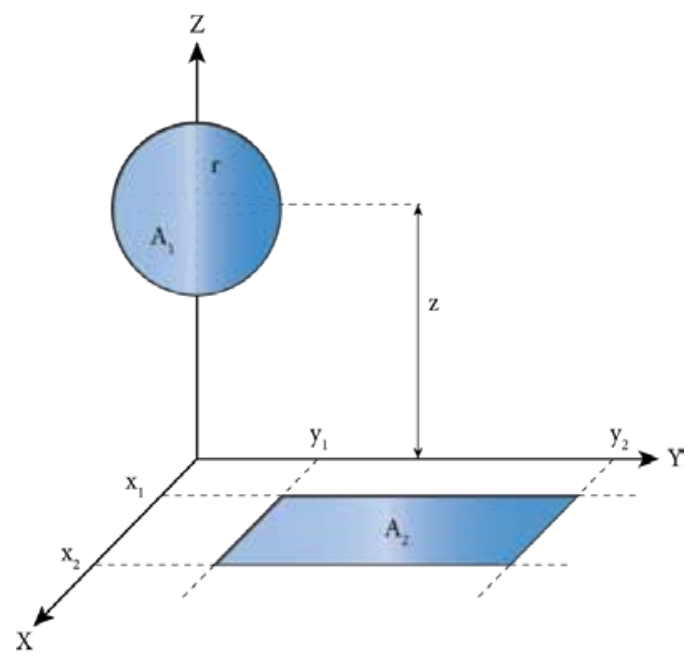

Figure 6. Configuration factor between a sphere and a parallel plane 


\section{Graphical visualization}

To help visualize the results of this research, some formulas have been programmed by the authors in Matlab® computational language, which greatly enhances understanding of radiative exchange between emitting surfaces and receiving planes. 3D graphs have been produced for a generic semicircular emitter.

Figure 7 shows a generic semicircular emitter that gives energy to a perpendicular plane in its base. Thanks to this new configuration factor, several radiative properties for these shapes can be clarified. For instance, a semicircular emitter is not capable of transferring more than $50 \%$ of its energy to a perpendicular plane; this is particularly important in some engineering lighting applications, such as lighted vaults or tunnels.

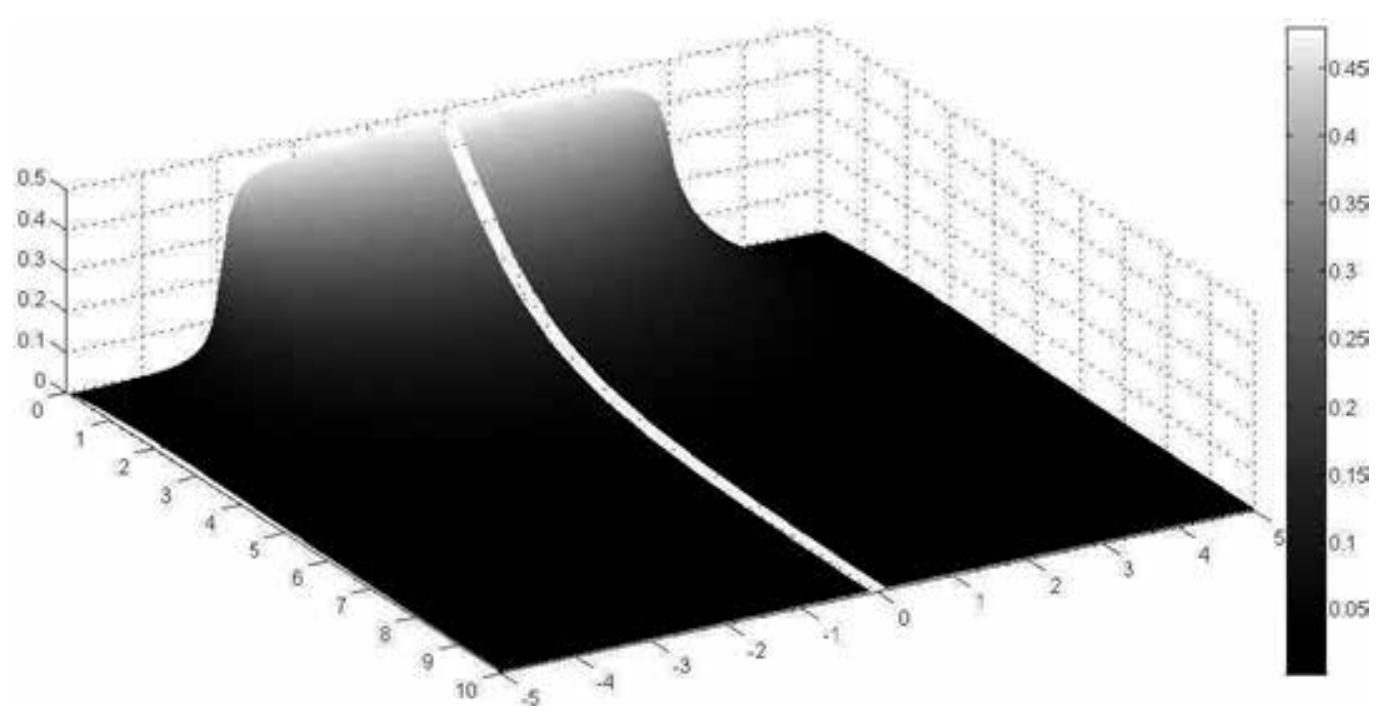

Figure 7. The radiative field generated by a half disk of radius $3 \mathrm{~m}$. Over the perpendicular plane that contains the straight edge of the disk in a grid of 10 by $10 \mathrm{~m}$.

Such new configuration factors can also be employed in the analysis of the architectural heritage in terms of environmental values and specifically in natural lighting; as was stated in the beginning of this chapter, several of these paradigms of architecture feature a balanced treatment of natural lighting coming from the sun but, as no calculation methods were available, their designs were merely the result of intuition and happenstance.

These new configuration factors find application in bringing light to the understanding of the said designs. In this sense, the authors would like to present the simulation cases of two epitomes of ancient Roman architecture, whose accurate radiative performance was largely unknown: the Pantheon (Figures 8, 9) and its superb baroque evolution the Church of Sant'Andrea all Quirinale (Figures 10, 11, 12). 


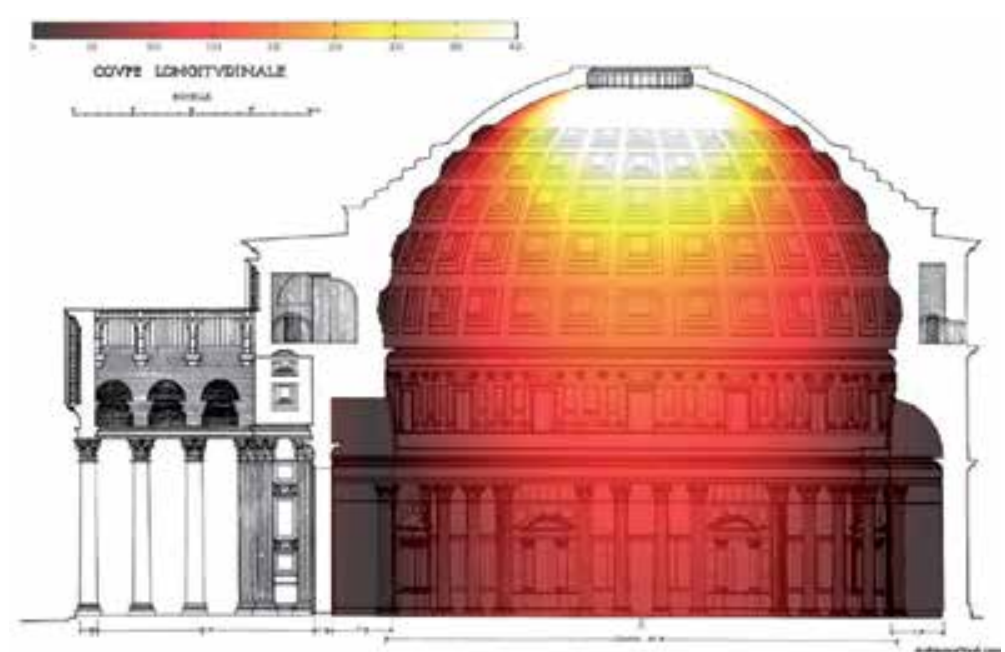

Figure 8. The Roman Pantheon illuminated by diffuse radiation of an intensity of $10000 \mathrm{lumen} / \mathrm{m}^{2}$ (lux). Typical situation in autumn and spring. Scale 0 to 400 lux.

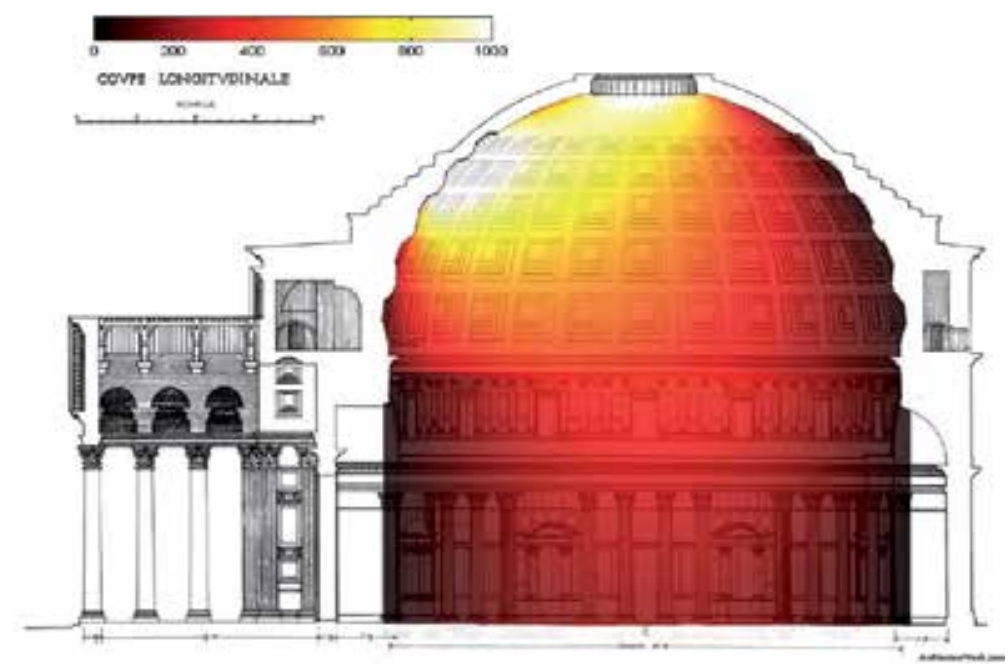

Figure 9. Simulations of the lighting field inside the Pantheon under clear sky conditions.

In Figures 8 and 9, luminous radiation is dimmed and constant for the lower spaces. It is outlined that the values for the Pantheon were not significant (sometimes, under 200 lux) and this fact may have led to the introduction of vertical windows in the drum of the cylinder by late Renaissance or Baroque epochs. Differences in the peak levels are remarkable (400 lux and 1000 lux) due to the amount of energy coming from the sun and the sky; also, in figure 9 the solar penetration inside the Pantheon can be distinctly noticed due to the reflection on the left side of the drawing. These simulations were only possible; thanks to the new configuration factors for circular emitters presented in this text. 
Radiative performance does not show an acute seasonal variation, but allows for sunshine to reveal certain decorative details of the structure adding to the reputation of spiritual luminous atmosphere that encompass the work of Bernini (Figures 10,11, 12).

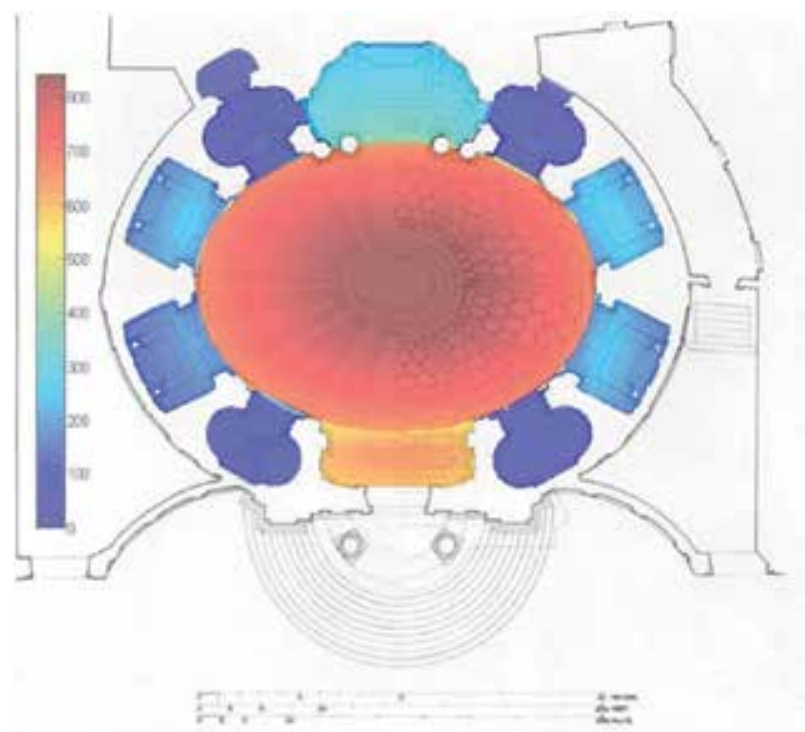

Figure 10. Plan of Sant'Andrea all Quirinale's Church by Bernini (Rome) illuminated by direct solar radiation in winter. Values in lux (0-800)

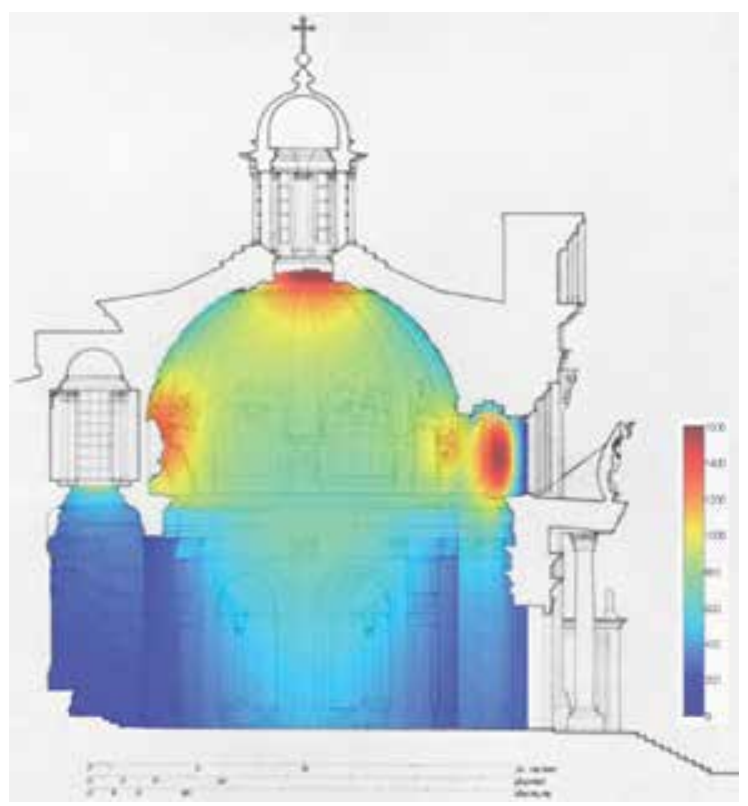

Figure 11. Sant'Andrea all Quirinale's Church. Transversal Section under direct solar radiation in winter. Values in lux (0-1600) 
The architect and sculptor of light, Gian Lorenzo Bernini completed this masterwork, considered to be his own spiritual retreat (Figure 12) and paved the way for further illumination achievements by Guarino Guarini Figure 13).

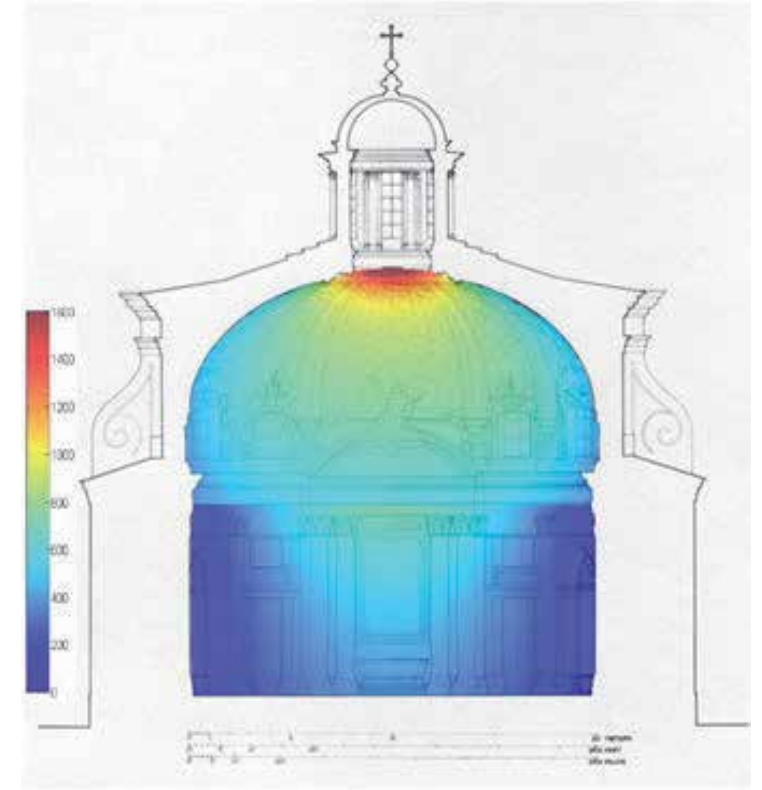

Figure 12. Sant'Andrea all Quirinale's Church. Longitudinal section under direct solar radiation in winter. Values in lux (0-1600)

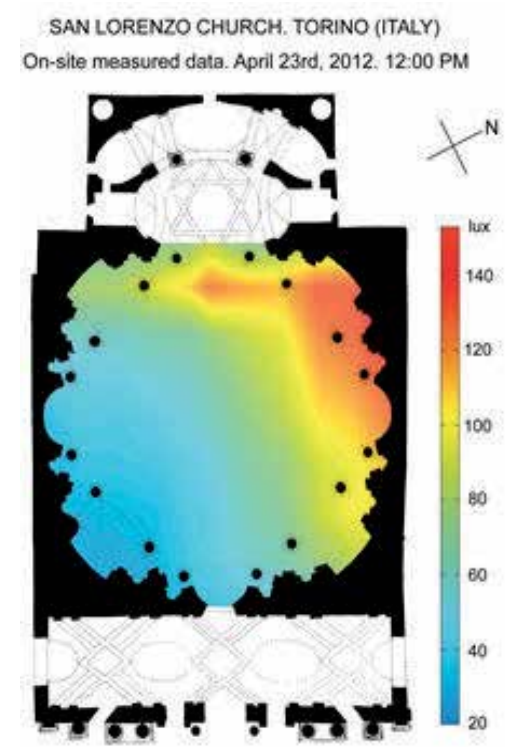

Figure 13. Values measured at Guarini's church in Torino 
In the same fashion of studying radiation due to circular emitters, a building currently under construction, the new railway station at the airport of Barcelona (Spain) is briefly presented in an effort to show how simulation can help in the design process and assessment (Figures 14, 15).

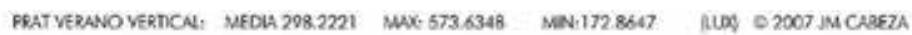

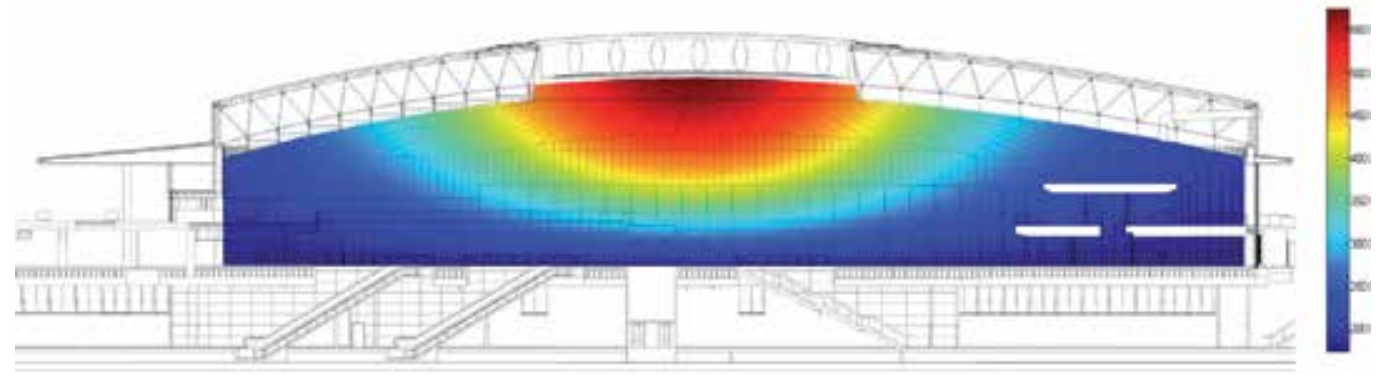

Figure 14. Section of the new railway station in Barcelona. Radiative performance design by the author. Project by the architects Cesar Portela and Antonio Barrionuevo. Values in lux (0-600)

\section{ESTACIÓN PRAT OTONO: MEDU 370.412 MAX:1970.8249 MIN:105.0571 (LUX) O 2007 JMCABEZA}
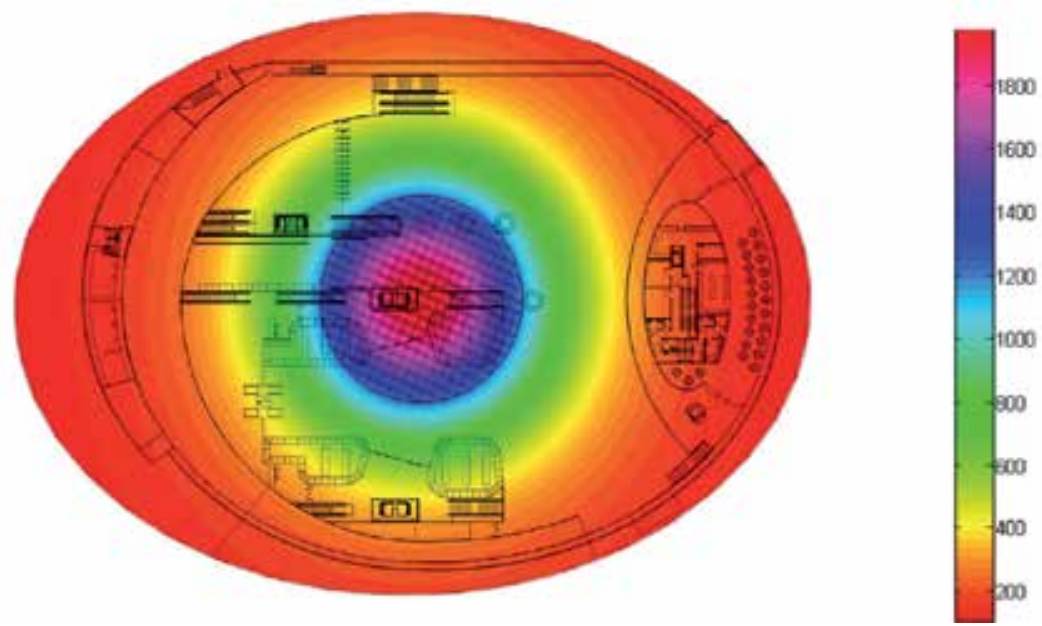

Figure 15. Plan of the railway station in autumn. Values in lux

Changing the scale for the modern requirements of transportation spaces which have become the cathedrals of our time, the author proposes a lighting design in which the oculus reaches a diameter of 30 metres and the radiative energy is distributed by means of massive aluminium louvers with a height exceeding 3 metres in total. The simulations show good values in winter and summer and an acceptable raise of temperature levels at the glazed aperture due to the solar protection and the mild climate of Barcelona. 


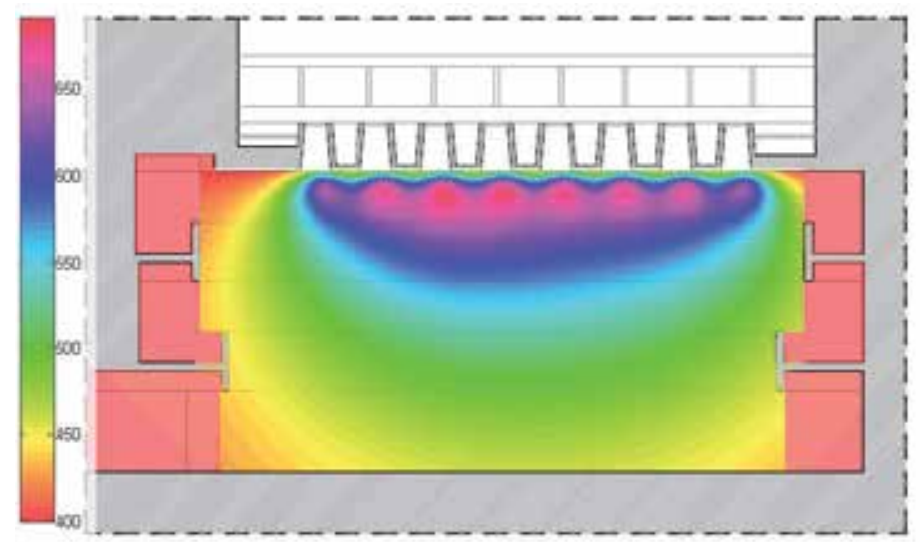

Figure 16. The Rautatalo building of 1955 by Alvar Aalto, Helsinki. Simulation of 40 skylights $\left(8^{*} 5\right)$, performed in June with direct sunlight and monitored on $21^{\text {st }}$ of June 2011. Values in lux

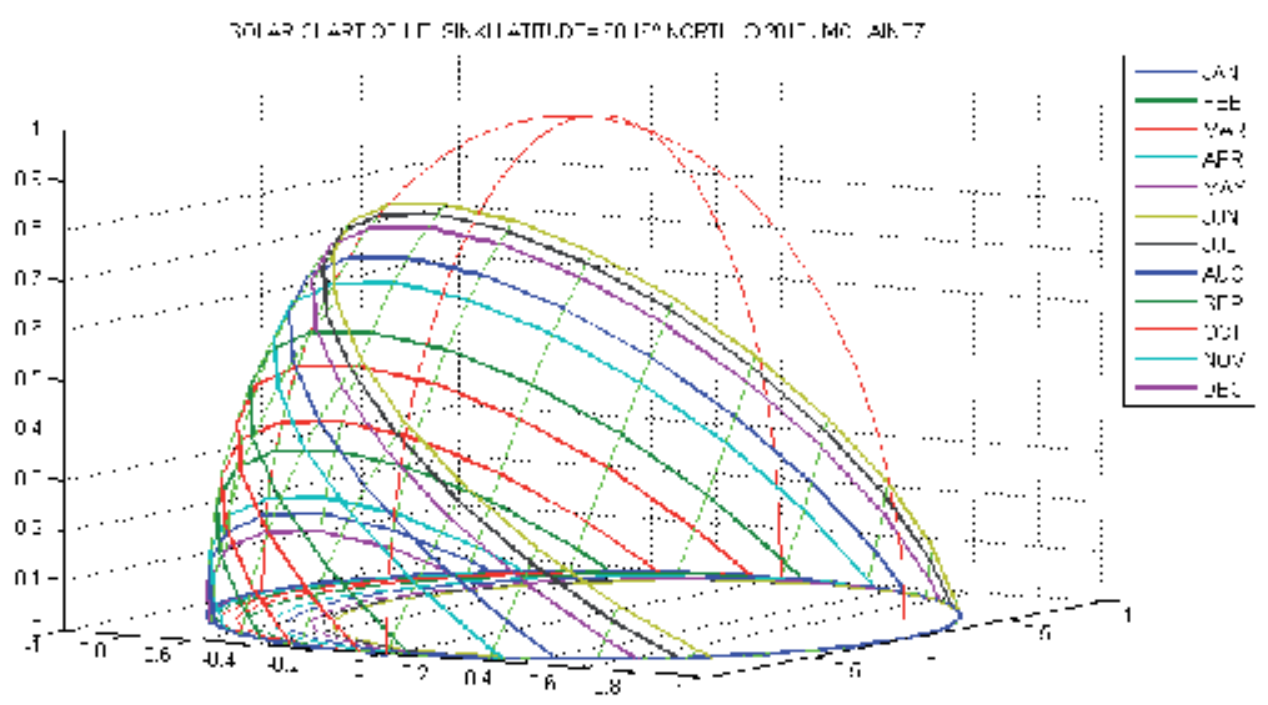

Figure 17. Solar chart of Helsinki. Latitude 61.16 degrees North

The final case to be introduced is the Rautatalo building of 1955, by the modern Finnish master Alvar Aalto. Originally a department store, it beckoned Helsinki's citizens by its intelligent use of luminous radiation, enhanced by conical skylights subtly adapted to the solar path in this lively northern city. (Figures 16,17)

The latter example, the Rautatalo building, brings the reader back to the efforts of the modern movement in architecture to control radiation. With 40 circular skylights it was subsequently 
adapted to many projects around the world, which generally speaking fared less well than the original for climatic and economic circumstances.

\section{Conclusions}

In this chapter four new configuration factors related to circular emitters have been presented. They have been deducted via direct analytical work, solving the integral according to the canonical expression of the theory of configuration factors.

In this sense, the components of the radiative field for the three directions of the space with respect to a circular emitter have been found. It is important to stress that thanks to this new factor radiative field can be assessed in any point of the space. In this way, former restrictions regarding the position of the receiving point [8],[9] have been superseded by the new expressions.

It is suggested that several complex surfaces can be estimated in a similar manner, provided that they allow for some decomposition into clusters of tangent circular elements; to perform this operation only the direction of the normal vector at each point considered is needed. With the aid of CAD software and simulation programs, such procedure is readily facilitated.

Following mathematical deduction this factors can be extended to three-dimensional emitters; the case of a spherical source is remarkable, as the viewed portion of a sphere from a receiving differential element can be assimilated to a circular emitter. Extension of this factor for a finite receiving surface, that is, a rectangle, allows for more complex calculations.

After this mathematical deduction, advances in the practical application of these new factors have been presented, mainly in the field of lighting engineering, natural lighting in architecture and thermal engineering but also in human comfort and medicine areas. The architectural examples, a set of climate-responsive buildings would remind the reader that, in order to produce universal results there is the need to consider local weather parameters.

Such a meticulous task can only be achieved in the case of solar radiation with the help of scientific Approach that we believe to have greatly facilitated by the discovery of new expressions to regulate the transfer of energy due to circular and other curved emitters and by creating and diffusing powerful and simple computer programs that successfully implement the desired algorithms.

\section{Acknowledgements}

Jose M Cabeza is grateful to the extraordinary librarians at Kansai Gaidai University (Japan). Professors Junko and Tsubasa were always very helpful. The authors would like to thank Juan Manuel Bonilla Martinez for his excellent drawing of figure 6. 


\section{Author details}

Jose M. Cabeza-Lainez ${ }^{1,2^{*}}$, Jesus A. Pulido Arcas ${ }^{3}$, Carlos Rubio Bellido',

Manuel-Viggo Castilla ${ }^{1}$, Luis Gonzalez-Boado ${ }^{1}$ and Benito Sanchez-Montanes Macias ${ }^{1}$

*Address all correspondence to: crowley@us.es

1 Universidad de Sevilla, Spain

2 Kansai Gaidai University, Japan

3 Canon Foundation Fellow, University of Shiga Prefecture, Japan

\section{References}

[1] John R. Howell, A Catalogue of Radiation Heat Transfer Configuration Factors. 3rd ed., 2010. On-line version available at: http://www.engr.uky.edu/rtl/ Catalog/.

[2] M.H.N. Naraghi, Radiation view factors from differential plane sources to disks - a general formulation, J. Thermophys. Heat Trans. 2 (3) (1988) 271-274

[3] M.H.N. Naraghi, B.T.F. Chung, Radiation configuration between disks and a class of axisymmetric bodies, J. Heat Transfer 104 (3) (1982) 426-431.

[4] Howell. R. John, Siegel. Robert, Menguç. M. Pinar. Thermal Radiation Heat Transfer $5^{\text {th }}$ edition. CRC Press 2010.

[5] Bronstein. Mr, Semendaev. R, Handbook of mathematics. Springer, 2007.

[6] J.M. Cabeza-Lainez, J.A. Pulido-Arcas, New configuration factors for curved surfaces, J. Quant. Spectrosc. Radiat. Transfer 117 (2013) 71-80.

[7] J.M. Cabeza-Lainez, Fundamentos de Transferencia Radiante Luminosa. (Including software for simulation), Netbiblo, Spain, 2010.

[8] K.G.T. Hollands, On the superposition rule for configuration factors, J. Heat Transfer 117 (1) (1995) 241-245.

[9] D.C. Hamilton, W.R. Morgan, Radiant-interchange configuration factors, NASA TN 2836, 1952. 



\section{Edited by Segun Raphael Bello}

Two essential components of solar energy which are derivable from the sun-radiant light (passive solar power) and heat (active solar powers) have been harnessed for decades using a range of continuously-evolving and cutting-edge technologies. Such technologies include solar heating, solar photovoltaics, solar thermal energy, solar architecture and photo emitters. Recently, there has been active research in solar energy resources due to improvements in solar panel geometry, photo-cell materials, glazing and panel orientation. Equally, more rigorous methods of modeling interreflections within curvilinear surfaces are now being evaluated for simplified analytical evaluations. Therefore, this book, Solar Radiation Applications, presents the outcomes of selective and classic works on the optimization of these essential fields in active solar energy research. 